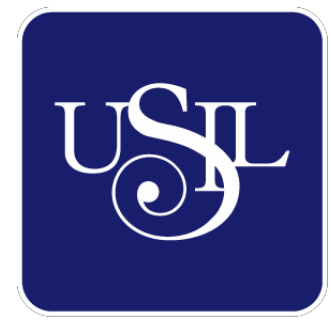

UNIVERSIDAD

SAN IGNACIO

DE LOYOLA

ESCUELA DE POSTGRADO

\title{
PLAN ESTRATÉGICO: EMPRESA XTERNAL TECHNOLOGICAL SOLUTIONS S.A.C.
}

Trabajo de Investigación para optar el grado de:

\author{
JUAN ALBERTO ALPONTE BELAPATIÑO
}

Maestro en Ciencias Empresariales con Mención en Gestión de Proyectos

PABLO JHONATAN CHAVEZ ESPINO

Maestro en Ciencias Empresariales con Mención en Gestión de Proyectos

ENRIQUE ALEXANDER GUERRA RIVERA

Maestro en Ciencias Empresariales con Mención en Gestión de Proyectos

FLORA MERCEDES NUÑEZ VENTURA

Maestro en Ciencias Empresariales con Mención en Gestión de Proyectos

Asesor:

Dr. Edmundo Rafael Casavilca Maldonado

Lima - Perú

2018 


\section{Resumen Ejecutivo}

El presente Plan Estratégico 2017- 2021 se elaboró para la empresa Xternal Technological Solutions S.A.C. con el objetivo de que éste sea el punto de partida para incrementar la rentabilidad, lograr un crecimiento sostenido dentro de un horizonte de tiempo determinado y que le permita alcanzar la visión propuesta.

Con la finalidad de desarrollar de manera eficiente este proyecto, se realizó el análisis de la empresa, considerando sus factores externos e internos, lo que permitió identificar las principales fortalezas y debilidades que presentan, así como las oportunidades y amenazas que esta podría enfrentar.

Los principales problemas que tiene la empresa son: La dependencia excesiva de ciertos puestos de trabajo, la plana directiva ligada a actividades operativas de la empresa, la carencia de un área dedicada a las ventas y la concentración de la cartera de clientes.

Como resultado de este análisis, se ha determinado también, que la estrategia que se implementará de manera intensiva es la Penetración de Mercado, teniendo como estrategia contingente el Desarrollo de Productos. Además, se ha considerado recomendable el desarrollo de las demás estrategias planteadas dentro del presente estudio.

En el Mapa de la Estrategia, se definen los objetivos, las metas e indicadores. Adicionalmente, se proponen 12 iniciativas, las cuales tendrán responsables a cargo de cada una de ellas, con un cronograma y presupuesto asignados. Las iniciativas propuestas están agrupadas de acuerdo con las perspectivas: Financiera, de los Clientes, de los Procesos Internos y de Formación y Crecimiento. Las principales iniciativas consisten en potenciar y mejorar el área de servicio enfocado a Business Analytics (BA) y Mobile. Crear nuevos servicios como: Soluciones Pyme y Capacitación. Mejorar la visión estratégica que se tiene en la empresa. 
Asimismo, se ha asignado un presupuesto a cada una de las iniciativas a lo largo de los cinco años de duración del proyecto, valorizado en un total de S/ 1’009,545.

Finalmente, se recomienda la implementación del presente plan estratégico y se espera que, con esta implementación, a finales del 2021 el incremento en ventas sea de 32\%; los indicadores financieros que se proyectan son una TIR de $24.09 \%$, un VAN de S/. 76,285 y un ROE de 20\%, calculados en un horizonte de cinco años, luego de implementar las iniciativas propuestas. 


\section{Agradecimiento}

Agradecemos a los socios de la empresa Xternal Technological Solutions S.A.C. por la confianza de habernos brindado la información necesaria para poder realizar el presente trabajo.

A nuestro asesor el Dr. Edmundo Casavilca, el cual nos guió desde el inicio del camino brindando su apoyo en cada paso que necesitábamos dar hasta alcanzar nuestra meta. 


\section{Tabla de Contenidos}

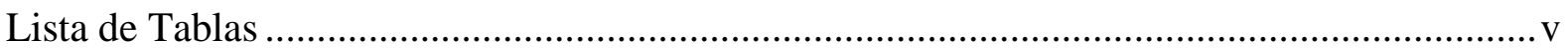

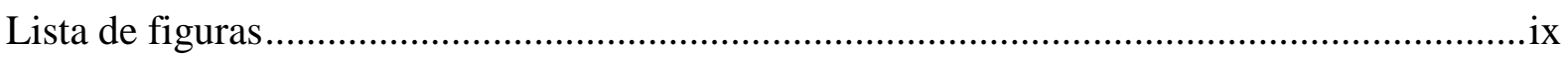

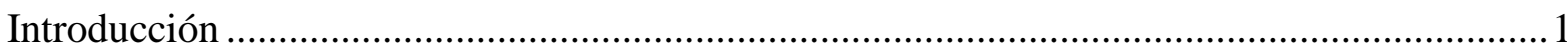

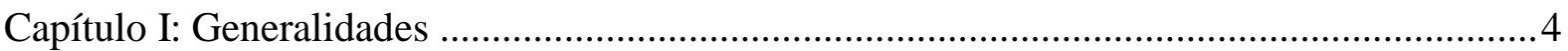

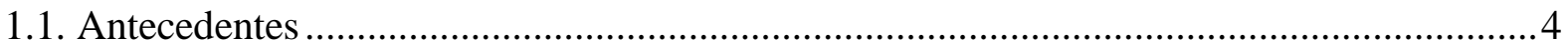

1.2. Determinación del Problema u Oportunidad ................................................................. 6

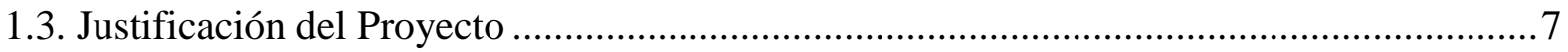

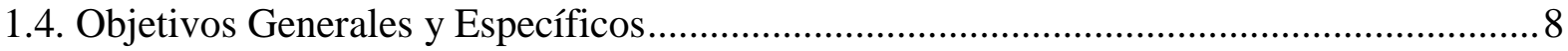

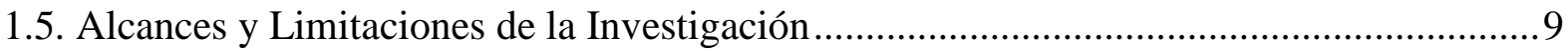

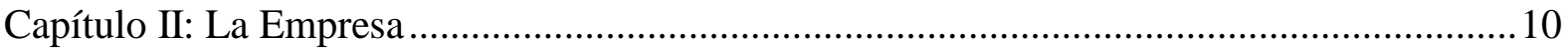

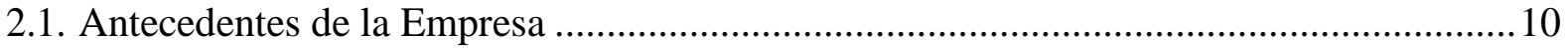

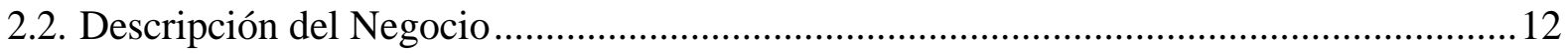

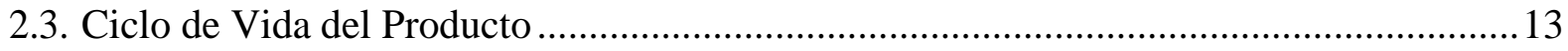

2.4. Estructura Organizacional Actual de la Empresa ......................................................... 16

2.5. Situación del Mercado y Financiera Actual de la Industria ............................................. 32

Capítulo III: Formulación de la Visión, Misión y Valores de la Empresa................................ 35

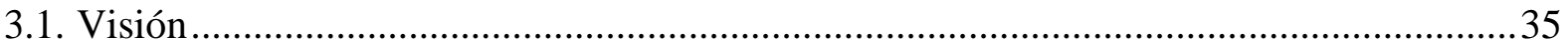

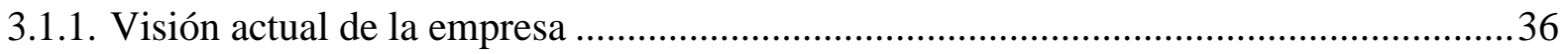

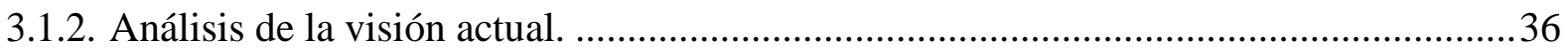

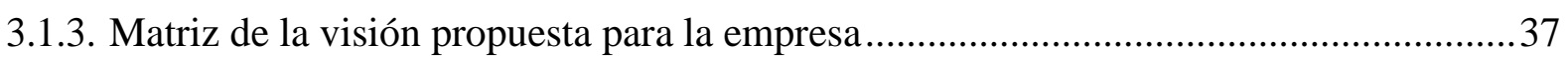


3.2.1. Misión actual de la empresa

3.2.2. Análisis de la misión actual.

3.2.3. Elementos de la misión propuesta para la empresa

3.2.4. Misión propuesta

3.3. Valores

3.3.1. Valores actuales de la empresa .45

3.3.2. Análisis de los valores actuales .45

3.3.3. Elementos de los valores propuestos para la empresa .46

3.3.4. Valores propuestos 47

3.4. Alineamiento Estratégico de la Visión, Misión y Valores de la Empresa .48

Capítulo IV: Análisis Externo .51

4.1. Tendencias de las Variables del Entorno .51

4.1.1. Análisis Político-Gubernamental. .51

4.1.2. Análisis Económico.

4.1.3. Análisis Legal.

4.1.4. Análisis Socio Cultural.

4.1.5. Análisis Tecnológico.

4.1.6. Análisis Ecológico

4.2. Impacto en Clientes/Proveedores de cada una de las Variables del Entorno .73

4.3. Efecto en la Empresa de cada una de las Variables del Entorno .76 
5.2.1. Sustitutos

5.2.2. Potenciales.

5.2.3. Clientes.

5.2.4. Proveedores.

5.2.5. Competencia en el mismo sector. .98

5.3. Matriz de Atractividad de cada una de las Cinco Fuerzas .99

5.4. Análisis del Grado de Atractividad de la Industria 103

5.5. Matriz de Perfil Competitivo MPC 105

Capítulo VI: Análisis Interno

6.1. Descripción de las Actividades de la Cadena de Valor de la Empresa

6.2. Indicadores de cada una de las Actividades de la Cadena de Valor 118

6.3. Benchmarking y Comparación con los Líderes de la Industria de cada una de las Actividades de la Cadena de Valor 120

6.4. Determinar las Competencias de la Empresa. 126

6.5. Identificación y Determinación de las Ventajas Competitivas de la Empresa. 128

6.6. Matriz de Evaluación de los Factores Internos EFI 
7.1.1. Objetivos estratégicos.

7.1.2. Análisis de los objetivos estratégicos.

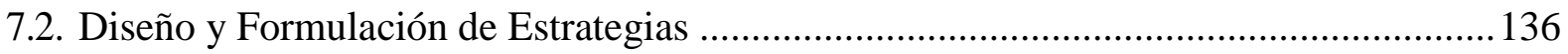

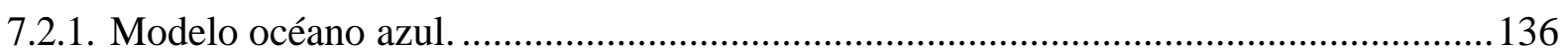

7.2.1.1. Lienzo de la estrategia actual de la empresa .........................................................137

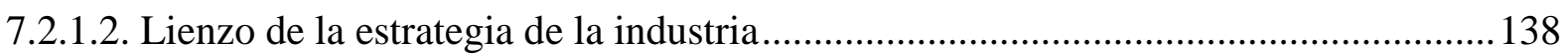

7.2.1.3. Matriz (eliminar, reducir, incrementar, crear) ……………………………............. 139

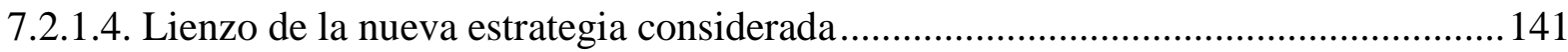

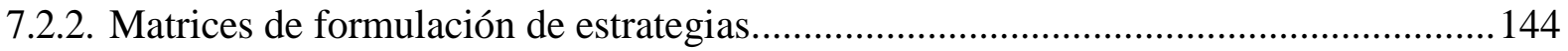

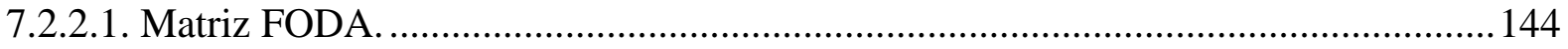

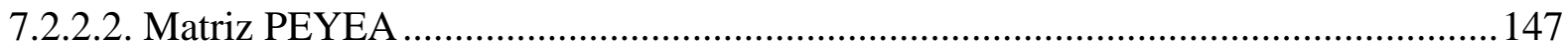

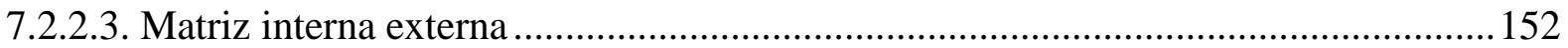

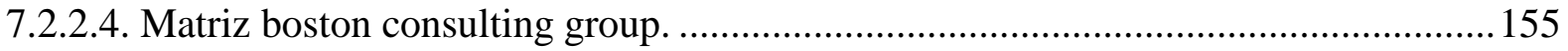

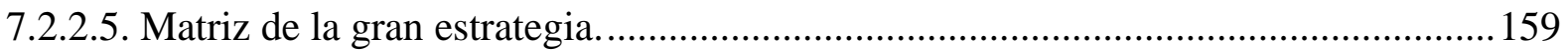

7.3. Resumen de las Estrategias Formuladas ........................................................................ 161

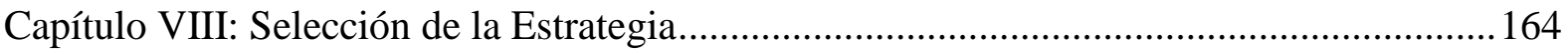

8.1. Método de Factores Estratégicos Claves ....................................................................... 164

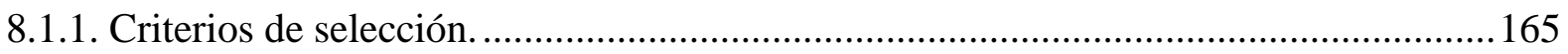

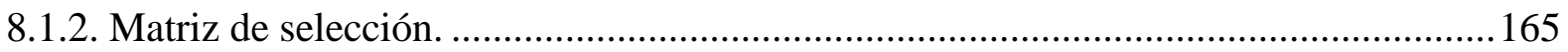

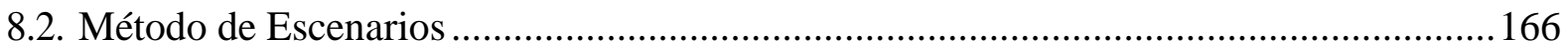

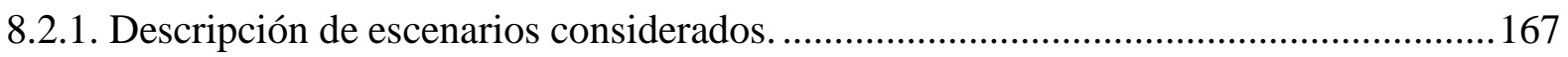


9.5. Iniciativas (acciones a llevar a cabo para cada uno de los objetivos específicos),

Estrategias, Programas, Políticas, Reglas, Procedimiento 182

9.6. Responsable de cada una de las iniciativas 188

9.7. Presupuesto de cada una de las iniciativas 190

9.8. Cronograma de cada una de las iniciativas

Capítulo X: Evaluación

10.1. Evaluación Cualitativa

10.1.1. Criterios de evaluación

10.1.2. Comparación de la estrategia con los criterios

10.2. Evaluación Financiera de la Estrategia

10.2.1. Proyección de estados financieros (situación actual y con la nueva estrategia) ........200

10.2.2. Estado de resultados (situación actual y con la nueva estrategia)

10.2.3. Balance general (situación actual y con la nueva estrategia) 
10.2.4. Flujo de efectivo (situación actuథlabfandachueva destrategia)

10.2.5. Proyección de flujos (situación actual y con la nueva estrategia)

10.2.6. Evaluación financiera (VAN, TIR y ratios financieros). 216

Conclusiones . .222

Recomendaciones .224

Referencias. .225

Anexos .229 


\section{Lista de Tablas}

Tabla 1 Utilidades Obtenidas por Línea de Negocio 15

Tabla 2 Ranking Latinoamérica RGTI

Tabla 3 Modelo de matriz de la visión propuesta para la empresa Xternal Technological

Solutions S.A.C .37

Tabla 4 Redacción de una declaración de visión. Que hacer, qué evitar S.A.C .38

Tabla 5 Modelo de matriz de elementos de la misión propuesta para la empresa Xternal Technological Solutions S.A.C .42

Tabla 6 Principales indicadores macroeconómicos .54

Tabla 7 PBI por sectores económicos (Variaciones porcentuales reales) .57

Tabla 8 Principales indicadores macroeconómicos .59

Tabla 9 Proyectos de investigación iniciados en 2014-2015

Tabla 10 Impacto en Clientes/Proveedores de cada Variable del Entorno .74

Tabla 11 Efecto en la empresa de cada una de las Variables del Entorno .77

Tabla 12 Matriz de Evaluación del Factor Externo (EFE) .81

Tabla 13 Matriz de Atractividad de los Sustitutos 99

Tabla 14 Matriz de Atractividad de los Proveedores 100

Tabla 15 Matriz de Atractividad de Rivalidad entre Competidores 101

Tabla 16 Matriz de Atractividad de Poder de Negociación de Clientes 102

Tabla 17 Matriz de Atractividad de Nuevos Competidores. 103

Tabla 18 Matriz de Grado de Atractividad de la Industria 104

Tabla 19 Ventas anuales entre competidores directos 106

Tabla 20 Matriz de Perfil Competitivo - MPC 108

Tabla 21 Indicadores de las actividades de la cadena de valor 119 
Tabla 22 Benchmarking y comparación con los líderes de la industria de las actividades de la cadena de valor 121

Tabla 23 B Matriz de ventaja competitiva sostenible

Tabla 24 Matriz de evaluación de factores internos (EFI) 130

Tabla 25 Características del servicio de consultoría de Xternal Technological Solutions

S.A.C.

Tabla 26 Matriz de las cuatro acciones del servicio de consultoría en TI de Xternal Technological Solutions S.A.C 141

Tabla 27 Matriz FODA de la empresa Xternal Technological Solutions S.A.C. 145

Tabla 28 Variables PEYEA 150

Tabla 29 Ventas y participación de Xternal Technological Solutions S.A.C. en la industria del software peruana 158

Tabla 30 Matriz de Selección 166

Tabla 31 Proyección de PBI escenario conservador 168

Tabla 32 Proyección de PBI escenario pesimista 169

Tabla 33 Proyección de PBI escenario optimista. 169

Tabla 34 Escenarios vs posibles estrategias a implementar. 170

Tabla 35 Matriz de planeación estratégica cuantitativa (MPEC) 171

Tabla 36 Indicadores de medición para cada objetivo específico. 180

Tabla 37 Metas para cada objetivo específico 181

Tabla 38 Línea temporal de las metas anualizadas planteadas 182

Tabla 39 Iniciativas para cada objetivo específico 183

Tabla 40 Responsable para cada iniciativa formulada 189

Tabla 41 Presupuesto por cada una de las iniciativas 191

Tabla 42 Cronograma de cada una de las iniciativas 192 
Tabla 43 Matriz Rumelt 196

Tabla 44 Proyección escenario optimista - Sin estrategia (Años 2017 - 2021).... 198

Tabla 45 Proyección escenario conservador - Sin estrategia (Años 2017 - 2021) 198

Tabla 46 Proyección escenario pesimista - Sin estrategia (Años 2017 - 2021). 199

Tabla 47 Proyección escenario optimista - Con estrategia (Años 2017 - 2021) 201

Tabla 48 Proyección escenario conservador - Con estrategia (Años 2017 - 2021)..... 201

Tabla 49 Proyección escenario pesimista - Con estrategia (Años 2017 - 2021) 202

Tabla 50 Estado de resultados proyectado de Xternal Technological Solutions - sin estrategia .203

Tabla 51 Presupuesto de ventas proyectado - Escenario conservador con estrategia ...........206

Tabla 52 Presupuesto de compras proyectado - Escenario conservador con estrategia ........206

Tabla 53 Presupuesto de gastos administrativos proyectado - Escenario conservador con estrategia 206

Tabla 54 Inversión de estrategia 207

Tabla 55 Depreciación de activos .... 208

Tabla 56 Presupuesto de gastos de ventas proyectado - Escenario conservador con estrategia .208

Tabla 57 Cronograma de la deuda 209

Tabla 58 Presupuesto de gastos financieros proyectados - Escenario conservador con estrategia 209

Tabla 59 Estado de resultados proyectados - escenario conservador con estrategia..... 210

Tabla 60 Balance general - Sin estrategia 211

Tabla 61 Balance general - Con estrategia 212

Tabla 62 Flujo de efectivo con estrategia

Tabla 63 Cálculo del capital de trabajo - Con estrategia. 214 
Tabla 64 Flujo de caja proyectado - Con estrategia ..........................................................215

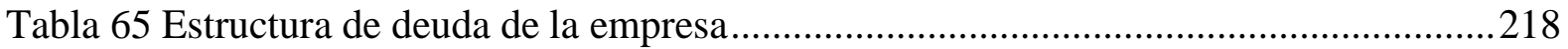

Tabla 66 Variables utilizadas en el cálculo del cok y su procedencia ..................................219

Tabla 67 Estructura de la deuda de la empresa Xternal Technological Solutions S.A.C......219

Tabla 68 Cálculo de cok y wacc de la inversión................................................................219

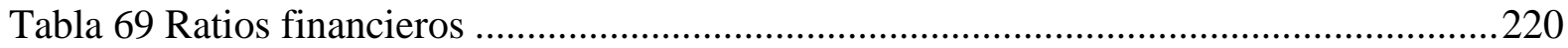




\section{Lista de figuras}

Figura 1. Ciclo de vida de los servicios de Xternal Technological Solutions S.A.C. Adaptado de Marketing (p. 273), por Philip Kotler y Gary Armstrong, 2012, México: Pearson Educación. Copyright 2012 por Pearson Educación .16

Figura 2. Organigrama de Xternal Technological Solutions S.A.C. Recuperado de http://xternal.biz

Figura 3. Crecimiento del PBI: Economía Mundial. Tomado de "Reporte de Inflación:

Panorama actual y proyecciones macroeconómicas 2016 -2018” por el Banco Central de

Reserva del Perú, 2016. Recuperado de http://www.bcrp.gob.pe/docs/Publicaciones/Reporte-

Inflacion/2016/diciembre/reporte-de-inflacion-diciembre-2016-presentacion.pdf

Figura 4. PBI: América Latina (Cambio porcentual anual). Tomado de "Reporte de Inflación:

Panorama actual y proyecciones macroeconómicas 2016 -2018” por el Banco Central de

Reserva del Perú, 2016. Recuperado de http://www.bcrp.gob.pe/docs/Publicaciones/Reporte-

Inflacion/2016/diciembre/reporte-de-inflacion-diciembre-2016-presentacion.pdf . .56

Figura 5. Tipo de Cambio e Intervención Cambiaria del BCRP. Tomado de "Programa

Monetario de febrero 2017” por el Banco Central de Reserva del Perú, 2017. Recuperado de http://www.bcrp.gob.pe/docs/Publicaciones/Presentaciones-Discursos/2017/presentacion-022017.pdf

Figura 6. Proyección de la inflación 2010-2018 (variación porcentual últimos doce meses). Tomado de "Reporte de Inflación: Panorama actual y proyecciones macroeconómicas 20162018” por el Banco Central de Reserva del Perú, 2017. Recuperado de http://www.bcrp.gob.pe/docs/Publicaciones/Reporte-Inflacion/2016/diciembre/reporte-deinflacion-diciembre-2016.pdf

Figura 7. Tasa de interés de referencia nominal y real (en porcentaje). Tomado de "Reporte de Inflación: Panorama actual y proyecciones macroeconómicas 2016-2018” por el Banco 
Central de Reserva del Perú, 2017. Recuperado de

http://www.bcrp.gob.pe/docs/Publicaciones/Reporte-Inflacion/2016/diciembre/reporte-deinflacion-diciembre-2016.pdf

Figura 8. Gasto en investigación y desarrollo en centros de investigación, 2014-2015

(Millones de soles y Porcentaje del PBI). Tomado de "I Censo Nacional de Investigación y

Desarrollo a Centros de Investigación 2016” por CONCYTEC, 2016. Recuperado de http://portal.concytec.gob.pe/images/publicaciones/censo_2016/libro_censo_nacional.pdf ..67

Figura 9. Gasto en I+D como porcentaje del PBI (Porcentaje). Tomado de "I Censo Nacional de Investigación y Desarrollo a Centros de Investigación 2016” por CONCYTEC, 2016.

Recuperado de

http://portal.concytec.gob.pe/images/publicaciones/censo_2016/libro_censo_nacional.pdf ..68

Figura 10. Uso de principales herramientas TIC en las empresas. Tomado de "Encuesta

Económica Anual 2014” por el Instituto Nacional de Estadística e informática, 2014.

Recuperado de http://www.inei.gob.pe/.

Figura 11. Ventas de las Empresas por Internet (Distribución Porcentual) Tomado de “Encuesta Económica Anual 2014” por el Instituto Nacional de Estadística e informática, 2014. Recuperado de http://www.inei.gob.pe/...... .86

Figura 12. Capacitación de Personal en el Uso de TIC. Tomado de "Encuesta Económica Anual 2014” por el Instituto Nacional de Estadística e informática, 2014. Recuperado de http://www.inei.gob.pe/

Figura 13. Cadena de valor genérica. Tomado de "Ventaja Competitiva" (p. 54) por Michael E. Porter, 1991, Argentina: Editorial Rei Argentina. Copyright 1987 compañía editorial continental S.A. 
Figura 14. Relación entre objetivos y jerarquía organizacional. Tomado de "Administración estratégica Teoría y casos” (18.a ed.). (p.118) por Thompson, A. A., Gamble, J., Peteraf, M., \& Strickland III, A. J., 2012, México: Editorial McGraw-Hill Interamericana. 133 Figura 15. Lienzo de la estrategia actual de la empresa. Adaptado de "La estrategia del océano azul”. (p.37) por Chan, Kim, \& Mauborgne, Renée, 2005, Colombia: Editorial Norma 138

Figura 16. Lienzo de la estrategia de la industria. Adaptado de "La estrategia del océano azul”. (p.37) por Chan, Kim, \& Mauborgne, Renée, 2005, Colombia: Editorial Norma. 139 Figura 17. Lienzo de la estrategia actual de la empresa vs estrategia de la industria. Adaptado de "La estrategia del océano azul”. (p.37) por Chan, Kim, \& Mauborgne, Renée, 2005, Colombia: Editorial Norma 139 Figura 18. Lienzo de la nueva estrategia considerada. Adaptado de "La estrategia del océano azul”. (p.37) por Chan, Kim, \& Mauborgne, Renée, 2005, Colombia: Editorial Norma. 142 Figura 19. Matriz FODA. Tomado de "Administración estratégica y política de negocios" (p. 197) por Hunger \& Wheeler, 2013, Colombia: Editorial Pearson. Copyright 2013 Editorial Delfin Ltda.....

Figura 20. Matriz PEYEA. Adaptado de “Conceptos de Administración estratégica” (p. 205) por David, Fred, 2013, México: Editorial Pearson. Copyright 2013 Editorial Pearson. 151 Figura 21. Matriz Multifactorial. Tomado de "Planeación estratégica" (p. 165) por Chiavenato \& Sapiro, 2011, España: Editorial McGraw Hill. Copyright 2011. 153 Figura 22. Matriz Interna-Externa. Adaptado de "Planeación estratégica" (p. 165) por Chiavenato \& Sapiro, 2011, España: Editorial McGraw Hill. Copyright 2011. 154

Figura 23. Matriz BCG. Tomado de "Administración estratégica y política de negocios” (p. 239) por Hunger \& Wheeler, 2013, Colombia: Editorial Pearson. Copyright 2013 Editorial Delfin Ltda 
Figura 24. Matriz BCG de la empresa Xternal Techological Solutions S.A.C. Adaptado de “Administración estratégica y política de negocios" (p. 239) por Hunger \& Wheeler, 2013, Colombia: Editorial Pearson. Copyright 2013 Editorial Delfin Ltda.

Figura 25. Matriz de la gran estrategia. Tomado de "Administración estratégica” por David, 2013, Editorial Pearson. Copyright 2013

Figura 26. Matriz de la gran estrategia de Xternal Technological Solutions S.A.C. Adaptado de “Administración estratégica” por David, 2013, Editorial Pearson. Copyright 2013 161 Figura 27. Modelo analítico para la formulación de estrategias. Tomado de "Conceptos de administración estratégica” por David, 2013, Editorial Pearson. Copyright 2013 164 Figura 28. Mapa de la estrategia Xternal Technological Solutions S.A.C. Adaptado de "El cuadro de mando integral” por Kaplan y Norton, 2014, Ediciones Gestión 2000. Copyright 2014 176 


\section{Dedicatoria}

A nuestros padres, cónyuges e hijos quienes nos han brindado su apoyo incondicional durante todo este arduo camino y que ha significado un peldaño más en nuestra vida académica y profesional. Su amor y comprensión han sido el aliciente necesario para enfrentar a los desafíos planteados durante toda la maestría, la cual estamos concluyendo de manera satisfactoria. 


\section{Introducción}

El "Plan Estratégico para la empresa proveedora de servicios de tecnología de información Xternal Technological Solutions S.A.” es un trabajo de investigación cuyo objetivo es la identificación de estrategias de negocio que permitan la elaboración de un plan de acción para alcanzar los objetivos deseados respecto al crecimiento sostenible de la empresa por los próximos cinco años (2017-2021).

En el capítulo 1, se describirán los motivos que fundamentan el estudio de investigación. Se conocerá la razón por la que el grupo de trabajo escogió realizar esta investigación en la empresa seleccionada, los objetivos principales y específicos del plan estratégico a elaborar, así como el alcance y las limitaciones a las que el grupo hace frente en este trabajo.

En el capítulo 2, se conocerá a la empresa sujeta de estudio. Se detallará su giro de negocio, el servicio o producto que ofrece en el mercado, su estructura organizacional y su situación actual en el sector. Esta información es sumamente importante para el análisis previo, ya que permite tener claro en donde se encuentra la empresa para posteriormente llegar hacia dónde quisiera estar.

En el capítulo 3, se analizará la visión, misión y valores actuales de la empresa y, de acuerdo con el marco teórico utilizado en la presente investigación, se propondrá una nueva visión, misión y valores. En este punto también se describirá el alineamiento estratégico de los mismos con el recurso humano de la empresa.

En el capítulo 4, se realizará el análisis externo de la empresa que se basa en realizar estudios comparativos con la competencia, con el objetivo de determinar amenazas y oportunidades y valorar la importancia de diferentes ideas innovadoras. El análisis externo se realiza a través de información suministrada por herramientas que van 
recopilando información en el día a día. En este capítulo se profundizará en el análisis a fin de determinar cómo afecta estas variables externas a la empresa.

En el capítulo 5, se realizará el análisis de la industria que tiene por objetivo revisar con detalle el tamaño, las normas del mercado, los productos, las empresas con las que se deberá competir, las características de los clientes objetivo, los principales proveedores de insumos y las empresas que podrían estar interesadas en entrar en el negocio. Es importante una definición adecuada de la industria donde se está compitiendo para en función de esto enfocar los esfuerzos de la investigación. En este capítulo se analizará a la empresa respecto a las cinco fuerzas de Porter.

En el capítulo 6, se realizará el análisis interno de la empresa que tiene como objetivo conocer los recursos y capacidades con los que cuenta la empresa e identificar sus fortalezas y debilidades. Asimismo, establecer objetivos en base a dichos recursos y capacidades, formular estrategias que le permitan potenciar o aprovechar dichas fortalezas, y reducir o superar dichas debilidades. En el análisis interno se consideran aspectos como los recursos humanos y materiales, entre otros. En este capítulo se analizará con detalle la cadena de valor de la empresa

En el capítulo 7, se realizará un análisis de los objetivos estratégicos de la empresa con la finalidad de determinar los beneficios que se podrán obtener dentro de la empresa, con la finalidad de formular las estrategias que aprovechen las fortalezas y oportunidades de la empresa orientadas a los objetivos de la empresa.

En el capítulo 8, se establecerán los posibles escenarios y los criterios de selección para determinar la mejor estrategia a seguir según los escenarios propuestos donde participará la empresa. Esta estrategia deberá estar alineada a los objetivos estratégicos.

En el capítulo 9, se elegirán las estrategias que serán implementadas para el logro de los objetivos, para las cuales se plantearán metas, indicadores y responsables de cada 
acción debidamente presupuestada y con los recursos disponibles de acuerdo con su cronograma para cada actividad que se lleve a cabo.

Por último, en el capítulo 10 se realizará la evaluación cualitativa y cuantitativa de las estrategias a implementar para analizar la diferencia entre la situación actual de la empresa y la situación futura, de esta manera la empresa evaluará la toma de decisiones con las mejoras planteadas. 


\section{Capítulo I: Generalidades}

\subsection{Antecedentes}

En el mundo actual cada empresa que desea tener un crecimiento sostenido en el tiempo y que desea diferenciarse de sus competidores, entiende la necesidad de la implementación de sistemas de información. Anteriormente, el tener un sistema de información integrado (ERP) por sus siglas en inglés, se consideraba un privilegio reservado para algunas empresas. Hoy en día es una necesidad para una toma de decisiones ágil, optimización de procesos y maximización de la rentabilidad esperada.

Las tendencias mundiales respecto a sistemas de información están orientadas a procesamientos de grandes volúmenes de información en tiempo real, almacenamiento de información y desarrollo de aplicaciones sobre internet, conceptos de colaboración entre proveedores y clientes de manera segura, desarrollo de aplicaciones que interactúen con redes sociales, conectividad entre objetos, realidad virtual y realidad aumentada.

En este contexto, las oportunidades de negocio que se presentan son muy grandes de acuerdo con un estudio hecho por Gardner (2016). Se espera la generación de más de 7,000 millones de dólares en ganancias en el rubro de la tecnología de información. A esto se debe la proliferación de empresas de desarrollo de software a nivel mundial.

En Latinoamérica, el Perú sólo exporta alrededor de 28 millones de dólares en lo que se refiere a software, de acuerdo con los datos encontrados en gestión (2016). A comparación de otros países de la región como Uruguay (\$420 millones) vemos que la industria del desarrollo del software en el país aún está muy incipiente.

De acuerdo con la información publicada por el Instituto Nacional de Estadística e Informática (2016), se aprecia que a principios del año 2016 el número de empresas creadas en el país ascendía a 235 mil 381, siendo la ciudad de Lima la que tiene el mayor número de emprendimientos con un $40 \%$ del total. En este mismo informe, se resalta que 3 
mil 858 de este total pertenecen al sector de información y comunicaciones, lo que equivale a $2 \%$.

Generalmente, estas empresas inician sus actividades con muy poca inversión inicial, aprovechando alguna oportunidad de negocio que el mercado les proporciona y siguiendo modelos de empresas similares ya con cierto grado de madurez. De acuerdo con lo establecido como características de micros, pequeñas y medianas empresas según el decreto supremo $\mathrm{N}^{\circ}$ 013-2013-PRODUCE (el peruano.pe, 2013), muchas de estas empiezan como microempresas. Es en este escenario en donde la elaboración de un plan estratégico se hace fundamental para que puedan alcanzar una mayor rentabilidad y crecer en participación en el mercado.

Teniendo una participación en el mercado del 1\%, de acuerdo con información de gestión (2016), el emprendimiento de estas empresas tiene un largo camino por delante. El principal obstáculo con el que se encuentran estas empresas es la desconfianza del empresario serio en invertir en este tipo de empresas, ya que la falta de formalidad de las pequeñas y medianas empresas (pymes) lo desalienta en esta apuesta. Es en este contexto en donde la diferenciación y formalidad de estos emprendimientos, con planes a largo plazo que garanticen crecimiento sostenido, contribuirá a una mejor imagen de la industria del desarrollo del software y un incremento en la participación del mercado.

En el presente estudio, analizamos a la empresa Xternal Technological Solutions S.A.C. que se constituyó como tal, el 1 de setiembre del 2008 y se dedica al desarrollo de soluciones en tecnología de información. La empresa surge de la oportunidad de brindar el servicio de programación sobre la plataforma SAP Netweaver Portal para la empresa TASA, aprovechando oportunidades que le ha permitido crecer de manera no planificada. También ha vivido una crisis que llevó a los dueños a replantear muchos aspectos relacionados al manejo de la empresa. Esta situación ocasionó que parte del equipo se 
retire, originando pérdidas económicas. También perdieron clientes debido a la incertidumbre propia de esta crisis organizacional. Luego de una serie de ajustes, han logrado estabilizar la situación y mantener la confianza de sus principales clientes.

Se espera que, a partir de la implementación de un plan estratégico, se pueda mejorar el manejo de la organización, para continuar con el crecimiento y lograr una madurez a nivel empresarial.

\subsection{Determinación del Problema u Oportunidad}

La empresa Xternal Technological Solutions S.A. ha mantenido un crecimiento debido a su experiencia en el mercado tecnológico, pero no ha podido establecer un plan estratégico para alcanzar los objetivos trazados.

Debido a esta coyuntura, la empresa presenta principalmente los siguientes problemas: La dependencia excesiva de ciertos puestos de trabajo, una plana directiva ligada a actividades operativas de la empresa, la carencia de un área dedicada a las ventas y la concentración de la cartera de clientes.

Según la estructura organizacional actual, existen puestos como el de "Arquitecto de Software" que tiene demasiada relevancia en el desarrollo de proyectos, dado que se le asigna funciones que son clave y que solo el colaborador que ocupa esta posición puede asumir, volviéndose indispensable para la realización del trabajo. Esta situación es reconocida como una problemática porque crea una dependencia excesiva de la persona que tiene este puesto.

Se observa también que la plana dirigencial de la empresa asume actualmente labores que no están acorde a su jerarquía dado que, en vez de realizar labores estratégicas, están involucrados en el desarrollo de las operaciones, restándoles tiempo y enfoque en las funciones directivas que son clave para el desarrollo y éxito de cualquier organización. 
Además, se ha observado que la empresa no cuenta con un área dedicada exclusivamente a las ventas y/o marketing. Esta deficiencia se ve reflejada en el hecho de que los nuevos clientes se consiguen principalmente a través de referencias por trabajos con clientes anteriores. Es necesario que se sume una fuerza de ventas y un plan de marketing para que el crecimiento de la empresa pueda ser mayor y sostenido.

La empresa ha sabido mantenerse dentro del mercado debido a un cliente principal con el cual ha mantenido contratos para el mantenimiento del software que utiliza. Además, brinda otros servicios a diferentes clientes, pero no en la envergadura que le permita una independencia de su cliente principal.

Esta dependencia creada con su principal cliente la hace vulnerable a la competencia de empresas que puedan formarse o ya existan en el mercado y que ofrezcan mejores oportunidades y precios competitivos.

Finalmente, la empresa requiere de un plan a futuro que le permita posicionarse y crecer sostenidamente en el mercado aprovechando las innovaciones que se presentan en el sector y diversificando su cartera de servicios.

\subsection{Justificación del Proyecto}

El presente trabajo permite aplicar los conocimientos adquiridos durante el periodo de formación perteneciente a la maestría de ciencias empresariales, dado que se han analizado los diversos factores necesarios para alcanzar el éxito de una organización. Este proyecto permitirá, a través de la elaboración de un plan estratégico, establecer el proceso a seguir para que una empresa pueda alcanzar sus objetivos organizacionales en el mediano y largo plazo.

Es en esta realidad en la que se encuentra la empresa Xternal Technological Solutions S.A.C., que luego de atravesar por un proceso de estabilización propio del 
comienzo de su actividad, se encuentra en un momento ideal para empezar a plantearse nuevos desafíos que le permitan crecer.

Asimismo, la empresa Xternal Technological Solutions S.A.C. no cuenta actualmente con un plan estratégico, lo que no le ha permitido un crecimiento sostenido ni ordenado, convirtiéndose así en una organización ideal para poner en práctica todos los conceptos relacionados a la administración estratégica de una empresa.

Por su parte, la administración estratégica ha resultado un instrumento valioso para que una empresa llegue a ser exitosa. Una administración estratégica, bien ejecutada, ofrece a las empresas una guía útil para alcanzar sus objetivos de una manera práctica y efectiva, basada en las experiencias previas y en la gestión del conocimiento.

El análisis detallado de los principales aspectos de la empresa sujeto de nuestro estudio nos permitirá aclarar los mecanismos necesarios que posibiliten el desarrollo de un plan estratégico que dirija los rumbos de la empresa en los próximos años, y así mejorar las estrategias de la empresa para alcanzar una mayor rentabilidad.

\subsection{Objetivos Generales y Específicos}

El objetivo general consiste en la elaboración de un plan estratégico para la empresa Xternal Technological Solutions S.A.C. para su crecimiento sostenible durante los próximos cinco años $2017-2021$.

Los objetivos específicos del trabajo son:

- Realizar un análisis interno y externo para identificar la situación actual de la empresa y plantear un nuevo enfoque.

- Reestructurar la misión y visión de acuerdo con el nuevo enfoque de la empresa.

- Realizar un análisis de la industria que permita la definición del perfil 
competitivo de la empresa.

- Definir el perfil competitivo de la empresa para generar valor a sus clientes y futuros clientes.

- Realizar la formulación de objetivos y diseñar las estrategias que le permita un crecimiento sostenido a la empresa

- Realizar un análisis financiero de la empresa para analizar sus costos ante la competencia y proponer una mejora en su situación a futuro.

- Seleccionar y recomendar la implementación de una estrategia que asegure el crecimiento sostenido de la empresa.

\subsection{Alcances y Limitaciones de la Investigación}

Como alcance para el presente trabajo se ha considerado:

- El plan estratégico para la empresa Xternal Technological Solutions S.A.C. abarcará un período de tiempo de cinco años, desde el 2017 hasta el 2021.

- Se trabajará con la información proporcionada por la empresa a nivel físico, así como la que se pueda obtener producto de las entrevistas con los socios y personal de la empresa. También se empleará información escrita y digital del sector en donde se desenvuelve.

Se han considerado las siguientes limitaciones:

- Alguna información de la empresa de carácter confidencial a la cual no se pueda acceder.

- Limitada disponibilidad de tiempo de parte de los socios para ser entrevistados.

- Poca información respecto a la competencia directa de la empresa por ser de carácter confidencial e inaccesible. 


\section{Capítulo II: La Empresa}

\subsection{Antecedentes de la Empresa}

Xternal Technological Solutions S.A.C. es una sociedad anónima cerrada que se constituyó el 1 de setiembre del 2008 por cuatro consultores expertos en el desarrollo de soluciones en tecnología de información. Su actividad económica pertenece al rubro de consultoría y otras actividades de informática, es decir, brinda servicios a empresas de diferentes sectores económicos tanto de consultoría como de desarrollo de soluciones de tecnología de información.

La idea de negocio surge cuando cada uno de los socios se encontraban trabajando en empresas que prestaban servicios en tecnología de información. Uno de los socios independientemente encontró una oportunidad de brindar el servicio de programación sobre la plataforma SAP Netweaver Portal, de la transnacional alemana SAP, para la empresa TASA., la cual se encontraba en ese momento en la búsqueda de un nuevo proveedor con conocimientos en dicha tecnología. Este socio había formado parte de un equipo encargado del desarrollo e implementación de un proyecto informático estratégico para la empresa. Finalizando el año 2008, uno de los socios decide retirarse y ceder sus acciones a otro miembro del equipo original que participó en el proyecto mencionado anteriormente, manteniendo la sociedad en cuatro participantes. Para el año 2009, la empresa Xternal Technological Solutions S.A.C. comienza su relación contractual con TASA debido al nexo que se inició con el servicio brindado por el socio que laboró en el año 2008. Se comenzó brindando servicios de programación java sobre la plataforma de SAP descrita anteriormente en la modalidad de mejora continua. De este modo inicia su primera línea de negocio programación SAP portal, formando un equipo con dos de los socios y tres nuevos colaboradores en las instalaciones de su cliente. 
En el año 2011, deciden ampliar los servicios brindados a las empresas con el ERP SAP abriendo una nueva línea de negocio en programación ABAP. Esta nueva idea de negocio surge de la necesidad de las empresas por contar con recursos de programación en el lenguaje ABAP de SAP para nuevos desarrollos o mejoras continuas de sus aplicaciones. Esta decisión permite que los dos socios restantes renuncien a sus trabajos como dependientes y se dediquen el 100\% a la consolidación de esta nueva línea de negocio. Es en este año que ya se trasladan a su local actual en el distrito de Pueblo Libre.

Durante los siguientes años los servicios que brindan tienen un crecimiento lento en el mercado debido principalmente a la poca inversión realizada en el área de comercialización y marketing. En el año 2014, se convierte en el proveedor exclusivo de su cliente TASA en servicios de programación, lo que permite la consolidación y madurez de las dos líneas de negocio de la empresa y el aumento del nivel de ventas al comenzar a captar nuevos clientes debido a las buenas referencias de la calidad de sus servicios.

A finales del año 2015, deciden incursionar en el mercado con dos nuevas líneas de negocio que son el desarrollo de aplicativos para dispositivos móviles y business analytics. La idea de negocio surge de la necesidad de sus clientes por seguir la tendencia tecnológica en sus soluciones de tecnología de información. La empresa decide realizar una inversión grande en el mejoramiento de su infraestructura física y tecnológica adquiriendo nuevos equipos y licencias de software. La demanda por sus servicios requiere también la contratación de nuevos colaboradores, llegando a ser cerca de 35 a principios del año 2016.

Durante el año 2016, la empresa sufre una crisis cuando dos de los socios deciden retirarse para formar cada uno una nueva empresa del mismo rubro. Estos socios eran los responsables de las líneas de negocio de programación ABAP y programación SAP portal, las cuales son las más importantes de la empresa. Esta situación ocasionó que parte del 
equipo que conformaban estas dos líneas de negocio se retire con ellos, originando pérdidas económicas dado que se tuvo que negociar mejores condiciones para el personal que se mantuvo en la empresa y también se realizó una inversión mayor en la contratación de nuevos colaboradores. También perdieron clientes debido a la incertidumbre propia de la división de la sociedad, ya que no veían con buenos ojos esta situación decidiendo por no renovarles la confianza.

El año 2017 se vislumbra como el de la recuperación de la empresa ya que han logrado estabilizar la situación interna vivida por la crisis descrita, además de mantener la confianza de sus clientes principales.

\subsection{Descripción del Negocio}

Xternal Technological Solutions S.A.C. provee servicios de consultoría y desarrollo de soluciones en tecnología de información para empresas de distintos sectores económicos.

Su cartera de servicios incluye las siguientes líneas de negocio:

- Programación SAP portal, la cual se realiza sobre la plataforma de SAP Netweaver de arquitectura informática dinámica que ayuda a las empresas en el diseño, implementación y ejecución de nuevas estrategias y procesos de negocios de manera flexible y rápida.

- Programación ABAP, en donde a través de este lenguaje de programación brindan soluciones integrales y efectivas de acuerdo con cada necesidad del cliente, cumpliendo las directrices de programación y rendimiento definidas por la transnacional SAP.

- Aplicativos móviles, orientado al desarrollo de aplicaciones que funcionan en dispositivos móviles y que brindan eficiencia y flexibilidad al 
colaborador que participa en cada uno de los procesos de la empresa.

- Business analytics, en donde se ofrecen soluciones de negocio que permitan el aprovechamiento de toda la información generada por las empresas para ayudarlos en la toma de decisiones, convirtiendo la información en conocimiento, el conocimiento en acción y la acción en resultados de negocio.

\subsection{Ciclo de Vida del Producto}

La empresa Xternal Technological Solutions S.A.C. ofrece servicios de programación e implementación de soluciones informáticas a medida para sus clientes, los cuales están agrupados en las siguientes líneas de negocio: (a) programación abap, (b) programación en SAP portal, (c) aplicativos móviles, y (d) business analytics.

La línea de negocio de programación ABAP tiene en el mercado cerca de siete años en los que ha sido requerida por empresas de distintos sectores tanto en la modalidad de asignación a tiempo completo de programadores para determinados proyectos propios, como también en servicios de programación externa para nuevos desarrollos o mejora continua de desarrollos internos liderados por consultores funcionales de las empresas. Esta última modalidad es la más requerida por sus clientes. Actualmente, este servicio se encuentra en una fase de su desarrollo en el que se aprecian características similares a las de la fase de Madurez. De acuerdo con lo señalado por Muñiz y Muñiz (2016), las principales características de la fase de madurez son:

(a) las ventas siguen creciendo, pero a menor ritmo, (b) las técnicas de fabricación están muy perfeccionadas, (c) los costes de fabricación son menores, (d) gran número de competidores, (e) bajan los precios de venta; puede llegarse a la lucha de precios, y (f) gran esfuerzo comercial para diferenciar el producto. (p. 192) 
La línea de negocio de programación en SAP portal fue la primera en desarrollarse en la empresa en el año 2008. Está en el mercado cerca de nueve años y, al igual que la línea de negocio de programación abap, tiene dos modalidades en la que es requerida por sus clientes: (a) la asignación a tiempo completo en el cliente de programadores para proyectos específicos, y (b) servicios de programación externa para nuevos desarrollos o mejora continua de desarrollos internos liderados por consultores funcionales de las empresas. Este servicio ha ido evolucionando de acuerdo con el desarrollo de la plataforma netweaver que ofrece la empresa SAP al mercado, por lo que se ha mantenido una demanda constante por parte de las empresas que tienen implementado este producto. Esto concuerda con lo afirmado por Kotler y Armstrong (2012).

Aunque parece que muchos productos en la etapa de madurez permanecen sin cambios durante mucho tiempo, la mayoría de los productos exitosos evolucionan en realidad para cubrir las necesidades cambiantes de los consumidores. (p. 277)

La línea de negocio de aplicativos móviles tiene cerca de un año en el mercado y surge por la necesidad de sus clientes por tener portabilidad en sus desarrollos, siguiendo la tendencia en el sector por realizar cada vez más aplicaciones para dispositivos móviles. Algunos de sus clientes incluso han modificado sus procesos internos a fin de incluir estos dispositivos buscando eficiencia y flexibilidad en sus colaboradores. Este servicio aún no tiene mucho volumen de ventas y se encuentra en un proceso de estandarización de metodología de desarrollo y puesta a punto. Se está ofreciendo a manera de proyectos pilotos entre sus clientes caracterizados por su poco volumen transaccional. Estas características concuerdan con lo señalado por Muñiz y Muñiz (2016) respecto a la etapa de lanzamiento o introducción.

Finalmente, la línea de negocio de business analytics también es nueva, con un período de un año de antigüedad. Este servicio surge de la necesidad de los clientes de 
aprovechar la información que tienen disponible en su empresa para apoyar la toma de decisiones con soluciones informáticas específicamente diseñadas y desarrolladas para ese fin. Debido a su corto tiempo de ofrecido este servicio, la empresa Xternal Technological Solutions S.A.C. aún no tiene una rentabilidad positiva debido al poco nivel de ventas y a la inversión original que ha realizado en recursos humanos y licencias de software, según lo mencionado por los socios. De acuerdo con lo señalado por Muñiz y Muñiz (2016) respecto a las etapas o fases del ciclo de vida del producto o servicio, estas características corresponden también a la etapa de lanzamiento o introducción.

A continuación, se muestra la utilidad obtenida por cada línea de negocio al finalizar el año 2016. Los montos que se visualizan en la columna de utilidad refuerzan lo mencionado anteriormente respecto a la etapa del ciclo de vida en que se encuentran las mismas. Ver Tabla 1.

Tabla 1

Utilidades Obtenidas por Línea de Negocio

\begin{tabular}{|c|c|c|c|c|c|c|}
\hline Línea de Negocio & 2011 & 2012 & 2013 & 2014 & 2015 & 2016 \\
\hline \multicolumn{7}{|c|}{ VENTAS } \\
\hline Programación SAP Portal & $180,234.60$ & $230,023.12$ & $305,212.45$ & $380,245.56$ & $435,533.22$ & $541,789.38$ \\
\hline Programación ABAP & $250,274.90$ & $390,345.67$ & $540,033.23$ & $670,230.44$ & $920,310.43$ & $1,017,907.32$ \\
\hline Business Analytics & & & & & $10,564.32$ & $32,835.72$ \\
\hline Aplicativos móviles & & & & & $12,543.23$ & $49,253.58$ \\
\hline TOTAL & $430,509.50$ & $620,368.79$ & $845,245.68$ & $1,050,476.00$ & $1,378,951.20$ & $1,641,786.00$ \\
\hline \multicolumn{7}{|c|}{ UTILIDADES } \\
\hline Programación SAP Portal & $63,082.11$ & $80,508.02$ & $106,824.36$ & $133,085.95$ & $152,436.63$ & $193,089.42$ \\
\hline Programación ABAP & $67,574.22$ & $105,393.31$ & $145,808.98$ & $180,962.22$ & $248,483.82$ & $283,146.69$ \\
\hline Business Analytics & & & & & $-70,322.21$ & $-66,792.84$ \\
\hline Aplicativos & & & & & $-20,239.56$ & $-13,014.27$ \\
\hline TOTAL & $130,656.33$ & $185,901.33$ & $252,633.34$ & $314,048.17$ & $310,358.68$ & $396,429.00$ \\
\hline
\end{tabular}

Nota. Adaptado de "Reportes de Gestión Administrativa Xternal Technological Solutions S.A.C. - 2016”. Recuperado de Intranet Xternal Technological Solutions S.A.C.

En el siguiente gráfico se muestra el ciclo de vida de cada uno de los productos/servicios que ofrece la empresa Xternal Technological Solutions S.A.C. Ver figura 1. 


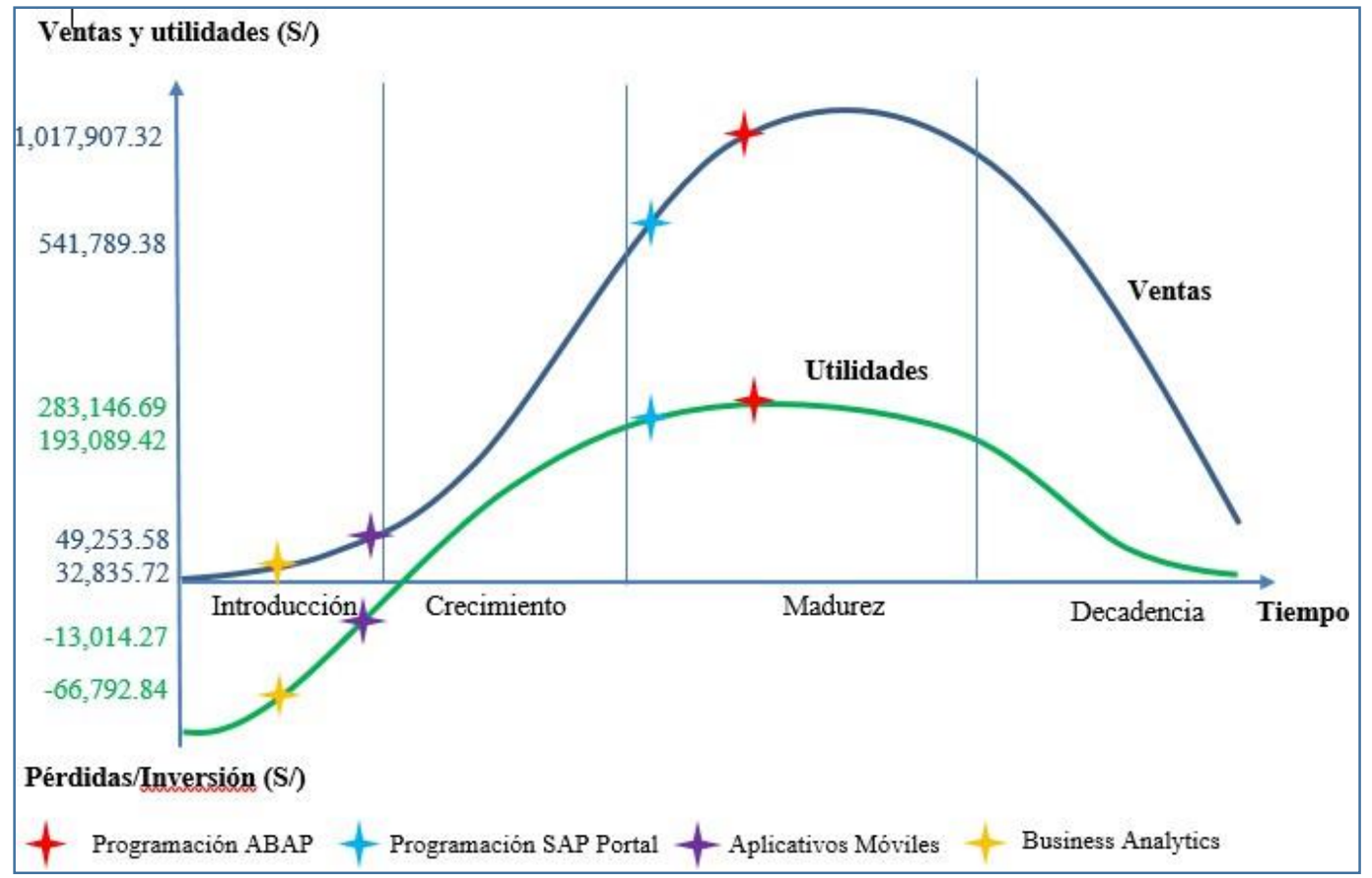

Figura 1. Ciclo de vida de los servicios de Xternal Technological Solutions S.A.C. Adaptado de Marketing (p. 273), por Philip Kotler y Gary Armstrong, 2012, México: Pearson Educación. Copyright 2012 por Pearson Educación.

\subsection{Estructura Organizacional Actual de la Empresa}

\section{Principales procesos de la organización}

Los principales procesos que se manejan en Xternal Technological Solutions

S.A.C. son los siguientes:

- Gestión Administrativa: En este proceso se contempla toda la labor administrativa realizada en la empresa, sobre todo la realizada en el área de Administración y Finanzas, en la que también se incluye el manejo de los recursos humanos y actividades de apoyo a la gestión comercial.

- Gestión Comercial: Si bien es cierto, en el organigrama se señala la posición de Gerente Comercial, la gestión comercial está bajo la supervisión del Gerente General, este proceso consiste principalmente en visitar potenciales clientes, presentar propuestas de trabajo y coordinar el servicio post venta. 
- Gestión de Operaciones: Las operaciones principales de Xternal Technological Solutions S.A.C. se dividen por áreas operativas, entre las cuales se encuentran: el Área Portal, donde se encuentran también los proyectos Mobile, el área ABAP y el área de Bussiness Analytics

\section{El entorno}

- Condiciones ambientales: El trabajo se realiza en condiciones ambientales adecuadas, en un espacio debidamente iluminado que permite realizar las tareas de manera óptima. Además, el ambiente de trabajo posee una temperatura promedio, y no existen mayores ruidos, ni interrupciones.

- Riesgos físicos: El trabajo se realiza en un entorno seguro, cómodo, limpio y con el mínimo de distracciones, teniendo las necesidades de interacción social cubiertas.

- Recursos materiales: Las instalaciones, el mobiliario y los instrumentos de trabajo son los adecuados, además de contar con tecnología actualizada.

- Diseño del puesto de trabajo: El grado de adaptación ergonómica al puesto de trabajo respeta las características corporales de los trabajadores.

- Valores, misión y carácter de la organización: Los valores que guían y orientan a los colaboradores de Xternal Technological Solutions S.A.C. son la honestidad, el compromiso, la calidad, el profesionalismo, la responsabilidad y la puntualidad. Estos determinan las prioridades que influyen en lo que se decide y atiende en cada momento y son aspectos con los que los trabajadores se pueden identificar, incrementándose la calidad del clima organizacional.

- Estructura de la empresa y ordenación jerárquica: La empresa tiene una estructura más horizontal que vertical. La distribución de responsabilidades 
se realiza de una manera adecuada y no se centraliza el poder solo en los directivos, más bien se reparte entre los integrantes del sistema.

- Políticas de incentivación, reconocimiento y promoción: Se mantienen políticas de incentivación, a manera de reconocimiento por parte de los jefes, se promueve el crecimiento y desarrollo de los colaboradores.

- Políticas de formación: Los directivos y colaboradores de la empresa coinciden en que Xternal Technological Solutions S.A.C. es un importante centro de formación de habilidades para nuevos consultores.

- Relaciones entre compañeros: Se percibe un ambiente adecuado entre los colaboradores, se suelen realizar actividades cooperativas, manejan de manera eficaz los conflictos.

- Posibilidades de conciliar la vida personal y profesional: Los colaboradores pueden lograr un equilibrio de todos los ámbitos de su vida, dado que se respetan los horarios ya fijados y esto permite que puedan realizar otras actividades, además de las profesionales.

\section{Los objetivos}

- Claridad de los objetivos: Según la información recogida, tanto de colaboradores, como de directivos, podemos mencionar que tienen claros los objetivos inmediatos y a mediano plazo, sin embargo, carecen de una visión estratégica.

- Grado de participación y aceptación de los objetivos por parte de los equipos: Los colaboradores sienten que suman a la consecución de los objetivos de la empresa y los aceptan de buena manera, porque son reforzados con un reconocimiento cuando realizan una labor óptima. 
- Niveles de exigencia: La exigencia de las tareas asignadas está regulada por la importancia del proyecto que se asume, dado que algunos se tienen que manejar con plazos reducidos y manteniendo el nivel de calidad esperado.

- Relación entre los objetivos y la valoración del desempeño: El desempeño que presenta cada colaborador está relacionado directamente con la consecución de los objetivos planteados, sin embargo, se valora también la puesta en práctica de habilidades blandas que faciliten un mejor resultado.

- Grado de coherencia de los objetivos personales con los de la organización: Por lo general, los objetivos que tiene cada colaborador de manera personal están en relación directa con los objetivos de la organización, dado que se resalta el desarrollo personal y profesional, como un objetivo recurrente en los colaboradores y ellos consideran que, al cumplir las metas organizacionales, crecerán junto con la empresa.

\section{El liderazgo}

- Tipo de liderazgo: En la empresa analizada se presenta un liderazgo predominantemente paternalista, pues el líder asume la responsabilidad de orientar y velar por el bienestar de sus subordinados, con la finalidad de obtener mejores resultados. El líder suele incentivar a los colaboradores ofreciéndoles recompensas, en caso de un trabajo bien hecho se les reconoce a través de reuniones periódicas, en las que el líder aprovecha para conocer mejor a cada uno de los miembros de su equipo.

- Grado de autonomía y supervisión: Los colaboradores de Xternal Technological Solutions S.A.C. consideran que cuentan con cierta autonomía dentro de los proyectos en los que participan. Sin embargo, siempre son 
supervisados y no están empoderados para tomar decisiones importantes dentro de la empresa.

- Estilo en la toma de decisiones: El estilo predominante que se tiene al momento de tomar decisiones es el estilo analítico, puesto que los líderes necesitan mucha información para optar por una postura, recaban mucha información, son capaces de solucionar problemas y adaptarse a diversas situaciones.

- Identificación con las características del líder: Los colaboradores de Xternal Technological Solutions S.A.C. se identifican principalmente con dos líderes, que son un referente para los empleados con menos tiempo en la empresa. Ellos ejercen su profesión de manera responsable, evalúan competencias y el desempeño de manera eficiente. Constantemente motivan a sus empleados, actuando de manera justa y adecuada. Por lo tanto, poseen muchas características que son imitadas y compartidas por sus subordinados.

\section{La comunicación interna}

La comunicación interna tiene como objetivo transmitir de manera coherente los valores, las normas, y los objetivos de la organización. Estos sistemas de intercambio de información se concretan en acciones comunicativas como: la asignación de tareas, las evaluaciones del desempeño, la valoración del trabajo, las peticiones de cambio, la información de resultados, las acciones para motivar, entre otros.

- Comunicación ascendente: La comunicación de propuestas y peticiones por parte de los colaboradores, hacia los directivos y líderes, se da a través del medio oral y escrito, para este fin se utilizan medios electrónicos, como el correo electrónico y aplicaciones como Skype y WhatsApp.

- Comunicación descendente: Los mensajes e interacciones que las figuras de 
poder dirigen a sus subordinados se da a través del medio oral y escrito, para este fin también se utilizan medios electrónicos, como el correo electrónico y aplicaciones como Skype y WhatsApp.

- Red informal de comunicación: Las comunicaciones informales, que favorecen al contacto entre compañeros a nivel socio afectivo, se transmiten de manera oral y escrita. En el caso de la utilización de medios electrónicos, predomina el uso de WhatsApp.

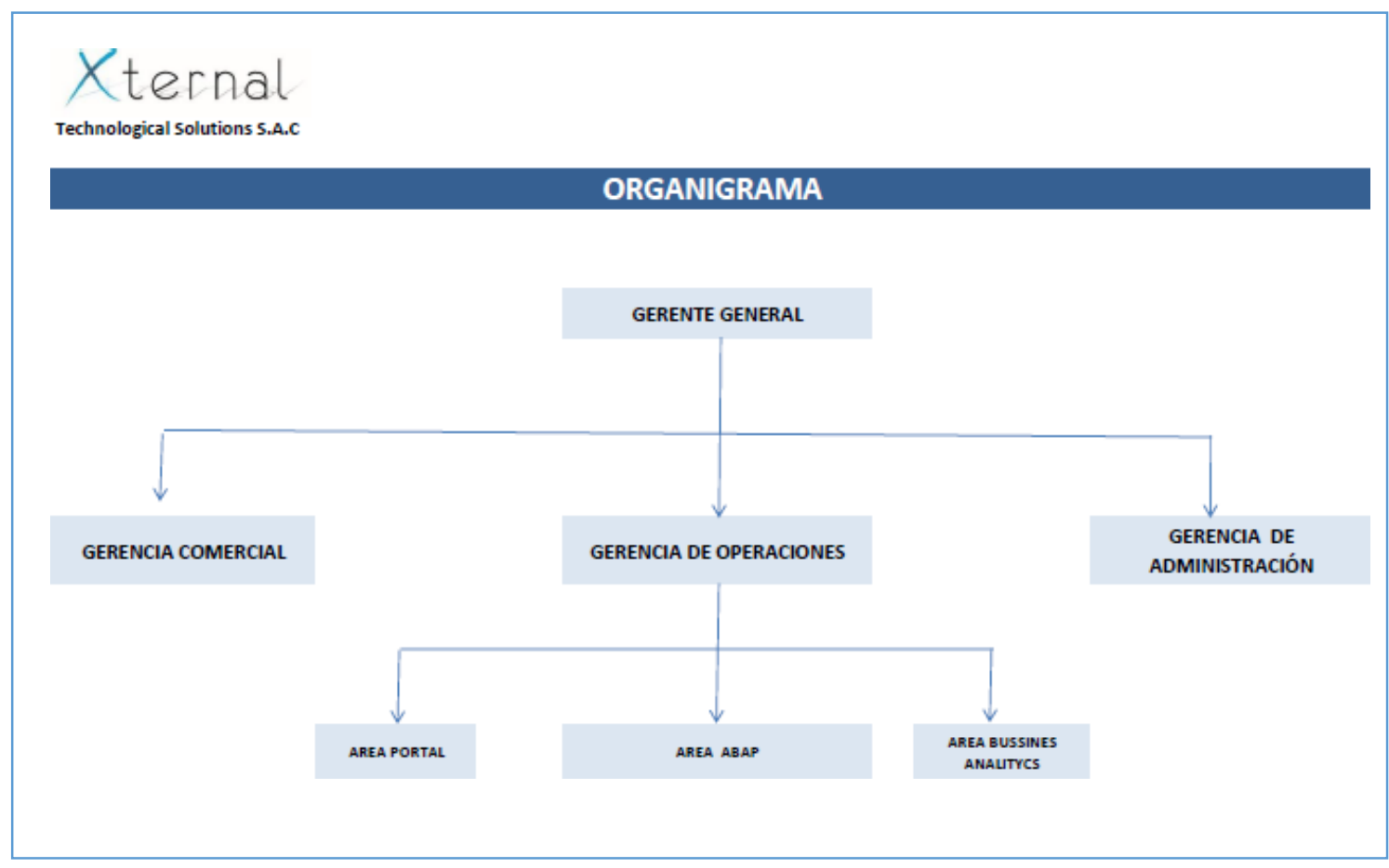

Figura 2. Organigrama de Xternal Technological Solutions S.A.C. Recuperado de http://xternal.biz

El organigrama actual de la empresa Xternal Technological Solutions S.A.C. se puede apreciar en la Figura 2.

La estructura organizacional actual de la empresa, dado el reducido número de trabajadores, no representa mayor complejidad. Son los propietarios quienes manejan directamente algunas áreas funcionales, pero se sugiere que en el futuro esta situación cambie, para que los propietarios se dediquen exclusivamente a temas de gestión. 
A continuación, se detallará cada una de las posiciones que conforman el organigrama de la empresa:

\section{Gerente General}

Objetivo del Puesto:

Plantear, organizar, dirigir y controlar la marcha administrativa y técnica de la empresa y la implementación de las políticas establecidas por los socios de la empresa; así como representar legal, administrativa y judicialmente a Xternal Technological Solutions S.A.C.

Estudios Requeridos:

Bachiller o Titulado en Administración, Ingeniería Industrial, Informática, Sistemas o Electrónica.

\section{Experiencia Requerida:}

Mínimo cinco años en puestos similares.

\section{Funciones:}

- Ejerce la representación legal, administrativa y judicial de la empresa, ante instituciones y organismos nacionales, públicos o privados.

- Propone a los socios políticas y estrategias de desarrollo de la empresa y controla su implementación.

- Dirige la elaboración del plan estratégico, así como los planes operativos de la empresa.

- Propone estudios, normas y acciones técnicas, administrativas y legales para asegurar el cumplimiento de las funciones y atribuciones de la empresa. 
- Dirige y coordina las acciones de las diferentes áreas a fin de cumplir con los fines y objetivos de la empresa.

- Orienta la gestión de la empresa al servicio al usuario, así como promueve su mejoramiento continuo.

- Controla y evalúa la ejecución presupuestal.

- Establece los mecanismos que aseguren el cumplimiento de las normas de control internas en la gestión de recursos de la empresa.

- Llevar los registros y realizar las operaciones contables derivadas del presupuesto institucional.

- Mantener actualizados los registros contables, así como la documentación de soporte de estos, para la consolidación de los estados financieros.

- Dirigir lo relacionado con la elaboración de normas, procedimientos, manuales de organización, y demás instrumentos de uso financiero y administrativos.

- Tramitar los pagos a proveedores, contratistas y personal, así como de cualquier otra obligación financiera de la institución.

- Preparar la información que de acuerdo con su competencia debe presentar a las autoridades internas o agentes externos.

- Formula lineamientos y propone normas y criterios uniforme bajo la supervisión del cumplimiento de los contratos de concesión para la explotación de la infraestructura a cargo de las entidades prestadoras.

- Asesora en la elaboración de propuestas, normas y reglamentos y los criterios para su aplicación y supervisión, de acuerdo de los requerimientos del marco normativo de la empresa. 


\section{Habilidades Técnicas:}

- Conocimiento y experiencia en planeación, dirección, supervisión y control en el área administrativa y de operación.

- Conocimientos de Administración de Recursos Humanos, Contabilidad Financiera, Finanzas Corporativas, Administración de la Logística Operacional

- Conocimientos de leyes y reglamentos en materia laboral, comercial e impuestos.

\section{Habilidades Blandas:}

- Visión estratégica del negocio.

- Pensamiento crítico y sistémico.

- $\quad$ Trabajo en equipo.

- Negociación.

- Escucha y comunicación efectiva.

\section{Gerente Comercial}

\section{Objetivos del Puesto:}

Coordinar las actividades de la fuerza de ventas, los planes de comercialización y mercadeo, a fin de lograr el posicionamiento de la empresa, en base a políticas establecidas para la promoción, distribución y venta de servicios a fin de lograr los objetivos de ventas.

\section{Estudios Requeridos:}

Bachiller en Administración, Ingeniería Industrial, Informática, Sistemas o Electrónica.

\section{Experiencia Requerida:}

Mínimo cinco años en puestos similares. 


\section{Funciones:}

- Definir, planificar y dirigir la estrategia comercial.

- Realizar plan de ventas orientado a resultados (semanal y mensual).

- Analizar e investigar mercados, (en conjunto con ventas y operaciones).

- Búsqueda permanente de nuevas ideas.

- Controlar que los objetivos y planes de acción se cumplan en los plazos y condiciones establecidos.

- Analizar y desarrollar productos y servicios.

- Evaluar las necesidades del área para establecer programas de capacitación, mejoramiento y crecimiento de departamento.

- Proponer los proyectos de desarrollo, así como los presupuestos de ventas, gastos e inversiones derivadas de estos.

- Generar estrategia y plan de marketing para los productos y servicios.

- Definir estrategia de posicionamiento de Xternal Technological Solutions

$$
\text { S.A.C. }
$$

- Monitorear el cumplimiento de objetivos de venta e indicadores de gestión establecidos.

- Desarrollar y liderar nuevas oportunidades de negocios.

\section{Habilidades Técnicas:}

- Conocimientos en dirección de equipos de venta.

- Capacidad para identificar segmentos y oportunidades comerciales atractivas para la empresa buscando mantener y desarrollar los negocios actuales y generar nuevos. 
- Habilidad para definir, proponer, coordinar y ejecutar las políticas de comercialización orientadas al logro de una mayor y mejor posición de la empresa en el mercado.

\section{Habilidades Blandas:}

- Habilidades de comunicación.

- Aptitud para trabajar en equipos de alto desempeño.

- Dinamismo y velocidad de respuesta.

- Habilidades de negociación.

- Autonomía.

- Creatividad.

- Visión de Negocio.

- Proactividad.

- Capacidad de adaptación y de aprendizaje.

\section{Gerente Administrativo}

\section{Objetivos del Puesto:}

Administrar los recursos humanos, materiales (logística) y financieros relacionados con el proceso de negocios, diseñando las políticas y procedimientos a seguir en materia presupuestal, flujos de efectivo, análisis financiero, movilidad del personal y control del gasto administrativo; garantizando el suministro oportuno de los recursos necesariamente requeridos en la implementación de los proyectos de producción.

\section{Estudios Requeridos:}

Bachiller en Administración, Ingeniería Industrial, Informática, Sistemas o Electrónica.

\section{Experiencia Requerida:}

Mínimo cinco años en puestos similares. 


\section{Funciones:}

- Formula y propone a la Gerencia General Normas, políticas y procedimientos para el mejor funcionamiento de las actividades relacionadas con la administración y contabilidad de la organización.

- Supervisa la formulación, ejecución y evaluación del presupuesto anual, de conformidad con las disposiciones legales aplicables.

- Elaboración y control de presupuestos.

- Revisar los cheques emitidos por diferentes conceptos, tales como: pagos a proveedores, pagos de servicios, aportes, asignaciones, avances a justificar, incremento o creación de fondos fijos, fondos especiales y de funcionamiento, alquileres, y otras asignaciones especiales.

- Aprobar y firmar el reporte de honorarios profesionales bajo la modalidad de horas-hombre y suma Global.

- Aprobar y firmar la emisión de cheques, notas de débito, entre otras, para la adquisición de bienes y servicios.

- Apoyar a la organización en todas las gestiones legales y reglamentarias. (asesorías externas fiscales, contables y/o laborales, etc.).

- Controlar y registrar por separado los gastos de los trabajos realizados de diferentes contratos que mantenga la empresa.

- Elaborar informe de estados financieros para su presentación a la Gerencia General.

- Otras que le sean asignadas por la Gerencia General dentro del ámbito de su competencia.

- Control de Cuentas por Cobrar y Cuentas por Pagar. 
- Análisis de los Estados Financieros para facilitar la toma de decisiones a la Gerencia.

- Control de Ingresos y Egresos con el fin de administrar el Capital de Trabajo.

- Control de Contratos en ejecución en cuanto al inicio, finalización y cobro de los trabajos realizados.

\section{Habilidades Técnicas:}

- Conocimientos de Administración de Recursos Humanos, Contabilidad Financiera, Finanzas Corporativas, Administración de la Logística Operacional

- Conocimientos de leyes y reglamentos en materia laboral, comercial e impuestos.

- Interpretación de estados financieros.

- Elaboración de presupuestos.

- Análisis de flujo de efectivo.

- Diseño y seguimiento a indicadores financieros.

- Administración del proceso de compras.

\section{Habilidades Blandas:}

- Visión estratégica del negocio.

- Pensamiento crítico y sistémico.

- $\quad$ Trabajo en equipo.

- Negociación.

- Escucha y comunicación efectiva. 


\section{Especialista ABAP}

Objetivos del Puesto: Implementar los requerimientos en base a las mejoras prácticas de desarrollo ABAP.

\section{Estudios Requeridos:}

Bachiller en Ingeniería Industrial, Informática, Sistemas o Electrónica.

\section{Experiencia Requerida:}

Mínimo tres años en puestos similares.

\section{Funciones:}

- Analizar soluciones propuestas a los requerimientos que realiza el área de negocio.

- Gestionar a los consultores de desarrollo ABAP que estén asignados a proyectos y/o requerimientos.

- Asegurar la fiabilidad de los desarrollos implementados.

- Proponer mejores prácticas en la elaboración de los desarrollos basados en tecnología ABAP.

- Cumplir con los tiempos establecidos para los proyectos en los que está involucrado.

- Extraer información de SAP para análisis derivados de requerimientos de las áreas de negocio.

\section{Habilidades Técnicas:}

- Programación Orientada a Objetos en ABAP

- Programación en ABAP.

- Desarrollo de BSP (Business Server Pages)

- Conocimientos en PI e interfaces 
Habilidades Blandas:

- Capacidad de Análisis

- Habilidad numérica

- Comunicación

- Trabajo en Equipo

- Negociación

\section{Especialista PORTAL}

Objetivos del Puesto: Implementar los requerimientos en base a las mejores prácticas de desarrollo PORTAL NETWEAVER.

\section{Estudios Requeridos:}

Bachiller en Ingeniería Industrial, Informática, Sistemas o Electrónica.

\section{Experiencia Requerida:}

Mínimo tres años en puestos similares.

\section{Funciones:}

- Recabar información de los usuarios o clientes, capacidad para manejar reuniones y expectativas.

- Analizar los requerimientos, diseñar y especificar técnicamente la mejor solución en base a la experiencia adquirida.

- Elaboración de documentación técnica para desarrollos SAP R3.

- Manejo y control de pruebas y ajustes.

- Responder consultas técnicas en SAP R3.

\section{Habilidades Técnicas:}

- Conocimientos en programación JAVA. 
- Manejo de SAP Certified Technology Professional - Platform Technology with SAP NetWeaver 7.0, SAP Certified Technology Consultant SAP NetWeaver '04- OS/DB Migration for SAP Systems.

- Experiencia administrando soluciones SAP: ECC, BW, SCM, SAP Business Object, Enterprise Portal, PI, SOLMAN.

Habilidades Blandas:

- Capacidad de Análisis

- Habilidad numérica

- Comunicación

- Trabajo en Equipo

- Negociación

\section{Especialista Business Analytics}

Objetivos del Puesto: Desarrollar y ejecutar estrategias de gestión empresarial, situando al cliente en el centro del negocio de comunicación e infraestructuras tecnológicas diseñadas con el objetivo de construir una relación duradera con los clientes, uno a uno, identificando, comprendiendo y satisfaciendo sus necesidades.

\section{Estudios Requeridos:}

Bachiller en Administración, Ingeniería Industrial, Informática, Sistemas o Electrónica.

\section{Experiencia Requerida:}

Mínimo tres años en puestos similares.

\section{Funciones:}

- Diseño y puesta en marcha de un sistema de información continuo y una metodología de trabajo para analizar la eficiencia y rentabilidad de las 
empresas clientes, así como un Dash Board mediante KPI’s, tanto numéricos como gráficos para los distintos niveles organizativos.

- Elaboración sistemática de análisis e informes de calidad y rentabilidad, tanto existente como potencial, y análisis de comportamientos históricos y tendencias futuras para las empresas clientes.

- Dar formación y soporte al resto de las áreas tanto en la metodología como en el uso de las herramientas definidas para llevar a cabo estos análisis.

- Desarrollar proyectos e iniciativas de mejora de productos y procesos junto con el resto de las áreas.

\section{Habilidades Técnicas:}

- Conocimiento de herramientas de Business Analytics.

- Participación en Proyectos de TI (Datawarehouse) y Business Intelligence en áreas de Sistemas.

- Conocimientos avanzados en herramientas de prospección.

\section{Habilidades Blandas:}

- Visión estratégica del negocio.

- Pensamiento crítico y sistémico.

- Trabajo en equipo.

- Negociación.

- Escucha y comunicación efectiva.

\subsection{Situación del Mercado y Financiera Actual de la Industria}

Recientemente el Foro Económico Mundial (WEF por sus siglas en inglés) publicó el informe global de tecnología de la información 2016, de acuerdo con una nota de prensa publicada por (cdi.org.pe, n.d.). En este informe se menciona a Finlandia, Suiza, Suecia, 
Israel, Singapur, Países Bajos y Estados Unidos como los países líderes en inversiones en tecnologías de información y comunicación. A nivel de Latinoamérica, es Chile quien se encuentra en el puesto 38 del ranking que muestra a Perú en el puesto noventa manteniendo su posición respecto al año anterior (Ver Tabla 2). El mismo informe indica como causas del poco desarrollo a una baja calidad en el sistema educativo, especialmente en lo que se refiere a las matemáticas y las ciencias, entre otros.

Tabla 2

Ranking Latinoamérica RGTI

\begin{tabular}{lccc}
\hline Economía/País & 2016 & 2015 & Puntaje \\
\hline Chile & 38 & 38 & 4.6 \\
Uruguay & 43 & 46 & 4.5 \\
Costa Rica & 44 & 49 & 4.5 \\
Panamán & 55 & 51 & 4.3 \\
Colombia & 68 & 64 & 4.1 \\
Brasil & 72 & 84 & 4.0 \\
México & 76 & 69 & 4.0 \\
Argentina & 89 & 91 & 3.8 \\
Perú & 90 & 90 & 3.8 \\
El Salvador & 93 & 80 & 3.7 \\
República Dominicana & 98 & 95 & 3.6 \\
Paraguay & 105 & 105 & 3.4 \\
\hline & 93.016 .0
\end{tabular}

Nota. Ranking Latinoamérica RGTI 2,016. Tomado de "Informe Global de Tecnología de Información 2,016", por Centro de Desarrollo Industrial (CDI), 2016. Recuperado de http://www.cdi.org.pe/InformeGlobaldeInformacion/GITR2016.html 
La industria del software peruana ha crecido en un promedio anual de $15 \%$ durante los últimos seis años, de acuerdo con Gestión (2016). Esta proyección fue realizada por la empresa VBG Sistemas. Su gerente general, el señor Héctor Vicuña Bermejo, afirma en ese mismo artículo que la inversión en tecnología de información ya no es un lujo sino una necesidad para que las empresas puedan crecer, y que la industria nacional de software está creciendo a tasas que están muy por encima de la dinámica de crecimiento de la economía del país. Un artículo publicado por Tineo (2016) indica que el Perú destina un $2.57 \%$ de su PBI a inversiones de tecnología, siendo el PBI per cápita del país de US\$ 6,168.

Hoy en día, las empresas deciden invertir en los sistemas ERP que les permiten obtener múltiples beneficios entre los que destacan la integridad/seguridad de la información y una mayor eficiencia en sus procesos, lo que se ve traducido en mejores resultados económicos.

El desarrollo de la industria del software nacional permite que cada día más empresas tengan la necesidad de contar con los servicios de empresas expertas en consultoría y desarrollo de soluciones en tecnología de información, ya sea para implementar un sistema ERP o para elaborar soluciones que funcionen en sincronía con este y siguiendo las tendencias informáticas del sector. 


\section{Capítulo III: Formulación de la Visión, Misión y Valores de la Empresa}

\subsection{Visión}

En el presente tópico se revisan los conceptos y herramientas que se requieren para evaluar y redactar la visión de una empresa. Se tiene la oportunidad de comprender mejor la visión de la empresa Xternal Technological Solutions S.A.C., dado que es un negocio que acaba de replantear su estrategia, luego de una crisis.

Thompson, Gamble, Peteraf, y Strickland III, señalaron que:

Las opiniones y conclusiones de la alta administración sobre el rumbo de la compañía en el largo plazo y sobre la mezcla de producto / mercado / cliente / tecnología que parezca óptima para el futuro constituye la visión estratégica de la empresa. (2012, p. 53)

Los dueños del negocio son los que plantean la filosofía de la empresa, con la intención de tener una imagen que atraiga a su público y comprometa a sus colaboradores. Cuando esta filosofía se pone por escrito resultan las declaraciones de visión y misión de una empresa. A medida que la empresa evoluciona en el tiempo esta filosofía puede y debe cambiar, para adaptarse a las nuevas exigencias de su estructura interna y las de su entorno, por lo que se requiere que las declaraciones de misión y visión deben ser evaluadas y actualizadas de acuerdo con estos aspectos.

La visión de una empresa debe ser expuesta tanto a los colaboradores como a los clientes de la empresa, es muy necesario que se dé a conocer porque transmite lo que la empresa quiere llegar a ser y todos los involucrados tienen que estar comprometidos con esta declaración, para que se llegue a concretar de la mejor manera y en el plazo esperado.

Por lo tanto, es muy importante que la declaración de la visión debe establecerse antes que la de la misión, dado que la visión dictará las pautas necesarias para desarrollar una misión que nos lleve a alcanzar lo planeado. La visión debe ser breve, de preferencia 
en una sola oración y es muy necesaria la participación de los gerentes de la empresa, dado que es lo que se espera de la empresa en un futuro a mediano o largo plazo.

\subsubsection{Visión actual de la empresa.}

La empresa Xternal Technological Solutions S.A.C. actualmente cuenta con la siguiente visión:

Nuestra visión es ser reconocida como una consultora confiable y eficiente, especializada en soluciones tecnológicas e integrada por un grupo de profesionales de comprobada experiencia que pueda servir a sus clientes de manera oportuna, transparente e inmediata.

\subsubsection{Análisis de la visión actual.}

En Thompson, Gamble, Peteraf, \& Strickland III (2012) se llega a la conclusión que la declaración de una visión debe cumplir con ciertas características, la cuales se analizarán respecto a la visión actual de la empresa:

- Distintiva, según el análisis se considera que la visión actual de Xternal Technological Solutions S.A.C. no la distingue de las demás empresas del mercado.

- Específica, tiene una visión muy general, que cualquier otra empresa de su sector podría tener y por lo tanto no cumpliría con este criterio.

- Direccionada, según esta premisa se evidencia que no tiene una dirección clara, no apunta hacia un objetivo audaz y tampoco se podría evidenciar un plazo determinado de cumplimento.

- Clara, se puede señalar que la visión actual si es bastante clara, pues utiliza un lenguaje sencillo y preciso. 
- Convincente, respecto a este punto, Xternal Technological Solutions S.A.C. sí plantea una visión que podría ser alcanzable y por lo tanto convincente, sin embargo, no resulta ser motivadora.

\subsubsection{Matriz de la visión propuesta para la empresa.}

En la Tabla 3 se muestra la matriz para la visión propuesta de la empresa:

Tabla 3

Modelo de matriz de la visión propuesta para la empresa Xternal Technological Solutions S.A.C

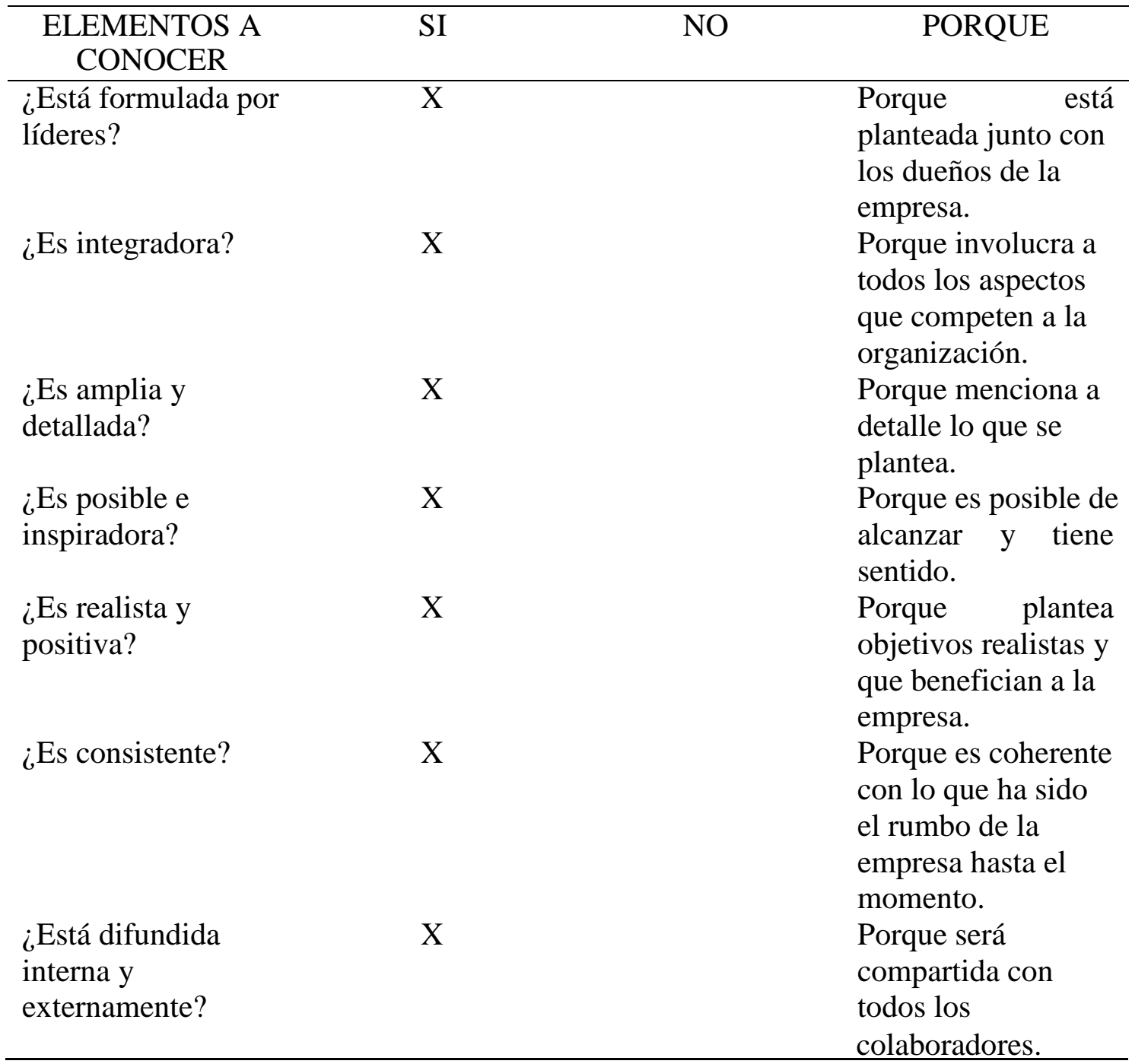




\subsubsection{Visión propuesta.}

En la Tabla 4 se aprecia los criterios guía que se tomarán en cuenta para redactar la

visión propuesta para la empresa.

Tabla 4

Redacción de una declaración de visión. Que hacer, qué evitar

\begin{tabular}{ll}
\hline Qué hacer & Qué evitar \\
\hline Sea gráfico. Presente una imagen clara del rumbo & Evite que sea ambigua o incompleta. No \\
de la empresa y de la posición o posiciones en el & escatime al especificar hacia dónde se dirige la \\
mercado que se pretende conseguir. & empresa ni cómo se prepara para el futuro. \\
Vea al futuro con sentido de dirección. Describa & No se ate al presente. Una visión no trata de lo \\
el curso estratégico que trazó la directiva y las & que la compañía alguna vez hizo o hace ahora, \\
clases de cambios de & sino de "hacia dónde vamos".
\end{tabular}

ayudarán a la compañía a prepararse para el

futuro.

Mantenga el tema. Sea lo bastante específico para ofrecer a los administradores una guía con la que tomen decisiones y asignen recursos.

Conserve un margen de maniobra. La

flexibilidad también es buena; el curso que trazó la directiva quizá deba ajustarse conforme cambien las circunstancias del producto/mercado/cliente/tecnología, y presentar una nueva declaración de visión cada uno o tres años es señal de falta de timón en la administración.

Asegúrese de su viabilidad. La ruta y la dirección deben plantearse dentro de las posibilidades razonables de lo que la empresa es capaz; con el tiempo, una compañía debe demostrar avances mensurables para el logro de la visión.

Mencione por qué la ruta es sensata respecto de los negocios. El rumbo elegido debe beneficiar los intereses de largo plazo de todos los interesados (en especial accionistas, empleados y clientes).

Procure que sea fácil de recordar. Para dar a la organización un sentido de dirección y propósito, la visión tiene que comunicarse con facilidad. Es ideal que se reduzca a unas cuantas líneas o a una No emplee un tono demasiado amplio. Se debe evitar un lenguaje tan general que permita que la empresa tome casi cualquier dirección, persiga casi cualquier oportunidad o entre en casi cualquier línea de negocios.

No exprese la visión en términos sosos o poco inspiradores. Las mejores declaraciones de visión tienen el poder de motivar al personal e inspirar confianza en los inversionistas sobre la dirección o perspectivas de la empresa.

No sea genérico. Una declaración de visión aplicable a compañías de una o varias industrias (o a cualquiera de varias compañías en la misma industria) no ofrecerá una identidad exclusiva a la compañía.

No recurra sólo a los superlativos. Las visiones que sostienen que el curso estratégico de la compañía es ser "el mejor", "el más exitoso", o un "líder reconocido" o "líder mundial" suelen ser engañosas al soslayar lo esencial y no revelar aspectos específicos sobre la ruta que la compañía eligió para llegar allí.

No sea farragoso. Las declaraciones de visión demasiado extensas tienden a perder enfoque y significado. Una declaración de visión que no sea frase memorable (como la famosa visión de breve ni directa tenderá a alejar a su audiencia. Henry Ford: "un auto en cada cochera").

Nota. Redacción de una declaración de visión. Que hacer, qué evitar. Tomado de Administración Estratégica - Teoría y Casos, 18a Edición, Thompson, Peteraf, Gamble y Strickland (2012, p. 24). 
Siguiendo los criterios guía anteriormente descritos, se ha propuesto la siguiente visión:

Ser una empresa líder e innovadora en soluciones de tecnología de información, reconocida por sus clientes por su calidad de servicio, como un aliado estratégico para sus negocios.

Esta nueva visión propuesta fue sometida al mismo análisis por el que pasó la visión actual de la empresa. Los resultados obtenidos son descritos a continuación.

- Distintiva, por ser un rubro con muchos competidores, la distinción se dará por el reconocimiento del servicio de calidad brindado a sus clientes.

- Específica, porque tiene como principal objetivo el convertirse en aliado estratégico de sus clientes.

- Direccionada, se menciona un objetivo claramente a alcanzar y por el cual quiere ser reconocida, que es ser un aliado estratégico de los negocios de sus clientes.

- Clara, si es bastante clara pues utiliza un lenguaje sencillo y preciso.

- Convincente, se aprecia que es alcanzable y motivadora a su vez, por lo que podría ser convincente para todos los colaboradores.

Los resultados obtenidos en la encuesta formulada a los dueños de la empresa fueron muy importantes para realizar la nueva visión propuesta. El formato de la encuesta es descrito en los Anexos.

\subsection{Misión}

Thompson, Peteraf, Gamble \& Strickland III (2012) señalaron que:

"una declaración de misión describe el propósito y el negocio actual de la empresa: quiénes somos, qué hacemos y por qué estamos aquí” (p. 26). 
La misión pone de manifiesto la identidad de la organización para ser reconocida en su entorno, las reglas, normas y principios que orientan la actividad de los integrantes, la cohesión alrededor de objetivos comunes, lo cual facilita la resolución de conflictos y motivación del personal. Se puede afirmar además que la declaración de la misión define el negocio al que se dedica la organización, las necesidades que cubren con sus productos y servicios, el mercado en el cual se desarrolla la empresa y la imagen pública de la empresa u organización.

Su importancia se basa principalmente en que ofrece una razón de existencia a la organización, imparte dirección a los esfuerzos individuales y colectivos, inspira y motiva al desempeño de excelencia, diferencia y distingue la organización de otras, propicia el compromiso con las ideas y causas que persigue la organización.

\subsubsection{Misión actual de la empresa.}

La empresa Xternal Technological Solutions S.A.C. actualmente cuenta con la siguiente misión:

Nuestra misión es ofrecer soluciones óptimas de acuerdo con las necesidades de nuestros clientes, con la finalidad de cubrir sus requerimientos en el ámbito tecnológico y ayudar en el logro de sus objetivos empresariales.

\subsubsection{Análisis de la misión actual.}

En el año 2012, Thompson, Peteraf, Gamble y Strickland III llegaron a la conclusión de que una declaración de misión debe utilizar un lenguaje específico para transmitir la identidad de la empresa.

La declaración de misión debe ser capaz de:

- Identificar los productos o servicios de la compañía.

- Especificar las necesidades del comprador que se pretende satisfacer. 
- Identificar los grupos de clientes o mercados que se empeña en atender.

- Precisar su enfoque para agradar a los clientes.

- Otorgar a la compañía su identidad propia.

La mayoría de las declaraciones de misión no logran transmitir todas las facetas del negocio de una empresa o no logran dejar clara la identidad de esta, dado que utilizan un lenguaje muy general que no las diferencia de las demás empresas que se encuentran dentro del mismo negocio o industria.

De esta manera, se evidencia que la empresa Xternal Technological Solutions S.A.C. posee una misión que transmite la razón de ser de la organización a través de la satisfacción de las necesidades de sus clientes y también comunica sus objetivos principales, que se transmiten a través de la intención de cubrir los requerimientos tecnológicos de sus clientes y así apoyarlos en la consecución de sus metas organizacionales, sin embargo continua siendo una misión muy general, que no transmite una identidad propia y particular de la organización.

\subsubsection{Elementos de la misión propuesta para la empresa.}

La Tabla 5 muestra los elementos que se han tomado en cuenta para la misión propuesta de la empresa. 
Tabla 5

Modelo de matriz de elementos de la misión propuesta para la empresa Xternal Technological Solutions S.A.C

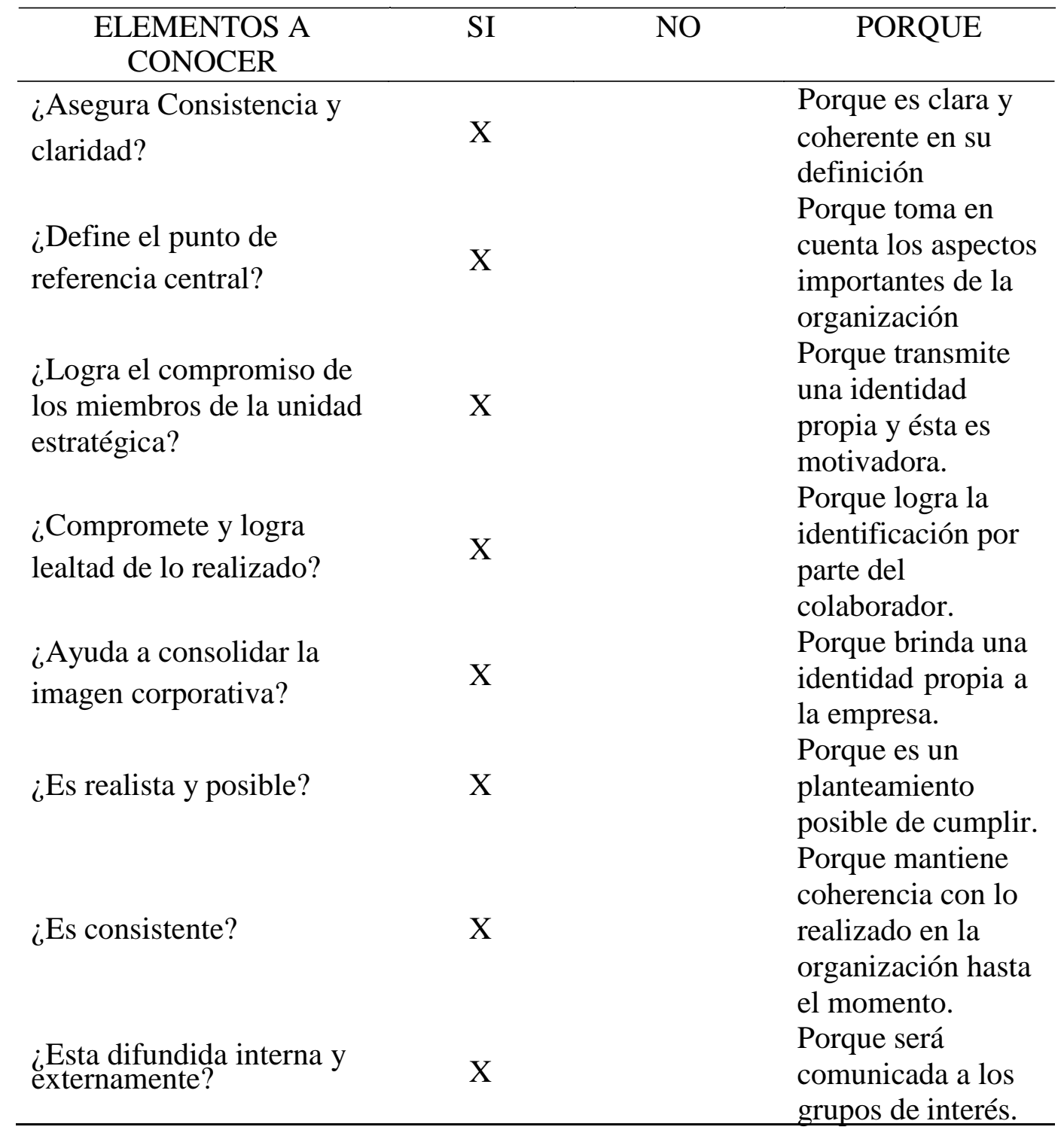

\subsubsection{Misión propuesta.}

Thompson, Gamble, Peteraf, \& Strickland III (2012) señalaron que:

La filosofía y la visión de una organización se expresan en una declaración de misión que básicamente consiste en desarrollar los siguientes puntos:

- Valores esenciales.

- Ámbito geográfico. 
- Dirección.

- Relaciones con quienes participan en ella.

- Visión del futuro (a menudo con base en la misión histórica).

Aunque pueden variar, los pasos para el desarrollo de una declaración de misión son los siguientes:

- Evaluación del perfil pasado y presente de la empresa.

- Contribución de los participantes en la empresa a la dirección futura.

- Consenso de las necesidades opuestas de los grupos interesados (p. ej., accionistas, acreedores, administradores, empleados y comunidad).

- Elaboración del enunciado de la misión que describa la dirección general de la organización, sus valores y filosofía, ámbito geográfico y contribución a la sociedad.

- Discusión de la declaración de misión con grupos de interesados, administradores y empleados, y realización de los ajustes necesarios.

- Comunicación de la declaración de misión a todos los que requieran conocerla y exposición tanto de sus implicaciones para la dirección estratégica de la organización como de sus objetivos organizacionales específicos, e incluso, de las metas y los objetivos concretos de cada unidad organizacional. (p. 110)

Siguiendo el marco teórico descrito anteriormente, se ha propuesto la siguiente declaración de misión:

Brindar soluciones en tecnologías de información innovadoras y de calidad que cubran con las necesidades de las empresas de los diferentes sectores económicos del país, con la excelencia e integridad de nuestros colaboradores. 
Se ha planteado esta declaración de misión dado que toma en cuenta los aspectos más importantes requeridos por la literatura. Transmite los valores esenciales de la organización, para que los colaboradores puedan sentirse identificados con ellos. Circunscribe un alcance geográfico en el cual se cumplirá la misión de la empresa. Señala la dirección en la cual debe ir la empresa para alcanzar sus objetivos. Transmite una visión de futuro, por lo tanto, puede lograr que la organización se comprometa con la consecución de ese escenario deseado y beneficioso para todos los grupos de interés.

Asimismo, se ha tomado en cuenta los resultados obtenidos en la encuesta formulada a los supervisores de cada línea de negocio y a los dueños de la empresa para la elaboración de la misión propuesta. Los formatos de estas se describen en los Anexos.

\subsection{Valores}

Thompson, Peteraf, Gamble y Strickland III (2012) señalan que:

Los valores de una compañía (algunas veces llamados valores esenciales) son las creencias, características y normas conductuales que la administración determinó que deben guiar el cumplimiento de su visión y misión. Los valores se relacionan con un trato justo, integridad, conducta ética, sentido innovador, trabajo en equipo, calidad suprema, servicio superior al cliente, responsabilidad social y ciudadanía comunitaria, entre otros aspectos.

Muchas compañías redactan una declaración de valores para destacar la expectativa de que los valores se reflejen en la conducción de las operaciones de la compañía y en la conducta de su personal (p. 27).

Cada empresa decide cuáles son los valores que guían sus acciones, dependiendo del momento histórico en que se encuentre. La existencia de una lista de valores esenciales para una empresa es muy importante, debido a que permiten que sus integrantes 
interactúen de una manera adecuada, facilitan la obtención de objetivos, promueven un cambio de pensamiento, son la base de las actitudes, motivaciones y expectativas de los colaboradores, orientan el comportamiento de sus integrantes y permiten posicionar una cultura empresarial.

Existen empresas con valores que no son más que una lista de palabras y frases decorativas de los ejecutivos, pero con un efecto muy pobre en la conducta del personal. Muchas empresas tienen una lista de valores simplemente porque es lo que se espera a partir de las nuevas tendencias organizacionales o porque su competencia también la tiene.

Por otro lado, existen empresas en la que los dirigentes están comprometidos con la transmisión y cumplimento de una serie de normas que generan una identidad propia en la organización, de manera tal que se integran en la cultura corporativa y por lo tanto plantean el rumbo a seguir.

La mayoría de las compañías identifica de cuatro a ocho valores esenciales.

\subsubsection{Valores actuales de la empresa.}

Como valores actuales de la empresa Xternal Technological Solutions S.A.C se pueden mencionar:

- Honestidad

- Compromiso

- Calidad

- Profesionalismo

\subsubsection{Análisis de los valores actuales.}

Los valores deben estar relacionados con la identidad de la empresa, que recoge las variables principales de comportamiento de una organización, así como acontecimientos relevantes de la historia y la trayectoria de ésta. 
La empresa Xternal Technological Solutions S.A.C. no tiene una lista de valores claramente definida, pero de las declaraciones de sus directivos se puede recoger que dan mucha importancia a los siguientes aspectos:

- Honestidad: Siendo el valor más importante para ellos y que le ha permitido una preferencia de sus clientes por sobre sus competidores directos.

- Compromiso: Hacen suyos los objetivos de sus clientes y los acompañan en la consecución de estos.

- Calidad: Característica primordial en cada una de sus soluciones.

- Profesionalismo: De cada uno de sus colaboradores.

\subsubsection{Elementos de los valores propuestos para la empresa.}

Para Thompson, Peteraf, Gamble y Strickland III (2012):

El término valor ha sido tratado por varios autores, entre los cuales se plantea que en la cultura organizacional existen tres niveles, con un núcleo central formado por las presunciones básicas como esencia de la cultura, la presencia de un conjunto de patrones que se identifican como valores y los comportamientos o conductas que los ponen de manifiesto.

Los valores representan la filosofía de cómo la dirección quiere llevar adelante la organización deben ser conocidos y compartidos por todos y redefinirse para adaptarlos al entorno económico y social.

La palabra valor tiene tres dimensiones que son: la creencia estable de que una determinada conducta es preferible a su modo opuesto (dimensión ética); el alcance de la importancia o significación de algo, lo que vale (dimensión económica) y es la cualidad moral asociada a afrontar sin miedo los peligros, o sea, la valentía (dimensión psicológica). 
Como elementos comunes se encuentran las creencias, los patrones que orientan la dirección de una organización en un contexto específico, que responden a satisfacer una necesidad humana, asociada a la personalidad y el cumplimiento de las funciones prácticas del individuo, en el contexto social y personal en que se desarrolla.

Para que los valores constituyan un instrumento de dirección es necesario integrarlos en un proceso de aprendizaje y comunicación continuos, de tal forma que constituyan conceptos relevantes e interiorizados, para ser puestos en práctica en las acciones cotidianas como apoyo al cumplimiento de los objetivos organizacionales. (p. 27).

\subsubsection{Valores propuestos.}

Se debe establecer los valores fundamentales de la empresa entre el equipo directivo y con la mayor participación de los trabajadores posible. Esto posibilitará que los valores sean congruentes con los de los clientes, trabajadores y los directivos. Los valores que sobrevivan serán los de la empresa, con los que será mucho más claro y fácil de matizar su visión y misión.

Los valores compartidos deben guiar la conducta cotidiana de todos en la empresa, puesto que constituyen el cimiento de la organización y generan beneficios para quienes los aplican.

Para poder establecer los valores compartidos es muy importante el trabajo en equipo y especificar los valores que tiene la organización, los valores que no tiene la empresa y necesita tener. Además, identificar y eliminar los antivalores de la organización.

Una vez que se han definido los valores de una empresa es importante entender que forman parte de una decisión estratégica a largo plazo, que son factores que definirán la 
manera de cómo debe vivir la organización y que la voluntad y perseverancia siempre serán necesarios para ponerlos en acción.

Siguiendo el marco teórico descrito anteriormente, se han planteado los siguientes valores sobre los que la empresa debe basar su cultura organizacional:

- Integridad: en este valor se engloba el compromiso, la ética y la honestidad que caracteriza al equipo de la empresa.

- Calidad: característica primordial de sus soluciones.

- Creatividad: cada solución propuesta debe caracterizarse por la originalidad y enfoque a la necesidad del cliente

- Excelencia: se busca siempre la mejora continua e innovación en sus procesos.

- Trabajo en equipo: una de sus fortalezas es el capital humano con el que cuenta, que forman una sola fuerza para la consecución de los objetivos de la empresa y a su vez de sus clientes.

\subsection{Alineamiento Estratégico de la Visión, Misión y Valores de la Empresa}

En Thompson, Peteraf, Gamble y Strickland III (2012) se menciona:

En las empresas donde los valores declarados son más reales que cosméticos, los directivos los conectan a la búsqueda de la visión estratégica y la misión en una de dos maneras. En las compañías con valores de larga tradición y bien integrados a la cultura corporativa, los directivos tienen cuidado de idear una visión, misión y estrategia que correspondan con los valores establecidos, y reiteran la manera en que las normas conductuales basadas en los valores contribuyen al éxito de la empresa. Si la compañía cambia a otra visión o estrategia, los ejecutivos tienen el cuidado de explicar cómo o por qué los valores esenciales aún son importantes. En empresas nuevas o con valores no especificados, la alta administración tiene que 
considerar qué valores, conductas y prácticas de negocios deben caracterizar a la compañía, y luego circular un borrador de la declaración de valores entre directivos y empleados para su análisis y posible modificación. Más adelante, se adopta de forma oficial una declaración de valores definitiva que incorpore las conductas y rasgos deseados, y se conecta a la visión y misión. Algunas compañías combinan su visión, misión y sus valores en una sola declaración o documento, lo circulan entre todos los miembros de la organización y en muchos casos lo publican en el sitio web de la compañía (p. 27).

Para lograr el alineamiento organizacional, debemos saber cuáles serán los requisitos de los colaboradores de una empresa, y también cuáles serán las necesidades de éstos. Esta información resulta ser uno de los principales insumos para poder diseñar la estrategia de Gestión de Personas y poder así, implementar las prácticas, políticas y programas que permitan lograr la satisfacción de los colaboradores. El nivel de satisfacción organizacional incide directamente en la satisfacción del cliente, que a su vez permite a la organización alcanzar lo planteado en el planeamiento estratégico y de esta manera poder realizar cambios que repercutan en el entorno interno y externo.

Este proceso se conoce como alineamiento estratégico, y dicta las acciones de la gestión organizativa que permite que los colaboradores miembros de una empresa se conduzcan como un conjunto unificado hacia los objetivos estratégicos de la organización.

El alineamiento estratégico no se logra de manera automática. Surge de la visión compartida que transmiten los líderes a toda la organización, para lo cual se requiere claridad de la meta empresarial, conecta el propósito de cada uno de los colaboradores, con el propósito colectivo.

Al lograr el alineamiento de los colaboradores a la visión, misión y valores, la adaptación de los sistemas, de la cadena productiva, de la labor comercial y otras de las 
misiones funcionales de las empresas se hacen más fáciles, aún en escenarios difíciles de mercado.

Con esta alineación, la energía de todo el equipo se concentra en un solo objetivo, se logra coherencia empresarial, y la cultura de la empresa se consolida. Puede parecer que el logro de este alineamiento es muy complicado de alcanzar, tanto que existen empresas en las que este proceso se asigna a equipos especiales y dedicados.

Sin embargo, se puede señalar que los pasos para lograrlo son los siguientes: Encontrar, valorar y retener el capital humano, en estos tiempos en los cuales la promesa de valor diferencial solo lo hacen las personas. Una organización crece si las personas que forman parte de esta logran también ese crecimiento y bienestar. La prosperidad y abundancia es extensible a todos y no solo a la dirección y los accionistas. De esta manera, se puede precisar que en Xternal Technological Solutions S.A.C. se realizará el alineamiento de la visión, la misión y los valores comenzando con el compromiso de los socios fundadores, quiénes son los principales interesados en que estos aspectos se comuniquen a toda la organización. Luego, se tiene que lograr el involucramiento de los jefes de área y que éstos se encarguen de comprometer a cada uno de los miembros de sus equipos para que en cada actividad que realicen tengan presente la razón de ser y los objetivos de la organización. Cuando cada uno de los colaboradores sienta que, con sus actividades diarias suma a lo planificado por la empresa, encontrará sentido a su labor y se sentirá cada vez más identificado y comprometido con Xternal Technological Solutions S.A.C. 


\section{Capítulo IV: Análisis Externo}

\subsection{Tendencias de las Variables del Entorno}

\subsubsection{Análisis Político-Gubernamental.}

En el ámbito político, según el plan de gobierno presentado, uno de los principales objetivos previstos para el periodo 2016-2021 es la recuperación del dinamismo económico en el cual se busca reactivar la economía en base a las fuentes de demanda interna (Peruanos por el Kambio, 2016). Esto beneficiaria a Xternal Technological Solutions de generarse una mayor demanda de requerimientos de servicios de potenciales clientes.

El Indicador de Bonos de Mercados Emergentes (EMBI) por sus siglas en inglés, estima el riesgo político de un país y su posibilidad de cumplir con las obligaciones de pago a sus acreedores internacionales. Al 22 de febrero del 2017, el riesgo país correspondiente al Perú cerró en 1.62 puntos porcentuales, siendo el riesgo más bajo en la región seguido por Colombia con 2.01 y México con 2.16 puntos. Según el banco de inversión JP Morgan, de acuerdo con un informe de gestion.pe (2017), el riesgo podría incrementarse debido a la evolución de las variables económicas como el déficit fiscal, la inflación, entre otras, del mismo modo según se comporte la política del país y los posibles riesgos que pudieran existir en la región.

El índice porcentual de riesgo país que mantiene el Perú, lo convierte en un país atractivo para generar inversiones sobre todo de empresas del sector privado locales o transnacionales, y en donde la tecnología juega un papel importante debido a la continua necesidad de las empresas de mantener sistemas informáticos que faciliten sus operaciones y dinamicen sus gestiones. Xternal Technological Solutions S.A.C., como empresa especializada en el rubro de tecnología de la información, podría capitalizar estas 
oportunidades ofreciendo a estas empresas inversionistas su cartera de servicios y su experiencia.

Por otro lado, el gobierno de turno tiene propuesto, como una de sus metas, la reducción del Impuesto General a las Ventas (IGV) en un punto porcentual a partir del 1 de julio del 2017. Esta reducción del IGV permitirá tener mayor liquidez a empresas como Xternal Technological Solutions S.A.C., quienes podrían mejorar la oferta de sus servicios al reducir sus gastos tributarios.

Dentro del avance de los sectores productivos para el mercado laboral peruano, se ha visto incrementada la necesidad de profesionales y técnicos especializados en tecnología para el desarrollo de software, creación de aplicaciones entre otras. (elcomercio.com.pe, 2017), los cuales son los rubros donde Xternal Technological Solutions puede participar para brindar servicios de calidad a otras empresas.

Asimismo, la presencia de instituciones dedicadas al desarrollo e innovación tecnológica sostiene la importancia del software que pueda utilizarse en distintas empresas para optimizar sus procesos. Algunas de estas instituciones son:

Instituto Nacional de Investigación y Capacitación de Telecomunicaciones (INICTEL): Institución encargada de fomentar el uso de las Tecnologías de Información y Comunicaciones de manera eficiente, así como hacer intensiva la demanda de empresas especializadas de innovación tecnológica.

Consejo Nacional de Ciencia, Tecnología e Innovación Tecnológica (CONCYTEC): Organismo encargado de formular políticas, en busca del desarrollo social y económico del país a través de la generación y transferencia del conocimiento científico y tecnológico.

Estos esfuerzos por las instituciones antes mencionadas tendría un impacto beneficioso a las empresas de tecnología de información, tal como se mencionó durante el 
XIII Encuentro por la Investigación "Cayetano Heredia" - EPICAH, en donde la presidente del CONCYTEC, Gisella Orjeda hizo mención que se tiene como objetivo la inyección de conocimiento en los procesos productivos del país, con lo cual Xternal Technological Solutions S.A.C. tendrá una gran participación pudiendo brindar servicios que ayuden a optimizar estos procesos y gestionarlos con tecnologías actuales desarrolladas por investigadores nacionales.

Por otro lado, de acuerdo con el Marco Macroeconómico Multianual 2017-2019, se tiene como lineamientos para la política económica el apuntalar el crecimiento potencial de la economía mediante medidas que incrementen la productividad, así como también liderar el crecimiento priorizando la estabilidad económica, con lo cual a pesar de mantenerse desfavorable el panorama internacional para la economía en el Perú, es mejor que en los últimos cuatro años.

A su vez, el gobierno debe fomentar el sector de Tecnología de la información con independencia de otros sectores y la necesidad del desarrollo de este, debiendo dirigir los esfuerzos de las empresas de este sector para el desarrollo de software a requerimiento de distintas empresas de diversos sectores para que sus procesos sean más eficientes e innovadores. Esto brindaría la posibilidad de ampliar la cartera de clientes con que cuenta Xternal Technological Solutions S.A.C. pero a su vez una mayor competencia en la participación de licitaciones públicas.

\subsubsection{Análisis Económico.}

Según lo mencionado por Hitt et al. (2015), la solidez de la economía de un país afecta a las empresas y a las industrias, y es por esta razón que las empresas deben estudiar su entorno económico a fin de identificar tendencias y cambios, así como sus implicancias 
estratégicas. Siguiendo con este lineamiento teórico, se analizarán los siguientes elementos de este segmento:

- Crecimiento económico del país - Producto Bruto Interno (PBI): De acuerdo con la información obtenida del Marco Macroeconómico Multianual 20172019 elaborado y revisado por el Ministerio de Economía y Finanzas (2016), se observa que la economía mundial mantendrá un crecimiento proyectado para el 2017 en el orden del 3\% al igual que el año 2016. La Tabla 6 muestra la variación porcentual en donde se aprecia un ligero crecimiento a corto plazo, pero a una tasa baja. Esto se explica en la incertidumbre que existe acerca del impacto del Brexit en el entorno de negocios y en las economías de otros países, el cambio de gobierno y las nuevas políticas económicas en Estados Unidos de Norteamérica, así como la no implementación de medidas para asegurar el crecimiento de las economías avanzadas.

Tabla 6

Principales indicadores macroeconómicos

\begin{tabular}{lccccccccc}
\hline & \multicolumn{1}{c}{ MMM 2017-2019 } & \multicolumn{7}{c}{ MMMR 2017-2019 } \\
& 2015 & 2016 & 2017 & 2018 & 2019 & 2016 & 2017 & 2018 & 2019 \\
\hline PBI Socios Comerciales & & & & & & & & & \\
Mundo (Variación porcentual real) & 3,1 & 3,0 & 3,2 & 3,4 & 3,5 & 3,0 & 3,0 & 3,2 & 3,4 \\
EEUU (Variación porcentual real) & 2,4 & 2,5 & 2,5 & 2,4 & 2,3 & 1,7 & 2,0 & 2,1 & 2,2 \\
Zona Euro (Variación porcentual real) & 1,6 & 1,5 & 1,5 & 1,5 & 1,4 & 1,4 & 1,3 & 1,2 & 1,2 \\
China (Variación porcentual real) & 6,9 & 6,0 & 5,5 & 5,0 & 5,0 & 6,5 & 5,7 & 5,2 & 5,0 \\
Socios Comerciales (Variación & 1,8 & 1,4 & 1,8 & 2,0 & 2,1 & 1,1 & 1,6 & 2,0 & 2,1 \\
porcentual real) & & & & & & & & &
\end{tabular}

Nota. Principales indicadores macroeconómicos. Tomado de "Marco Macroeconómico Multianual 2017-2019 Revisado” por el Ministerio de Economía y Finanzas (MEF), 2016. Recuperado de https://www.mef.gob.pe/contenidos/pol_econ/marco_macro/MMM_2017_2019_Revisado.pdf 
En la figura 3 se explica cómo se ha dado la evolución del PBI mundial a lo

largo de los últimos diez años, haciendo énfasis en las variaciones de Estados

Unidos de Norteamérica, China y América Latina.

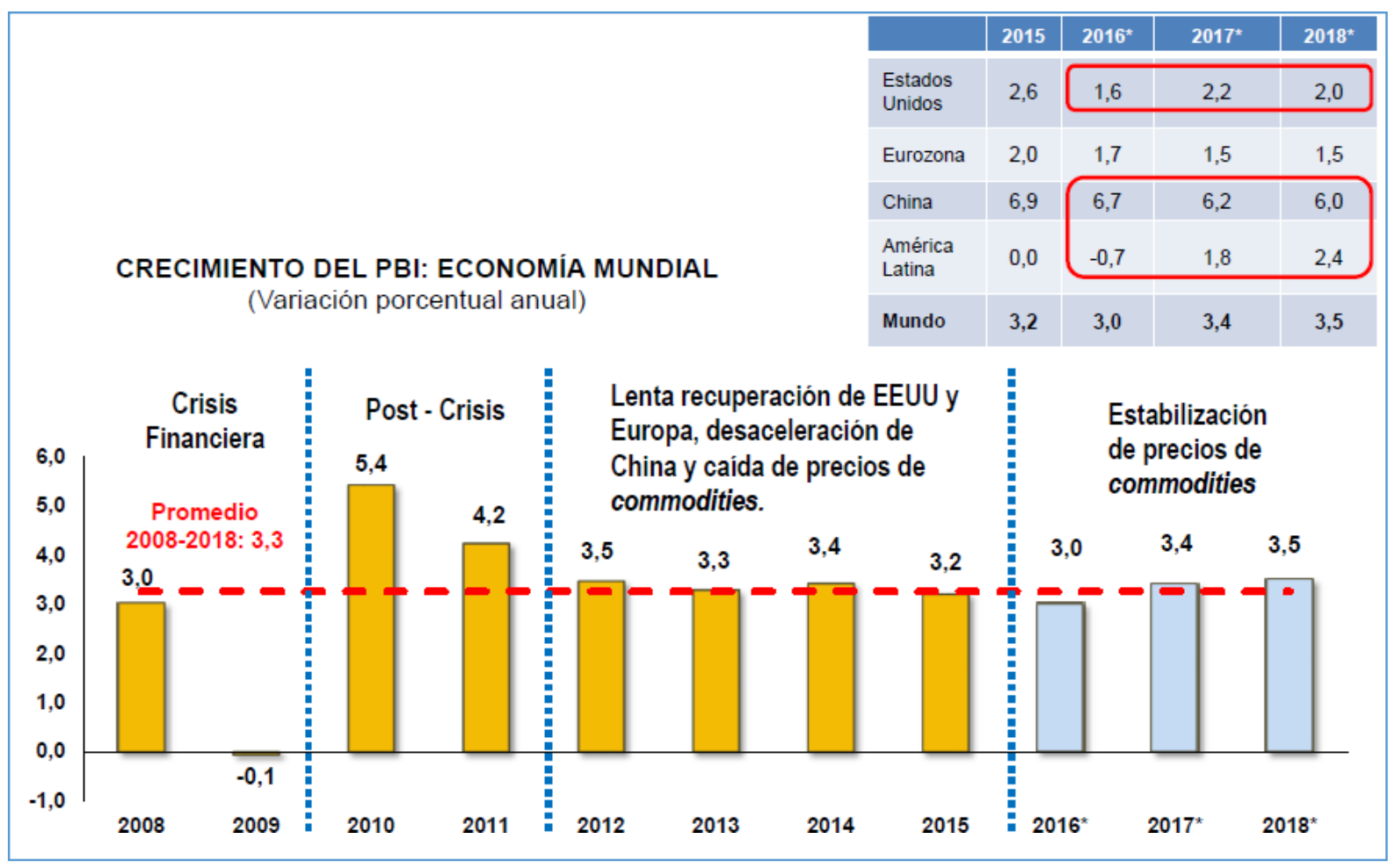

Figura 3. Crecimiento del PBI: Economía Mundial. Tomado de "Reporte de Inflación: Panorama actual y proyecciones macroeconómicas 2016 -2018" por el Banco Central de Reserva del Perú, 2016. Recuperado de http://www.bcrp.gob.pe/docs/Publicaciones/Reporte-Inflacion/2016/diciembre/reporte-deinflacion-diciembre-2016-presentacion.pdf

Como se observa en la figura 3, existe una desaceleración gradual de China justificada, de acuerdo con los datos obtenidos del Banco Central de Reserva del Perú (2016), por la implementación de un nuevo modelo basado en el consumo, inversión y servicios.

Respecto a América Latina, se aprecia una recuperación significativa y está asociada al mayor precio en los commodities respecto a la caída que tuvieron en 
los últimos tres años. En la figura 4 se puede visualizar una comparación entre los años 2016 y 2017 siendo Perú el país con mayor PBI en la región.

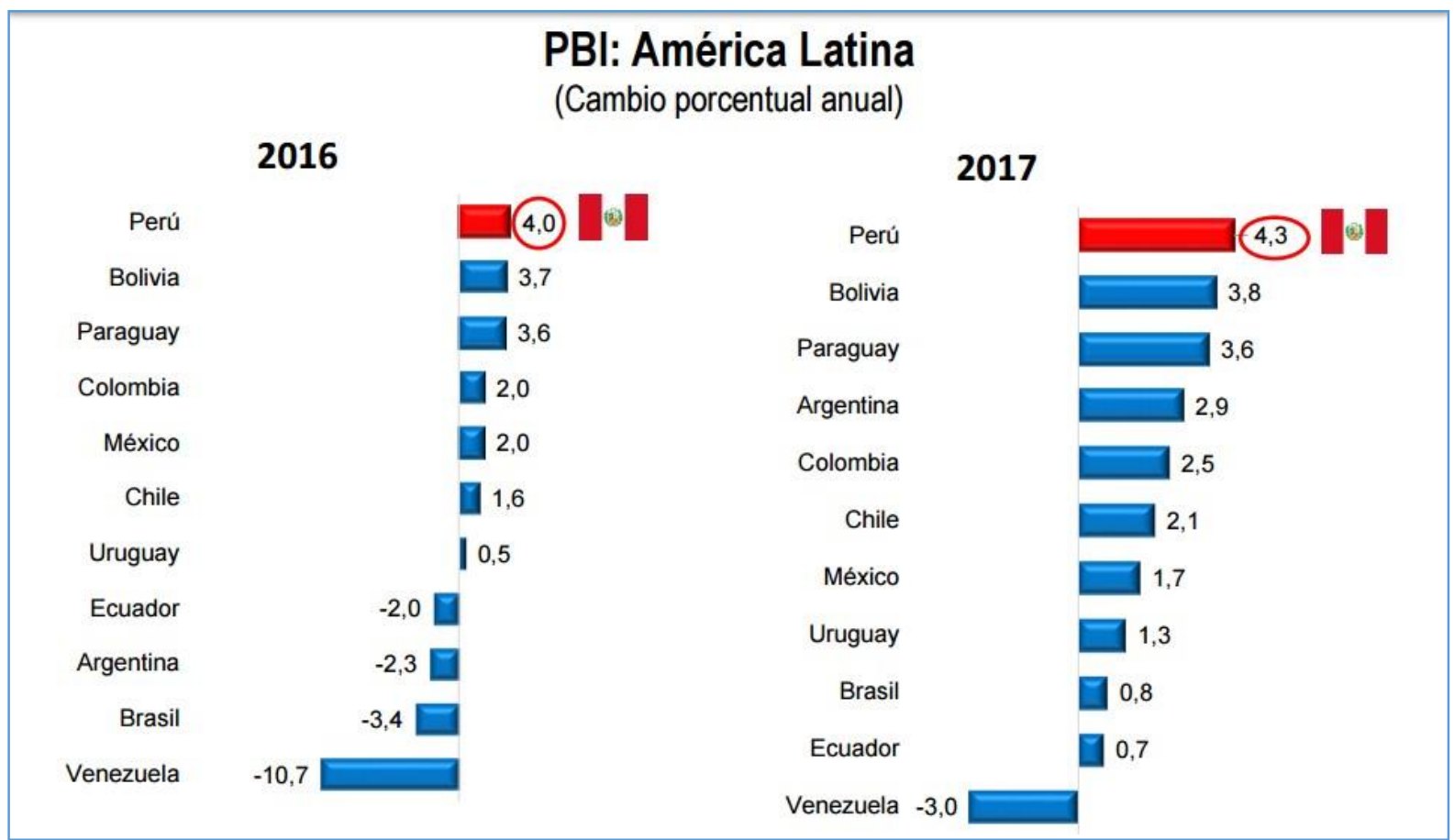

Figura 4. PBI: América Latina (Cambio porcentual anual). Tomado de "Reporte de Inflación: Panorama actual y proyecciones macroeconómicas 2016 -2018” por el Banco Central de Reserva del Perú, 2016. Recuperado de http://www.bcrp.gob.pe/docs/Publicaciones/Reporte-Inflacion/2016/diciembre/reporte-deinflacion-diciembre-2016-presentacion.pdf

Respecto al Perú, las proyecciones hechas por el MEF y el BCR muestran una recuperación del sector pesquero, manufactura y construcción. En la Tabla 7 se puede visualizar el PBI por sectores económicos. 
Tabla 7

PBI por sectores económicos (Variaciones porcentuales reales)

\begin{tabular}{lrrrrrr}
\hline & 2015 & \multicolumn{2}{c}{$2016^{*}$} & $2017^{*}$ & $2018^{*}$ \\
& Ene.-Set. & Año & Ene.-Set. & Año & Año & Año \\
\hline Agropecuario & 3,6 & 3,4 & 1,1 & 1,3 & 2,8 & 5,0 \\
Agrícola & 2,3 & 2,1 & $-0,4$ & $-0,3$ & 2,3 & 5,5 \\
Pecuario & 5,8 & 5,5 & 3,6 & 3,7 & 3,6 & 4,2 \\
Pesca & 9,1 & 15,9 & $-22,2$ & $-12,8$ & 34,7 & 5,7 \\
Minería e hidrocarburos & 7,5 & 9,5 & 18,4 & 16,6 & 7,4 & 5,1 \\
Minería metálica & 13,3 & 15,5 & 23,5 & 21,7 & 7,5 & 5,0 \\
Hidrocarburos & $-12,3$ & $-11,5$ & $-3,8$ & $-5,5$ & 7,1 & 6,6 \\
Manufactura & $-2,4$ & $-1,5$ & $-3,0$ & $-2,2$ & 3,5 & 4,0 \\
Recursos primarios & $-2,1$ & 1,8 & $-4,8$ & $-2,2$ & 10,0 & 4,1 \\
Manufactura no primaria & $-2,6$ & $-2,6$ & $-2,3$ & $-2,1$ & 1,7 & 4,0 \\
Electricidad y agua & 5,2 & 5,9 & 8,1 & 7,6 & 5,5 & 5,0 \\
Construcción & $-7,4$ & $-5,8$ & $-0,4$ & $-2,7$ & 3,6 & 5,5 \\
Comercio & 3,9 & 3,9 & 2,1 & 2,0 & 3,3 & 3,8 \\
Servicios & 4,2 & 4,2 & 4,2 & 4,0 & 3,9 & 3,8 \\
PRODUCTO BRUTO & 2,8 & 3,3 & 4,2 & 4,0 & 4,3 & 4,2 \\
INTERNO & & & & & & \\
Nota: & & & & & & \\
PBI primario & 5,0 & 6,9 & 9,7 & 9,6 & 7,1 & 5,0 \\
PBI no primario & 2,3 & 2,4 & 2,7 & 2,5 & 3,5 & 4,0 \\
\hline Nota. PBI por sectores & & & & & &
\end{tabular}

Nota. PBI por sectores económicos (variaciones porcentuales reales). Tomado de "Reporte de Inflación: Panorama actual y proyecciones macroeconómicas 2016 -2018” por el Banco Central de Reserva del Perú, 2016. Recuperado de http://www.bcrp.gob.pe/docs/Publicaciones/Reporte-Inflacion/2016/diciembre/reporte-deinflacion-diciembre-2016-presentacion.pdf

En el caso del sector pesquero, la normalización de las condiciones

climatológicas que afectaban la temperatura del mar peruano vislumbra un año en el que se recupere el recurso marino (anchoveta) y en donde se pueda volver a pescar las cuotas correspondientes a un año normal. Para el sector de manufactura, se espera una recuperación sobre todo en la manufactura no primaria, es decir, en sectores ligados a inversión y exportaciones. En el sector de construcción, se espera una mayor inversión. 
Dentro de los puntos negativos, se observa una disminución en la contribución del sector minería e hidrocarburos. Esto se justifica por la disminución del precio de los metales y el petróleo.

Estas proyecciones anteriormente mencionadas impactan de manera positiva y negativa en la empresa Xternal Technological Solutions S.A.C. Su principal cliente es la empresa Tecnológica de Alimentos S.A., que realiza sus actividades en el sector pesquero. En lo proyectado se aprecia una recuperación importante en dicho sector, lo que posiblemente permitirá el desbloqueo de inversiones que se tenían pensado hacer en diferentes áreas (una de ellas la de tecnología de información) lo que le podría brindar una oportunidad de negocio.

Asimismo, las proyecciones para el sector de manufactura son alentadoras mostrando una recuperación importante. En esta línea sus clientes en dicho rubro podrían reactivar los proyectos postergados sobre tecnología de información, lo que le ofrecería otra posibilidad de negocio.

Del mismo modo, la disminución del sector de minería afectará a sus clientes en ese rubro y, en consecuencia, podría provocar una paralización en las inversiones tal como sucedió en su cliente en el sector pesquero.

- Tipo de cambio: De acuerdo con las proyecciones realizadas en el marco macroeconómico multianual 2017-2019, elaborado y revisado por el Ministerio de Economía y Finanzas (2016), se estima que el tipo de cambio termine el año 2017 cerca de los S/ 3.5 y que llegue para el año 2018 y 2019 los S/ 3.55. En la Tabla 8 se puede observar dichas estimaciones: 
Tabla 8

Principales indicadores macroeconómicos

\begin{tabular}{|c|c|c|c|c|c|c|c|c|c|}
\hline & \multirow{2}{*}{2015} & \multicolumn{4}{|c|}{ MMM 2017-2019 } & \multicolumn{4}{|c|}{ MMMR 2017-2019 } \\
\hline & & 2016 & 2017 & 2018 & 2019 & 2016 & 2017 & 2018 & 2019 \\
\hline \multicolumn{10}{|l|}{ PRECIOS } \\
\hline Precios (Variación porcentual acumulada) & 4,4 & 3,5 & 3,0 & 2,9 & 2,0 & 3,1 & 2,8 & 2,6 & 2,0 \\
\hline Tipo de Cambio Promedio (Soles por US dolar) & 3,19 & 3,57 & 3,68 & 3,73 & 3,75 & 3,37 & 3,48 & 3,55 & 3,55 \\
\hline Términos de Intercambio (Variación porcentual) & $-6,3$ & 0,2 & $-2,7$ & 0,5 & 0,3 & $-1,9$ & $-0,3$ & 0,0 & 0,2 \\
\hline Índice de Precios de Exportación (Variación porcentual) & $-14,9$ & $-6,1$ & 0,3 & 2,8 & 1,8 & $-5,2$ & 2,4 & 1,4 & 0,9 \\
\hline Índice de Precios de Importación (Variación porcentual) & $-9,2$ & 5,9 & 3,0 & 2,4 & 1,5 & $-3,3$ & 2,7 & 1,4 & 0,7 \\
\hline
\end{tabular}

Nota. Principales indicadores macroeconómicos. Tomado de "Marco Macroeconómico Multianual 2017-2019 Revisado" por el Ministerio de Economía y Finanzas (MEF), 2016. Recuperado de https://www.mef.gob.pe/contenidos/pol_econ/marco_macro/MMM_2017_2019_Revisado. pdf

"En lo que va del año 2017, el sol se ha apreciado en $2.6 \%$ en un contexto de depreciación del dólar a nivel internacional y mayores precios de commodities" (Banco Central de Reserva del Perú, 2017,p.10). La figura 5 muestra la fluctuación del tipo de cambio en los últimos dos años y la intervención cambiaria del BCRP: 


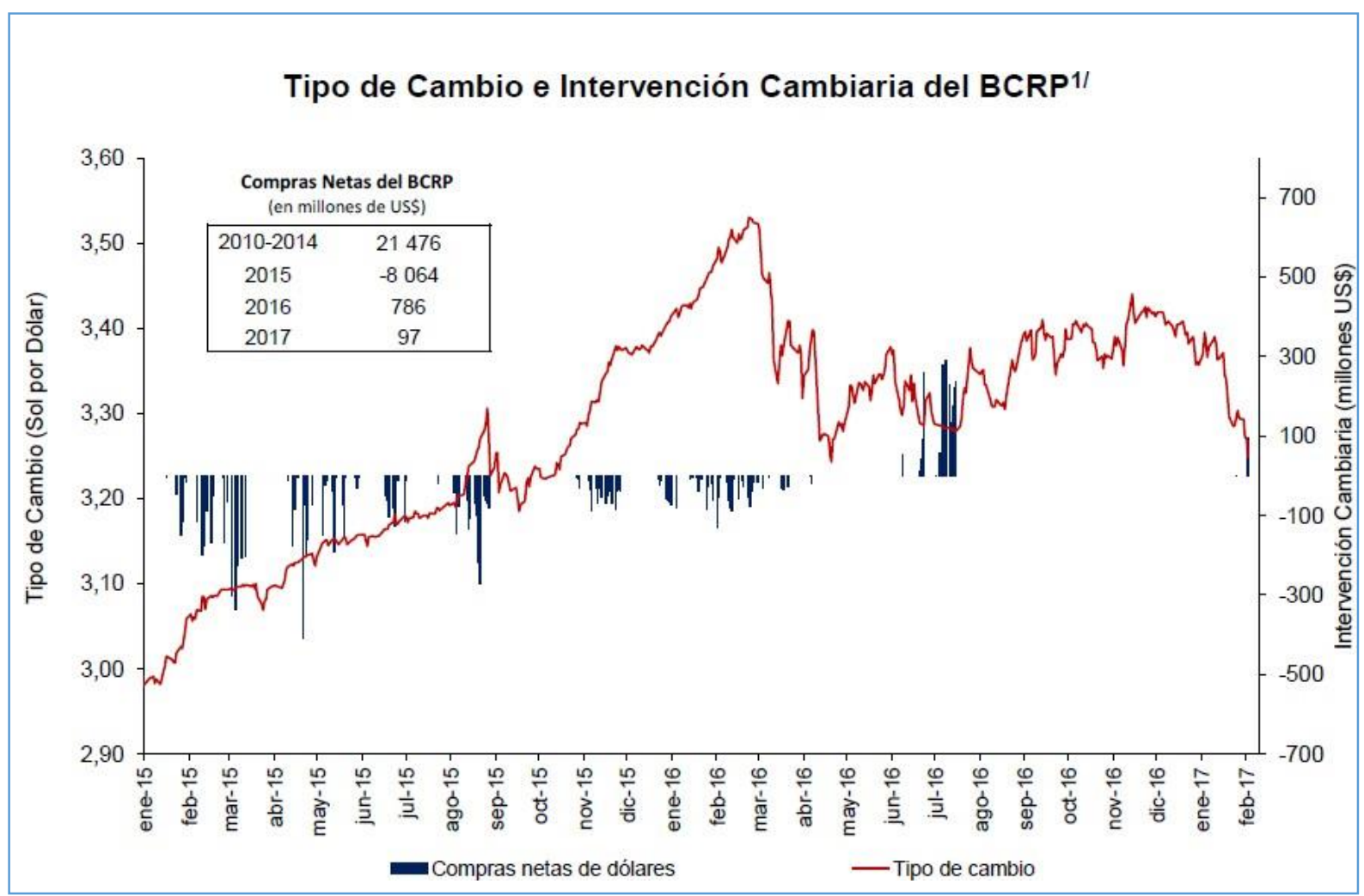

Figura 5. Tipo de Cambio e Intervención Cambiaria del BCRP. Tomado de "Programa Monetario de febrero 2017" por el Banco Central de Reserva del Perú, 2017. Recuperado de http://www.bcrp.gob.pe/docs/Publicaciones/Presentaciones-

Discursos/2017/presentacion-02-2017.pdf

La volatilidad apreciada en la figura anterior respecto al tipo de cambio podría representar en una amenaza para la empresa Xternal Technological Solutions S.A. Al respecto, resulta sumamente importante que la empresa mantenga sus deudas y facturación en la moneda local. Los contratos anuales que realiza con sus clientes o proveedores podrían verse afectados si es que se celebran en una moneda distinta a la local, dado que la proyección para años venideros muestra una tendencia al alza.

Al ser una empresa de tecnología de información, en la mayoría de los casos se ve en la obligación de realizar compras de herramientas para desarrollar su actividad (como computadoras, impresoras, equipos de comunicación o licencias de software) en países en donde se maneja una moneda distinta. 
Esencialmente la empresa realiza la compra de las licencias del software con el que trabaja en dólares, ya que los proveedores de ellas tienen sede en los Estados Unidos de Norteamérica. De igual manera, puede verse tentada de asumir responsabilidades de pago en moneda extranjera aprovechando una menor tasa de interés, pero a expensas de la volatilidad cambiaria.

Respecto a la facturación por sus servicios, deberá evaluar sus precios respecto a proyectos con clientes en el exterior y que trabajen con moneda extranjera. Adicionalmente, debe tomar en cuenta que esta volatilidad afecta también directamente a sus clientes, especialmente a los que realizan exportaciones en moneda extranjera. Esta situación podría afectar la solvencia de algunas empresas y perjudicar las obligaciones de pago programadas para con Xternal Technological Solutions S.A.

- Tasa de Inflación: Según la información obtenida del reporte de inflación elaborado por el Banco Central de Reserva del Perú (2016), la inflación del año 2016 estuvo en el orden del 3.3\% siendo las proyecciones para el año 2017 el mantenerse en un 2.3\% anual. La figura 6 muestra la proyección de la inflación en los últimos ocho años: 


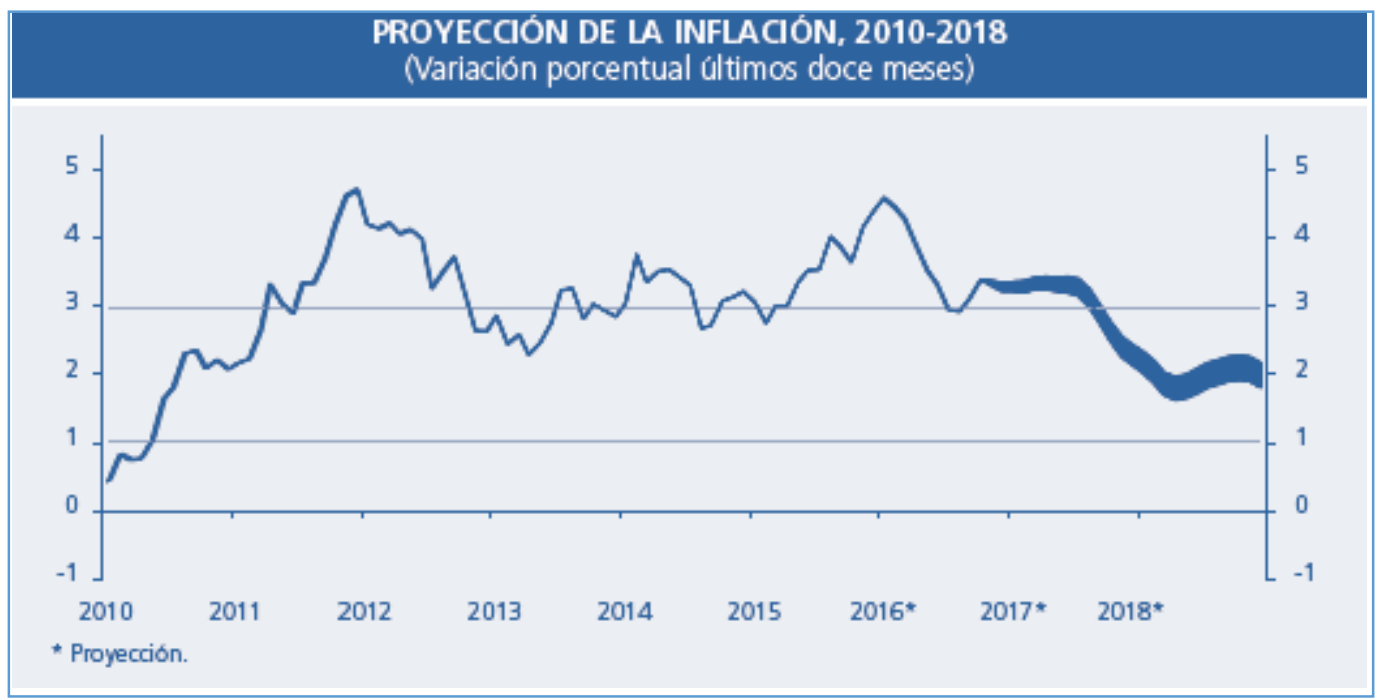

Figura 6. Proyección de la inflación 2010-2018 (variación porcentual últimos doce meses). Tomado de "Reporte de Inflación: Panorama actual y proyecciones macroeconómicas 2016-2018” por el Banco Central de Reserva del Perú, 2017. Recuperado de http://www.bcrp.gob.pe/docs/Publicaciones/Reporte-

Inflacion/2016/diciembre/reporte-de-inflacion-diciembre-2016.pdf

Contrariamente a la incertidumbre observada en las proyecciones a nivel mundial respecto a la inflación, en el país se respira un aire de confianza empresarial lo que explica en cierta forma las proyecciones optimistas respecto a la inflación local. De acuerdo con lo mencionado en el reporte de inflación elaborado por el BCRP, se destaca consistencia entre las proyecciones inflacionarias y el crecimiento económico del país, el cual estaría alrededor del 4\%. Esto también explica la expectativa inflacionaria para el horizonte de tiempo 2017-2018.

Ante este panorama, la empresa Xternal Technological Solutions S.A. se encuentra optimista. La tendencia a la baja de la tasa de inflación se traduce en un crecimiento mayor en el país y por lo tanto la confianza de la inversión privada regresa. Es un muy buen contexto tanto para la inversión y el crecimiento de la empresa, como para la realización de negocios con empresas 
de distintos sectores económicos. Esta estabilidad en la inflación se refleja en los costos fijos de la empresa, los cuales se pueden mantener sin problemas en esta coyuntura económica.

- Tasa de interés: Alineado a lo mencionado anteriormente respecto a la tasa de inflación, el optimismo que se observa en la inversión privada permite la manifestación de oportunidades de negocio en donde se requerirá en algunos casos de financiamiento económico. Al respecto, el BCR ha mantenido su tasa de referencia en $4.25 \%$ de acuerdo con lo publicado en el reporte de inflación de diciembre del 2016. Esto hace referencia a la posición de política monetaria expansiva impulsada por el gobierno. La figura 7 muestra la variación en esta tasa a lo largo de los últimos tres años:

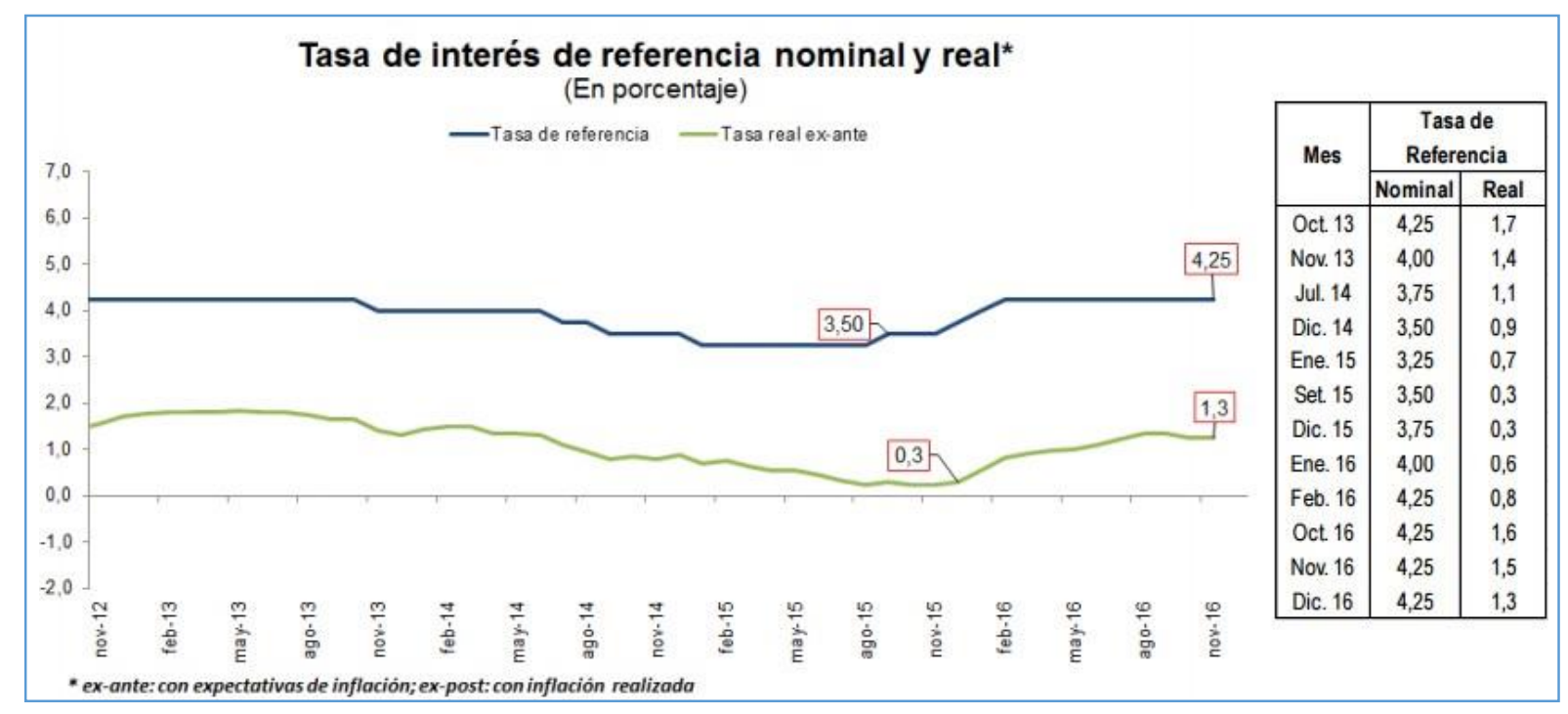

Figura 7. Tasa de interés de referencia nominal y real (en porcentaje). Tomado de "Reporte de Inflación: Panorama actual y proyecciones macroeconómicas 2016-2018" por el Banco Central de Reserva del Perú, 2017. Recuperado de http://www.bcrp.gob.pe/docs/Publicaciones/Reporte-Inflacion/2016/diciembre/reporte-deinflacion-diciembre-2016.pdf 


\subsubsection{Análisis Legal.}

De acuerdo con la legislación peruana, se detalla las leyes que influyen en el análisis.

La ley marco de ciencia, tecnología e innovación tecnológica, Ley $\mathrm{N}^{\circ} 28303$ el Consejo Nacional de Ciencia, Tecnología e innovación tecnológica (CONCYTEC), es el organismo rector del Sistema, encargado de dirigir, fomentar, coordinar, supervisar y evaluar las acciones del Estado en el ámbito de la ciencia, tecnología e innovación tecnológica. Esta ley tiene como objetivo principal normar el desarrollo, promoción, consolidación, difusión y transferencia de la ciencia, tecnología e innovación tecnológica en el país.

Asimismo, la Ley $\mathrm{N}^{\circ} 30309$, ley que promueve la investigación científica, desarrollo tecnológico e innovación tecnológica, tiene como objetivo brindar un beneficio tributario aplicable a los gastos en proyectos de investigación científica, desarrollo tecnológico e innovación tecnológica. Estas deducciones serán de: 175\% si el proyecto es realizado directamente por el contribuyente o mediante centros de investigación científica, de desarrollo tecnológico o de innovación tecnológica domiciliados en el país; y de $150 \%$ si el proyecto es realizado mediante centros de investigación científica, de desarrollo tecnológico o de innovación tecnológica no domiciliadas en el país.

Según gestión.pe (2016), para las micro y pequeñas empresas que decidan invertir en proyectos de investigación científica, desarrollo tecnológico, e innovación tecnológica (I+D+i), se fijó en S/5.75 millones el monto de deducción del Impuesto a la Renta.

Estas dos leyes favorecen a Xternal Technological Solutions S.A.C., ya que las Mypes y empresas en general, con el fin de reducir sus gastos tributarios, podrían requerir de sus servicios tecnológicos para lograr sus proyectos de investigación, incrementando así sus servicios y diversificando su cartera de clientes. 
En cuanto a la formalización de la empresa, Xternal Technological Solutions S.A.C. se basa en la Ley Nro. 28015, ley de promoción y formalización de la micro y pequeña empresa, que tiene por objetivo la promoción de la competitividad, formalización y desarrollo de las micro y pequeñas empresas para incrementar el empleo sostenible.

Esta ley establece a una microempresa como aquella que cuenta de uno hasta diez trabajadores y un monto máximo de 150 Unidades Impositivas Tributarias (UIT) y una pequeña empresa como aquella que cuenta de uno hasta cien trabajadores y un monto máximo de 1700 UIT. La cual beneficia a la empresa por permitirle participar en concursos públicos y adjudicaciones directas como proveedores de productos o servicios, no tienen restricciones en el ingreso al mercado para ofertar productos y competir con sus competidores, tienen facilidades para acceder al crédito formal.

En el campo laboral, Xternal Technological Solutions S.A.C se basa en la ley 29783, Ley de seguridad y salud en el trabajo, cuyo objetivo principal es promover una cultura de prevención de riesgos laborales en el país. Para ello es importante el rol de fiscalización y el control del Estado, de parte de la empresa es de gran ayuda la participación de los trabajadores y sus organizaciones sindicales quienes se encargan de velar por la promoción, difusión y cumplimiento de la normativa sobre la materia.

\subsubsection{Análisis Socio Cultural.}

Muchas de las empresas para aumentar su grado de eficiencia y su productividad implementan nuevas tendencias, una de ellas es el uso de las TIC (tecnologías de la información y de la comunicación), que son el conjunto de herramientas, equipos, programas informáticos, aplicaciones, redes y medios, que permiten el procesamiento, almacenamiento y transmisión de información. Para ello las empresas utilizan la telefonía móvil y fija, las computadoras personales, Internet, intranet, e-commerce, el uso de 
programas como whatsapp, Facebook, Linkedin y los blogs. Existen también TIC más avanzadas como los ERP (Enterprise Resource Planning), que son usados para la planificación de recursos empresariales y el CRM (Customer Relationship Management), usados en la administración de relaciones con los consumidores.

Una característica de las empresas que se especializan en servicios de tecnología de la información es que tienen un modelo de negocio Business to Business (B2B), el cual consiste en brindar sus servicios a otras empresas de diferentes sectores a fin de optimizar sus procesos en búsqueda de su excelencia operativa o desarrollar nuevos productos de tecnología. Xternal Technological Solutions S.A.C cuenta con este modelo de negocio en el cual puede brindar estos servicios tanto a las empresas grandes como a las Mypes.

Según el Censo Nacional de Investigación y desarrollo a Centros de Investigación 2016 realizado por CONCYTEC, los gastos de los Centros de Investigación en I+D alcanzaron los S/ 517.5 millones para el año 2015 , un aumento de $18.1 \%$ con respecto a lo gastado el 2014, cuando alcanzó S/ 438.1 millones. Sin embargo, como porcentaje del PBI de Perú, el gasto en I+D se mantuvo en $0.08 \%$, que representa la primera base de datos confiable sobre investigación y desarrollo. Ver figura 8. 


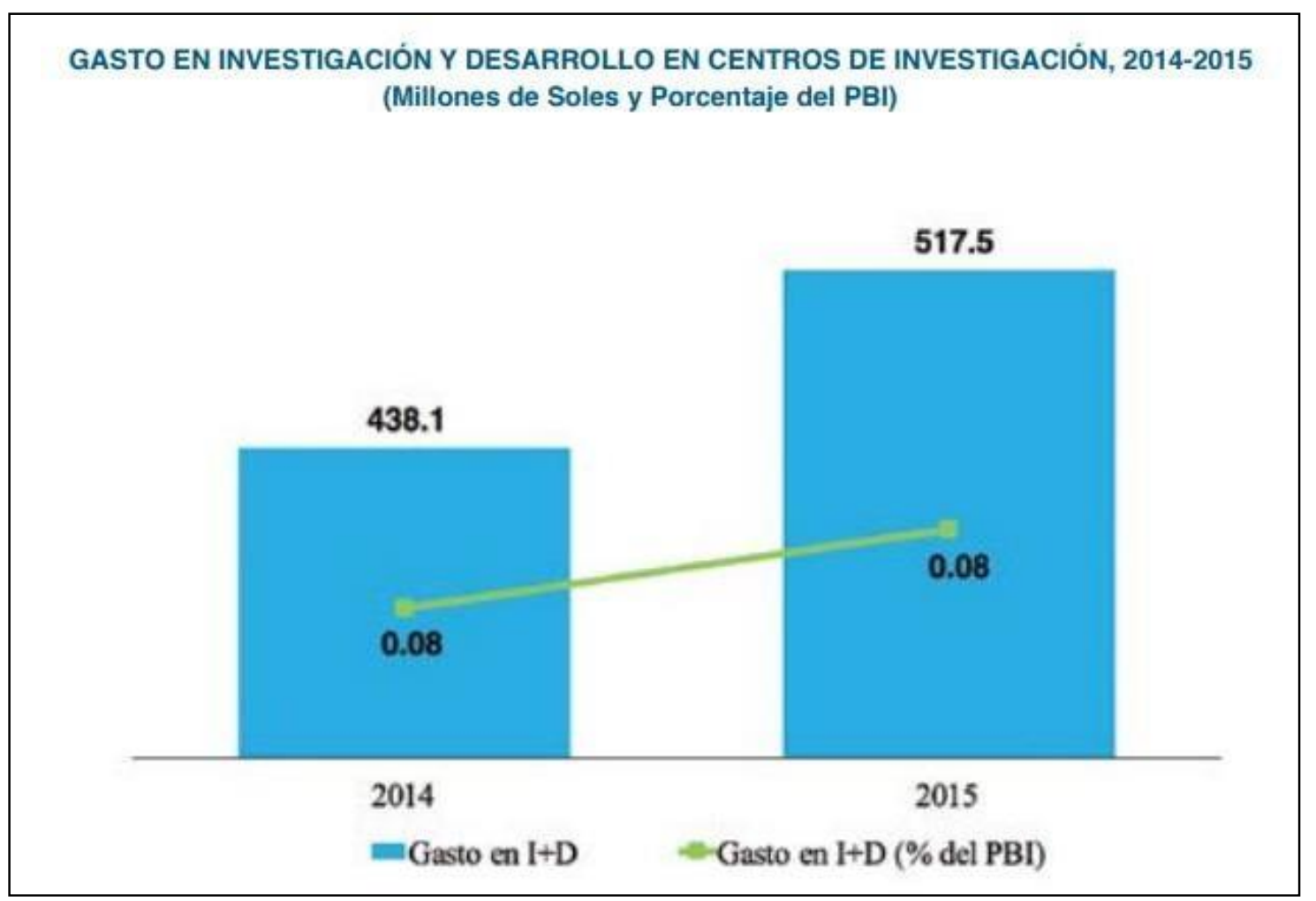

Figura 8. Gasto en investigación y desarrollo en centros de investigación, 2014-2015 (Millones de soles y Porcentaje del PBI). Tomado de "I Censo Nacional de Investigación y Desarrollo a Centros de Investigación 2016" por CONCYTEC, 2016. Recuperado de http://portal.concytec.gob.pe/images/publicaciones/censo_2016/libro_censo_nacional.pdf

A nivel internacional, esta cifra es la más baja con relación a los demás miembros de la Alianza del Pacífico, siendo el país más cercano Colombia, con un gasto en I+D que llega al $0.25 \%$ del PBI, mientras en América Latina llega a 0.75\% del PBI. Ver figura 9. 


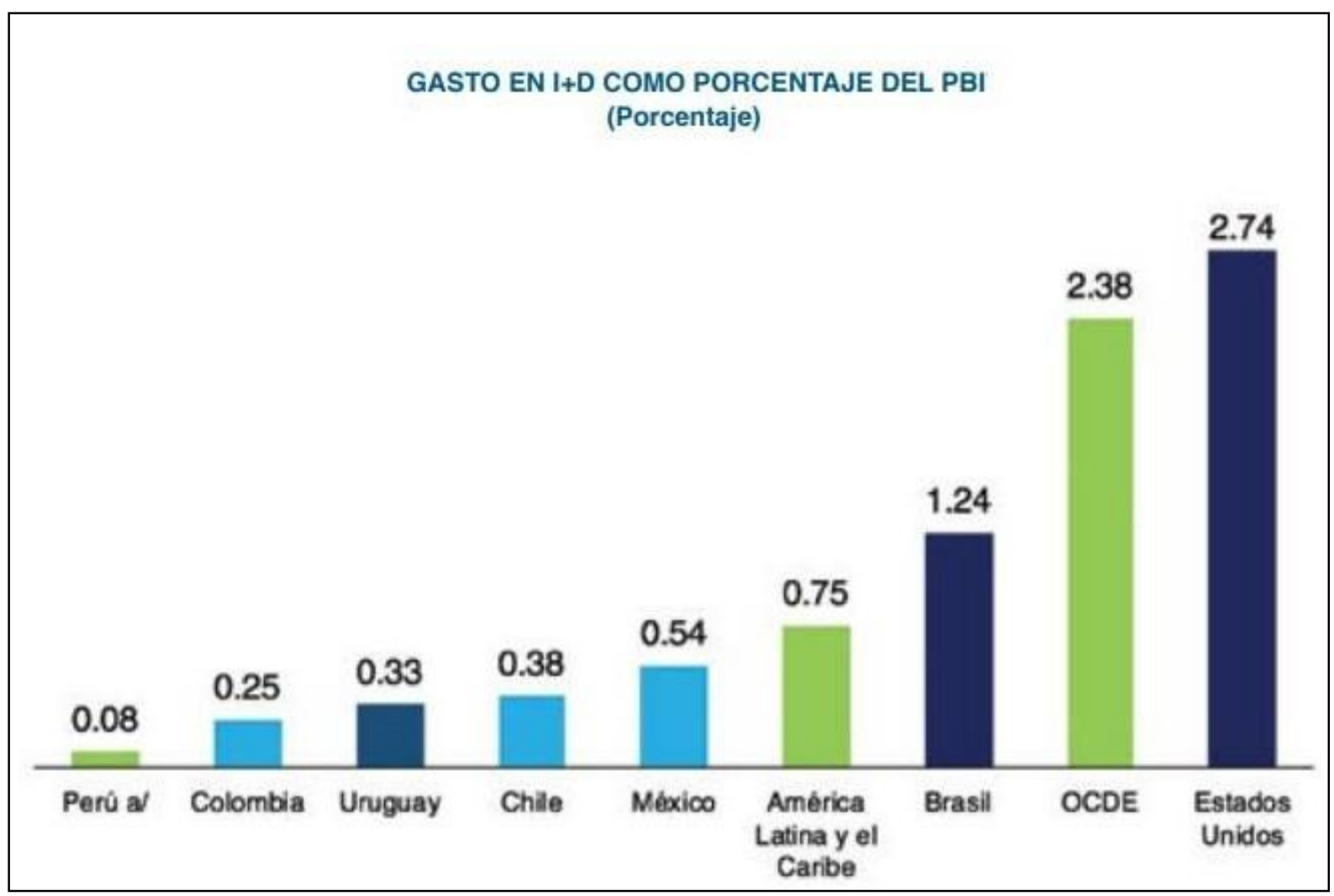

Figura 9. Gasto en I+D como porcentaje del PBI (Porcentaje). Tomado de "I Censo Nacional de Investigación y Desarrollo a Centros de Investigación 2016” por CONCYTEC, 2016. Recuperado de http://portal.concytec.gob.pe/images/publicaciones/censo_2016/libro_censo_nacional.pdf

La brecha se acrecienta frente a los países de la OCDE (Organización para la cooperación y el desarrollo económico) y Estados Unidos, que alcanzan gastos en I+D de $2.38 \%$ y $2.74 \%$, respectivamente.

Como una oportunidad para las empresas de Tecnología de la Información, pueden buscar la participación en estos proyectos de investigación y desarrollo brindando servicios para la implementación de nuevas tecnologías según las necesidades de las distintas empresas, así como brindar el servicio de soporte luego del desarrollo de estos y la evolución del alcance de cada proyecto a fin de optimizar de manera continua los soportes informáticos a las empresas. 
Para el 2015, se iniciaron 3,394 proyectos de investigación, lo que significó un incremento de $6.1 \%$ respecto de los proyectos iniciados en el año 2014 que fueron 3200. Las áreas de conocimiento con mayores proyectos iniciados en el año 2015 fueron las de Ciencias Sociales, Ciencias Naturales e Ingeniería y Tecnología, con una participación del 23.5, 21.6 y $21.3 \%$ respectivamente del número total de proyectos de investigación iniciados. Ver Tabla 9.

Tabla 9

Proyectos de investigación iniciados en 2014-2015

\begin{tabular}{lcccc}
\hline \multicolumn{1}{c}{ Área del Conocimiento } & \multicolumn{2}{c}{2014} & \multicolumn{2}{c}{2015} \\
& Proyectos & $\%$ & Proyectos & $\%$ \\
\hline Ciencias naturales & 689 & 21.5 & 733 & 21.6 \\
Ingeniería y tecnología & 667 & 20.8 & 722 & 21.3 \\
Liencias mearcas y ae ıa & 427 & 13.3 & 558 & 16.4 \\
salud & 332 & 10.4 & 363 & 10.7 \\
Ciencias agrícolas & 797 & 24.9 & 793 & 23.4 \\
Ciencias sociales & 288 & 9.0 & 225 & 6.6 \\
Humanidades & 3200 & 100.0 & 3394 & 100 \\
Total & &
\end{tabular}

Nota. Proyectos de investigación iniciados en 2014-2015. Tomado de "I Censo Nacional de Investigación y Desarrollo a Centros de Investigación 2016" por CONCYTEC, 2016. Recuperado de

http://portal.concytec.gob.pe/images/publicaciones/censo_2016/libro_censo_nacional.pdf

Con esta información podemos afirmar que más empresas están destinando inversiones a proyectos de Ingeniería y Tecnología lo que conviene a la empresa Xternal Technological Solutions S.A.C por la gama de servicios que brinda.

La Asociación Peruana de Software y Tecnologías (APESOFT) busca dar soporte integral para el desarrollo de la industria del software, fomentando las exportaciones de programas informáticos y promoviendo los objetivos nacionales, así como también los intereses económicos empresariales aunando esfuerzos para la creación de la base 
tecnológica y económica con la finalidad de mejorar la competitividad del software peruano. Xternal Technological Solutions S.A.C, puede aprovechar este soporte para la creación de software y negociarlo a nivel nacional e internacional.

\subsubsection{Análisis Tecnológico.}

La industria nacional del software ha crecido en los últimos seis años a un ritmo promedio del $15 \%$ anual, de acuerdo con la información proporcionada por el diario gestion.pe (2016). Cada vez son más las empresas que entienden que el tener un sistema de información integrado es sumamente importante para su desarrollo y crecimiento. Hace ya mucho tiempo que dejó de ser un lujo y se ha convertido en una necesidad.

La labor de formalización de empresas que viene realizando la Superintendencia Nacional de Administración Tributaria (SUNAT), impulsa a las empresas a tratar de implementar sistemas integrados que le permitan cumplir con los requerimientos que realiza esta última y, a su vez, mejorar y volver más eficientes sus procesos internos para optimizar recursos y aumentar su rentabilidad.

Dentro de los elementos a analizar en este segmento y que son mencionados en Hitt et al. (2015), se han tomado en consideración los siguientes:

- Innovaciones de producto: la innovación es un factor clave para mantener una competitividad, crecimiento y aumento en la participación del mercado. Respecto a este elemento se aprecia una tendencia mundial hacia el desarrollo en internet. $\mathrm{Y}$ en ese sentido, el desarrollo en la nube (término informático que deriva de la palabra cloud o nube en español y que permite la interacción de información sin necesidad de un equipo físico de procesamiento o almacenamiento) está migrando de sólo ser una posibilidad real de almacenamiento de información casi ilimitada, a ser una posibilidad 
real de desarrollo de software. Ya se ha desarrollado productos que permiten la programación desde la nube lo que genera un gran ahorro y eficiencia en los equipos de desarrollo de software. Existen ya productos innovadores como el Cloud9, Codio, Codenvy, Nitrous que permiten estos entornos de desarrollo integrados (IDES) por sus siglas en inglés. Esta tendencia abre una serie de oportunidades de negocio en donde la empresa Xternal Technological Solutions S.A.C. puede ser competitivo en precios y diferenciarse de su competencia directa.

Otra innovación de producto se da en el desarrollo de interfaces de desarrollo de aplicaciones (API) por sus siglas en inglés. Empresas que están orientando sus servicios a internet utilizan estos API para su relación con sus clientes o proveedores buscando agilizar y facilitar esta interacción. Esto va de la mano con lo descrito anteriormente del procesamiento en nube y la tendencia en el uso de dispositivos móviles. Las oportunidades de negocio en este segmento son muy grandes ya que son pocas las empresas en el Perú que ofrece este tipo de integración en sus desarrollos. Las empresas cada vez más requieren de procesamiento de grandes volúmenes de información. En ese sentido, el concepto de Big Data (término informático con el que se conoce al procesamiento de grandes volúmenes de información) cobra más vigencia, pero ya no sólo por la capacidad de procesar este volumen de datos sino por hacerlo en tiempo real. Ya ha salido al mercado tecnología como Apache Spark, que es una plataforma de computación de código abierto (es decir que no hay una empresa propietaria por lo que es software libre) cuyos tiempos para cálculos en memoria son de diez a cien veces más rápido que otro software 
propietario. Xternal Techonological Solutions S.A.C. tiene una oportunidad de incursionar en un rubro cada vez más solicitado por grandes empresas consolidadas.

- Nuevas tecnologías de comunicación: Respecto a este elemento se puede decir que las tendencias mundiales apuntan a los desarrollos en lo que se conoce como el internet de las cosas (IoT) por sus siglas en inglés y la realidad virtual, realidad aumentada y wearables (término en inglés que se refiere a cualquier prenda o elemento de vestir que incorpore elementos tecnológicos o electrónicos).

El IoT ofrece un cambio de acción muy amplio sobre todo en empresas de manufactura que invierten en equipos que ya cuentan con software incluido que permite su interacción directa. Justamente, la idea de este concepto es la conectividad entre objetos. De acuerdo con lo estimado por la consultora Gardner (2016), se espera que el mercado de IoT genere ingresos de 7,000 millones de dólares con más de 20,000 millones de objetos conectados. Del mismo modo, el concepto de wearables junto con la realidad virtual ofrece oportunidades muy importantes en empresas que necesitan el ploteo de su información para recrear condiciones reales de su operación.

\subsubsection{Análisis Ecológico.}

Siendo un aspecto importante la preocupación por el cuidado del ambiente, el Perú con la Ley 28611 - Ley General del Ambiente estableció los principios y normas básicas para ejercer el derecho a un ambiente saludable, equilibrado y adecuado para el desarrollo de la vida, del mismo modo el cumplimiento de contar con una gestión ambiental adecuada 
con la que se logre proteger el ambiente, para mejorar la calidad de vida de la población y lograr la sostenibilidad del país.

$\mathrm{Al}$ respecto, la empresa a fin de participar activamente con la normativa ambiental vigente en el Perú cuenta con una política ambiental demostrando su responsabilidad y compromiso de sus colaboradores dentro de la empresa en el cuidado de los recursos, así como la disposición final de los residuos que generan.

Siendo una empresa de servicios de tecnología de la información, no es significativo su impacto con el ambiente, siendo el principal recurso que utilizan con consumo la energía eléctrica requerida para los trabajos, así como material de oficina lo cual no impacta el desarrollo de la empresa.

Por otro lado, siendo uno de sus principales clientes una empresa dedicada al sector pesquero, este se ve afectado por el Fenómeno el Niño el cual se caracteriza por las corrientes cálidas en las costas de América, así como por una alteración del sistema global océano-atmosfera que se origina en el Océano Pacifico Ecuatorial que se ocasiona usualmente entre los meses de diciembre y marzo. Esta situación ocasiona cambios en la temperatura que afecta en la salinidad de las aguas, y los ecosistemas marinos se ven modificados en sus condiciones ambientales que afectan a las poblaciones de peces del área del Pacifico americano y por lo tanto la actividad pesquera (Senamhi, 2016). Al verse afecta la actividad pesquera, cabe la posibilidad que las empresas reduzcan sus necesidades de implementación de software al tener que reducir sus costos de operación por la baja productividad.

\subsection{Impacto en Clientes/Proveedores de cada una de las Variables del Entorno}

La tabla 10 muestra el impacto de cada una de las variables del entorno en los clientes y proveedores de la empresa Xternal Technological Solutions S.A.C.: 
Tabla 10

Impacto en Clientes/Proveedores de cada Variable del Entorno

\begin{tabular}{|c|c|c|c|}
\hline Variable & Tendencia & Impacto Cliente & Impacto Proveedores \\
\hline \multirow{5}{*}{$\begin{array}{l}\text { Político } \\
\text { Guberna } \\
\text { mental }\end{array}$} & $\begin{array}{l}\text { Reactivación de la economía } \\
\text { en base a fuentes internas }\end{array}$ & $\begin{array}{l}\text { Clientes aumentan sus } \\
\text { requerimientos en base a la } \\
\text { reactivación de la economía }\end{array}$ & $\begin{array}{l}\text { Al generarse mayor } \\
\text { demanda esto } \\
\text { ocasionara aumento en } \\
\text { los requerimientos a } \\
\text { los proveedores }\end{array}$ \\
\hline & Aumento del Riesgo País & $\begin{array}{l}\text { Disminución de inversión en } \\
\text { proyectos que requieran } \\
\text { tecnología }\end{array}$ & $\begin{array}{l}\text { Baja demanda de } \\
\text { nuevos requerimientos }\end{array}$ \\
\hline & $\begin{array}{l}\text { Reducción del IGV en un } \\
\text { punto porcentual }\end{array}$ & $\begin{array}{l}\text { Mayor liquidez para los } \\
\text { servicios y/o adquisiciones a } \\
\text { contratar }\end{array}$ & $\begin{array}{l}\text { Mejorar su oferta al } \\
\text { reducir sus gastos } \\
\text { tributarios }\end{array}$ \\
\hline & $\begin{array}{l}\text { Incremento en la demanda de } \\
\text { profesionales y técnicos en } \\
\text { tecnología }\end{array}$ & $\begin{array}{l}\text { Mejor calidad en los } \\
\text { servicios brindados }\end{array}$ & $\begin{array}{l}\text { Mayores } \\
\text { requerimientos de } \\
\text { infraestructura acorde a } \\
\text { las nuevas necesidades }\end{array}$ \\
\hline & $\begin{array}{l}\text { Interés de Instituciones } \\
\text { dedicadas al desarrollo e } \\
\text { innovación tecnológica }\end{array}$ & $\begin{array}{l}\text { Desarrollo de productos } \\
\text { acordes a las necesidades de } \\
\text { los clientes }\end{array}$ & $\begin{array}{l}\text { Mayor demanda de } \\
\text { requerimientos para } \\
\text { implementación de } \\
\text { proyectos }\end{array}$ \\
\hline
\end{tabular}


Tabla 10

Impacto en Clientes/Proveedores de cada Variable del Entorno

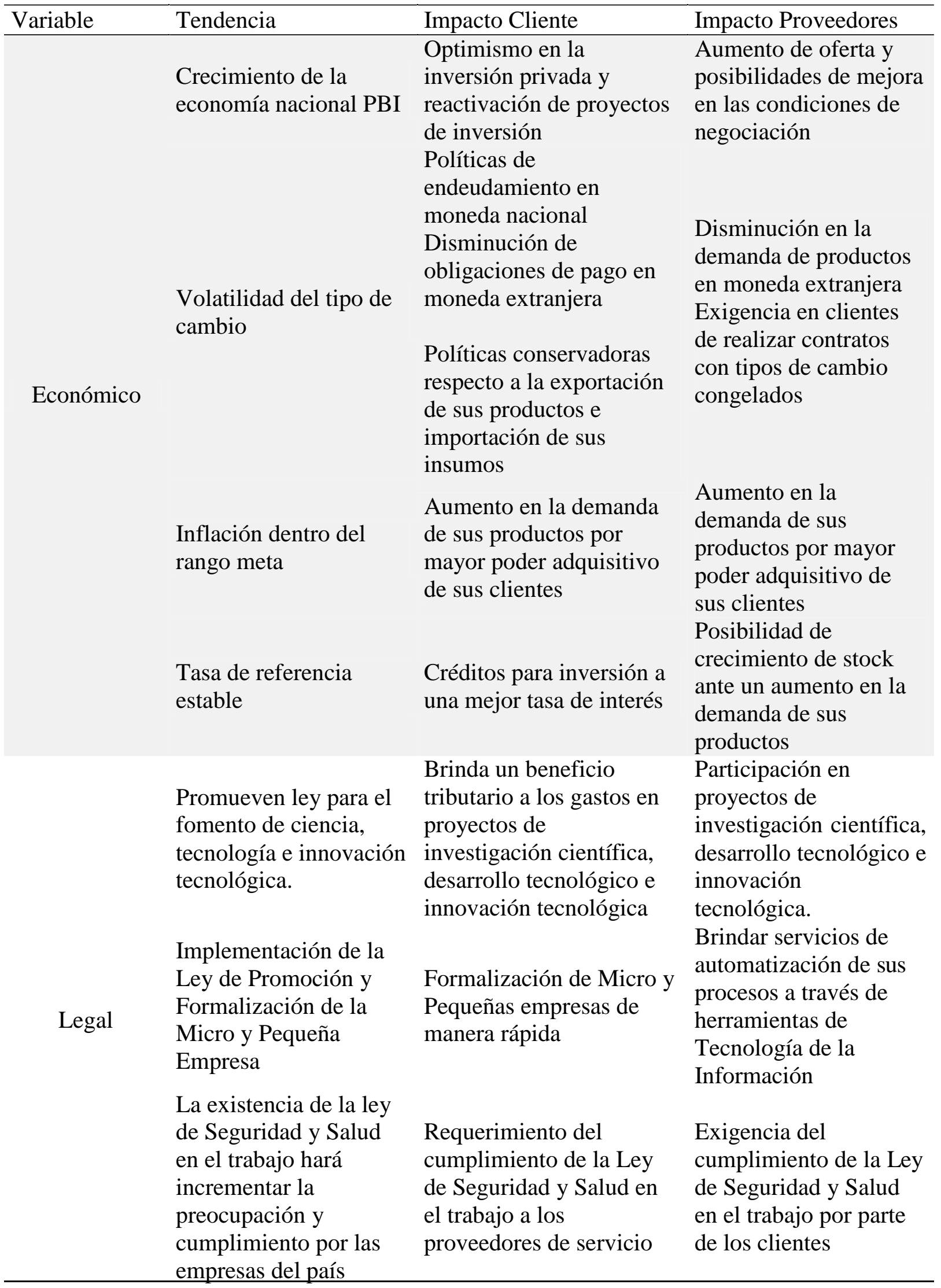


Tabla 10

Impacto en Clientes/Proveedores de cada Variable del Entorno

\begin{tabular}{|c|c|c|c|}
\hline Variable & Tendencia & Impacto Cliente & Impacto Proveedores \\
\hline \multirow{3}{*}{ Cultural } & $\begin{array}{l}\text { Uso de las Tecnología de } \\
\text { la Información en las } \\
\text { empresas }\end{array}$ & $\begin{array}{l}\text { Automatización de sus } \\
\text { procesos }\end{array}$ & $\begin{array}{l}\text { Demanda de nuevos } \\
\text { servicios de Tecnología } \\
\text { de la Información para } \\
\text { empresas }\end{array}$ \\
\hline & $\begin{array}{l}\text { Incremento en proyectos } \\
\text { de investigación de } \\
\text { tecnología }\end{array}$ & $\begin{array}{l}\text { Uso de mejores } \\
\text { herramientas tecnológicas }\end{array}$ & $\begin{array}{l}\text { Participación conjunta } \\
\text { con las empresas en el } \\
\text { desarrollo de proyectos } \\
\text { de Tecnología de la } \\
\text { Información }\end{array}$ \\
\hline & $\begin{array}{l}\text { APESOFT fomenta la } \\
\text { creación de programas } \\
\text { informáticos }\end{array}$ & $\begin{array}{l}\text { Mejor software para ser } \\
\text { implementado en sus } \\
\text { empresas }\end{array}$ & $\begin{array}{l}\text { Mayor demanda de } \\
\text { servicios de Tecnología } \\
\text { de la Información }\end{array}$ \\
\hline \multirow[t]{2}{*}{ Tecnológico } & Innovación de productos & $\begin{array}{l}\text { Necesidad de integración } \\
\text { de sus sistemas con los de } \\
\text { sus clientes y proveedores }\end{array}$ & $\begin{array}{l}\text { Ampliación de sus } \\
\text { catálogos de productos } \\
\text { Necesidad de } \\
\text { integración de sus } \\
\text { procesos de comercio } \\
\text { de manera segura con } \\
\text { sus clientes }\end{array}$ \\
\hline & $\begin{array}{l}\text { Nuevas tecnologías de } \\
\text { comunicación }\end{array}$ & $\begin{array}{l}\text { Necesidad de } \\
\text { actualización de su } \\
\text { plataforma tecnológica }\end{array}$ & $\begin{array}{l}\text { Ampliación de sus } \\
\text { catálogos de productos }\end{array}$ \\
\hline \multirow{3}{*}{ Ecológico } & $\begin{array}{l}\text { Cumplimiento de la } \\
\text { normativa ambiental } \\
\text { vigente }\end{array}$ & $\begin{array}{l}\text { Requerimiento del } \\
\text { cumplimiento de la Ley } \\
\text { General del Ambiente }\end{array}$ & $\begin{array}{l}\text { Exigencia del } \\
\text { cumplimiento de un } \\
\text { sistema de gestión } \\
\text { ambiental por parte de } \\
\text { la empresa }\end{array}$ \\
\hline & $\begin{array}{l}\text { Establecimiento de un } \\
\text { Sistema de Gestión } \\
\text { Ambiental }\end{array}$ & $\begin{array}{l}\text { Confiabilidad en trabajos } \\
\text { alineados con el cuidado } \\
\text { del ambiente }\end{array}$ & $\begin{array}{l}\text { Exigencia del } \\
\text { cumplimiento de un } \\
\text { sistema de gestión } \\
\text { ambiental por parte de } \\
\text { la empresa }\end{array}$ \\
\hline & $\begin{array}{l}\text { Presencia del Fenómeno El } \\
\text { Niño }\end{array}$ & $\begin{array}{l}\text { Disminución en la } \\
\text { productividad en las } \\
\text { empresas del sector } \\
\text { pesquero }\end{array}$ & $\begin{array}{l}\text { Disminución de } \\
\text { inversiones en } \\
\text { proyectos de } \\
\text { Tecnología de la } \\
\text { Información }\end{array}$ \\
\hline
\end{tabular}

\subsection{Efecto en la Empresa de cada una de las Variables del Entorno}

La tabla 11 describe el impacto de cada variable del entorno en la empresa Xternal

Technological Solutions S.A.C.: 
Tabla 11

Efecto en la empresa de cada una de las Variables del Entorno

\begin{tabular}{|c|c|c|}
\hline Variable & Tendencia & Efecto en la Empresa \\
\hline \multirow{5}{*}{$\begin{array}{c}\text { Político } \\
\text { Gubernamental }\end{array}$} & $\begin{array}{l}\text { Reactivación de la economía } \\
\text { en base a fuentes internas }\end{array}$ & $\begin{array}{l}\text { Empresas requieren mejorar sus procesos para } \\
\text { atender la demanda creciente }\end{array}$ \\
\hline & Aumento del Riesgo País & Disminución de requerimientos de servicios \\
\hline & $\begin{array}{l}\text { Reducción del IGV en un } \\
\text { punto porcentual }\end{array}$ & $\begin{array}{l}\text { Aumento en los servicios atendidos al reducir } \\
\text { sus gastos tributarios }\end{array}$ \\
\hline & $\begin{array}{l}\text { Incremento en la demanda } \\
\text { de profesionales y técnicos } \\
\text { en tecnología }\end{array}$ & $\begin{array}{l}\text { Aumento en la demanda de servicios de } \\
\text { tecnología que sean de calidad }\end{array}$ \\
\hline & $\begin{array}{l}\text { Interés de Instituciones } \\
\text { dedicadas al desarrollo e } \\
\text { innovación tecnológica }\end{array}$ & $\begin{array}{l}\text { Mayores oportunidades para participar en } \\
\text { nuevas empresas que desarrollen sistemas que } \\
\text { requieran mantenimiento }\end{array}$ \\
\hline \multirow{5}{*}{ Económico } & $\begin{array}{l}\text { Crecimiento de la economía } \\
\text { nacional PBI }\end{array}$ & $\begin{array}{l}\text { Mejora en su entorno de negocios al tener sus } \\
\text { clientes mayor demanda por sus servicios, } \\
\text { debido a reactivación de proyectos de } \\
\text { tecnología de información }\end{array}$ \\
\hline & & $\begin{array}{l}\text { Dependiendo del valor del tipo de cambio } \\
\text { puede pagar más o menos por los }\end{array}$ \\
\hline & $\begin{array}{l}\text { Volatilidad del tipo de } \\
\text { cambio }\end{array}$ & $\begin{array}{l}\text { licenciamientos anuales de las herramientas } \\
\text { que utiliza para brindar sus servicios. } \\
\text { Sus clientes exigirán clausulas especiales de } \\
\text { congelamiento del tipo de cambio para } \\
\text { servicios con cobranza en moneda extranjera. }\end{array}$ \\
\hline & $\begin{array}{l}\text { Inflación dentro del rango } \\
\text { meta }\end{array}$ & $\begin{array}{l}\text { Estabilidad en los precios de los principales } \\
\text { recursos necesarios para realizar su actividad }\end{array}$ \\
\hline & Tasa de referencia estable & $\begin{array}{l}\text { Posibilidades de inversión en infraestructura y } \\
\text { equipos a mediano plazo con tasas favorables }\end{array}$ \\
\hline \multirow{3}{*}{ Legal } & $\begin{array}{l}\text { Promueven ley para el } \\
\text { fomento de ciencia, } \\
\text { tecnología e innovación } \\
\text { tecnológica. }\end{array}$ & $\begin{array}{l}\text { Mayor demanda en los servicios de } \\
\text { Tecnología de Información }\end{array}$ \\
\hline & $\begin{array}{l}\text { Implementación de la Ley } \\
\text { de Promoción y } \\
\text { Formalización de la Micro y } \\
\text { Pequeña Empresa }\end{array}$ & $\begin{array}{l}\text { Posibilidad de desarrollo de proyectos de } \\
\text { investigación relacionados con la tecnología e } \\
\text { innovación en Pequeñas y Mediana empresas }\end{array}$ \\
\hline & $\begin{array}{l}\text { La existencia de la ley de } \\
\text { Seguridad y Salud en el } \\
\text { trabajo hará incrementar la } \\
\text { preocupación y } \\
\text { cumplimiento por las } \\
\text { empresas del país }\end{array}$ & $\begin{array}{l}\text { Alto costo para la implementación de la Ley } \\
\text { de Seguridad y Salud en el Trabajo }\end{array}$ \\
\hline
\end{tabular}


Tabla 11

Efecto en la empresa de cada una de las Variables del Entorno

\begin{tabular}{cll}
\hline Variable & Tendencia & Efecto en la Empresa \\
\hline \multirow{2}{*}{ Cultural } & Uso de tecnología móvil & $\begin{array}{l}\text { Mejor comunicación y rapidez en respuesta } \\
\text { para los requerimientos de la organización } \\
\text { Incremento de la demanda en servicios } \\
\text { tecnológicos debido a las iniciativas de } \\
\text { Tecnológico } \\
\text { transferencia de tecnología } \\
\text { desarrollo y transferencia de tecnología. }\end{array}$ \\
$\begin{array}{lll}\text { Innovación de productos } \\
\text { Nuevas tecnologías de }\end{array}$ & $\begin{array}{l}\text { Necesidad de capacitación en el uso de los } \\
\text { nuevos productos en el mercado } \\
\text { Inversión en recursos humanos y técnicos } \\
\text { para cubrir la necesidad del mercado }\end{array}$ \\
& $\begin{array}{l}\text { Cumplimiento de la } \\
\text { normativa ambiental vigente }\end{array}$ & $\begin{array}{l}\text { Reducción de costos fijos, optimizando el } \\
\text { uso de los recursos }\end{array}$ \\
& $\begin{array}{l}\text { Establecimiento de un } \\
\text { Sistema de Gestión }\end{array}$ & $\begin{array}{l}\text { Reducción de costos fijos, optimizando el } \\
\text { uso de los recursos }\end{array}$ \\
& $\begin{array}{l}\text { Ambiental } \\
\text { Presencia del Fenómeno El }\end{array}$ & $\begin{array}{l}\text { Reducción de servicios requeridos por } \\
\text { empresas del sector pesquero }\end{array}$ \\
\hline
\end{tabular}

\subsection{Oportunidades}

Como resultado de los análisis de cada una de las variables del entorno de la empresa, se han identificado la siguiente lista de oportunidades y amenazas.

Oportunidades:

- O1. Incremento en la demanda de servicios.

- O2. Captación de profesionales y técnicos altamente capacitados.

- O3. Crecimiento en los sectores económicos de Pesca, Manufactura y Minería.

- O4. Tendencia a celebrar contratos anuales con precio fijo en moneda nacional.

- O5. Inversión privada en el rubro de tecnología de información.

- O6. Debido a la promoción y fomento de la ciencia, tecnología e innovación tecnológica basada en la ley 28303, las empresas necesitarán proveedores de servicios de tecnología. 
- O7. Diversificación de los servicios a ofrecer orientados a otros mercados (PYMES).

- O8. Alta demanda de los servicios que brinda la empresa.

- O9. Disponibilidad de nuevo software que permite el desarrollo sobre la nube.

- O10. Nueva plataforma de desarrollo orientada al procesamiento de grandes volúmenes de información.

\section{Amenazas:}

- A1. Aumento en la competencia en el rubro de servicios de tecnología.

- A2. Reducción de servicios de tecnología requeridos.

- A3. Alta rotación de personal debido a la demanda de la competencia.

- A4. Creación de nuevas empresas en el rubro de tecnología de información.

- A5. Fluctuación de la Tasa de Cambio de moneda extranjera

- A6. Riesgo de fracaso en la implementación de proyectos.

- A7. Evolución rápida de la tecnología.

- A8. Desfase tecnológico por nuevas versiones de herramientas de software orientadas a programación en nube.

- A9. Reducción de requerimientos por clientes del sector pesquero.

\subsection{Matriz de Evaluación de los Factores Externos EFE}

De acuerdo con lo mencionado por David (2013), la matriz de evaluación de factores externos permite la evaluación de información concerniente a los ámbitos económico, social, cultural, demográfico, ambiental, político, gubernamental, legal, tecnológico y competitivo, teniendo en consideración las diferentes oportunidades y 
amenazas que afectan tanto a la empresa misma como a la industria en donde se desenvuelve.

Los pasos por seguir para la elaboración de la matriz EFE indican, en primer lugar, la elaboración de una lista de factores externos clave separados entre oportunidades y amenazas (en ese orden) que impactan tanto a la empresa como a la industria en donde se desenvuelve.

A continuación, se le debe asignar una ponderación a cada uno de los factores identificados. El rango de ponderación debe estar entre 0.0 (no es importante) y 1.0 (muy importante), tomando en consideración que tan relevante es el factor para que se alcance el éxito en la industria en donde se desenvuelve la empresa. La suma de estas ponderaciones siempre debe dar 1.0. Estas ponderaciones se pueden obtener ya sea comparando a empresas competidoras que tienen éxito de las que no, o producto de un análisis de los factores llegando a un acuerdo grupal.

Adicionalmente, a cada factor identificado se le debe asignar un valor numérico que va desde 1 a 4 puntos para determinar la eficacia de la respuesta de las estrategias que actualmente utiliza la empresa a ese factor. Los valores representan 1=la respuesta es deficiente, $2=$ la respuesta es promedio, $3=$ la respuesta está por encima del promedio y 4=la respuesta es superior al promedio. La calificación se basa en la empresa y la ponderación se basa en la industria. Tanto las oportunidades como las amenazas pueden recibir calificaciones del 1 al 4 .

Finalmente, se haya la puntación ponderada multiplicando la ponderación de cada factor por su calificación. Este último valor se suma para todas las variables y se obtiene la puntuación ponderada total. Una puntuación ponderada total de 4 puntos indica que la empresa está respondiendo muy bien a las oportunidades y amenazas de su industria, con estrategias eficaces que aprovechan las oportunidades y minimizan los efectos adversos de 
las amenazas. Una puntuación ponderada total de 1 revela que las estrategias de la empresa no están aprovechando las oportunidades ni evitando las amenazas. La puntuación ponderada total promedio es 2.5 .

Para determinar los factores externos clave se han realizado entrevistas a profundidad con expertos del sector (anexo 2), los socios de la empresa Xternal Technological Solutions S.A.C. (anexo 1) y Gerentes de TI de empresas que no utilizan los servicios de Xternal Technological Solutions S.A.C. (anexo 3)

A continuación, se muestra la matriz de evaluación de los factores externos (EFE) con las oportunidades y amenazas valorizadas y ponderadas. La tabla 12 muestra la matriz EFE:

Tabla 12

Matriz de Evaluación del Factor Externo (EFE)

\begin{tabular}{|c|c|c|c|}
\hline FACIIUKES EX IEKIVUS & reso & C alificación & Ponderado \\
\hline \multicolumn{4}{|l|}{ OPORTUNIDADES } \\
\hline O1: Incremento de la demanda de servicios & 0.03 & 2 & 0.06 \\
\hline $\begin{array}{l}\text { O2: Captación de profesionales y técnicos altamente } \\
\text { calificados }\end{array}$ & 0.05 & 4 & 0.2 \\
\hline $\begin{array}{l}\text { O3: Crecimiento en sectores económicos de Pesca, } \\
\text { Manufactura y Minería }\end{array}$ & 0.09 & 3 & 0.27 \\
\hline O4: Contratos anuales con precio fijo en moneda nacional & 0.07 & 3 & 0.21 \\
\hline $\begin{array}{l}\text { O5: Inversión privada en el rubro de tecnología de } \\
\text { información }\end{array}$ & 0.09 & 3 & 0.27 \\
\hline $\begin{array}{l}\text { O6: Las empresas necesitarán proveedores de servicios de } \\
\text { información }\end{array}$ & 0.05 & 3 & 0.15 \\
\hline $\begin{array}{l}\text { O7: Diversificación de servicios a ofrecer orientados a otros } \\
\text { mercados (PYMES) }\end{array}$ & 0.09 & 4 & 0.36 \\
\hline O8: Alta demanda en los servicios que brinda la empresa & 0.04 & 3 & 0.12 \\
\hline $\begin{array}{l}\text { O9: Disponibilidad de nuevo software que permite el } \\
\text { desarrollo sobre la nube }\end{array}$ & 0.04 & 3 & 0.12 \\
\hline $\begin{array}{l}\text { O10: Nueva plataforma de desarrollo orientada al } \\
\text { procesamiento de grandes volúmenes de información }\end{array}$ & 0.06 & 3 & 0.18 \\
\hline
\end{tabular}


Tabla 12

Matriz de Evaluación del Factor Externo (EFE)

\begin{tabular}{|c|c|c|c|}
\hline FACTORES EXTERNOS & Peso & Calificación & $\begin{array}{c}\text { Peso } \\
\text { Ponderado }\end{array}$ \\
\hline \multicolumn{4}{|l|}{ AMENAZAS } \\
\hline $\begin{array}{l}\text { A1: Aumento en la competencia en el rubro de servicios de } \\
\text { tecnología de información }\end{array}$ & 0.07 & 2 & 0.14 \\
\hline $\begin{array}{l}\text { A2: Disminución de ingresos por reducción de servicios } \\
\text { requeridos. }\end{array}$ & 0.04 & 1 & 0.04 \\
\hline $\begin{array}{l}\text { A3: Alta rotación de personal debido a la demanda de la } \\
\text { competencia }\end{array}$ & 0.05 & 2 & 0.1 \\
\hline $\begin{array}{l}\text { A4: Creación de nuevas empresas en el rubro de tecnología } \\
\text { de información }\end{array}$ & 0.05 & 2 & 0.1 \\
\hline A5: Fluctuación de la tasa de cambio de moneda extranjera & 0.03 & 1 & 0.03 \\
\hline A6: Riesgo de fracaso en la implementación de proyectos & 0.04 & 2 & 0.08 \\
\hline A7: Evolución rápida de la tecnología & 0.04 & 2 & 0.08 \\
\hline $\begin{array}{l}\text { A8: Desfase tecnológico por nuevas versiones de } \\
\text { herramientas de software orientadas a programación en nube }\end{array}$ & 0.04 & 2 & 0.08 \\
\hline $\begin{array}{l}\text { A9: Reducción de requerimientos por clientes del sector } \\
\text { pesquero }\end{array}$ & 0.03 & 1 & 0.03 \\
\hline TOTAL & 1.00 & & 2.62 \\
\hline
\end{tabular}

La puntuación obtenida muestra que la empresa tiene un ligero éxito aprovechando las oportunidades que se le presentan y respondiendo a las amenazas que enfrenta $(2.62$ superior al promedio 2.5). Aun así, se encuentra lejos de aprovechar completamente las oportunidades y minimizar todas las amenazas por lo que se puede visualizar analizando cada uno de los factores.

Se puede apreciar valores importantes referentes a oportunidades relacionadas con la diversificación de servicios, inversión privada en tecnología de información y crecimiento de sectores económicos. De acuerdo con ello, se hace factible el proponer estrategias relacionadas con desarrollo de productos o servicios siguiendo tendencias tecnológicas actuales como data analytics o aplicativos para dispositivos móviles. Estrategias de penetración de mercado o desarrollo de mercado también podrían aprovechar estas oportunidades, como la de incursionar en los sectores económicos que 
están bien aspectados según las proyecciones, o reorientar el enfoque a empresas de menor envergadura, pero más flexibles respecto a desarrollos tecnológicos como las PYMES.

Asimismo, se puede visualizar que las amenazas con mayor valor son las que se refieren al aumento en los emprendimientos referentes a la tecnología de información. Las pocas barreras de entrada del sector y la diversidad de tendencias actuales que pueden ser aprovechadas para el sector empresarial (sólo el 1\% del mercado se ha cubierto en desarrollo de software empresarial, según informe del diario gestión (2016)).

Este aumento de la competencia no sólo se refleja en nuevos emprendimientos, sino que también las empresas ya existentes están diversificando su cartera de servicios a ofrecer. En ese sentido, las estrategias de penetración de mercado reorientando el enfoque a un nuevo mercado como el de las PYMES, podría resultar beneficioso en la búsqueda de océanos azules por explotar. 


\section{Capítulo V: Análisis de la Industria}

\subsection{Descripción del Mercado (Demanda) e Industria (Oferta) \\ Mercado (demanda):}

Actualmente los sistemas de información permiten que las empresas puedan organizar adecuadamente toda la información que manejan en sus procesos, así como también el control de sus productos, de forma que puedan tomar decisiones para optimizar sus recursos mejorando el desempeño de la empresa (Laudon \& Laudon, 2016)

Es así como la demanda por estos servicios se ha visto incrementada durante los últimos años a nivel mundial. La consultora Gartner presentó las tendencias para el año 2017 que las empresas implementarán como parte de sus estrategias para poder mantenerse en el mercado como organizaciones productivas y competitivas. Entre las tendencias mencionadas se encuentran las plataformas de tecnología digital, que son bloques básicos que facilitan la construcción de un negocio digital, y en donde se identifican cinco principales: sistemas de información, experiencia del cliente, analíticas e inteligencia, IoT (internet of things) y ecosistemas de negocio. (Gartner, 2017)

A nivel nacional, la industria del software ha venido teniendo un incremento del 15\% anual en los últimos seis años según gestion.pe (2016), siendo uno de sus principales productos la elaboración de sistemas administrativos contables, debido a las exigencias por parte del órgano de administración tributaria (SUNAT) por formalizar y aumentar el pago de tributos en el Perú.

Por otro lado, las empresas nacionales han visto que la implementación de un ERP es una inversión para sus organizaciones optimizando sus procesos administrativos y productivos, lo cual según gestion.pe (2017) ha posicionado al Perú entre los cinco países de mayor demanda de ERP en Latinoamérica, principalmente en los sectores de comercio 
y manufactura, pero a pesar de esto aún no se destaca en el mercado en comparación con otros países de la región como Argentina, Chile y Colombia.

Al respecto, según el INEI las empresas en el Perú utilizan la Tecnología de la Información principalmente para la comunicación siendo el $61.4 \%$ de las empresas que utilizan estas herramientas para correo electrónico y chat, así como también las operaciones de banca electrónica con un 42.7\% como se muestra en la figura 10.

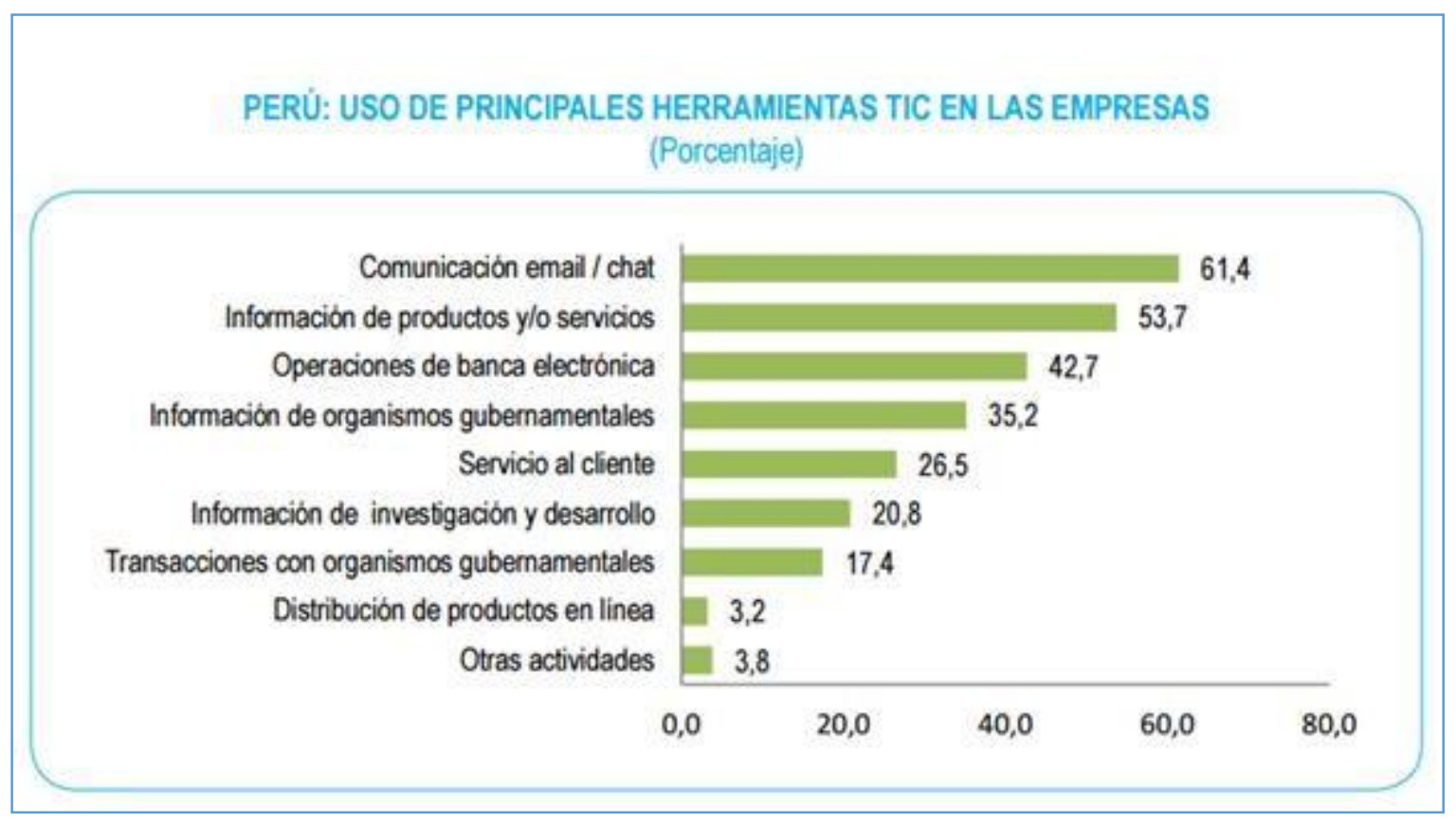

Figura 10. Uso de principales herramientas TIC en las empresas. Tomado de "Encuesta Económica Anual 2014” por el Instituto Nacional de Estadística e informática, 2014. Recuperado de http://www.inei.gob.pe/

Del mismo modo el comercio electrónico, es muy bajo alcanzando solo el $2.9 \%$ del total de empresas que realizan ventas a través de internet, como se ve en la figura 11. 


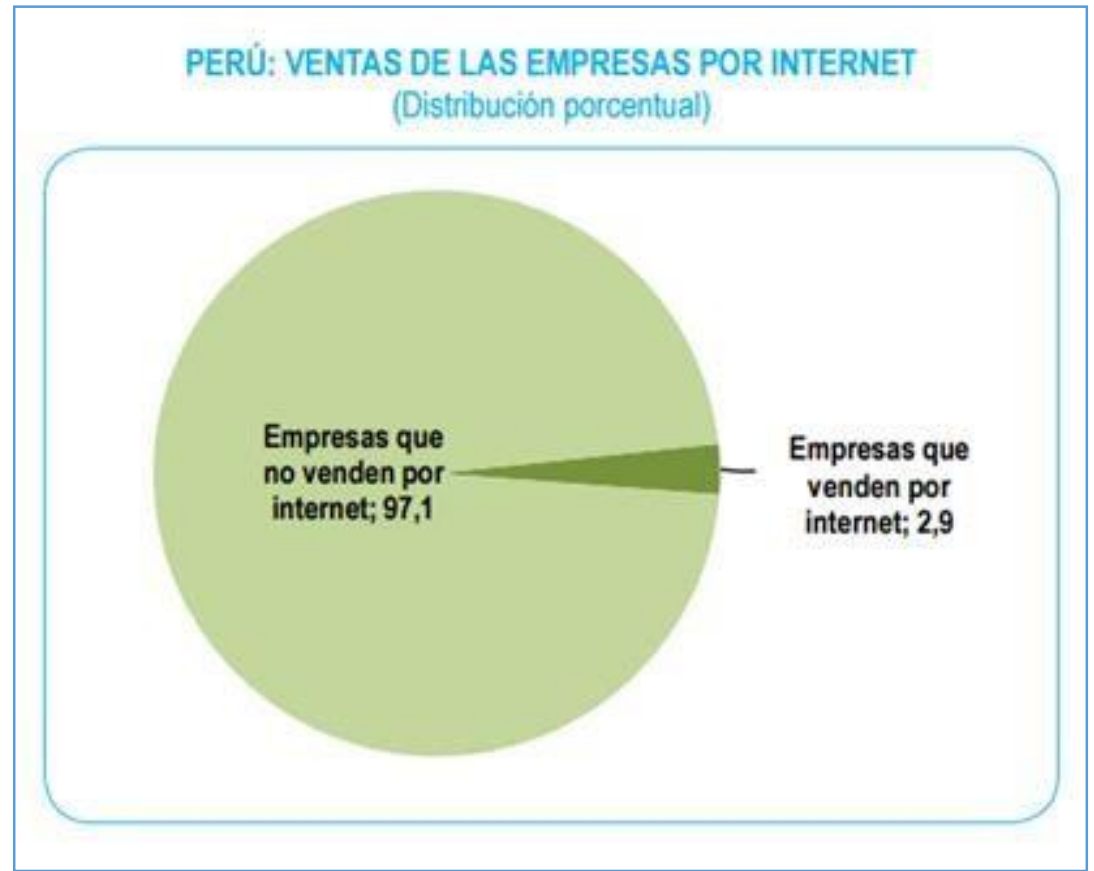

Figura 11. Ventas de las Empresas por Internet (Distribución Porcentual) Tomado de "Encuesta Económica Anual 2014" por el Instituto Nacional de Estadística e informática, 2014. Recuperado de http://www.inei.gob.pe/

Esta falta de demanda de usos de servicios de internet tiene entre sus principales inconvenientes que únicamente el $20.1 \%$ de las empresas capacita a sus trabajadores en los beneficios en el uso de las Tecnologías de Información y comunicaciones como se muestra en la figura 12. 


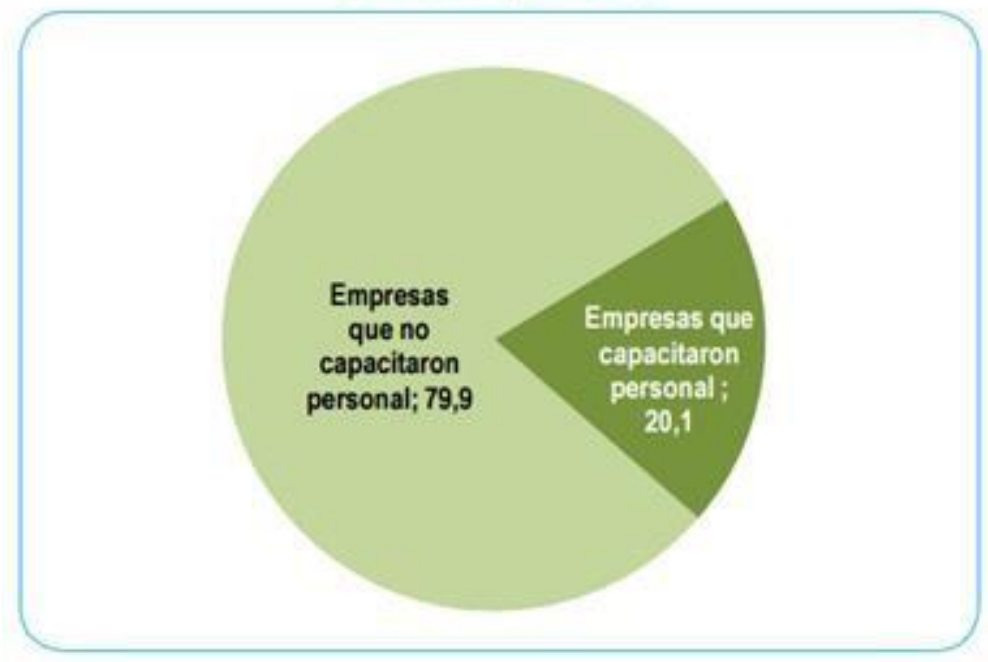

Figura 12. Capacitación de Personal en el Uso de TIC. Tomado de "Encuesta Económica Anual 2014" por el Instituto Nacional de Estadística e informática, 2014. Recuperado de http://www.inei.gob.pe/

En este contexto, según gestion.pe (2016), la demanda de profesionales de redes de Tecnología de la Información y Comunicación es de alrededor de 20,000 personas, lo que demuestra la necesidad de las empresas de contar con sistema de información para gestionar sus organizaciones para la mejora de sus procesos.

\section{Industria (oferta)}

Existen diversas empresas dedicadas a la consultoría de soluciones tecnológicas, las cuales se dedican a brindar desde la implementación del software necesario para gestionar una empresa, así como el mantenimiento de este, y el diseño de nuevas herramientas que faciliten los procesos de las organizaciones.

Entre las principales empresas se tiene a Tgestiona, OmniaSolution, Deloitte, Indra, Novis entre otras, estas son empresas grandes consolidadas en el mercado de tecnología de la información que brinda servicios de calidad a otras organizaciones. 
$\mathrm{Al}$ respecto, según Strategy\&, la consultora estratégica del grupo $\mathrm{PwC}$, la plataforma SAP se encuentra en tercer lugar dentro de los principales proveedores de productos, servicios e infraestructura relacionada a la digitalización a empresas y otras organizaciones (strategy\&, 2015).

En el caso de Xternal Technological Solutions, es una empresa en crecimiento la cual busca posicionarse en el mercado de tecnología brindando servicios principalmente en la plataforma SAP Netweaver Portal, así como también en el lenguaje de programación ABAP, estos servicios dentro del mercado local son compartidos con otras empresas compitiendo principalmente con las siguientes organizaciones:

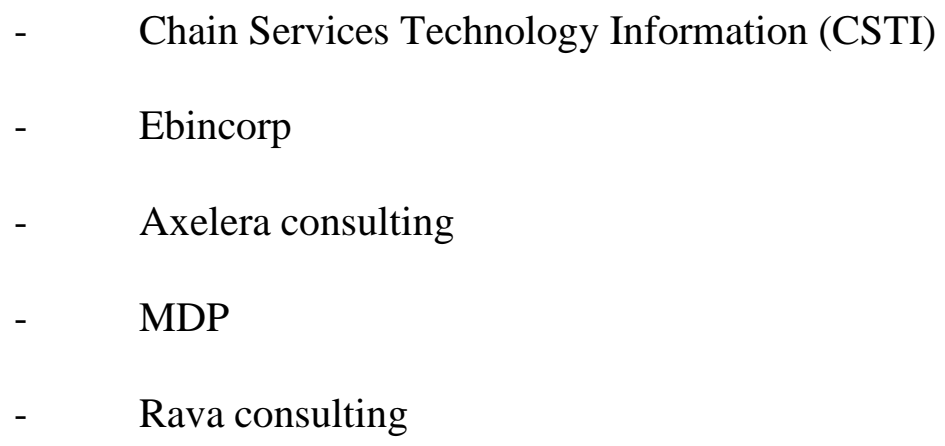

Como principal servicio brindado por las empresas se encuentra la consultoría en la plataforma SAP, contando con servicios adicionales como son los aplicativos móviles, Microsoft Sharepoint, Portales Liferay, entre otros.

\subsection{Descripción de las Cinco Fuerzas Competitivas de la Industria}

Las empresas requieren analizar su entorno para poder desarrollar estrategias para mejorar su posicionamiento en el sector. Para esto, según Thompson, Gamble, Peteraf, \& Strickland III (2012), la herramienta más poderosa y de uso más común para determinar las principales intensidades competitivas dentro del sector viene a ser el modelo de competencia de cinco fuerzas, con la cual se logra evaluar las fortalezas y la importancia de cada una de ellas, las cuales son: (a) la competencia de vendedores rivales, (b) la 
competencia de nuevos participantes a la industria, (d) la competencia de los productores de productos sustitutos, (e) el poder de negociación de los proveedores y (f) el poder de negociación de los clientes (p. 54).

\subsubsection{Sustitutos.}

Según Hernández \& Gómez (2014), los productos sustitutos son los que cumplen con las mismas funciones de otro producto. Son una fuerza que determina el atractivo de la industria, al reemplazar los productos y servicios que se ofrecen o bien representar una alternativa para satisfacer la demanda. Representan una amenaza para el sector si cubren las mismas necesidades a un precio menor, con rendimiento y calidad superior.

Las empresas de un sector pueden estar en competencia directa con las de un sector diferente si los productos pueden sustituir al otro bien.

Una empresa ha de estar pendiente de aquellos productos que puedan sustituir a los ofrecidos por ella. Por ejemplo, Xternal Technological Solutions S.A.C. tiene presente la amenaza de las empresas que comercializan software estándar pero no sólo eso, su competencia también sería el software que las empresas puedan desarrollar de manera interna. En ese sentido estarían compitiendo con los desarrolladores de software, que realizan esta labor de manera interna y con los fabricantes de software.

El impacto que la amenaza de sustitutos tiene sobre la rentabilidad de la industria depende de factores tales como:

- Disponibilidad de sustitutos: Se refiere a la existencia de productos sustitutos y a la facilidad de acceso.

- Precio relativo entre el producto sustituto y el ofrecido: Se refiere a la relación entre el precio del producto sustituto y el analizado. Un bien sustituto con un precio competitivo establece un límite a los precios que se pueden ofrecer en un 
sector.

- Rendimiento y calidad comparada entre el producto ofrecido y su sustituto: Los clientes se inclinarán por el producto sustituto si la calidad y el rendimiento son superiores al producto usado.

- Costos de cambio para el cliente: Si los costos de cambio son reducidos los compradores no tendrán problema en utilizar el bien sustituto, mientras que si son altos es menos probable que lo hagan.

La entrada de productos sustitutos según sean su calidad, disponibilidad, costos y rendimiento, pone un tope al precio que se puede cobrar antes de que los consumidores opten por un producto sustituto.

El análisis de la amenaza del ingreso de productos sustitutos permite diseñar estrategias destinadas a impedir la penetración de las empresas que vendan estos productos o, en todo caso, estrategias que permitan competir con ellas.

Si se habla de la calidad de los servicios ofrecidos, se puede decir que Xternal Technological Solutions S.A.C. se distingue por ofrecer un servicio integral, este aspecto lo diferencia del resto de competidores. Existen otras empresas que ofrecen el mismo servicio, pero con menos prestaciones. Es decir, que la empresa motivo de estudio, ofrece un desarrollo de software customizado y adecuado a la realidad de cada empresa cliente. De esta manera, existe una variedad de servicios sustitutos que se constituyen como alternativas al servicio ofrecido por Xternal Technological Solutions S.A.C., pero las características del servicio, como son los conocimientos específicos y la experiencia del personal, suponen un valor añadido que en muchos casos es reconocido por el mercado. Un mercado o segmento deja de ser atractivo cuando, por ventajas de precio, avances tecnológicos u otras razones, los consumidores pueden considerar la compra del producto 
sustituto en lugar del producto propio. Los sustitutos establecen límites en los precios y por tanto en los beneficios. En ocasiones, pueden eliminar sectores completos. La industria de la fotografía digital prácticamente ha expulsado del mercado la industria de la película fotográfica. La irrupción del software de código abierto representa una amenaza para las compañías de software con licencia de propietario. Si se observan estos ejemplos y los de nuevos competidores, se puede concluir que la amenaza más grande para una compañía no son los competidores existentes, sino los nuevos competidores y los fabricantes de productos sustitutos.

Algunas empresas que comercializan software con licencia de propietario en el mercado son: OFISIS, SAP, ORACLE, MICROSOFT, PEOPLE SOFT, DEFONTANA.

\subsubsection{Potenciales.}

En la industria de desarrollo de software en el Perú existe una segmentación muy marcada y determinada particularmente por la magnitud o envergadura de las empresas del sector. Es así, que se tienen tres segmentos plenamente identificados: (a) empresas transnacionales con sede en el Perú, (b) empresas medianas o partners de desarrollo, y (c) empresas pequeñas de consultoría especializada.

Dentro del primer segmento se identifican empresas como SAP, Microsoft, Oracle y Google, que tienen sede en el país y que participan de proyectos de implementación de sus propios productos en las distintas empresas de los sectores económicos del país.

Dentro del segundo segmento se identifican empresas que también tienen productos propios de menor envergadura y que además ofrecen servicios de consultoría para la implementación de los productos ofrecidos por las empresas del primer segmento descrito anteriormente. Aquí se encuentran empresas como Ofisis, Omnia Solutions, Indra, Cosapi Soft, GMD (Graña y Montero Digital), Novatronic, entre otras. 
Finalmente, en el tercer segmento se encuentra la empresa Xternal Technological Solutions S.A.C. junto con su competencia directa como CSTI (Chain Services Technology Information), EBINCORP, AXELERA Consulting, MDP y RAWA Consulting.

En este contexto, una nueva empresa podría encontrar atractivo el mercado o el segmento identificado en donde se encuentra Xternal Technological Solutions S.A.C o no, si es que le resulta fácil el poder franquear las barreras de ingreso propias de este sector.

Porter identificó seis barreras de entrada, las cuales se analizarán a continuación en la realidad de Xternal Technological Solutions S.A.C.

- Economías de escala: En este punto Xternal Technological Solutions S.A.C. no cuenta con una gran cantidad de clientes, ni tampoco con los recursos que poseen las empresas de los dos sectores anteriormente descritos, por lo que para una nueva empresa ingresar en este segmento será relativamente fácil.

Incluso si tuviese un mejor respaldo económico, esta posible empresa competidora podría apoderarse de un sector importante del mercado. Estos factores hacen que la atractividad sea alta.

- Diferenciación del producto: En el segmento en el que se encuentra la empresa Xternal Technological Solutions S.A.C., no hay una diferenciación muy marcada en los servicios que las empresas ofrecen. Cada una maneja sus propios estándares de calidad y son muy similares entre ellas. Básicamente se diferencian sobre los beneficios adicionales que pueden brindar y que tienen que ver básicamente con una reducción en el precio del servicio a cambio de una extensión en el tiempo del contrato. Una empresa con estándares de calidad definidos, experiencia, con recursos humanos 
conocidos en el sector y con un precio competitivo podría marcar la diferencia rápidamente.

- Requisitos de capital: La mayoría de las empresas en este segmento del sector han empezado sus operaciones con muy poca inversión inicial. Un nuevo competidor no tendría esta barrera para empezar a competir con Xternal Technological Solutions S.A.C.

- Desventajas en costos independientemente de las economías de escala: Xternal Technological Solutions S.A.C. cuenta con la ventaja del precio de su servicio sobre sus otros competidores. Adicionalmente, ya se ha posicionado con empresas referentes de los sectores de manufactura y pesca, demostrando calidad en su servicio a un costo por debajo de la media de mercado. Esto le ha garantizado continuidad mínima de un año en sus contratos de mejora continua de los desarrollos e implementaciones de tecnología de información con dichas empresas. Esta podría ser una barrera no muy fácil de romper por una nueva empresa competidora, aunque dependerá en gran medida de la estrategia de ingreso que elija.

- Acceso a los canales de distribución: Este no es un punto en el que Xternal Technological Solutions S.A.C. tenga alguna ventaja competitiva respecto a sus competidores directos. El esquema por el que la empresa proporciona sus servicios a sus clientes es similar a las demás. Los proveedores del servicio de comunicación son tres y no hay mayor diferencia entre ellos. Respecto a los licenciamientos de software, las condiciones son las mismas para todas las empresas del sector.

- Política gubernamental: Este tampoco es un punto en el que Xternal Technological Solutions S.A.C. tenga alguna ventaja competitiva. Las leyes 
establecidas en el país no favorecen en especial a ninguna empresa del sector.

\subsubsection{Clientes.}

Actualmente las empresas están apostando por la tecnología e información para construir estrategias que las diferencien de sus competencias con el propósito de conseguir mejoras en sus procesos. Según Diego Pantoja Navajas, CEO y visionario de la industria de la logística y cadena de suministro de LogFire, señala que "aproximadamente el $40 \%$ de las empresas en el Perú, entre grandes y medianas, trabajan con tecnología en la nube”. El experto sostiene que, las empresas peruanas están siguiendo la tendencia de las grandes tiendas como Apple y Amazon con el objetivo de ser competitivos y eficientes en el mercado mediante el uso de tecnologías en la nube, con esto esperan tener la velocidad de respuesta ante la demanda de los clientes (gestion.pe, 2015).

Según Martin García, Gerente de Soluciones de Ofisis, "los sectores comercio, manufactura y servicios son un foco potencial para el software ERP en el mercado peruano" (gestion.pe, 2017) en ese sentido Xternal Technological Solutions S.A.C. ya cuenta con clientes en esos dos sectores, lo que le permite tener una ventaja sobre su competencia directa.

Xternal Technological Solutions S.A.C. cuenta con cinco principales clientes quienes son: Corporación Lindley, Perú LNG, Minería Goldfields - La Cima, TASA y Grupo Livit a los cuales brinda servicios a la plataforma de tecnología, siendo el principal de ellos la empresa TASA puesto que cuenta con un contrato anual a diferencia del resto de los clientes que cuenta con contratos por proyectos según el cumplimiento de objetivos del cliente. 
Por tal motivo el poder de negociación de TASA es alto y Xternal Technological Solutions S.A.C. debe adaptarse a los cambios de implementación de software de su cliente principal, para poder cubrir la demanda existente por este.

Según David (2013), indica que “es posible que el poder de negociación de los consumidores sea la más importante de las fuerzas que afectan la ventaja competitiva".

Por otro lado, el modelo de contratación por proyectos que se utiliza con el resto de las empresas limita a Xternal Technological Solutions S.A.C. a desarrollar posibles soluciones ajenas a lo establecido a los objetivos específicos del proyecto contratado.

\subsubsection{Proveedores.}

Según Moragues (2014), Los proveedores definen el posicionamiento de una empresa en el mercado de acuerdo con el poder de negociación que mantienen con quienes les suministran los insumos para la producción de sus bienes y/o servicios. Las condiciones del mercado en el sector de los proveedores y la importancia que tienen para el producto del sector que se está estudiando determinarán la intensidad de esta fuerza.

El poder negociador de los proveedores dependerá de:

- Las condiciones del mercado

- Del resto de los proveedores

- La importancia del producto que proporcionan.

Su fuerza se verá disminuida si el producto que ofrecen es estándar y puede obtenerse en el mercado con facilidad, es decir que existe un gran número de proveedores. En este caso el comprador estará en una buena posición para elegir la mejor oferta. Por el contrario, el proveedor estará en posición ventajosa si el producto que ofrece escasea y los compradores necesitan adquirirlo para sus procesos. Las variables más relevantes de esta fuerza son: 
- Concentración de proveedores: Se requiere identificar si la mayor parte de la provisión de insumos o recursos para las empresas del sector, las realizan pocas o muchas compañías.

- Importancia del volumen para los proveedores: Es la importancia del volumen de compra que hacen las compañías del sector a los proveedores (es decir, las ventas al sector con relación a las ventas totales de los proveedores).

- Diferenciación de insumos: Si los productos ofrecidos por los proveedores están o no diferenciados.

- Costos de cambio: Se refiere a los costos que incurre el comprador cuando cambia de proveedor. La existencia de estos costos puede dar un relativo poder a los proveedores.

- Disponibilidad de insumos sustitutos: Es la existencia, disponibilidad y acceso a insumos sustitutos que por sus características pueden reemplazar a los tradicionales.

- Impacto de los insumos: Se trata de identificar si los insumos ofrecidos mantienen, incrementan o mejoran la calidad del bien.

Mientras menor cantidad de proveedores existan, mayor será su capacidad de negociación ya que, al no haber tanta oferta de insumos, éstos pueden fácilmente aumentar sus precios. Además de la cantidad de proveedores que existan, el poder de negociación de los proveedores también podría depender del volumen de compra, la cantidad de materias primas sustitutas que existan, el costo que implica cambiar de materias primas, etc. El análisis del poder de negociación de los proveedores permite diseñar estrategias destinadas a lograr mejores acuerdos con nuestros proveedores o estrategias que nos permitan adquirirlos o tener un mayor control sobre ellos. Un número creciente de empresas exige a 
sus proveedores que mejoren la calidad ambiental de sus componentes, a través de garantías de reciclaje o reutilización, mayor eficiencia energética o menor toxicidad.

El sector en el que se encuentra la empresa análisis de estudio tiene varios tipos de proveedores de servicios. La calidad de estos proveedores favorece a que haya plazos de intervención, costos y calidad distintos. En cuanto a Xternal Technological Solutions S.A.C. existen varios tipos de proveedores: Proveedores de equipos, licencias de software de desarrollo, servicio técnico, servicios de telefonía, internet, entre otros. Este tipo de proveedores debe ser de total calidad y profesionalismo, ya que lo que desean los clientes es un servicio rápido y fiable.

En cuanto al poder de los proveedores, se pueden encontrar productos de calidad a buen precio, pero en la parte del servicio post venta, los materiales o servicios requeridos son más específicos y costosos. Un mercado o segmento deja de ser atractivo en el momento en el que los suministradores se pueden permitir subir los precios o reducir la calidad o la cantidad de la entrega. Esto suele ocurrir si los proveedores son pocos y están muy organizados; cuando hay pocos sustitutos; cuando el producto suministrado es una parte relevante de nuestro producto; cuando los costos de cambiar de proveedores son altos, o cuando los proveedores pueden integrarse hacia abajo, es decir, producir y distribuir lo que nuestra empresa ofrece. Intel o Microsoft han sido durante años proveedores con un altísimo poder de negociación en el mercado de ordenadores personales, como IBM en el mercado de ordenadores mainframe, u Oracle entre los gestores de bases de datos.

Algunas empresas proveedoras:

- Hardware: DELL, HP, IBM, CISCO, LG

- Internet: Claro, Entel, Telefónica

- Telefonía: Claro, Entel, Telefónica 
- Licencias de Software de Desarrollo: SAP, SQL (MICROSOFT), QLIKVIEW (QLICK), MACAFFE, WINDOWS SERVER (MICROSOFT)

- Servicio Técnico: DELL, MICROSOFT

\subsubsection{Competencia en el mismo sector.}

Según el experto en tecnología, Édgar Mantilla, las empresas tecnológicas cuentan con planes de desarrollo, y de acuerdo con la tendencia van modificando sus objetivos para ir evolucionando con el mercado, para que perduren en el tiempo, manteniéndose como las más cotizadas y marcando una tendencia a nivel mundial con sus proyectos. También mencionó que "la tecnología va a seguir avanzando rápidamente, sobre todo en el internet de las cosas y los robots, que a lo mejor en 20 años los vamos a tener en todos lados y va a ser muy natural" (gestion.pe, 2016c).

Según David (2013), la fuerza más poderosa de las cinco fuerzas de Porter es la rivalidad entre empresas competidoras y su intensidad se incrementa cuando ingresan nuevos competidores y cuando los consumidores pueden cambiar de marca. Como resultado del incremento de la rivalidad de las empresas competidoras la utilidad de la industria se ve afectada, por ello es importante que las empresas encuentren la oportunidad que brinda su negocio (p. 76,77).

En el mercado existen diversas empresas dedicadas al servicio de tecnología, tanto a nivel nacional como internacional, siendo para Xternal Technological Solutions S.A.C. sus principales competidores: Chain Services Technology Information (CSTI), EBINCORP, AXELERA Consulting, MDP, RAVA Consulting, quienes cuentan similares características como: servicios brindados, alianzas estratégicas, años de experiencia en el sector, personal calificado, buscan ser las empresas líderes del sector y generar valor a sus clientes con los servicios brindados. 


\subsection{Matriz de Atractividad de cada una de las Cinco Fuerzas}

A continuación, se muestra las matrices de atractividad de cada una de las cinco fuerzas de Porter. Se pueden visualizar en las tablas 13, 14, 15, 16 y 17.

Tabla 13

Matriz de Atractividad de los Sustitutos

\begin{tabular}{|c|c|c|c|c|c|}
\hline $\begin{array}{l}\text { Elementos de } \\
\text { Análisis }\end{array}$ & Poder & $\begin{array}{l}\text { Factor de } \\
\text { Relevancia }\end{array}$ & $\begin{array}{l}\text { Criterios que lo } \\
\text { hacen poco } \\
\text { atractivos }\end{array}$ & $\begin{array}{c}\text { Grado de } \\
\text { Atractividad }\end{array}$ & $\begin{array}{c}\text { Criterios que lo } \\
\text { hacen muy } \\
\text { atractivos }\end{array}$ \\
\hline $\begin{array}{l}\text { Disponibilidad de } \\
\text { sustitutos }\end{array}$ & Alto & 0.30 & $\begin{array}{l}\text { Facilidad de acceso } \\
\text { a productos } \\
\text { sustitutos }\end{array}$ & 4 & $\begin{array}{l}\text { No existencia o } \\
\text { dificultad de acceso } \\
\text { a productos } \\
\text { sustitutos. }\end{array}$ \\
\hline $\begin{array}{l}\text { Precio relativo entre } \\
\text { el producto sustituto } \\
\text { y el ofrecido }\end{array}$ & Medio & 0.24 & $\begin{array}{l}\text { Precio del producto } \\
\text { sustituto es menor } \\
\text { que el ofrecido }\end{array}$ & 3 & $\begin{array}{l}\text { Precio del producto } \\
\text { sustituto es mayor } \\
\text { que el ofrecido }\end{array}$ \\
\hline $\begin{array}{l}\text { Rendimiento y } \\
\text { calidad comparada } \\
\text { entre el producto } \\
\text { ofrecido y su } \\
\text { sustituto }\end{array}$ & Medio & 0.24 & $\begin{array}{l}\text { Rendimiento y/o } \\
\text { calidad del producto } \\
\text { sustituto es mayor o } \\
\text { igual al ofrecido }\end{array}$ & 3 & $\begin{array}{l}\text { Rendimiento y/o } \\
\text { calidad del } \\
\text { producto sustituto } \\
\text { es inferior al } \\
\text { ofrecido }\end{array}$ \\
\hline $\begin{array}{l}\text { Costos de cambio } \\
\text { para el cliente }\end{array}$ & Bajo & 0.22 & $\begin{array}{l}\text { Costos de cambio } \\
\text { para el cliente son } \\
\text { reducidos }\end{array}$ & 2 & $\begin{array}{l}\text { Costos de cambio } \\
\text { para el cliente son } \\
\text { altos }\end{array}$ \\
\hline $\begin{array}{l}\text { Resultado } \\
\text { Ponderado }\end{array}$ & & & & 3.08 & \\
\hline
\end{tabular}

Nota. El grado de atractividad tiene los siguientes valores: 1=Muy poco grado de atractividad, 2=Poco grado de atractividad, 3=Alto grado de atractividad, y 4=Muy alto grado de atractividad 
Tabla 14

Matriz de Atractividad de los Proveedores

\begin{tabular}{|c|c|c|c|c|c|}
\hline $\begin{array}{l}\text { Elementos de } \\
\text { Análisis }\end{array}$ & Poder & $\begin{array}{l}\text { Factor de } \\
\text { Relevancia }\end{array}$ & $\begin{array}{l}\text { Criterios que lo } \\
\text { hacen poco } \\
\text { atractivos }\end{array}$ & $\begin{array}{c}\text { Grado de } \\
\text { Atractividad }\end{array}$ & $\begin{array}{l}\text { Criterios que lo } \\
\text { hacen muy } \\
\text { atractivos }\end{array}$ \\
\hline $\begin{array}{l}\text { Concentración de } \\
\text { proveedores }\end{array}$ & Alto & 0.30 & $\begin{array}{l}\text { Provisión de } \\
\text { insumos o recursos } \\
\text { lo hacen pocas } \\
\text { empresas. }\end{array}$ & 4 & $\begin{array}{l}\text { Provisión de } \\
\text { insumos o recursos } \\
\text { lo hacen muchas } \\
\text { empresas. }\end{array}$ \\
\hline $\begin{array}{l}\text { Importancia del } \\
\text { volumen para los } \\
\text { proveedores }\end{array}$ & Alto & 0.20 & $\begin{array}{l}\text { Volumen de compra } \\
\text { que hacen las } \\
\text { compañías del } \\
\text { sector a los } \\
\text { proveedores es alto. }\end{array}$ & 3 & $\begin{array}{l}\text { Volumen de } \\
\text { compra que hacen } \\
\text { las compañías del } \\
\text { sector a los } \\
\text { proveedores es } \\
\text { baio. }\end{array}$ \\
\hline $\begin{array}{l}\text { Diferenciación de } \\
\text { insumos }\end{array}$ & Medio & 0.15 & $\begin{array}{l}\text { Si los insumos o } \\
\text { recursos ofrecidos } \\
\text { por los proveedores } \\
\text { están } \\
\text { estandarizados. }\end{array}$ & 3 & $\begin{array}{l}\text { Si los insumos o } \\
\text { recursos ofrecidos } \\
\text { por los } \\
\text { proveedores están } \\
\text { diferenciados. }\end{array}$ \\
\hline Costos de cambio & Medio & 0.15 & $\begin{array}{l}\text { Los costos por } \\
\text { cambiar de } \\
\text { proveedor son bajos. }\end{array}$ & 4 & $\begin{array}{l}\text { Los costos por } \\
\text { cambiar de } \\
\text { proveedor son } \\
\text { altos. }\end{array}$ \\
\hline $\begin{array}{l}\text { Disponibilidad de } \\
\text { insumos sustitutos }\end{array}$ & Bajo & 0.10 & $\begin{array}{l}\text { Existencia, } \\
\text { disponibilidad y } \\
\text { acceso de insumos } \\
\text { sustitutos en el } \\
\text { mercado. }\end{array}$ & 2 & $\begin{array}{l}\text { El costo de los } \\
\text { insumos sustitutos } \\
\text { puede ser alto }\end{array}$ \\
\hline $\begin{array}{l}\text { Impacto de los } \\
\text { insumos }\end{array}$ & Bajo & 0.10 & $\begin{array}{l}\text { Los insumos } \\
\text { mantienen, } \\
\text { incrementan o } \\
\text { mejoran la calidad } \\
\text { del bien. }\end{array}$ & 2 & $\begin{array}{l}\text { Los insumos no } \\
\text { impactan en la } \\
\text { calidad del bien. }\end{array}$ \\
\hline $\begin{array}{l}\text { Resultado } \\
\text { Ponderado }\end{array}$ & & & & 3.25 & \\
\hline
\end{tabular}

Nota. El grado de atractividad tiene los siguientes valores: 1=Muy poco grado de atractividad, 2=Poco grado de atractividad, 3=Alto grado de atractividad, y 4=Muy alto grado de atractividad 
Tabla 15

Matriz de Atractividad de Rivalidad entre Competidores

\begin{tabular}{|c|c|c|c|c|c|}
\hline $\begin{array}{c}\text { Elementos de } \\
\text { Análisis }\end{array}$ & Poder & $\begin{array}{l}\text { Factor de } \\
\text { Relevancia }\end{array}$ & $\begin{array}{c}\text { Criterios que lo } \\
\text { hacen poco } \\
\text { atractivos }\end{array}$ & $\begin{array}{c}\text { Grado de } \\
\text { Atractividad }\end{array}$ & $\begin{array}{c}\text { Criterios que lo } \\
\text { hacen muy } \\
\text { atractivos }\end{array}$ \\
\hline Concentración & Alto & 0.23 & $\begin{array}{l}\text { Mayor cantidad de } \\
\text { empresas } \\
\text { compiten por los } \\
\text { mismos clientes }\end{array}$ & 2 & $\begin{array}{l}\text { La creación del } \\
\text { valor agregado } \\
\text { para sus clientes. }\end{array}$ \\
\hline $\begin{array}{l}\text { Diversidad de } \\
\text { competidores }\end{array}$ & Alto & 0.18 & $\begin{array}{l}\text { Existen una gran } \\
\text { variedad de } \\
\text { competidores } \\
\text { formales e } \\
\text { informales }\end{array}$ & 2 & $\begin{array}{l}\text { Las empresas } \\
\text { buscan } \\
\text { proveedores } \\
\text { formales. }\end{array}$ \\
\hline $\begin{array}{l}\text { Diferenciación entre } \\
\text { los productos }\end{array}$ & Medio & 0.21 & $\begin{array}{l}\text { Los servicios que } \\
\text { brindan se } \\
\text { encuentran } \\
\text { estandarizados }\end{array}$ & 3 & $\begin{array}{l}\text { La tecnología va } \\
\text { evolucionando y } \\
\text { puede incrementar } \\
\text { la gama de } \\
\text { servicios } \\
\text { brindados. }\end{array}$ \\
\hline $\begin{array}{l}\text { Crecimiento de la } \\
\text { demanda }\end{array}$ & & 0.23 & $\begin{array}{l}\text { Ingreso de nuevos } \\
\text { competidores }\end{array}$ & 3 & $\begin{array}{l}\text { Mayor cantidad de } \\
\text { clientes a quienes } \\
\text { atender. }\end{array}$ \\
\hline $\begin{array}{l}\text { Costos fijos } \\
\text { elevados }\end{array}$ & Medio & 0.15 & $\begin{array}{l}\text { Las ventas tienen } \\
\text { que ser altas para } \\
\text { cubrir los costos } \\
\text { fijos y llegar a su } \\
\text { punto de } \\
\text { equilibrio. }\end{array}$ & 2 & $\begin{array}{l}\text { Las empresas } \\
\text { buscan alcanzar } \\
\text { economías a } \\
\text { escala. }\end{array}$ \\
\hline $\begin{array}{l}\text { Resultado } \\
\text { Ponderado }\end{array}$ & & & & 2.42 & \\
\hline
\end{tabular}

Nota. El grado de atractividad tiene los siguientes valores: 1=Muy poco grado de atractividad, 2=Poco grado de atractividad, 3=Alto grado de atractividad, y 4=Muy alto grado de atractividad 
Tabla 16

Matriz de Atractividad de Poder de Negociación de Clientes

\begin{tabular}{|c|c|c|c|c|c|}
\hline $\begin{array}{c}\text { Elementos de } \\
\text { Análisis }\end{array}$ & Poder & $\begin{array}{l}\text { Factor de } \\
\text { Relevancia }\end{array}$ & $\begin{array}{l}\text { Criterios que lo hacen } \\
\text { poco atractivos }\end{array}$ & $\begin{array}{c}\text { Grado de } \\
\text { Atractividad }\end{array}$ & $\begin{array}{c}\text { Criterios que lo } \\
\text { hacen muy } \\
\text { atractivos }\end{array}$ \\
\hline $\begin{array}{l}\text { Concentración de } \\
\text { clientes }\end{array}$ & Alto & 0.25 & $\begin{array}{l}\text { Incremento de nuevos } \\
\text { competidores. }\end{array}$ & 4 & $\begin{array}{l}\text { Se han } \\
\text { incrementado las } \\
\text { empresas que } \\
\text { solicitan servicios } \\
\text { en tecnología. }\end{array}$ \\
\hline $\begin{array}{l}\text { Volumen de } \\
\text { compra }\end{array}$ & Alto & 0.25 & $\begin{array}{l}\text { Clientes que realizan } \\
\text { contratos grandes, } \\
\text { solicitarán mejores } \\
\text { beneficios. }\end{array}$ & 3 & $\begin{array}{l}\text { Solicitar a la } \\
\text { empresa ser } \\
\text { proveedor } \\
\text { exclusivo }\end{array}$ \\
\hline Diferenciación & Medio & 0.18 & $\begin{array}{l}\text { Las empresas solicitan } \\
\text { servicios } \\
\text { estandarizados. }\end{array}$ & 3 & $\begin{array}{l}\text { Algunas empresas } \\
\text { realizan novedosas } \\
\text { solicitudes de } \\
\text { requerimiento. }\end{array}$ \\
\hline $\begin{array}{l}\text { Identificación de la } \\
\text { marca }\end{array}$ & Medio & 0.2 & $\begin{array}{l}\text { Las empresas se } \\
\text { preocupan por los } \\
\text { costos que generan los } \\
\text { servicios de } \\
\text { tecnología. }\end{array}$ & 4 & $\begin{array}{l}\text { Las empresas se } \\
\text { identifican con la } \\
\text { empresa como } \\
\text { consecuencia de la } \\
\text { experiencia } \\
\text { brindada. }\end{array}$ \\
\hline $\begin{array}{l}\text { Productos } \\
\text { sustitutos }\end{array}$ & Bajo & 0.12 & $\begin{array}{l}\text { Ingreso de productos } \\
\text { sustitutos al mercado. }\end{array}$ & 2 & $\begin{array}{l}\text { El costo de los } \\
\text { productos sustitutos } \\
\text { puede ser alto }\end{array}$ \\
\hline $\begin{array}{l}\text { Resultado } \\
\text { Ponderado }\end{array}$ & & & & 3.13 & \\
\hline
\end{tabular}

Nota. El grado de atractividad tiene los siguientes valores: 1=Muy poco grado de atractividad, 2=Poco grado de atractividad, 3=Alto grado de atractividad, y 4=Muy alto grado de atractividad 
Tabla 17

Matriz de Atractividad de Nuevos Competidores

\begin{tabular}{|c|c|c|c|c|c|}
\hline $\begin{array}{c}\text { Elementos de } \\
\text { Análisis }\end{array}$ & Poder & $\begin{array}{l}\text { Factor de } \\
\text { Relevancia }\end{array}$ & $\begin{array}{l}\text { Criterios que lo hacen } \\
\text { poco atractivos }\end{array}$ & $\begin{array}{c}\text { Grado de } \\
\text { Atractividad }\end{array}$ & $\begin{array}{c}\text { Criterios que lo } \\
\text { hacen muy } \\
\text { atractivos }\end{array}$ \\
\hline $\begin{array}{l}\text { Economías de } \\
\text { escala }\end{array}$ & Alto & 0.25 & $\begin{array}{l}\text { Mucha inversión en } \\
\text { infraestructura }\end{array}$ & 4 & $\begin{array}{l}\text { Poca inversión en } \\
\text { infraestructura }\end{array}$ \\
\hline $\begin{array}{l}\text { Diferenciación del } \\
\text { producto }\end{array}$ & Alto & 0.25 & $\begin{array}{l}\text { Producto muy } \\
\text { diferenciado }\end{array}$ & 4 & $\begin{array}{l}\text { Producto poco } \\
\text { diferenciado }\end{array}$ \\
\hline $\begin{array}{l}\text { Requisitos del } \\
\text { capital }\end{array}$ & Bajo & 0.10 & $\begin{array}{l}\text { Mucha inversión de } \\
\text { capital inicial }\end{array}$ & 4 & $\begin{array}{l}\text { Poca inversión de } \\
\text { capital inicial }\end{array}$ \\
\hline $\begin{array}{l}\text { Acceso a canales } \\
\text { de distribución }\end{array}$ & Medio & 0.15 & $\begin{array}{l}\text { Difícil acceso a los } \\
\text { canales de } \\
\text { distribución }\end{array}$ & 3 & $\begin{array}{l}\text { Fácil acceso a los } \\
\text { canales de } \\
\text { distribución }\end{array}$ \\
\hline $\begin{array}{l}\text { Desventajas en } \\
\text { costos }\end{array}$ & Medio & 0.15 & $\begin{array}{l}\text { Costos altos } \\
\text { adicionales a la } \\
\text { economía de escala }\end{array}$ & 2 & $\begin{array}{l}\text { Costos bajos } \\
\text { adicionales a la } \\
\text { economía de escala }\end{array}$ \\
\hline $\begin{array}{l}\text { Política } \\
\text { gubernamental }\end{array}$ & Bajo & 0.10 & $\begin{array}{l}\text { Mayores trabas en } \\
\text { normatividad vigente }\end{array}$ & 4 & $\begin{array}{l}\text { Menores trabas en } \\
\text { normatividad } \\
\text { vigente }\end{array}$ \\
\hline $\begin{array}{l}\text { Resultado } \\
\text { Ponderado }\end{array}$ & & & & 3.55 & \\
\hline
\end{tabular}

Nota. El grado de atractividad tiene los siguientes valores: 1=Muy poco grado de atractividad, 2=Poco grado de atractividad, 3=Alto grado de atractividad, y 4=Muy alto grado de atractividad

\subsection{Análisis del Grado de Atractividad de la Industria}

De acuerdo con los resultados obtenidos en las matrices descritas en el punto 5.3, podemos consolidar estos en una sola matriz que muestre los resultados por fuerzas. Estos resultados se muestran en la tabla 18 . 
Tabla 18

Matriz de Grado de Atractividad de la Industria

\begin{tabular}{|c|c|c|c|c|}
\hline Fuerzas & $\begin{array}{l}\text { Muy poco } \\
\text { grado de } \\
\text { atractividad }\end{array}$ & $\begin{array}{c}\text { Poco grado de } \\
\text { atractividad }\end{array}$ & $\begin{array}{l}\text { Alto grado de } \\
\text { atractividad }\end{array}$ & $\begin{array}{l}\text { Muy alto } \\
\text { grado de } \\
\text { atractividad }\end{array}$ \\
\hline Sustitutos & & & $\mathrm{X}$ & \\
\hline Clientes & & & $\mathrm{X}$ & \\
\hline Proveedores & & & $X$ & \\
\hline $\begin{array}{l}\text { Rivalidad entre } \\
\text { competidores }\end{array}$ & & $\mathrm{X}$ & & \\
\hline $\begin{array}{l}\text { Potenciales } \\
\text { competidores }\end{array}$ & & & $X$ & \\
\hline
\end{tabular}

Las X representan el resultado ponderado obtenido en el análisis de las matrices individuales de cada fuerza. De acuerdo con esto, se puede observar que la industria tiene un alto grado de atractividad en el segmento en el que se desempeña la empresa Xternal Technological Solutions S.A.C.

Este alto grado de atractividad es justificado por la poca participación que se tiene a nivel del país en el mercado de la industria del software, lo que representa una gran oportunidad para estos emprendimientos a fin de poder consolidarse en un mercado relativamente amplio.

La formalización de estos emprendimientos podría beneficiarlos con la confianza del sector empresarial privado, que normalmente prefiere empresas de los segmentos a y b (de acuerdo con lo descrito en el punto 5.2.2 cuando se analizó la fuerza de los nuevos o potenciales competidores) pero cuyos costos son muy elevados. Es por esta razón que hay muy poca participación en el mercado a comparación de otros países de la región. 


\subsection{Matriz de Perfil Competitivo MPC}

Según David (2013), la matriz de perfil competitivo permite conocer a los principales competidores de la empresa, analizando fortalezas y debilidades de manera particular en relación con la posición estratégica de la empresa que está siendo evaluada.

Respecto a los factores críticos para el éxito en una MPC, estos deben analizarse tanto del punto de vista interno como externo, por lo que las calificaciones que se utilicen refieren a las fortalezas y debilidades que tiene cada empresa. Los valores tomados en cuenta para la calificación son 4 = fortaleza principal, $3=$ fortaleza menor, $2=$ debilidad menor, 1 = debilidad principal. Como resultado de este análisis comparativo se obtiene información muy valiosa desde el punto de vista estratégico interno.

De acuerdo con los resultados obtenidos en las entrevistas a profundidad con expertos del sector (ver Anexo 2), se han incluido los siguientes factores clave de éxito en orden de relevancia:

Calidad del servicio (20\%), es un factor muy importante que los clientes toman en consideración para decidir su preferencia. Valoran mucho la atención post venta en donde se convierten en socios estratégicos en la consecución de los objetivos empresariales.

Especialización en el sector (20\%), tiene alta importancia ya que las empresas con el objetivo de ser competitivas buscan tener herramientas actualizadas y eficaces para el desarrollo de sus actividades. El nivel de especialización que tengan los puede colocar como primera opción para sus posibles clientes dependiendo del proyecto que quieran desarrollar.

Infraestructura tecnológica (15\%), es un factor relevante que da solidez a la propuesta para sus clientes. Una empresa que brinda servicios de tecnología de información que no cuente con equipos o software de última generación, no sería muy confiable al momento de participar en un proceso de selección. 
Recursos humanos (15\%), su relevancia radica en contar con el personal adecuado que pueda atender las consultas durante la implementación de los servicios tecnológicos y a su vez durante los servicios post venta. Es un factor de diferenciación que pueden utilizar las empresas al momento de ofrecer su cartera de servicios.

Participación del mercado (10\%), tiene relevancia porque indica la posición de la empresa dentro del sector de tecnología con relación a las ventas que realiza. Esto es valorado por algunas empresas al momento de realizar una elección buscando el respaldo que brinda la cartera de clientes con la que cuenta este tipo de empresas, ya sea por la cantidad o por el nivel de las empresas que tiene como clientes. La tabla 19 muestra un benchmarking realizado por la empresa Xternal Technological Solutions S.A.C. en la que se aprecia la diferencia respecto a participación respecto a las ventas anuales de sus competidores directos.

Tabla 19

Ventas anuales entre competidores directos

\begin{tabular}{cc}
\hline Empresa & Ventas anuales \\
\hline Xternal Technological Solutions S.A.C. & S/. 1200000.00 \\
Axelera Consulting & S/. 525000.00 \\
Ebimcorp & S/. 363000.00 \\
\hline
\end{tabular}

Alianzas estratégicas (10\%), es un factor para considerar como ventaja para poder tener una mayor capacidad de brindar un mejor servicio a sus clientes. De igual manera es un respaldo dependiendo de la magnitud de proyecto que se quiera llevar a cabo.

Solidez financiera (10\%), tiene un impacto como respaldo para soportar los recursos necesarios para mantener su cartera de servicios y mantener el funcionamiento de las demás áreas de la empresa. 
En la matriz de perfil competitivo se ha realizado una comparación con dos de los principales competidores de la empresa Xternal Technological Solutions S.A.C. Se han elegido estos competidores porque son referentes en el segmento en el que la empresa se desenvuelve. Se han considerado unos factores críticos de éxito de acuerdo con lo señalado por el juicio de expertos (anexo 2). El resultado de esta comparación se puede apreciar en la tabla 20. 
Tabla 20

Matriz de Perfil Competitivo - MPC

\section{Xternal ebimcorp ATEELERA}

\begin{tabular}{|c|c|c|c|c|c|c|c|c|c|c|}
\hline \multirow{2}{*}{$\begin{array}{l}\text { Factores críticos } \\
\text { para el éxito } \\
\text { Participación en el } \\
\text { mercado }\end{array}$} & \multirow{2}{*}{\begin{tabular}{|c} 
Ponderado Clasi \\
0.1
\end{tabular}} & \multirow{2}{*}{$\begin{array}{r}\text { firarión } \\
2\end{array}$} & \multirow{2}{*}{$\begin{array}{c}\text { Puntuación pn } \\
\text { Ponderada } \\
0.20\end{array}$} & \multirow{2}{*}{$\begin{array}{c}\text { nderado Clasificación } \\
0.1\end{array}$} & $\begin{array}{c}\text { Puntuación Po } \\
\text { Ponderada }\end{array}$ & \multirow{2}{*}{$\begin{array}{c}\text { nderado Clasificación } \\
0.1\end{array}$} & \multirow{2}{*}{$\begin{array}{rr}\text { n Puntuación } & \begin{array}{c}\text { Po } \\
\text { Ponderada }\end{array} \\
1 & 0.1\end{array}$} & \multirow{2}{*}{$\begin{array}{c}\text { nderado Clasificación } \\
0.1\end{array}$} & \multicolumn{2}{|c|}{$\begin{array}{l}\text { Puntuación } \\
\text { Ponderada }\end{array}$} \\
\hline & & & & & 0.10 & & & & 4 & 0.4 \\
\hline $\begin{array}{l}\text { Infraestructura } \\
\text { tecnológica }\end{array}$ & 0.15 & 3 & 0.45 & 0.15 & 0.45 & 0.15 & 0.45 & 0.15 & 4 & 0.6 \\
\hline Calidad del servicio & 0.2 & 4 & 0.80 & 0.2 & 0.60 & 0.2 & 0.60 & 0.2 & 4 & 0.8 \\
\hline $\begin{array}{l}\text { Especialización en el } \\
\text { sector }\end{array}$ & 0.2 & 3 & 0.6 & 0.2 & 0.60 & 0.2 & 0.60 & 0.2 & 4 & 0.8 \\
\hline $\begin{array}{l}\text { Alianzas } \\
\text { estratégicas }\end{array}$ & 0.1 & 2 & 0.2 & 0.1 & 0.20 & 0.1 & 0.30 & 0.1 & 4 & 0.4 \\
\hline Recursos humanos & 0.15 & 3 & 0.45 & 0.15 & 0.45 & 0.15 & 0.45 & 0.15 & 4 & 0.6 \\
\hline Solidez financiera & 0.1 & 2 & 0.2 & 0.1 & 0.20 & 0.1 & 0.20 & 0.1 & 4 & 0.4 \\
\hline TOTAL & 1 & & 2.9 & 1 & 2.6 & 1 & 2.7 & 1 & & 4 \\
\hline
\end{tabular}


Los resultados obtenidos en la matriz anterior permiten demostrar que la empresa Xternal Technological Solutions S.A.C. es la más fuerte con un puntaje de 2.9 a comparación de sus competidores directos, sin embargo, está por debajo de la empresa líder IBM. Dentro de sus competidores directos, se puede apreciar que Axelera es la empresa más equilibrada con mayores fortalezas menores, teniendo una debilidad mayor que es la participación en el mercado y teniendo debilidades menores como la infraestructura tecnológica y la solidez financiera. Este último factor se muestra como una debilidad menor en todos los emprendimientos analizados en la matriz anterior.

Un factor importante para Xternal Technological Solutions S.A.C. es el referente a la calidad de su servicio. Es una fortaleza importante reconocida incluso por los socios de la empresa como una ventaja competitiva que les ha permitido mantener relaciones a pesar de los momentos de crisis por los que atravesó la empresa en el 2016. Aún en esas circunstancias la empresa supo mantener los compromisos pactados demostrando esta fortaleza.

En lo referente a las alianzas estratégicas, estas representan una debilidad de Xternal Technological Solutions S.A.C. respecto a sus competidores directos. Esto se puede explicar en el poco tiempo para gerenciar que tienen los socios, abocados principalmente a labores operativas que no les permite desligarse totalmente para enfocarse en el crecimiento de la empresa. A pesar de no ser una fortaleza, la participación del mercado es mejor respecto a sus competidores directos. El crecimiento se ha ido dando de acuerdo con las necesidades o requerimientos de sus clientes y no necesariamente a un plan elaborado con detenimiento.

Asimismo, Axelera Consulting considera como una ventaja respecto a su competencia las alianzas estratégicas que mantiene con algunas empresas, lo que le permite una diversificación de su cartera de servicios y por ende una mayor probabilidad de aprovechamiento de las oportunidades generadas para el sector. 
Xternal Technological Solutions S.A.C. debe aprovechar su fortaleza mayor, que es la calidad del servicio, y sobre esto mejorar los puntos en donde se aprecian debilidades como la participación de mercado y alianzas estratégicas. Dentro de las acciones a considerar se puede mencionar el homogeneizar sus procesos de desarrollo con lo recomendado por SAP a fin de poder ser considerado por ellos como un partner de negocios (esto en lo que se refiere a las alianzas estratégicas). Esto les daría una imagen sólida y confiable frente a posibles clientes que cuentan con este ERP, lo que se traduciría en un incremento en los proyectos, aumento en la participación de mercado y mayores ingresos económicos que se reflejarían en la solidez financiera. Otra acción para tomar en cuenta es el reenfoque de mercado orientándolo al mercado de las pymes, lo que también se reflejaría en un incremento en los factores antes mencionados. 


\section{Capítulo VI: Análisis Interno}

\subsection{Descripción de las Actividades de la Cadena de Valor de la Empresa}

De acuerdo con lo planteado por Aybar (como se cita en Porter, 2008), "la cadena de valor de una empresa y la forma que desempeña sus actividades individuales son un reflejo de su historia, de su estrategia, de su enfoque para implementar la estrategia y las economías fundamentales para las actividades mismas" (p. 52).

La Figura 13 muestra la cadena de valor propuesta genérica de las empresas propuesta por Michael Porter:

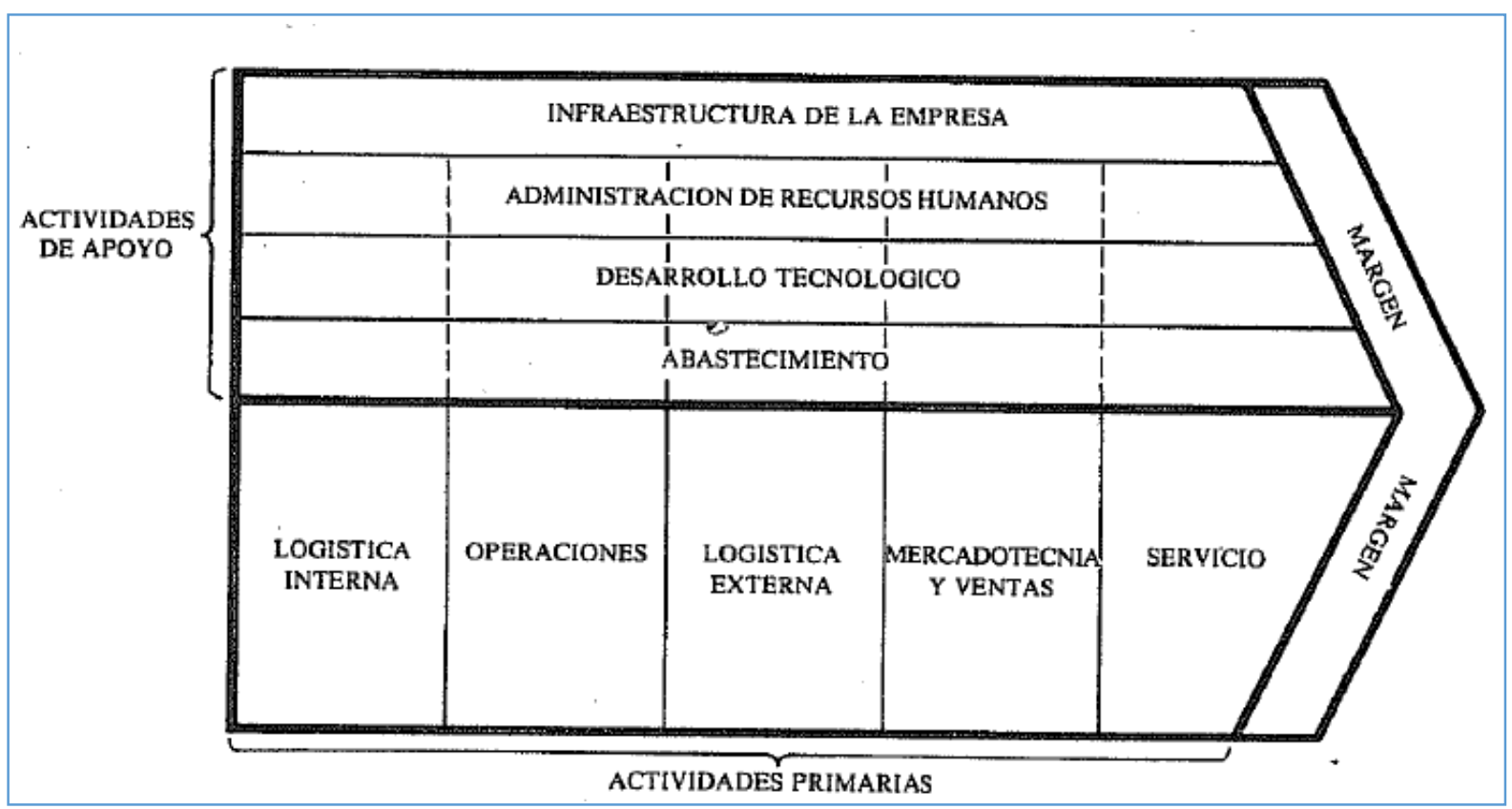

Figura 13. Cadena de valor genérica. Tomado de "Ventaja Competitiva" (p. 54) por Michael E. Porter, 1991, Argentina: Editorial Rei Argentina. Copyright 1987 compañía editorial continental S.A.

En base a este marco teórico, se han descrito las actividades de la cadena de valor de la empresa Xternal Technological Solutions S.A.C.

\section{Logística interna}

Esta actividad comprende la adquisición de software especializado para los servicios que brinda la empresa, lo cual puede derivarse desde la adquisición de software con licencia, renovación de licencias, actualizaciones, y hardware de soporte del sistema. 
Considerando la importancia de estas actividades para efectuar un servicio de calidad, este debe estar alineado con las necesidades del cliente, de tal manera que la empresa debe estar en constante contacto con sus clientes para ver los nuevos servicios que requieren y obtener el software que le permitan ejecutarlos, de manera de solucionar los requerimientos del mercado.

Debido a que se trata de una empresa que brinda servicios tecnológicos, fue necesaria la adquisición de dos servidores que están proyectados para operar aplicaciones de gran escala como varias cuentas de correo electrónico, compartir datos de forma colaborativa ya que sirve como un repositorio de documentos, imágenes, aplicaciones, programas entre otros archivos. Además, sirve como intranet de la empresa para que los colaboradores puedan compartir información necesaria de manera rápida.

\section{Operaciones}

La empresa Xternal Technological Solutions S.A.C. ofrece servicios de consultoría y desarrollo de soluciones en tecnologías de información a sus clientes en cuatro líneas de negocio que son: (a) programación ABAP, (b) programación SAP portal, (c) aplicativos móviles, y (d) business analytics.

Cada línea de negocio de la empresa sigue estándares de calidad y gestión de proyectos de acuerdo con la naturaleza de la tecnología utilizada. Para la línea de negocio de programación en ABAP, se han definido estándares de programación acordes con lo propuesto por el proveedor del producto (en este caso el ERP SAP) para los desarrollos tecnológicos sobre esta plataforma. Estos estándares garantizan la calidad del servicio, el mismo que puede ser proporcionado a través de una fábrica de software externa para sus clientes o proporcionando recursos de programación que participen directamente en un equipo de desarrollo local en su cliente. En la modalidad de fábrica de software, la 
coordinación se realiza de manera directa con los consultores internos funcionales de sus clientes. La cantidad de recursos de programación es definida en el contrato de locación de servicios celebrado entre ambas partes.

Respecto a la línea de negocio de programación en portal SAP, se realizan desarrollos de soluciones tecnológicas sobre la plataforma SAP Netweaver. Al igual que en la programación ABAP, el servicio es proporcionado a través de la fábrica de software externa o con asignación directa de recursos a proyectos internos de sus clientes.

El desarrollo de aplicaciones para dispositivos móviles es un servicio que se ofrece en coordinación con funcionales internos de sus clientes y como parte de proyectos puntuales en esta tecnología. No se ofrece el servicio como parte de una fábrica de software externa. Los clientes reciben la solución implementada en los dispositivos móviles que determinen. Todo el desarrollo de la solución es realizado en las oficinas de Xternal Technological Solutions S.A.C.

Finalmente, business analytics es un servicio de consultoría integral que abarca el diseño, programación e implementación de la solución en el cliente final. Este servicio es brindado por un equipo especializado en este tipo de soluciones, teniendo como actividades principales el análisis, diseño y elaboración de los llamados cubos de procesamiento de información. La información es visualizada en software especializado como el Qlikview o el SAP business objects, por ejemplo.

El valor agregado proporcionado por la empresa Xternal Technological Solutions S.A.C. es el seguimiento post implementación de cada una de las soluciones realizadas en cada línea de negocio en sus clientes. Este seguimiento incluye la asignación de recursos de programación sin costo alguno (ante una eventualidad o ajuste) más allá de lo estipulado originalmente en el contrato de locación de servicios. Este es uno de los rasgos que más la distinguen de sus competidores directos. 


\section{Logística Externa}

La logística externa refiere al movimiento del producto ofrecido por una empresa a través de los canales de distribución hacia sus clientes. En las empresas que prestan servicios la logística externa es escasa, y en el caso de la empresa Xternal Technological Solutions S.A.C. que brinda servicios de Tecnología de la Información, su logística externa también es mínima, considerando canales de distribución de sus servicios como entrega de productos en el caso de proyectos realizados a través de CD-ROM, así como también, cuando sea necesario el traslado del personal y sus equipos hacia los locales de los clientes, para la realización de proyectos específicos.

Del mismo modo para brindar de forma efectiva y rápida sus servicios, emplean el Virtual Private Network (VPN) donde los colaboradores de forma remota tienen acceso a las informaciones del servidor desde distintos lugares con acceso a internet. También estos servidores, les sirve como respaldo en caso de pérdida de información a causa de un desperfecto de una computadora. Este canal se establece en coordinación con sus clientes a fin de poder trabajar bajo las condiciones de su red interna.

\section{Tecnología}

Dentro de la cadena de valor de la empresa Xternal Technological Solutions S.A.C., las actividades de tecnología están orientadas al desarrollo de metodologías, procedimientos o estándares que permitan un manejo más eficiente de los proyectos que la empresa maneja con sus clientes. De acuerdo con ello, cada línea de negocio cuenta con metodologías propias de la tecnología que se usa para brindar el servicio.

Estas metodologías son complementadas con el uso de software especializado en la gestión de proyectos de tecnología de información. Esto le da un soporte adecuado a las actividades que realiza la empresa respecto al servicio que ofrece a sus clientes. En el caso 
particular de la gestión de los avances de los proyectos con sus clientes, el software usado es el MS Project de la empresa Microsoft. Para el control de manera global o con una visión macro, el software que se utiliza es el Feng Office conocido anteriormente como Open Goo.

De manera complementaria a lo anteriormente mencionado, dentro del servicio que brinda a sus clientes, la empresa ha considerado la figura de un arquitecto de software como parte fundamental para la aplicación de los estándares definidos para cada uno de sus proyectos. El alcance de sus funciones abarca desde la determinación de la factibilidad técnica de las especificaciones funcionales de los consultores internos de sus clientes, hasta la estimación de tiempos y gestión del desarrollo en sus distintas etapas. Es una persona con comprobada experiencia en la gestión de proyectos.

\section{Abastecimiento}

Xternal Technological Solutions S.A.C. con el propósito de la continuidad de su negocio para conseguir la lealtad de sus clientes, cuenta con una metodología de abastecimiento de suministro para evitar altos inventarios y contar con los insumos necesarios para el desarrollo de las actividades de la empresa. Con estas actividades se lograr tener un stock moderado y ahorro en costos.

Las actividades que se realizan para el abastecimiento son: identificar las necesidades de la empresa, evaluar al proveedor del insumo, comprar los insumos, almacenamiento de los insumos, distribución de los insumos, control de stock de los insumos.

Xternal Technological Solutions S.A.C. requiere de insumos, artículos de oficina, máquinas equipos y software de oficina. 


\section{Infraestructura}

La infraestructura de la empresa comprende la planificación del Gerente General en diversos asuntos como realización de contratos, tramites de licencias, pago a los proveedores, pagos financieros, entre otras actividades.

A diferencia de otras actividades de apoyo, esta coordina con la cadena completa brindándoles soporte.

Actualmente, la Gerencia General conjuntamente con la Gerencia Comercial, de Operaciones y de Administración definen los objetivos de la empresa, ellos tienen reuniones periódicas para revisar las actividades, verificar los avances y el cumplimiento de los objetivos.

Con estas actividades se busca lograr un mejor desempeño y soporte de la empresa por sus directivos.

\section{Mercadotecnia}

La mercadotecnia se refiere al conjunto de principios y prácticas que buscan el aumento del comercio, especialmente de la demanda. También consiste en el proceso de exponer clientes específicos ante un producto mediante técnicas y canales apropiados, calibrando sus reacciones para finalmente facilitar el camino al éxito del negocio.

Xternal Technological Solutions S.A.C. actualmente no invierte mayores recursos en este aspecto y no tiene un área propiamente dicha que se encargue de la mercadotecnia, lo que representa una desventaja bastante grande frente a sus competidores, dado que no aprovecha los beneficios que esta actividad puede ofrecer, y es sabido que una organización debe utilizar la mayor cantidad de recursos que tiene a su disposición para conseguir sus objetivos organizacionales. Como consecuencia de ello, no cuenta con una amplia cartera de 
clientes (dependiendo de uno principalmente por su magnitud a nivel de sus ventas), lo cual lo coloca en una posición vulnerable y con poca capacidad de negociación.

En el caso de Xternal Technological Solutions S.A.C. el principal medio para promocionar sus servicios es a través de las referencias que pueden dar sus clientes actuales. Además, cuenta con una página web, que cuenta con información bastante básica y que no se actualiza con la frecuencia ideal. También se puede señalar que no cuenta con presencia en redes sociales, aspecto tan necesario en las estrategias de mercado actuales.

\section{Recursos Humanos}

La gestión de recursos humanos contribuye a que las personas que forman parte de una empresa apoyen en el logro de los objetivos. Resulta importante la forma en que las empresas encuentran a los empleados más adecuados para cada puesto, dado que es necesario que tengan la formación suficiente para desempeñar las tareas encomendadas y desarrollen su trabajo de manera eficiente.

La importancia de la gestión de los recursos humanos radica en que actualmente la empresa debe dar respuestas a los cambios experimentados en la sociedad en general y del mundo laboral.

El reto actual es lograr que las personas se sientan y actúen como socias de la organización, participen activamente en un proceso de desarrollo continuo a nivel personal y organizacional y sean los protagonistas del cambio y las mejoras.

Cabe señalar que actualmente, Xternal Technological Solutions S.A.C. no cuenta con un Departamento de Recursos Humanos, lo cual crea deficiencias en este aspecto, pues quien se hace cargo de las actividades relacionadas a la gestión de recursos humanos es el área administrativa. De continuar el manejo empírico del personal, se seguirán presentando problemas por la falta de una normatividad clara para desarrollar las actividades dentro de la 
organización. Aun así, la empresa ha logrado tener un clima laboral agradable entre sus colaboradores basado en su cultura organizacional. Esto se concluye de acuerdo con el focus group realizado al personal de la empresa (anexo 5).

\subsection{Indicadores de cada una de las Actividades de la Cadena de Valor}

Algunas actividades de la cadena de valor de la empresa Xternal Technological

Solutions S.A.C. no se han venido realizando de la mejor manera. Sin embargo, los directivos de dicha empresa cuentan de igual forma con indicadores que les permite un control en cada actividad y que les dé información para poder realizar una mejor toma de decisiones. Dentro de cada actividad mencionada en el punto 6.1, se han identificado los siguientes indicadores los cuales se visualizan en la tabla 21 . 
Tabla 21

Indicadores de las actividades de la cadena de valor

\begin{tabular}{|c|c|c|}
\hline Actividad & Indicador & Fórmula \\
\hline \multirow{3}{*}{ Logística interna } & Licenciamiento de software & $\begin{array}{l}\text { Software con licencia vigente / } \\
\text { Software adquirido }\end{array}$ \\
\hline & Actualización de software & $\begin{array}{l}\text { Software actualizado / Software } \\
\text { adquirido }\end{array}$ \\
\hline & Capacidad de hardware & $\begin{array}{l}\text { Dispositivos adecuados para } \\
\text { soportar sistema / Dispositivos } \\
\text { adquiridos }\end{array}$ \\
\hline \multirow{2}{*}{ Operaciones } & $\begin{array}{l}\text { Porcentaje de cumplimiento } \\
\text { de requerimientos a tiempo }\end{array}$ & $\begin{array}{l}\text { \# requerimientos atendidos a } \\
\text { tiempo / \# total de requerimientos }\end{array}$ \\
\hline & Calidad de servicio & $\begin{array}{l}\text { \# requerimientos con incidencias / } \\
\text { \# requerimientos totales }\end{array}$ \\
\hline \multirow{2}{*}{ Logística externa } & Horas Hombre Consumidas & $\begin{array}{l}\text { \# horas hombre ejecutadas / \# } \\
\text { horas hombre trabajadas }\end{array}$ \\
\hline & Tiempo de servicio eficiente & $\begin{array}{l}\text { \# horas de fallas VPN / \# horas } \\
\text { atendidas }\end{array}$ \\
\hline \multirow{2}{*}{ Mercadotecnia } & Índice de compra media & $\begin{array}{l}\text { Compra media del servicio / } \\
\text { compra media del sector }\end{array}$ \\
\hline & Penetración & $\begin{array}{l}\text { \# compradores del servicio / \# } \\
\text { mercado meta }\end{array}$ \\
\hline Tecnología & $\begin{array}{l}\text { Porcentaje máximo de atraso } \\
\text { en matriz de gestión de } \\
\text { proyectos }\end{array}$ & $\begin{array}{l}\text { \# requerimientos atrasados / \# } \\
\text { requerimientos ingresados }\end{array}$ \\
\hline \multirow{2}{*}{ Abastecimiento } & $\begin{array}{l}\text { Control de requerimientos de } \\
\text { stock }\end{array}$ & $\begin{array}{l}\text { Requerimientos de insumos } \\
\text { atendidos/ total de requerimientos }\end{array}$ \\
\hline & Gestión del stock & $\begin{array}{l}\text { Demanda anual insumo / Stock } \\
\text { medio insumo }\end{array}$ \\
\hline \multirow{2}{*}{$\begin{array}{l}\text { Recursos } \\
\text { Humanos }\end{array}$} & Capacitación & $\begin{array}{l}\text { Total de trabajadores capacitados } \\
\text { / Total de trabajadores }\end{array}$ \\
\hline & Rotación de personal & $\begin{array}{l}\text { Total de trabajadores retirados / \# } \\
\text { promedio de trabajadores }\end{array}$ \\
\hline \multirow[b]{2}{*}{ Infraestructura } & Retorno sobre la inversión & Utilidad neta / Inversión \\
\hline & Capitalización a largo plazo & $\begin{array}{l}\text { Pasivo a largo plazo / } \\
\text { capitalización total }\end{array}$ \\
\hline
\end{tabular}




\subsection{Benchmarking y Comparación con los Líderes de la Industria de cada una de las Actividades de la Cadena de Valor}

Se ha realizado una comparación con empresas líderes en el sector de consultoría y desarrollo de soluciones de tecnología de información. Las empresas tomadas en cuenta como líderes del sector en el país fueron IBM del Perú y GMD (Graña y Montero Digital). Lo que se puede apreciar luego de realizar la comparación es que las empresas líderes del sector tienen una infraestructura implantada difícil de igualar principalmente por economías de escala. En actividades como mercadotecnia, manejo del recurso humano e infraestructura, se aprecia una diferencia muy marcada principalmente por ser actividades que la empresa Xternal Technological Solutions S.A.C. no viene realizando correctamente.

Las empresas líderes tienen una maquinaria de marketing agresiva respecto a sus productos o servicios, aprovechando muy bien el nombre de la marca debido al tiempo que tienen en el mercado. Asimismo, tienen metodologías de gestión de proyectos y software especializado que les permite manejar una gran cantidad de estos en simultáneo. Los recursos con los que cuentan son abundantes. A pesar de ello, la empresa Xternal Technological Solutions S.A.C. cuenta también con una buena metodología que le permite manejar adecuadamente los proyectos que tiene en proporción a la cantidad de recursos con los que dispone. La misma magnitud de estas empresas líderes les permite tener canales de distribución y logísticas de entrada y salida muy bien definidas y consolidadas, a diferencia de Xternal Technological Solutions S.A.C. que es de menor envergadura y no necesita tener tanto recurso.

También se ha realizado una comparación con las empresas líderes de similar envergadura y que son competencia directa con Xternal Technological Solutions S.A.C. Esto nos ha permitido tener mejor claridad respecto al funcionamiento de la empresa con relación a organizaciones de similares características tanto en capacidad instalada como en nivel de 
ventas. Tomando en consideración que las empresas líderes tienen de por si una calificación elevada de 4 (de acuerdo con lo definido con los expertos del sector) y que equivale a un nivel MB = Muy Bueno, luego del análisis realizado en base a las comparaciones del funcionamiento interno de la empresa contra los datos proporcionados por sus socios y expertos del sector (anexos 1 y 2), se ha obtenido como resultado lo que se aprecia en la tabla 22.

Tabla 22

Benchmarking con los líderes de la industria de las actividades de la cadena de valor

\begin{tabular}{lcccccc}
\hline \multicolumn{1}{c}{ Actividad } & Xternal & CSTI & EbinCorp & Axelera & IBM & GMD \\
\hline Logística interna & MEB & B & B & MEB & MB & MB \\
Operaciones & MB & B & MEB & B & MB & MB \\
Logística externa & MB & B & MEB & NO & NO & NO \\
Tecnología & MEB & MB & B & B & MB & MB \\
Abastecimiento & M & MEB & MEB & MEB & MB & MB \\
Infraestructura & MEB & B & MEB & MEB & NO & NO \\
Mercadotecnia & M & MB & MB & MEB & MB & MB \\
Recursos humanos & $\mathrm{M}$ & MB & MEB & NO & NO & NO \\
\hline
\end{tabular}

Nota. $\mathrm{MB}=$ Muy Bueno, $\mathrm{B}=\mathrm{Bueno}, \mathrm{MEB}=$ Medianamente Bueno, $\mathrm{M}=$ Malo, $\mathrm{NO}=$ No precisa

Como resultado de la comparación respecto a las empresas líderes del sector, podríamos determinar algunas fortalezas y debilidades por actividad:

\section{Logística interna}

Los competidores directos como CSTI y EbinCorp cuentan con alianzas estratégicas (al igual que Xternal Technological Solutions S.A.C.) para el aprovisionamiento de los equipos necesarios para realizar sus servicios. Esto les garantiza la actualización de sus equipos y software (garantía) de manera constante sin necesidad de tener personal dedicado exclusivamente a esta tarea. 
Xternal Technological Solutions S.A.C. cuenta, a diferencia de sus competidores, con acuerdos con diferentes proveedores de servicios de internet. Esto le asegura una línea de comunicación constante y disminuye los riesgos de paradas en su servicio.

Dentro de las fortalezas identificadas para la creación de valor en esta actividad se mencionan las siguientes:

- F1: Contrato ventajoso con proveedor de servicios de internet para disminuir costos.

\section{Operaciones}

Los principales competidores cuentan con mayor poder adquisitivo para realizar inversiones en lo referente al personal e infraestructura y de esta manera incrementar su capacidad de respuesta frente a requerimientos de sus clientes. Son más eficientes en lo que respecta al alcance de sus servicios a comparación de Xternal Technological Solutions S.A.C. que le cuesta delimitar el fin de estos. A pesar de ello, los clientes valoran mucho eso ya que lo aprecian como un servicio personalizado que no lo reciben de otras empresas del sector.

Las fortalezas que se han podido observar para la creación de valor en esta actividad son:

- F2: Experiencia en el equipo de desarrollo.

- F3: Servicio post implementación de calidad.

Las debilidades identificadas en esta actividad de la cadena de valor son:

- D1: Número limitado de recursos de programación.

- D2: Falta de delimitación del alcance de su servicio post implementación. 


\section{Logística Externa}

La concentración de clientes de la que sufre Xternal Technological Solutions S.A.C. le permite tener prácticamente líneas dedicadas de atención directa con estos. Esto contribuye a la percepción de sus clientes de la personalización del servicio que brindan. Sus principales competidores no son capaces de realizar ese tipo de personalización ya que tienen una cartera más variada.

Las fortalezas identificadas que generan valor en esta actividad de la cadena son:

- F4: Línea dedicada para atender remotamente a sus clientes.

- F5: Personal altamente capacitado para la atención al cliente.

\section{Tecnología}

El esquema de trabajo para la atención y manejo de requerimientos de sus clientes se basa en una estructura organizacional en donde los roles de arquitecto de software son sumamente importantes. Esta persona tiene la responsabilidad de la estimación, seguimiento y control de los proyectos en los que participa, incluyendo la supervisión técnica de los desarrollos. En los principales competidores se aprecia una distinta estructura organizacional (dato proporcionado por los dueños de la empresa) en donde este rol está dividido en diferentes personas con responsabilidades específicas procurando no mezclar lo técnico de la gestión del proyecto.

Dentro de las fortalezas identificadas para la creación de valor en esta actividad se tienen:

- F6: Metodología de gestión de proyectos para cada línea de negocio.

- F7: Software especializado para la gestión de proyectos.

- F8: Personal especializado en la gestión de proyectos. 
Dentro de las debilidades identificadas en esta actividad de la cadena de valor se tienen:

- D3: Dependencia excesiva de los arquitectos de software.

- D4: Desfase de tiempo en la comunicación de los informes de avance a los clientes.

\section{Infraestructura}

Las empresas con las que compite Xternal Technological Solutions S.A.C. cuentan con una plana directiva dedicada exclusivamente a gerenciar y en donde se han delegado las responsabilidades operativas a gente especializada. Esto les permite tener el espacio para poder elaborar estrategias tanto de mejoras en sus procesos como en lo referente a la captación de clientes.

Producto del análisis comparativo realizado por los socios de la empresa, se considera que su experiencia en el sector es uno de los factores por los que los prefieren al momento de realizar una elección para realizar proyectos informáticos.

Como fortalezas para la creación de valor en esta actividad se han identificado:

- F9: Experiencia en el sector tecnológico de la plana directiva.

Como debilidades para la creación de valor en esta actividad se han identificado:

- D5: Poca experiencia de gestión de negocios de sus directivos.

- D6: Plana directiva ligada a actividades operativas en la empresa.

- D7: Carencia de un plan estratégico para un crecimiento sostenido 


\section{Mercadotecnia}

Este es el punto más débil de la empresa ya que no existe un área que se dedique exclusivamente a la comercialización y marketing. La reputación que tiene es ganada por la publicidad de boca en boca producto de las recomendaciones de sus clientes. Las otras empresas con las que compite si cuentan con un área específica para este fin.

Dentro de las fortalezas identificadas para la creación de valor en esta actividad de la cadena se encuentran:

- F10: Buena reputación ganada en el sector de tecnología de información

Dentro de las debilidades identificadas en esta actividad de la cadena de valor se encuentran:

- D8: Carencia de un área dedicada a las ventas y comercialización

- D9: Falta de un plan de marketing para sus servicios

- D10: Concentración de cartera de clientes

\section{Recursos Humanos}

Producto de las entrevistas a los socios (anexo1) se ha podido determinar que han conseguido un grato ambiente de trabajo y en donde se establece una fortaleza respecto a la cultura organizacional en lo referente a la preocupación por la formación del colaborador. Los mismos colaboradores lo resaltan (anexo 5) aunque no exista un área propiamente dicha que se encargue del reclutamiento y retención del talento.

Dentro de las fortalezas identificadas para la creación de valor en esta actividad de la cadena se encuentran:

- F11: Clima laboral agradable.

- F12: Sólida cultura organizacional. 
Dentro de las debilidades identificadas en esta actividad de la cadena de valor se encuentran:

- D11: Manejo empírico del personal.

- D12: Falta de políticas de gestión del personal.

\subsection{Determinar las Competencias de la Empresa}

Para determinar las fortalezas que pueden convertirse en competencias que nos permitan generar una ventaja competitiva en comparación de nuestros competidores, se ha utilizado una matriz de ventaja competitiva sostenible. En dicha matriz, se realizan preguntas respecto a si la fortaleza evaluada representa una capacidad valiosa, si es rara en comparación con sus competidores, si es difícil de imitar y si es insustituible. Como resultado de esta evaluación, se determina la implicancia competitiva que luego nos llevará a la priorización, identificación y determinación de las ventajas competitivas de la empresa. Esta matriz se puede apreciar en la tabla 23. 
Tabla 23

Matriz de ventaja competitiva sostenible

\begin{tabular}{|c|c|c|c|c|c|}
\hline Fortalezas & $\begin{array}{l}\text { Capacidad } \\
\text { valiosa }\end{array}$ & Rara & $\begin{array}{l}\text { Difícil de } \\
\text { imitar }\end{array}$ & Insustituible & $\begin{array}{l}\text { Implicancia } \\
\text { competitiva }\end{array}$ \\
\hline $\begin{array}{l}\text { F1: Contrato ventajoso con proveedor } \\
\text { de servicios de internet para disminuir } \\
\text { costos. }\end{array}$ & SI & SI & NO & $\mathrm{NO}$ & VCT \\
\hline $\begin{array}{l}\text { F2: Experiencia en el equipo de } \\
\text { desarrollo. }\end{array}$ & SI & NO & NO & NO & $\mathrm{PC}$ \\
\hline $\begin{array}{l}\text { F3: Servicio post implementación de } \\
\text { calidad. }\end{array}$ & SI & SI & SI & SI & VCS \\
\hline $\begin{array}{l}\text { F4: Línea dedicada para atender } \\
\text { remotamente a sus clientes. }\end{array}$ & SI & SI & SI & SI & VCS \\
\hline $\begin{array}{l}\text { F5: Personal altamente capacitado para } \\
\text { la atención al cliente. }\end{array}$ & SI & SI & SI & NO & VCT \\
\hline $\begin{array}{l}\text { F6: Metodología de gestión de } \\
\text { proyectos para cada línea de negocio. }\end{array}$ & SI & SI & NO & NO & PC \\
\hline $\begin{array}{l}\text { F7: Software especializado para la } \\
\text { gestión de proyectos. }\end{array}$ & SI & NO & NO & NO & $\mathrm{PC}$ \\
\hline $\begin{array}{l}\text { F8: Personal especializado en la } \\
\text { gestión de proyectos. }\end{array}$ & SI & NO & NO & NO & $\mathrm{PC}$ \\
\hline $\begin{array}{l}\text { F9: Experiencia en el sector } \\
\text { tecnológico de la plana directiva. }\end{array}$ & SI & NO & NO & NO & PC \\
\hline $\begin{array}{l}\text { F10: Buena reputación ganada en el } \\
\text { sector de tecnología de información }\end{array}$ & SI & NO & NO & NO & $\mathrm{PC}$ \\
\hline F11: Clima laboral agradable. & SI & SI & NO & NO & VCT \\
\hline F12: Sólida cultura organizacional. & SI & SI & SI & SI & VCS \\
\hline
\end{tabular}

Nota . CNE = Capacidad no estratégica, $\mathrm{PC}=$ Paridad competitiva, $\mathrm{VCT}=$ Ventaja competitiva temporal, VCS = Ventaja competitiva sostenible 


\subsection{Identificación y Determinación de las Ventajas Competitivas de la Empresa}

Luego de realizada la matriz de ventaja competitiva sostenible, se han identificado todas aquellas fortalezas que tengan una implicancia competitiva que las lleve a convertirse en ventaja competitiva temporal o ventaja competitiva sostenible. Estas fortalezas son las siguientes:

- F2: Contrato ventajoso con proveedor de servicios de internet para disminuir costos.

- F4: Servicio post implementación de calidad.

- F6: Línea dedicada para atender remotamente a sus clientes.

- F7: Personal altamente capacitado para la atención al cliente.

- F14: Clima laboral agradable.

- F15: Sólida cultura organizacional.

Las fortalezas anteriormente seleccionadas representan la ventaja competitiva de Xternal Technological Solutions S.A.C. respecto a sus competidores directos y coinciden con la diferenciación del servicio post implementación por lo cual la prefieren sus clientes.

\subsection{Matriz de Evaluación de los Factores Internos EFI}

Según David (2013), la matriz de evaluación de factores internos es una herramienta que identifica y evalúa las fortalezas y debilidades más significativas encontradas en las áreas funcionales de la empresa. Estos factores ponderados y calificados darán como resultado la puntuación ponderada total de la organización, lo que permitirá dar a conocer la posición interna de la empresa.

Para realizar esta matriz, se enumeran los factores claves tanto fortalezas como debilidades en un listado de 10 a 20 factores internos si es posible con un buen nivel de 
detalle que incluye porcentajes o cifras. Posteriormente, se le asigna un valor de ponderación a cada factor que va desde 0.0 si no tiene importancia a 1.0 si es muy importante. Sin importar si un valor clave es una fortaleza o una debilidad los valores más altos son los que producen los mayores efectos en el rendimiento de la empresa. La sumatoria de los valores de ponderación deberá ser igual a 1.0.

Luego se deberá de colocar una clasificación de uno a cuatro a cada factor, en caso sea una debilidad mayor deberá colocarse 1 , una debilidad menor se colocará 2 , una fortaleza menor se colocará 3 y una fortaleza mayor se colocará 4 . Las debilidades deben de tener la clasificación de 1 ó 2 y las fortalezas de 3 ó 4 . Es importante tener en cuenta que las clasificaciones se basarán en aspectos de la empresa y los valores de ponderación se basarán en la industria.

Para determinar un valor ponderado para cada variable, se multiplica cada ponderación con su clasificación y para obtener el valor ponderado total se suma todos los valores ponderados de cada variable.

La matriz de evaluación de factores internos (EFI) de la empresa Xternal Technological Solutions S.A.C. se puede apreciar en la tabla 24. Las debilidades que se aprecian en ella son producto de la identificación de cada una de ellas en las actividades de la cadena de valor y de las entrevistas a profundidad con los directivos de la empresa (anexo 1), así como de clientes y no clientes de esta (anexo 4 y 3 ). 
Tabla 24

Matriz de evaluación de factores internos (EFI)

\begin{tabular}{|c|c|c|c|}
\hline Factores Internos & Peso & Calificación & $\begin{array}{c}\text { Peso } \\
\text { Ponderado }\end{array}$ \\
\hline \multicolumn{4}{|l|}{ Fortalezas } \\
\hline $\begin{array}{l}\text { F2: Contrato ventajoso con proveedor de } \\
\text { servicios de internet para disminuir costos. }\end{array}$ & 0.05 & 3 & 0.15 \\
\hline F4: Servicio post implementación de calidad. & 0.14 & 4 & 0.56 \\
\hline $\begin{array}{l}\text { F6: Línea dedicada para atender remotamente a } \\
\text { sus clientes. }\end{array}$ & 0.09 & 3 & 0.27 \\
\hline $\begin{array}{l}\text { F7: Personal altamente capacitado para la } \\
\text { atención al cliente. }\end{array}$ & 0.09 & 4 & 0.36 \\
\hline F14: Clima laboral agradable. & 0.05 & 3 & 0.15 \\
\hline F15: Sólida cultura organizacional. & 0.05 & 3 & 0.15 \\
\hline \multicolumn{4}{|l|}{ Debilidades } \\
\hline $\begin{array}{l}\text { D1: Número limitado de recursos de } \\
\text { programación. }\end{array}$ & 0.03 & 1 & 0.03 \\
\hline $\begin{array}{l}\text { D2: Falta de delimitación del alcance de su } \\
\text { servicio post implementación. }\end{array}$ & 0.05 & 2 & 0.10 \\
\hline $\begin{array}{l}\text { D3: Dependencia excesiva de los arquitectos de } \\
\text { software. }\end{array}$ & 0.06 & 2 & 0.12 \\
\hline $\begin{array}{l}\text { D4: Desfase de tiempo en la comunicación de } \\
\text { los informes de avance a los clientes. }\end{array}$ & 0.04 & 2 & 0.08 \\
\hline $\begin{array}{l}\text { D5: Poca experiencia de gestión de negocios de } \\
\text { sus directivos }\end{array}$ & 0.04 & 1 & 0.04 \\
\hline $\begin{array}{l}\text { D6: Plana directiva ligada a actividades } \\
\text { operativas en la empresa. }\end{array}$ & 0.06 & 2 & 0.12 \\
\hline $\begin{array}{l}\text { D7: Carencia de un plan estratégico para un } \\
\text { crecimiento sostenido }\end{array}$ & 0.05 & 2 & 0.10 \\
\hline $\begin{array}{l}\text { D8: Carencia de un área dedicada a las ventas y } \\
\text { comercialización }\end{array}$ & 0.06 & 2 & 0.12 \\
\hline $\begin{array}{l}\text { D9: Falta de un plan de marketing para sus } \\
\text { servicios }\end{array}$ & 0.02 & 1 & 0.02 \\
\hline D10: Concentración de la cartera de clientes & 0.06 & 1 & 0.06 \\
\hline D11: Manejo empírico del personal. & 0.04 & 1 & 0.04 \\
\hline D12: Falta de políticas de gestión del personal & 0.02 & 2 & 0.04 \\
\hline Total & 1.00 & & 2.51 \\
\hline
\end{tabular}

por encima del promedio (2.5), lo cual es bueno, pero demuestra que se puede aún mejorar mucho más.

Si se analiza de manera individual las fortalezas y debilidades de la empresa, se puede apreciar valores altos muy diferenciados respecto a su fortaleza en los servicios post- 
implementación y su personal altamente capacitado. Adicionalmente, también se aprecia una fortaleza en la línea de comunicación dedicada que mantiene con algunos clientes, lo que le permite una rápida reacción sobre todo en etapas de implementación de soluciones.

En este punto, se podrían formular estrategias que permitan aprovechar estas fortalezas ya sea en la generación de nuevos mercados como en la creación de nuevas líneas de negocio. Ejemplo de ello podría ser líneas de negocio que tengan que ver con la capacitación de personal técnico o usuarios de procesos claves en sus clientes. También se podría incrementar participación de mercado actual aprovechando estas mismas fortalezas usándolas como ventajas competitivas respecto a su competencia directa.

Respecto a las debilidades, se ha podido apreciar que los valores obtenidos hacen incidencia a la dedicación que tienen los socios a la operatividad diaria, dejando de lado la parte gerencial y de ventas que son necesarias para asegurar un crecimiento sostenido en el tiempo. Las estrategias de ampliación de mercado y desarrollos de productos obligarían a la plana gerencial a dejar las actividades de operación diaria y de desarrollo para orientarse a labores acordes a su condición dentro de la empresa. La elaboración de un plan estratégico se hace fundamental para tener una guía de hacia donde se quiere llegar, cómo y en qué tiempo. 


\section{Capítulo VII: Formulación de los Objetivos y Diseño de las Estrategias}

\subsection{Alcance y Planteamiento de los Objetivos Estratégicos}

Uno de los principales puntos para establecer un plan estratégico es definir adecuadamente los objetivos que quieren alcanzar. En Thompson et al. (2012) se menciona que el propósito gerencial para la definición de los objetivos estratégicos es transformar la visión y misión en objetivos de desempeño específicos, que puedan ser cuantificables o medibles y definiendo un plazo para el logro de estos.

Basados en la visión, misión y valores propuestos para la empresa en el capítulo III del presente trabajo, se ha realizado una evaluación de la información necesaria para la formulación de los objetivos estratégicos de Xternal Technological Solutions S.A.C.

Asimismo, para determinar el alcance de los objetivos se está considerando el periodo de cinco años, el cual abarca el presente plan estratégico para la empresa Xternal Technological Solutions S.A.C.

\subsubsection{Objetivos estratégicos.}

Es importante que para la definición de los objetivos estratégicos se efectúe la jerarquización de objetivos de manera que no se establezcan objetivos individuales específicos.

Es así como, según Thompson et al. (2012), la jerarquización va desde la meta amplia hasta los objetivos individuales específicos, teniendo en su punto superior la misión de la empresa.

Esta jerarquización se muestra en la figura 14, en donde los objetivos estratégicos se encuentran por debajo de la misión siendo la responsabilidad de su gestión de los administradores de nivel superior. 


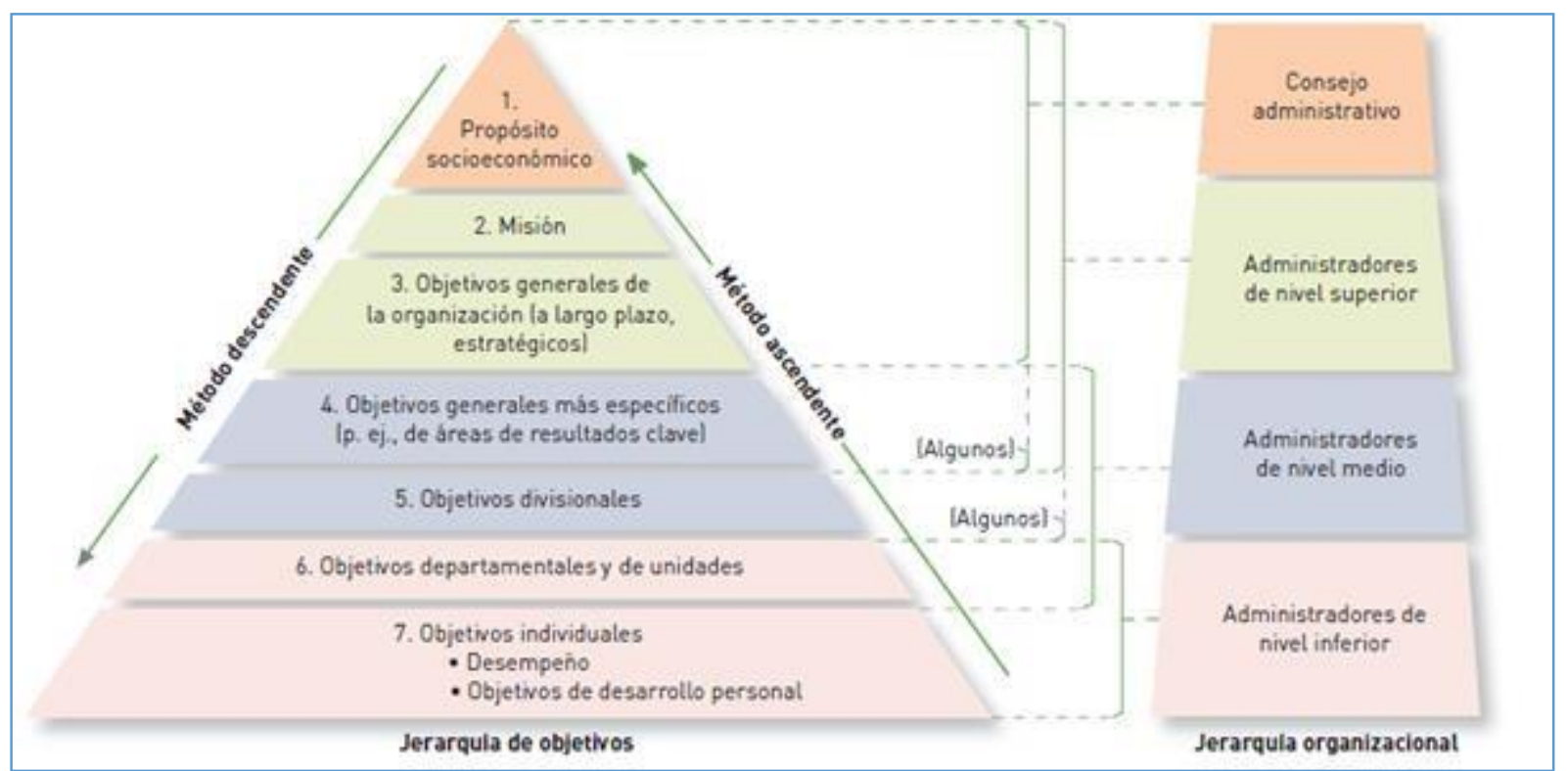

Figura 14. Relación entre objetivos y jerarquía organizacional. Tomado de "Administración estratégica Teoría y casos" (18.a ed.). (p.118) por Thompson, A. A., Gamble, J., Peteraf, M., \& Strickland III, A. J., 2012, México: Editorial McGraw-Hill Interamericana.

Siguiendo el marco teórico planteado, se han determinado los siguientes objetivos estratégicos:

- Maximizar el valor de la empresa, incrementando el ROE en 11 puntos porcentuales (20\%) en un plazo de cinco años.

- Crecimiento en la participación del mercado, incrementando el porcentaje de clientes en las líneas de BA y Mobile a un 40\% en un período de cinco años

- Excelencia en el servicio, manteniendo un nivel de aceptación de este por encima del $85 \%$

\subsubsection{Análisis de los objetivos estratégicos.}

\section{Maximizar el valor de la empresa}

El objetivo primordial de toda empresa es el de maximizar el valor de esta. Xternal Technological Solutions S.A.C. a pesar de haber tenido un año 2016 difícil por la separación de dos de sus socios fundadores, ha podido mantener las relaciones establecidas con sus 
clientes principales manteniendo de esta manera su flujo proyectado de ingresos, pero aumentando sus costos operativos debido a una estrategia de fidelización de su personal que consistió, entre otras cosas, en ajustes y reestructuración de las bandas salariares. Durante todo el segundo semestre, los socios restantes enfocaron sus esfuerzos en superar la crisis en la que se encontraban, tratando principalmente de mantener a sus clientes y personal en puestos críticos. Esta coyuntura hizo que las expectativas económicas disminuyeran afectando los resultados finales del año, lo que se vio reflejado en el ROE cuyo porcentaje fue de $9.37 \%$.

Superada esta crisis, la empresa espera para el año 2017 y para los siguientes años venideros mantener las relaciones con sus clientes actuales e incrementar el número de estos. Las proyecciones económicas para el país son optimistas sobre todo en sectores económicos en donde la empresa ya cuenta con clientes fidelizados (sector pesquero y manufactura). Estas expectativas, sumadas a una reformulación de la estrategia actual respecto a procesos internos de la empresa para los siguientes cinco años, hacen totalmente factible el poder alcanzar el objetivo planteado.

\section{Crecimiento en la participación del mercado}

Xternal Technological Solutions S.A.C. cuenta con una cartera de clientes reducida que le ha permitido mantener un relativo crecimiento a través de los años que tiene en el mercado. Este crecimiento se basa en la relación de confianza y contratos a largo plazo que mantiene con su principal cliente que es la empresa Tecnológica de Alimentos S.A., lo que le ha permitido obtener cierta estabilidad financiera y poder iniciar otras líneas de negocio en busca de un aumento en su captación de clientes y, por consecuencia, un aumento en su nivel de ventas. La crisis por la que atravesó la empresa en el año 2016 ha dejado al descubierto la dependencia excesiva que tiene sobre su cliente principal (su mayor fuente de ingresos) y la deficiente labor en el área de comercialización que se ve reflejada en el reducido número de 
clientes con la que cuenta. Cada uno de los socios que decidieron retirarse de la empresa han llevado a cabo un emprendimiento similar, pasando a ser competencia directa de la empresa. Incluso se puede decir que empiezan con la ventaja de conocer los procesos internos y la realidad financiera de Xternal Technological Solutions S.A.C. Estos emprendimientos podrían amenazar la poca participación en el mercado que tiene la empresa por lo que plantearse como objetivo estratégico el incrementar su participación (número de clientes) es fundamental para su supervivencia.

Por otro lado, la industria del software en el Perú está creciendo a un ritmo de 15\% anual desde hace seis años como ya se ha mencionado en el análisis tecnológico del entorno de la empresa. En la medida en que Xternal Technological Solutions S.A.C. replantee su estrategia actual podría aprovechar este crecimiento para poder captar un mayor número de clientes, lo que hace alcanzable este objetivo estratégico planteado.

\section{Excelencia en el servicio}

Durante la crisis que atravesó la empresa en el pasado año 2016, una de sus principales preocupaciones fue el mantener la relación que existe con sus principales clientes y, sobre todo, buscar que renovarla para los siguientes años venideros. Esta situación no esperada pudo poner en tela de juicio su capacidad para cumplir con los compromisos establecidos, lo que hubiese sido catastrófico para su imagen y reputación.

Durante el tiempo que la empresa opera en el mercado se ha caracterizado por ofrecer un servicio de calidad que se ajusta a lo requerido por sus clientes, soportado por la experiencia de su personal en el sector. Esta es la principal característica por la que sus clientes la prefieren por sobre su competencia directa.

Al no tener un plan a largo plazo que permita seguir acciones específicas para lograr una mejora en su servicio, la empresa se ha preocupado por construir una relación de confianza basada en la reputación individual de los socios, en primera instancia, y en la 
competencia técnica de sus colaboradores. Hasta el momento ha bastado para mantener el estado actual respecto a sus clientes, pero tiene muy claro que no es suficiente con una apreciación subjetiva por parte de estos. Por ello, la empresa se debe plantear el desafío de medir el nivel de aceptación del servicio realizando un levantamiento de información detallado sobre cada punto que interviene en el mismo, a fin de mantenerlo y/o mejorarlo de acuerdo con los resultados obtenidos luego de este estudio. El valor de aceptación fijado en $85 \%$ lo obtiene después de realizar un benchmarking entre las empresas referentes en el sector de tecnología de la información, cuyos valores están en ese orden.

El replanteamiento de la estrategia actual que se basa en la subjetividad de la apreciación de sus clientes es fundamental para conseguir el objetivo trazado.

\subsection{Diseño y Formulación de Estrategias}

\subsubsection{Modelo océano azul.}

De acuerdo a lo mencionado por Lay, Lazaro, \& Randish (como se cita en Chan \& Mauborgne, 2005), el Modelo Océano Azul consiste en establecer una estrategia de ampliación de mercado, a través de la innovación y no caer en la competencia regular, en donde el éxito se basa en saber desempeñarse hábilmente, sin tener en cuenta que existen otros espacios no explotados, en donde la competencia se torna irrelevante y la posibilidad de crecimiento y de obtener mayor rentabilidad se tornan interesante y con una duración de largo plazo.

La empresa Xternal Technological Solutions S.A.C. brinda servicios de consultoría en tecnología de información, los cuales consisten en brindar soluciones a la medida de lo requerido por las empresas que escogen su servicio.

Las características de su servicio han sido clasificadas en cinco grupos, para luego ser evaluadas y calificadas en comparación con los parámetros de la industria (en donde se han 
considerado a las empresas EbinCorp y Axelera Consulting como competidores directos). En la tabla 25 se visualiza esta calificación.

Tabla 25

Características del servicio de consultoría de Xternal Technological Solutions S.A.C.

\begin{tabular}{cllll}
\hline & \multicolumn{1}{c}{ Características del Servicio } & Xternal & Industria \\
\hline ralidad dal & 1.1 Metodología dedesarrollo & 4 & Bueno & 4 Bueno \\
Servicin & 1.2 Cumplimiento de plazos & 4 & Bueno & 4 Bueno \\
& 1.3 Satisfacción del cliente & 4 & Bueno & 5 Muy Bueno \\
Servicio de Post & 2.1 Seguimiento deimplementaciones & 5 & Muy Bueno & 4 Bueno \\
Venta & 2.2 Asistencia Técnica & 5 & Muy Bueno & 4 Bueno \\
& 3.1 Capacidad Instalada & 4 & Bueno & 4 Bueno \\
Infraestructura & 3.2 Proveedores decomunicación & 3 & Regular & 5 Muy Bueno \\
& 3.3 Cobertura geográfica & 3 & Regular & 4 Bueno \\
& 4.1 Conocimiento técnico & 4 & Bueno & 4 Bueno \\
Penurco & 4.2 Trato con el cliente & 4 & Bueno & 4 Bueno \\
Hımann & 4.3 Experiencia en elsector & 4 & Bueno & 4 Bueno \\
& 4.4 Responsabilidad y compromiso & 5 & Muy Bueno & 5 Muy Bueno \\
& 4.5 Visión Estratégica & 2 & Malo & 4 Bueno \\
& 5.1 ABAP & 4 & Bueno & 4 Bueno \\
Líneas de & 5.2 Portal & 4 & Bueno & 4 Bueno \\
Negocio & 5.3 BA & 3 & Regular & 4 Bueno \\
& 5.4 Mobile & 1 & Muy Malo & 4 Bueno \\
\hline
\end{tabular}

Nota. Los valores visualizados para la columna de Industria han sido obtenidos del promedio de la calificación obtenida por las dos empresas que son competencia directa de Xternal Technological Solutions S.A.C. (Ebimcorp y Axelera Consulting).

\subsubsection{Lienzo de la estrategia actual de la empresa.}

En base a lo visualizado en el punto anterior se ha podido realizar el lienzo de la estrategia actual en donde se puede apreciar, de acuerdo con la calificación realizada anteriormente, los puntos altos y bajos de la misma. Los puntos bajos podrán ser analizados posteriormente para, luego de realizar la matriz de las cuatro acciones, tomar las acciones pertinentes a fin de proponer una estrategia mejorada y adecuada a la consecución de los objetivos estratégicos planteados. La figura 15 muestra el lienzo de la estrategia actual de la empresa. 


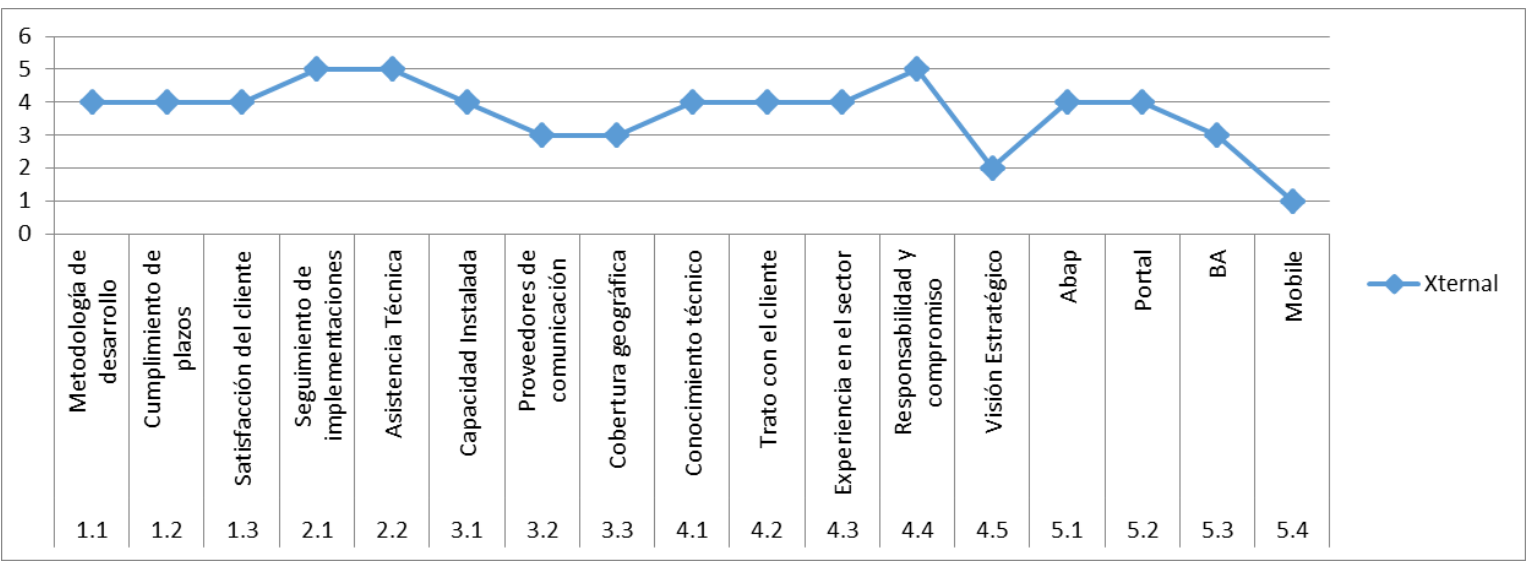

Figura 15. Lienzo de la estrategia actual de la empresa. Adaptado de "La estrategia del océano azul”. (p.37) por Chan, Kim, \& Mauborgne, Renée, 2005, Colombia: Editorial Norma

De acuerdo con lo mostrado en la figura 15 , se puede apreciar claramente que hay dos características que están calificadas con valores de malo y muy malo (2 y 1). Estas calificaciones corresponden a los puntos de visión estratégica y mobile. También se aprecian puntos como los de proveedores de comunicación, cobertura geográfica y BA que se encuentran calificados como regular (3) y que deben ser tratados a fin de tomar acción para su mejora.

\subsubsection{Lienzo de la estrategia de la industria.}

Los valores de calificación obtenidos para la industria en donde se desenvuelve la empresa Xternal Technological Solutions S.A.C. son resultado de la evaluación de juicio de expertos (anexo 2) respecto a las empresas que son competidores directos de la misma. Para ello, se han evaluado a las empresas Ebimcorp y Axelera Consulting de las que se ha calculado un promedio de calificación, siendo esta última tomada en cuenta como valor de obtenido para la industria.

Con esta evaluación, se ha podido realizar un lienzo de la estrategia de la industria y que es visualizado de manera gráfica en la figura 16. 


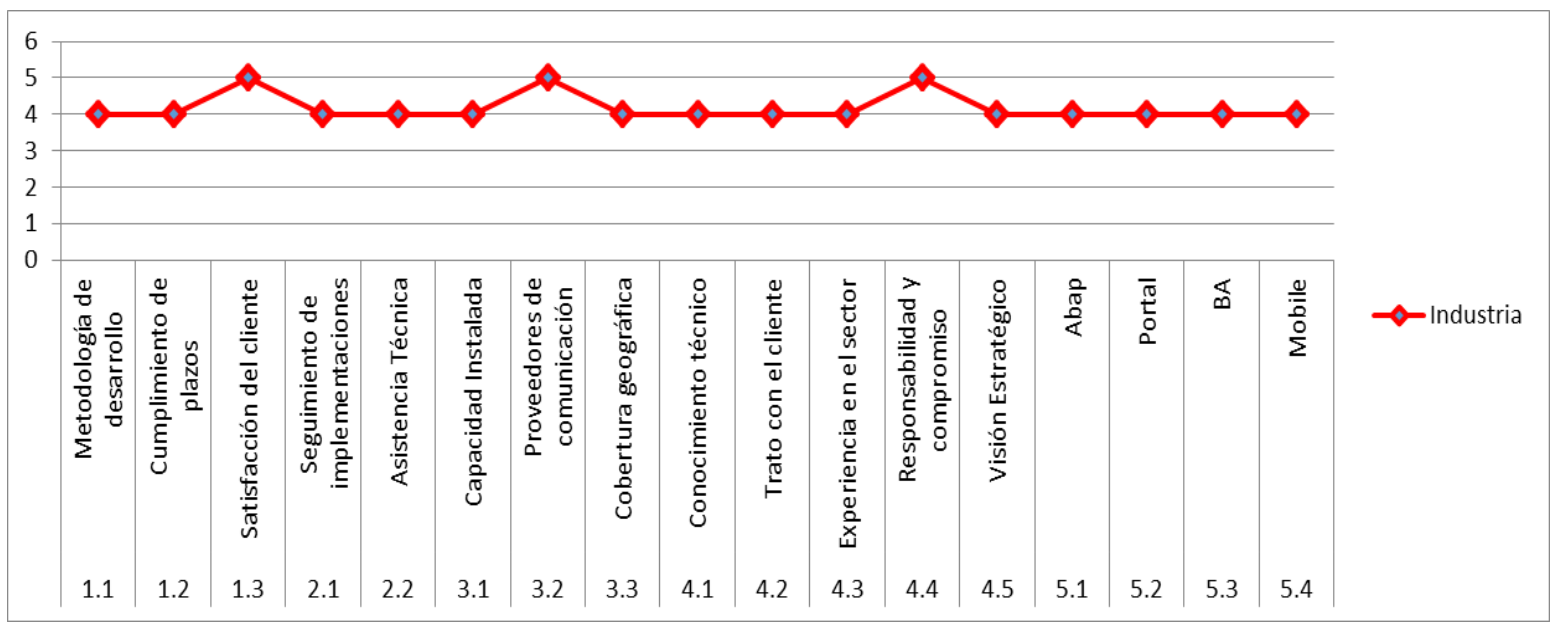

Figura 16. Lienzo de la estrategia de la industria. Adaptado de "La estrategia del océano azul”. (p.37) por Chan, Kim, \& Mauborgne, Renée, 2005, Colombia: Editorial Norma.

Luego de analizar de manera individual cada uno de los lienzos, se ha realizado una comparación de los valores obtenidos y que pueden ser visualizados en la figura 17.

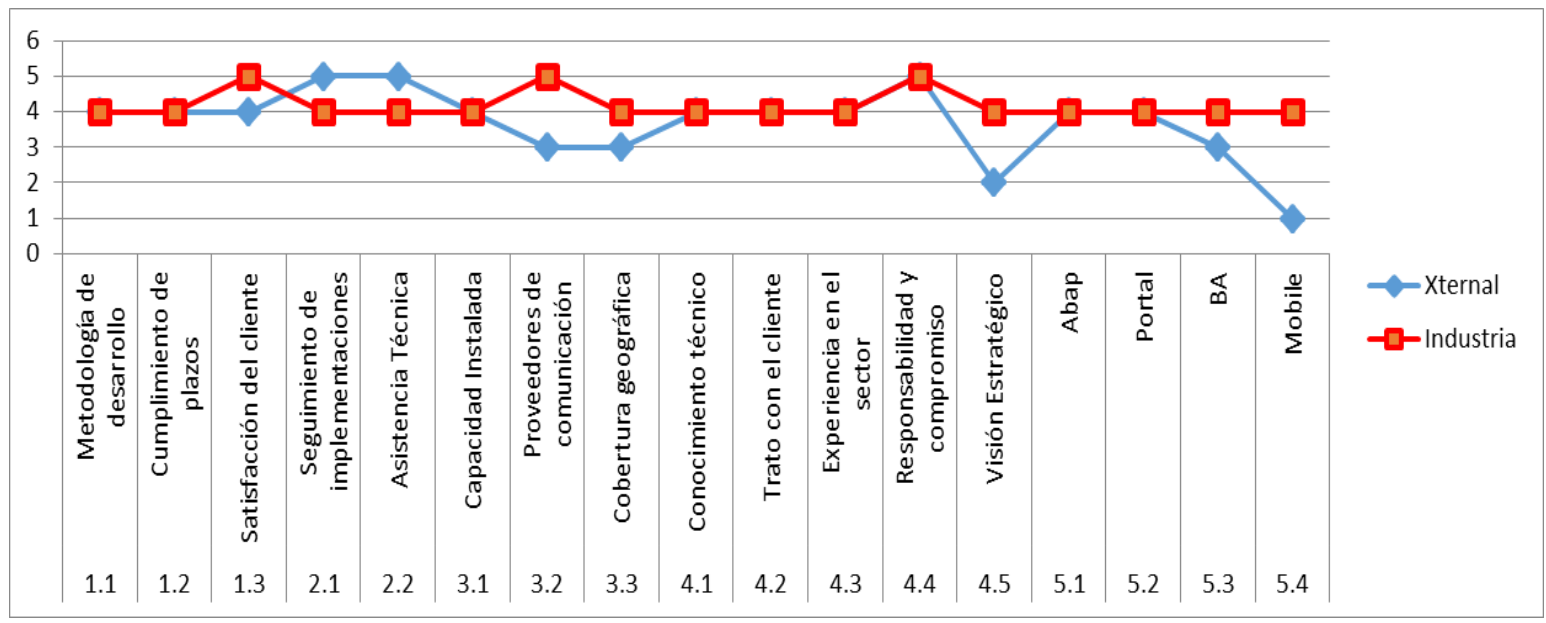

Figura 17. Lienzo de la estrategia actual de la empresa vs estrategia de la industria. Adaptado de "La estrategia del océano azul". (p.37) por Chan, Kim, \& Mauborgne, Renée, 2005, Colombia: Editorial Norma.

\subsubsection{Matriz (eliminar, reducir, incrementar, crear).}

La Matriz Eliminar-Reducir-Incrementar-Crear (ERIC), según Lay, Lazaro, \& Randish (como se cita en Chan \& Mauborgne, 2005), es una herramienta analítica que utilizando el esquema de cuatro acciones impulsa a las empresas a actuar en cada etapa para crear una nueva curva de valor a fin de liberar un nuevo océano azul, buscando de manera 
simultánea la diferenciación y bajo costo para romper el equilibrio entre valor y costo, evitando que las empresas solo se enfoquen en incrementar y crear un exceso de productos y servicios lo cual aumentaría su estructura de costos. Con la matriz (eliminar, reducir, incrementar, crear) se trata determinar si hay características que debemos eliminar o reducir, incrementar o crear nuevas características que el mercado no recibe aún en servicios de TI.

Luego de realizar una evaluación individual de las características del servicio de consultoría en TI que brinda la empresa Xternal Technological Solutions S.A.C., y luego de realizar una comparación con la calificación obtenida de la industria en donde se desenvuelve, se ha procedido a realizar la matriz de las cuatro acciones en la que se podrá apreciar en detalle las acciones que se deben de realizar para mejorar la estrategia actual, y que permita la generación de una estrategia propuesta que ayuda a la consecución de los objetivos estratégicos planteados.

La tabla 26 muestra la matriz con las acciones que se tomarán en cuenta para el planteamiento de un nuevo lienzo propuesto. 
Tabla 26

Matriz de las cuatro acciones del servicio de consultoría en TI de Xternal Technological Solutions S.A.C.

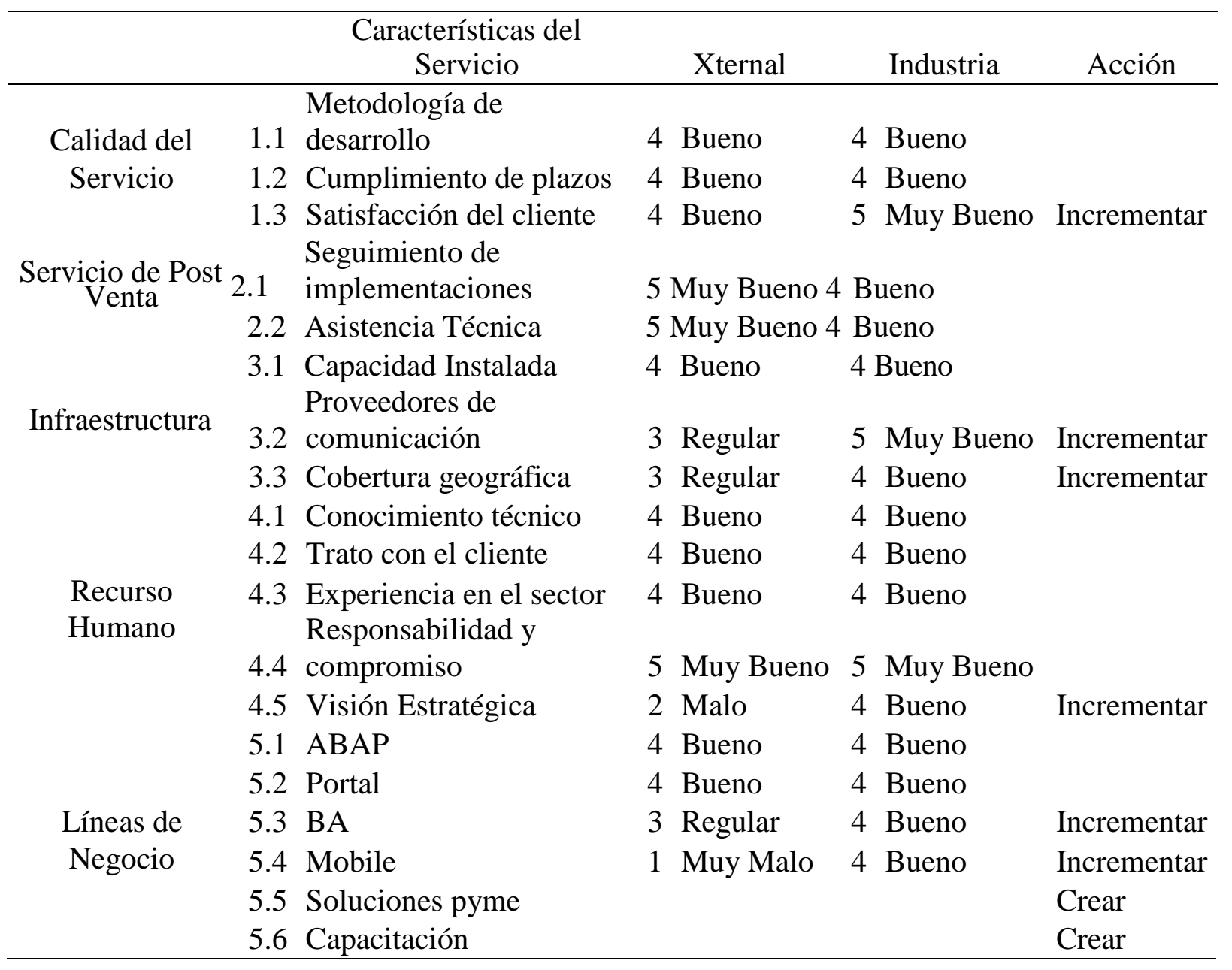

Las acciones que se han planteado en esta matriz serán plasmadas en un nuevo lienzo propuesto, el cual se describe en detalle en el siguiente punto.

\subsubsection{Lienzo de la nueva estrategia considerada.}

Luego de haber determinado las acciones a llevar a cabo para una mejora en la estrategia actual de la empresa, se ha realizado un nuevo lienzo en el que se puede visualizar las mejoras propuestas en cada uno de los puntos descritos en acciones concretas en la matriz de las cuatro acciones. La figura 18 muestra el lienzo de la nueva estrategia considerada. 


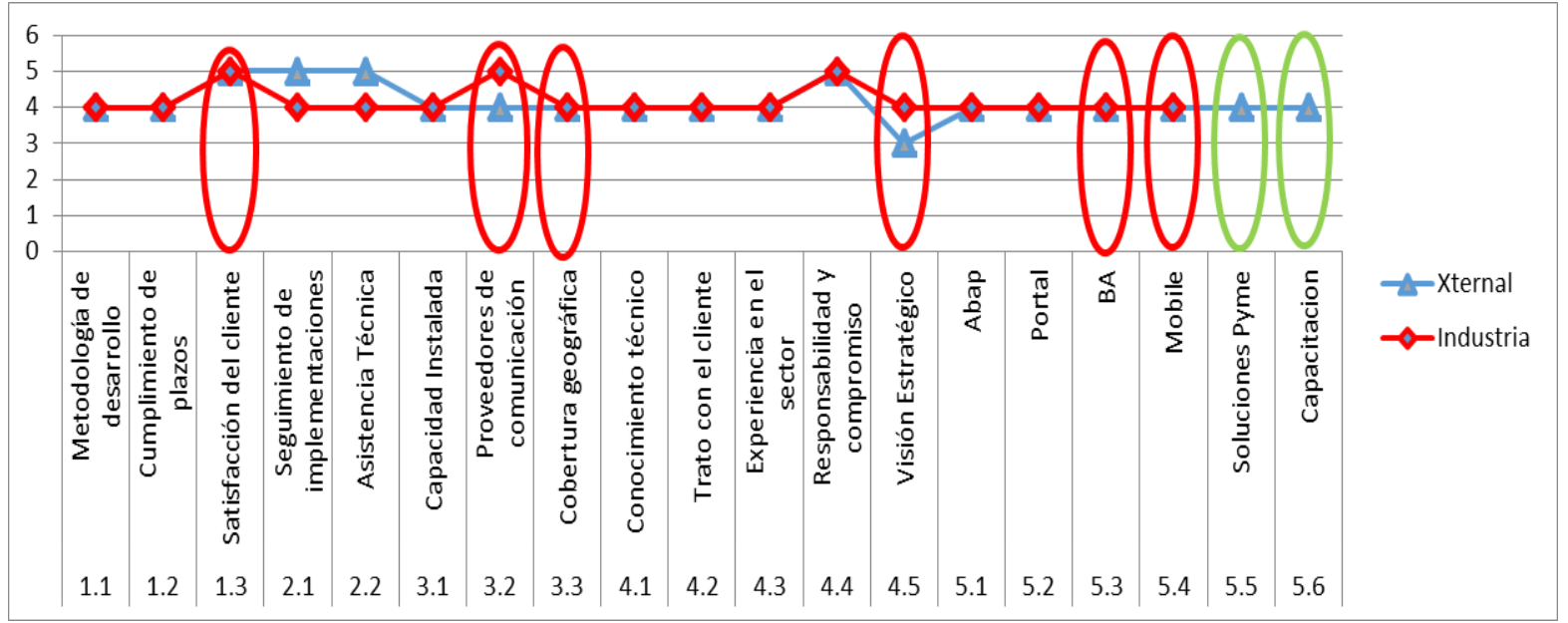

Figura 18. Lienzo de la nueva estrategia considerada. Adaptado de "La estrategia del océano azul”. (p.37) por Chan, Kim, \& Mauborgne, Renée, 2005, Colombia: Editorial Norma.

Como se aprecia en la figura 18, las acciones consideradas en color rojo son las correspondientes a incrementar los valores para poder igualarse o acercarse al promedio de la industria. En esa línea están las características correspondientes a la metodología de desarrollo, satisfacción del cliente, capacidad instalada, proveedores de comunicación, cobertura geográfica, visión estratégica, BA y mobile. En cada una de estas características se está proponiendo el incremento de por lo menos un número respecto a su valor anterior:

- Satisfacción al cliente (5 - Muy bueno), incrementar aplicando encuestas de satisfacción a sus clientes automatizadas, las cuales servirán como punto de partida para realizar mediciones periódicas y planes de acción respecto a la mejora de su servicio.

- Proveedores de comunicación (4 - Bueno), incrementar el valor tratando de conseguir mejores condiciones de servicio con los operadores actuales y evitar que se presenten problemas que los mantengan incomunicados con sus clientes.

- Cobertura geográfica (4 - Bueno), incrementar en función a una nueva capacidad instalada que le permita presencia remota y física a los nuevos 
clientes que se piensa captar. También está complementado con una mejora en los proveedores de comunicación.

- Visión estratégica (3 - Regular), incrementar tratando de que los dueños de la empresa se desliguen de actividades netamente operativas y puedan orientar sus esfuerzos en una planificación estratégica que les permita crecer sostenidamente en el tiempo. Es algo que se debe materializar en el corto plazo.

- BA y Mobile (4 - Bueno), incrementar complementando el servicio que ya se brinda con una mayor inversión en herramientas y en personal capacitado. En estos casos se plantea un incremento en por lo menos dos puntos debido a que son líneas de negocio que recién se están desarrollando y sobre las que se van a apoyar las estrategias de crecimiento de la empresa.

- Soluciones Pyme y Capacitación (4 - Bueno), se ha planteado la creación de estas dos líneas de negocio que permitirán una diferenciación y una penetración en otros mercados aún no explorados por la empresa y en donde se vislumbra un futuro prometedor. Respecto a las soluciones pyme se está planteando el incursionar en un mercado en el que se pueda aprovechar las automatizaciones ya existentes en empresas que no cuenten con el sistema SAP, desarrollando soluciones que las complementen. Respecto a la capacitación, se está planteando realizar capacitaciones en las empresas, pero enfocadas a sus procesos internos y no a como actualmente la orienta el mercado de manera modular respecto a los módulos que ofrece SAP. 


\subsubsection{Matrices de formulación de estrategias.}

\subsubsection{Matriz FODA.}

De acuerdo con lo especificado por Hunger \& Wheeler (2013), "FODA es un acrónimo que se usa para describir las Fortalezas, Oportunidades, Debilidades y Amenazas particulares que son factores estratégicos para una empresa específica” (p.190). En ese sentido, la matriz FODA permite describir de manera gráfica como las diferentes amenazas y oportunidades, a las que está expuesta la empresa, se pueden relacionar con las fortalezas y debilidades de esta a fin de poder tener una serie de estrategias agrupadas en cuatro sectores dentro de la matriz: FO (fortalezas/oportunidades), FA (fortalezas/amenazas), DO (debilidades/oportunidades) y DA (debilidades/amenazas).

Hunger \& Wheeler (2013), proponen como una técnica para generar estas estrategias en cada uno de los grupos a la del Brainstorming (lluvia de ideas), de forma tal que se puedan recoger estrategias que de manera normal no serían consideradas en la evaluación.

En la Figura 19 se aprecia la forma de elaborar una matriz FODA:

\begin{tabular}{|c|c|c|}
\hline $\begin{array}{l}\begin{array}{r}\text { FACTORES } \\
\text { INTERNOS }\end{array} \\
\text { (OFAS) } \\
\text { FACTORES } \\
\text { EXTERNOS } \\
\text { (EFAS) }\end{array}$ & $\begin{array}{l}\text { Fortalezas }(\boldsymbol{F}) \\
\text { Enumere aqui de } 5 \text { a } 10 \\
\text { brtalezas hternas }\end{array}$ & $\begin{array}{l}\text { Debilidades (D) } \\
\text { Enumere aqui de } 5 \text { a } 10 \\
\text { debilidades hternas }\end{array}$ \\
\hline Oportunidades(O) & ESTRATEGIAS FO & ESTRATEGIAS DO \\
\hline $\begin{array}{l}\text { Enumere aqui de } 5 \text { a } 10 \\
\text { oportunidades externas }\end{array}$ & $\begin{array}{l}\text { Oree aqui estrabgias } \\
\text { que usen fortalezas } \\
\text { para aprovechar las } \\
\text { oportunidades }\end{array}$ & $\begin{array}{l}\text { Oee aqui estrabgias } \\
\text { que aprovechen las } \\
\text { oportunidades al } \\
\text { superar las debilidades }\end{array}$ \\
\hline Amenazas (A) & ESTRATEGIAS FA & ESTRATEGIAS DA \\
\hline $\begin{array}{l}\text { Enumere aqui de } 5 \text { a } 10 \\
\text { amenazas externas }\end{array}$ & $\begin{array}{l}\text { Oree aqui estrabegias que } \\
\text { wilicen fortalezas para } \\
\text { evitar amenazas }\end{array}$ & $\begin{array}{l}\text { Cree aqui estralegias que } \\
\text { minimicen las debilidades } \\
\text { y eliminen las amenazas }\end{array}$ \\
\hline
\end{tabular}

Figura 19. Matriz FODA. Tomado de "Administración estratégica y política de negocios" (p. 197) por Hunger \& Wheeler, 2013, Colombia: Editorial Pearson. Copyright 2013 Editorial Delfin Ltda. 
Siguiendo el marco teórico anteriormente descrito, se ha procedido a elaborar la matriz FODA de la empresa Xternal Technological Solutions S.A.C, la cual se puede apreciar en la tabla 27.

Tabla 27

Matriz FODA de la empresa Xternal Technological Solutions S.A.C. 
F2: Contrato ventajoso con proveedor de servicios de internet para disminuir costos.

F4: Servicio post implementación de calidad.

F7: Personal altamente capacitado para la atención al cliente.

F14: Clima laboral agradable.

F15: Sólida cultura organizacional.
F6: Línea dedicada para atender remotamente a sus clientes.

\section{XTERNAL TECHNOLOGICAL SOLUTIONS}

\author{
S.A.C.
}

D1: Número limitado de recursos de programación.

D2: Falta de delimitación del alcance de su servicio post

mplementación.

D3: Dependencia excesiva de los arquitectos de software.

D4: Desfase de tiempo en la comunicación de los informes de

avance a los clientes.

D5: Poca experiencia de gestión de negocios de sus directivos

D6: Plana directiva ligada a actividades operativas en la empresa.

D7: Carencia de un plan estratégico para un crecimiento sostenido

D8: Carencia de un área dedicada a las ventas y

comercialización

D9: Falta de un plan de marketing para sus servicios

D10: Concentración de la cartera de clientes

D11: Manejo empírico del personal.

D12: Falta de políticas de gestión del personal

\begin{tabular}{l} 
OPORTUNIDADES \\
\hline O1: Incremento de la demanda de servicios \\
O2: Captación de profesionales y técnicos altamente calificados \\
O3: Crecimiento en sectores económicos de Pesca, Manufactura y \\
Minería \\
O4: Contratos anuales con precio fijo en moneda nacional \\
O5: Inversión privada en el rubro de tecnología de información \\
O6: Las empresas necesitarán proveedores de servicios de \\
información \\
O7: Diversificación de servicios a ofrecer orientados a otros mercados \\
(PYMES) \\
O8: Alta demanda en los servicios que brinda la empresa \\
O9: Disponibilidad de nuevo software que permite el desarrollo sobre \\
la nube \\
O10: Nueva plataforma de desarrollo orientada al procesamiento de \\
grandes volúmenes de información
\end{tabular}

ESTRATEGIAS FO

Desarrollo de Mercado:

Innovación en nuevas líneas de negocio (O1,O3,O5, O6, O7,O9,O10,F4,F7)

Potenciar la línea de negocio de BA y Mobile (O3,O4,O7,O8,O9, F7, F6)

Penetración de Mercado:

ESTRATEGIAS DO

Fortalecimiento de la marca empleadora (F14,F15,O2, O7)

Mejora del capital humano (D1, D5, D11, D12, O3)

Mejora Continua:

Desarrollo de nuevos procesos organizacionales (D3, D3,D4,

Incrementar las operaciones de la empresa ampliando el número de servicios

ofrecidos $(\mathrm{O} 3, \mathrm{O} 4,05, \mathrm{O} 7, \mathrm{O}, \mathrm{F} 2, \mathrm{~F} 6, \mathrm{~F} 7)$

\section{AMENAZAS}

ESTRATEGIAS FA

A1: Aumento en la competencia en el rubro de servicios de tecnología de información

A2: Disminución de ingresos por reducción de servicios requeridos.

A3: Alta rotación de personal debido a la demanda de la competenci

A4: Creación de nuevas empresas en el rubro de tecnología de información

A5: Fluctuación de la tasa de cambio de moneda extranjera

A6: Riesgo de fracaso en la implementación de proyectos

A6: Riesgo de fracaso en la implemen

A8: Desfase tecnológico por nuevas versiones de herramientas de

software orientadas a programación en nube

A9: Reducción de requerimientos por clientes del sector pesquero

\section{Fidelización de Cliente:}

Medición del grado de satisfacción del cliente (A1, A2, F2, F4, F7)

Diversificación:

Diversificación de cartera de servicios (A2, A4, A5, A8, A7, A8, F7, F4, F6)
ESTRATEGIAS DA

\section{De Aprendizaje:}

Fortalecimiento de las capacidades gerenciales de los dueños de la empresa (A1, A2, D2, D5, D6, D7, D8, D10, D11, D12)

Mejora Continua:

Desarrollo de una nueva estructura organizacional. (D1, D3, D6, A4) 


\subsubsection{Matriz PEYEA.}

Es conocida como la matriz de posición estratégica y la evaluación de la acción (PEYEA). En esta matriz se aprecian cuatro cuadrantes que determinan si la estrategia debe ser agresiva, conservadora, defensiva o competitiva. También se aprecia la representación de dos dimensiones internas (fuerza financiera-FF y ventaja competitiva-VC) y dos dimensiones externas (estabilidad del ambiente-EA y fuerza de la industria-FI) en los ejes de la matriz.

Para determinar hacia donde se debe de orientar el vector de la estrategia, se deben de analizar los factores que forman parte de las dimensiones, asignándole un valor de +1 (peor) a +6 (mejor) a cada variable de las dimensiones de FF y FI. Luego asignar un valor de -1 (mejor) y -6 (peor) para las que corresponden a las dimensiones de VC y EA. De acuerdo a David (2013), los siguientes pueden ser algunos ejemplos de los factores que pueden estar en los ejes de la matriz PEYEA:

Fuerza Financiera

- Rendimiento sobre la inversión

- Apalancamiento

- Liquidez

- Capital de trabajo

- Flujos de efectivo

- Facilidad para salir del mercado

- Riesgos implícitos del negocio

Estabilidad del ambiente

- Cambios tecnológicos

- Tasa de inflación

- Variabilidad de la demanda

- Escala de precios de productos competidores 
- Barreras para entrar en el mercado

- Presión competitiva

- Elasticidad de la demanda

Ventaja competitiva

- Participación en el mercado

- Calidad del producto

- Ciclo de vida del producto

- Lealtad de los clientes

- Utilización de la capacidad de la competencia

- Conocimientos tecnológicos

- Control sobre los proveedores y distribuidores

Fuerza de la industria

- Potencial de crecimiento

- Potencial de utilidades

- Estabilidad financiera

- Conocimientos tecnológicos

- Aprovechamiento de recursos

- Intensidad de capital

- Facilidad para entrar en el mercado

- Productividad, aprovechamiento de la capacidad

Siguiendo con el marco teórico descrito anteriormente, se ha procedido a elaborar la matriz PEYEA de la empresa Xternal Technological Solutions S.A.C. Los factores que han sido considerados para cada vector son los siguientes: 
Ventaja competitiva (VC)

- Servicio de calidad reconocida

- Personal altamente capacitado y con experiencia en el sector

- Contratos de exclusividad con empresas referentes en sectores económicos

- Clima laboral agradable

Fortaleza de la industria (FI)

- Pocas barreras de ingreso al mercado

- Aumento en las inversiones privadas en tecnología de la información

- Abundancia de recurso humano de programación

- Crecimiento de la industria del software en el país

Fortaleza financiera (FF)

- Rendimiento sobre la inversión

- Apalancamiento

- Flujos de efectivo

Estabilidad ambiental (EA)

- Inflación controlada

- Recuperación de los sectores de pesca, manufactura y minería

- Formalización de empresas

- Nuevas tendencias tecnológicas

- Incremento en demanda de servicios de consultoría de TI

Siguiendo con la metodología, se ha procedido a calificar cada factor en base a la dimensión en donde corresponden y el juicio de expertos (anexo 2) consultados. La tabla 28 muestra los resultados de cada evaluación. 
Tabla 28

Variables PEYEA

\begin{tabular}{lc}
\hline FACTORES & VALOR \\
\hline Ventaja Competitiva & VC
\end{tabular}

Servicio de calidad reconocida $\quad-2$

Personal altamente capacitado y con experiencia en el sector $\quad-2$

Contratos de exclusividad con empresas referentes en sectores económicos

Clima laboral agradable

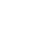

Promedio

Fortaleza de la industria

FI

Pocas barreras de ingreso al mercado

Aumento en las inversiones privadas en tecnología de información

Abundancia de recursos humanos de programación

Crecimiento de la industria del software

FI

Promedio

\title{
FI
}

Fortaleza Financiera

FF

Rendimiento sobre la inversión

Apalancamiento

3

Flujos de efectivo

Promedio

Estabilidad Ambiental

EA

\begin{tabular}{lr} 
Inflación controlada & -2 \\
Recuperación de los sectores de pesca y manufactura & -1 \\
Formalización de empresas & -3 \\
Nuevas tendencias tecnológicas & -1 \\
Incremento de demanda en servicios de TI & -2 \\
Promedio & -1.80 \\
\hline
\end{tabular}

Luego de realizar la valoración de cada factor, se ha procedido a calcular los vectores direccionales para obtener las coordenadas en donde se encuentra la empresa, y de esta manera determinar la estrategia más adecuada de acuerdo con el cuadrante adonde pertenece. La figura 20 muestra el resultado de esta evaluación. 


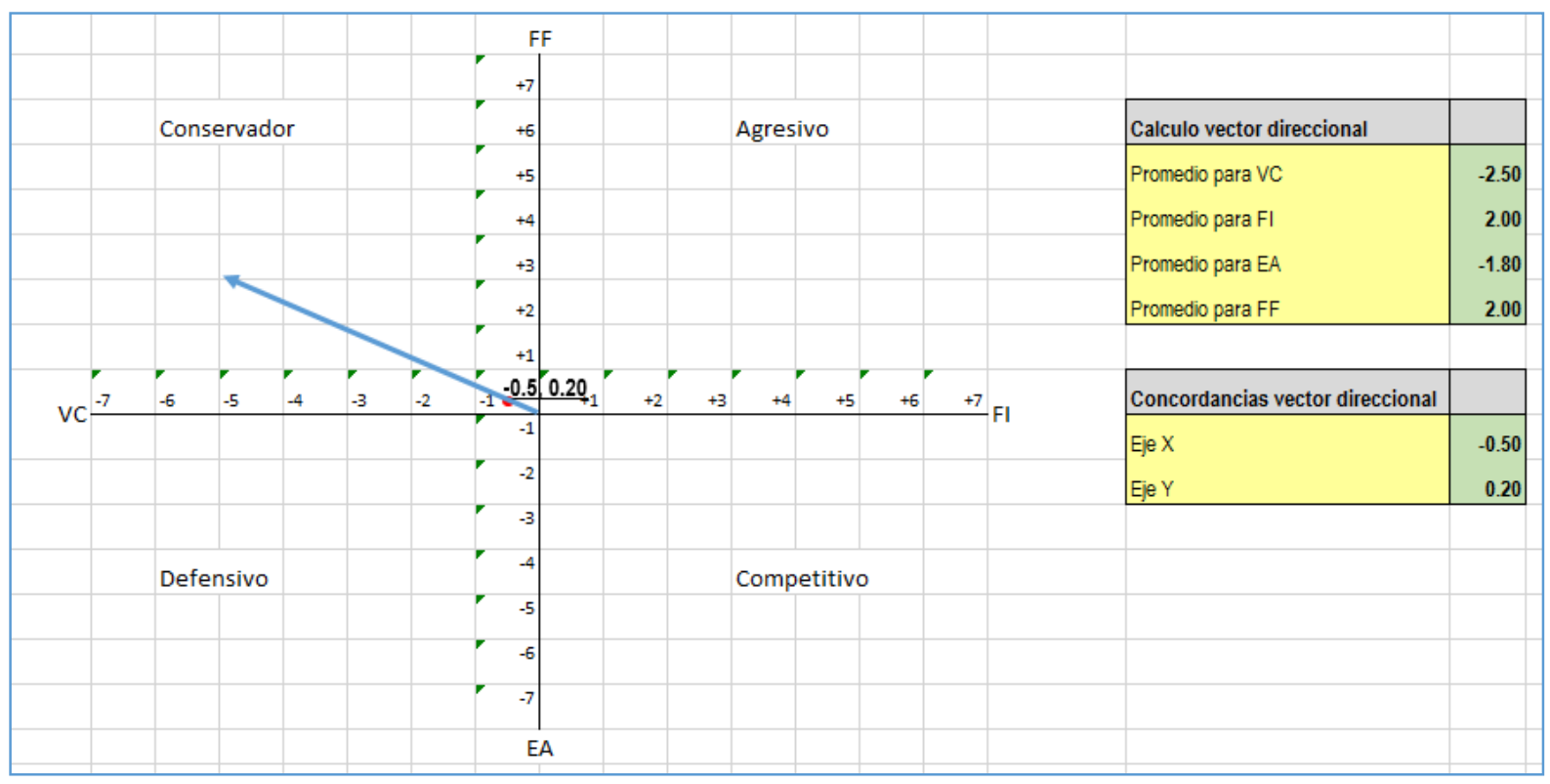

Figura 20. Matriz PEYEA. Adaptado de "Conceptos de Administración estratégica” (p. 205) por David, Fred, 2013, México: Editorial Pearson. Copyright 2013 Editorial Pearson.

Como resultado del análisis de los factores considerados se ha obtenido un valor para el eje X de - 0.50 y para el eje Y de 0.20. Al plasmar estas coordenadas en el gráfico se puede apreciar que el vector direccional aparece en el cuadrante de conservador. De acuerdo con lo mencionado por David (2013), el cuadrante conservador implica que se debe de aprovechar las capacidades básicas de la empresa sin tomar riesgos excesivos.

Como estrategias que se pueden aplicar está la de desarrollo de mercado, repotenciando las líneas de negocio existentes como BA y Mobile y aprovechando la demanda creciente justificada por las actuales tendencias tecnológicas. Para las empresas de gran envergadura es imperativo el incorporar soluciones tecnológicas que involucren el análisis de grandes volúmenes de información (para la toma de decisiones gerenciales) y que brinden flexibilidad a sus colaboradores en la realización de sus labores cotidianas. En ese sentido, las soluciones de aplicaciones móviles son las más solicitadas.

Otra estrategia compatible con este cuadrante es el desarrollo de productos o servicios y la penetración de mercados. La empresa puede elaborar una estrategia de creación de una 
nueva línea de negocio que permita la captación de clientes de un sector del mercado en el que originalmente no se estaba enfocando, como es el de las empresas catalogadas como Pymes. Estas empresas se caracterizan mayormente en tener sistemas integrados de gestión o ERP's que no necesariamente son de SAP, y sobre los cuales se necesitan también soluciones en tecnología de información. Entre las soluciones más solicitadas están las de aplicaciones Web en la nube, que permiten portabilidad, y desarrollo de aplicaciones móviles sobre todo para su fuerza de ventas. La empresa tiene como una de sus fortalezas la experiencia y el conocimiento de estas tecnologías, orientadas actualmente a empresas con el ERP SAP, pero que pueden ser aprovechadas perfectamente en beneficio o desarrollo de este nuevo mercado al que apunta.

Como diversificación concéntrica podría también aprovechar el conocimiento técnico reconocido de su personal, que junto a la capacidad de análisis de sus arquitectos podrían ser explotados bajo un enfoque de brindar capacitaciones orientadas a procesos internos de las empresas que los requieran. En este punto, la diferenciación de lo que ofrece el mercado actualmente está en el enfoque de procesos y no de módulos SAP, cambiando la orientación vertical de los mismos por una horizontal que es lo que más demandan las empresas que desean que el conocimiento se quede en la organización. Actualmente, los cursos propuestos en el mercado sólo se centran en la especialización de la herramienta técnica enfocada en el área a la que da soporte, dejando de lado un enfoque más holístico en donde se pueda visualizar todos los actores que intervienen en un proceso determinado y en donde las automatizaciones pueden ser diversas.

\subsubsection{Matriz interna externa.}

Esta matriz también es conocida como la matriz multifactorial. De acuerdo con lo mencionado en Chiavenato \& Sapiro (2011), la matriz multifactorial evalúa las líneas de 
negocio de la empresa de acuerdo a dos dimensiones: la actividad del sector y la capacidad potencial para competir.

Para la primera dimensión se debe evaluar los resultados obtenidos en la matriz EFE (factores externos). El atractivo del sector se califica como alto, mediano o bajo. Dentro de esta evaluación se toman en cuenta criterios como el tamaño del sector, el crecimiento de este, la competencia y número de competidores.

Para la segunda dimensión se debe evaluar los resultados obtenidos en la matriz EFI (factores internos). La capacidad potencial se califica como alta, mediana o baja. En esta evaluación se han tomado en cuenta criterios como participación del mercado, solidez financiera, nivel de tecnología, investigación y desarrollo de procesos.

Esta matriz genera seis cuadrantes y dependiendo de los valores obtenidos en cada eje se especifica el cuadrante al que pertenece. La Figura 21 muestra dichos cuadrantes en la matriz:

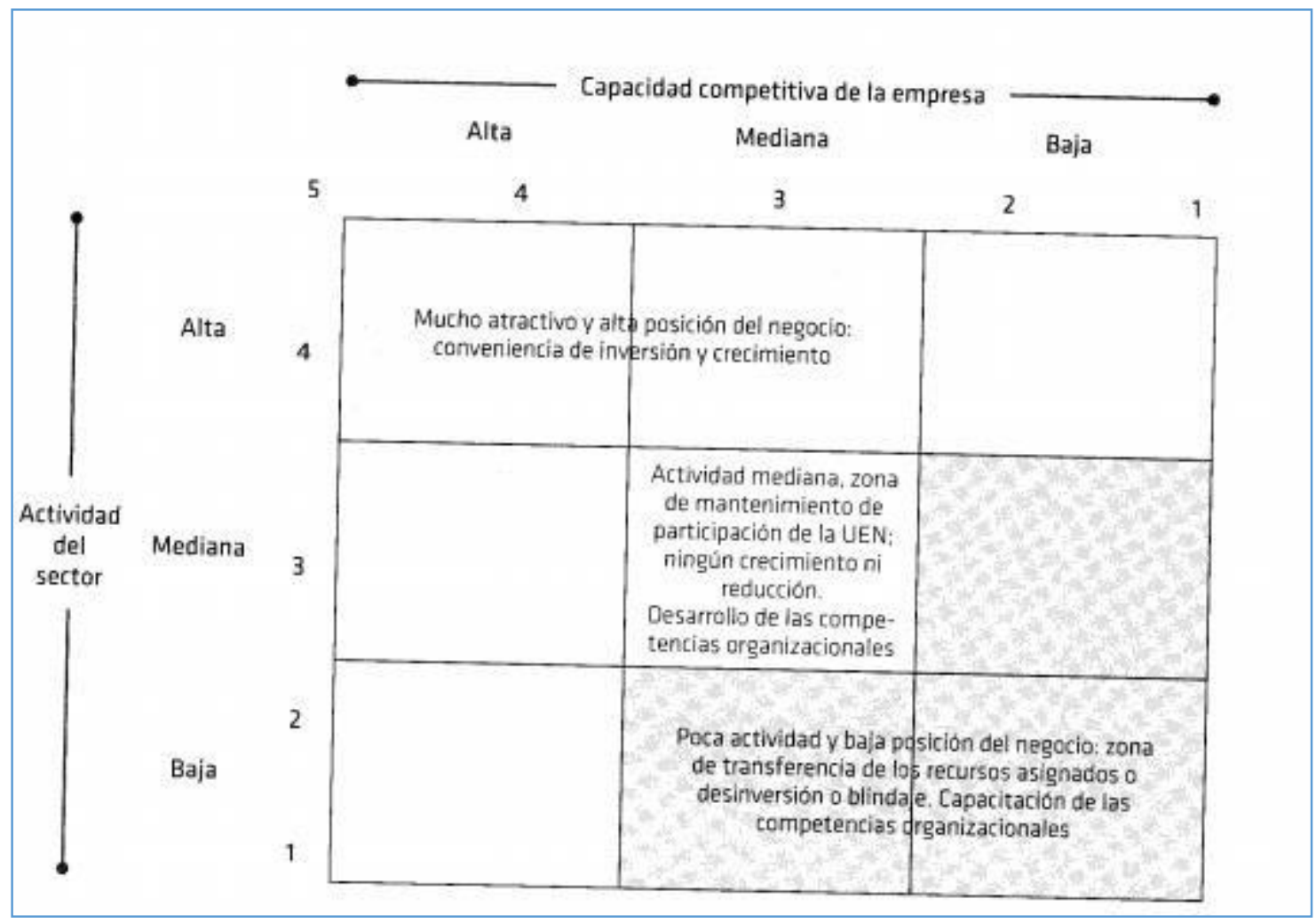

Figura 21. Matriz Multifactorial. Tomado de "Planeación estratégica" (p. 165) por Chiavenato \& Sapiro, 2011, España: Editorial McGraw Hill. Copyright 2011. 
La interpretación de la matriz se debe hacer tomando los bloques de la diagonal que va desde el cuadrante inferior izquierda hasta el superior derecho. Ese bloque lo conforman negocios de fuerza media. Los bloques por encima de esa diagonal lo conforman negocios fuertes en los que se debe de invertir y los bloques por debajo de la diagonal son los de menor fuerza y en los cuales no se debe invertir.

Siguiendo este marco teórico, se ha procedido a realizar la matriz interna-externa o multifactorial de la empresa Xternal Technological Solutions S.A.C. Tomando como referencia los resultados obtenidos por las matrices EFI y EFE, explicadas en el capítulo anterior, el cuadrante en donde se encuentra actualmente la empresa se puede visualizar en la figura 22.

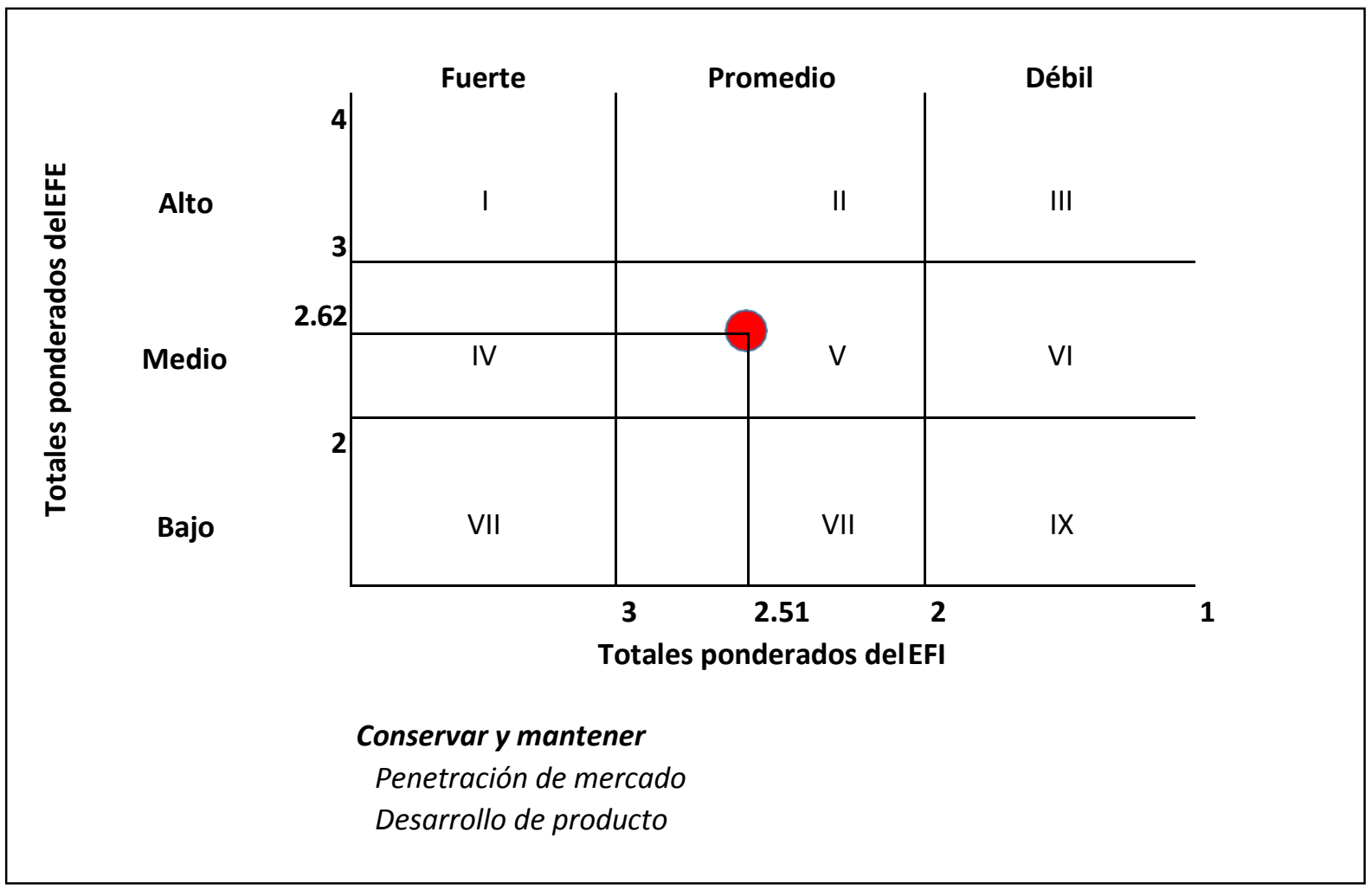

Figura 22. Matriz Interna-Externa. Adaptado de "Planeación estratégica" (p. 165) por Chiavenato \& Sapiro, 2011, España: Editorial McGraw Hill. Copyright 2011.

En el cuadrante V, en donde se encuentra actualmente la empresa, las estrategias que mejor se adaptan son las de conservar y mantener. Para ello, las estrategias de penetración de 
mercado y la de desarrollo de producto son las más adecuadas. Esto coincide con las estrategias planteadas como resultado de la evaluación de la matriz PEYEA y las del FODA.

Respecto a la estrategia de penetración de mercado, se ha planteado el potenciamiento de las líneas de negocio de BA y Mobile, enfocándose en las empresas pertenecientes o catalogadas como Pymes. La realidad de estas empresas permite el desarrollo de soluciones orientadas al análisis de datos y movilidad independientemente del ERP que estén usando.

Respecto al desarrollo de productos/servicios, se ha planteado la creación de una línea de negocio orientada a soluciones diversas fuera del sistema SAP (actual punto de referencia de la empresa). Esto permitirá aprovechar la fortaleza interna con la que cuenta la empresa y que es la experiencia y conocimiento reconocido de su personal técnico. Este tipo de soluciones están orientadas a captar una mayor demanda de las empresas Pymes.

Adicionalmente, se ha planteado la creación de una línea de negocio orientada a brindar servicios de capacitación, en primera instancia orientadas al sistema SAP (del cual tienen reconocida experiencia) pero con una diferenciación en el enfoque de procesos. Actualmente, el mercado ofrece este tipo de capacitaciones a nivel de los módulos del SAP, pero no direccionado o personalizado a los perfiles de puestos o procesos internos de las empresas. Esto podría aprovechar la demanda creciente de este tipo de capacitaciones, sobre todo en empresas de gran envergadura.

\subsubsection{Matriz boston consulting group.}

“La matriz BCG (Boston Consulting Group) de crecimiento-participación es la forma más sencilla de representar el portafolio de inversiones de una empresa" (Hunger \& Wheeler, 2013). De acuerdo con lo señalado por estos autores, se debe de ubicar en la matriz cada línea de negocio o producto de la empresa de acuerdo con la tasa de crecimiento de la industria en donde se desenvuelve y la participación de estos en el mercado. A fin de determinar en qué 
posición se encuentra una línea de negocio determinada respecto al eje correspondiente a la participación de mercado, se debe dividir la participación relativa de la empresa sobre la de su mayor competidor. Si es mayor o igual a 1 se determina que la empresa es líder del mercado. El eje de tasa de crecimiento de negocio es igual al porcentaje de crecimiento del mercado. Esto está determinado sobre el nivel de ventas que alcanza determinada línea de negocio.

La matriz muestra cuatro clasificaciones que se les da a las líneas de negocio o producto de acuerdo con cómo se visualizan dentro de la matriz:

- Signos de interrogación, aquellos que productos que tienen muchas posibilidades de éxito pero que requieren de una fuerte inversión para desarrollarse.

- Estrellas, líderes del mercado y en el mejor momento de su ciclo de vida.

- Vacas lecheras, aquellos que generan más dinero del que necesitan para mantenerse en el mercado.

- Perros, aquellos que tienen baja participación en el mercado y que se encuentran en un mercado poco atractivo.

La figura 23 muestra la matriz BCG: 


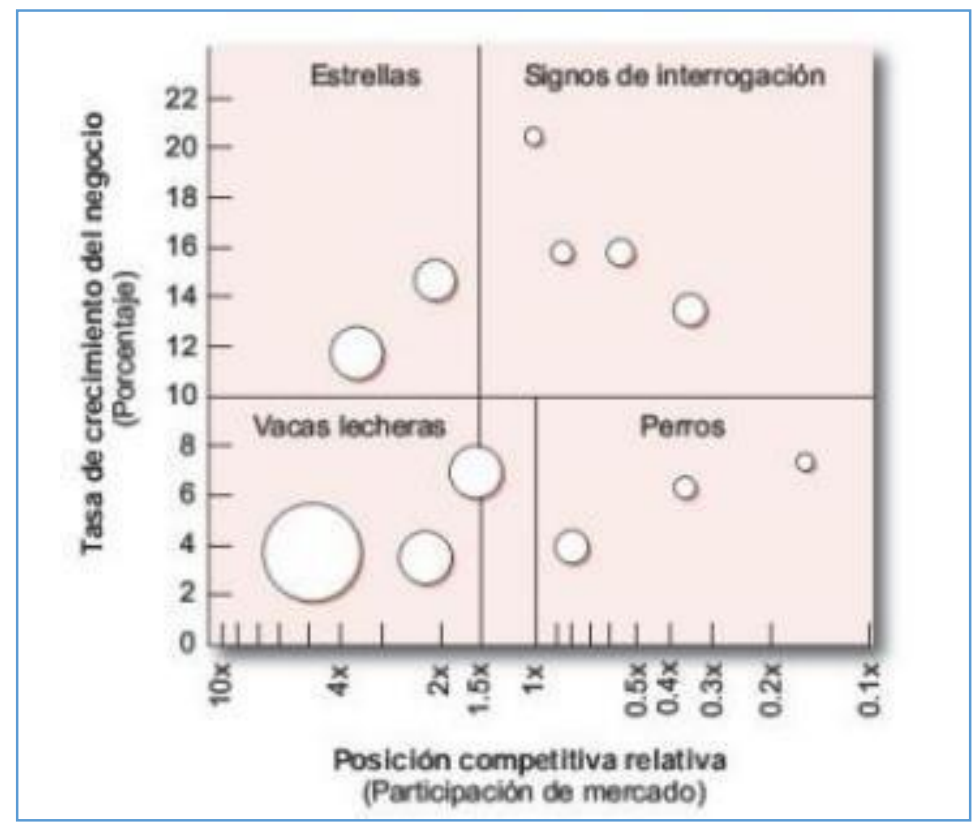

Figura 23. Matriz BCG. Tomado de "Administración estratégica y política de negocios" (p. 239) por Hunger \& Wheeler, 2013, Colombia: Editorial Pearson.

Copyright 2013 Editorial Delfin Ltda.

De acuerdo con el marco teórico que se ha descrito con anterioridad, se ha procedido a realizar la matriz BCG para la empresa Xternal Technological Solutions S.A.C. Para poder ubicar el servicio de consultoría que brinda la empresa en la coordenada correcta a la que pertenece, se han tomado en cuenta información proporcionada por la misma empresa como facturación anual y la facturación generada en la industria de software peruano (datos obtenidos de APESOFT (2014)). Adicionalmente, el nivel de crecimiento de la industria ha sido obtenido de un informe de gestión (2016), basado en una proyección de la empresa VBG Sistemas. La tabla 29 muestra los datos anteriormente descritos y que son la base para la clasificación de su servicio en la matriz. 
Tabla 29

Ventas y participación de Xternal Technological Solutions S.A.C. en la industria del software peruana

\begin{tabular}{lcccccccc}
\hline & $\begin{array}{c}\text { Ventas } \\
\text { Xternal } \\
2015 \\
\text { (Millones } \\
\text { de \$) }\end{array}$ & $\begin{array}{c}\text { Ventas } \\
\text { Xternal } \\
2016 \\
\text { (Millones } \\
\text { de \$) }\end{array}$ & $\begin{array}{c}\text { Ventas } \\
\text { Referente } \\
\text { Industria } \\
\text { (Millones } \\
\text { de \$) }\end{array}$ & $\begin{array}{c}\text { Ventas } \\
\text { industria } \\
\text { (Millones } \\
\text { de \$) }\end{array}$ & $\begin{array}{c}\text { Market } \\
\text { Share } \\
\text { Xternal } \\
(\%)\end{array}$ & $\begin{array}{c}\text { Market } \\
\text { Share } \\
\text { Referente } \\
(\%)\end{array}$ & $\begin{array}{c}\text { PRM } \\
(\%)\end{array}$ & $\begin{array}{c}\text { Tasa } \\
\text { crecimiento } \\
\text { industria } \\
(\%)\end{array}$ \\
$\begin{array}{l}\text { Servicio } \\
\begin{array}{l}\text { Consultoría } \\
\text { /desarrollo } \\
\text { de software }\end{array}\end{array}$ & 0.59 & 0.6 & 20 & 450 & 0.13 & 4.4 & 0.03 & $15 \%$ \\
\hline
\end{tabular}

Con estos valores se ha podido ubicar el cuadrante al que pertenece el servicio prestado por la empresa, el cual es mostrado en la figura 24.

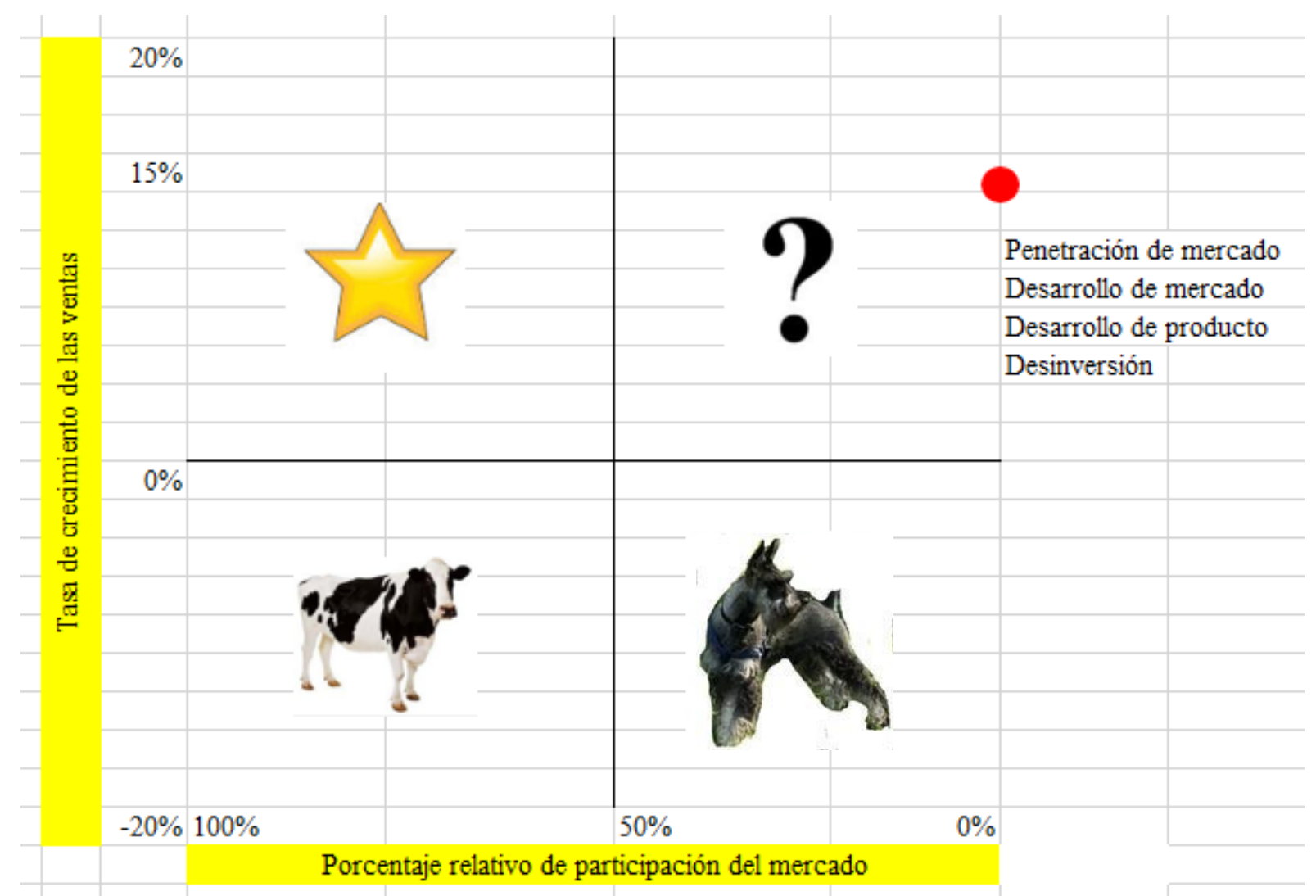

Figura 24. Matriz BCG de la empresa Xternal Techological Solutions S.A.C. Adaptado de "Administración estratégica y política de negocios" (p. 239) por Hunger \& Wheeler, 2013, Colombia: Editorial Pearson. Copyright 2013 Editorial Delfin Ltda.

Como se aprecia en la matriz anterior, el servicio proporcionado por la empresa

Xternal Technological Solutions S.A.C. se ubica en el cuadrante I que corresponde a las llamadas interrogantes o incógnitas. De acuerdo con el marco teórico ya explicado 
anteriormente, las estrategias que pueden aplicar las empresas que pertenecen a este cuadrante son la de penetración de mercado, desarrollo de mercado, desarrollo de producto/servicio o desinversión.

Las estrategias mencionadas coinciden con el planteamiento propuesto en matrices anteriores (Interna-Externa, FODA, PEYEA), en donde se está haciendo énfasis en el repotenciamiento de su línea de negocio de BA y Mobile para penetrar en el mercado, y el desarrollo de dos líneas de negocio adicionales de soluciones diversas y capacitación para contribuir al desarrollo de un mercado orientado a las pymes.

\subsubsection{Matriz de la gran estrategia.}

De acuerdo con lo mencionado por David (2013), la matriz de la gran estrategia se basa en dos dimensiones evaluativas: la posición competitiva y el crecimiento del mercado.

Este es un instrumento de común uso para la formulación de estrategias alternativas. En esta matriz se aprecian cuatro cuadrantes, en donde las estrategias son agrupadas y clasificadas de acuerdo con el nivel de atractividad.

En la figura 25 se aprecian las estrategias de acuerdo con los cuadrantes descritos anteriormente: 


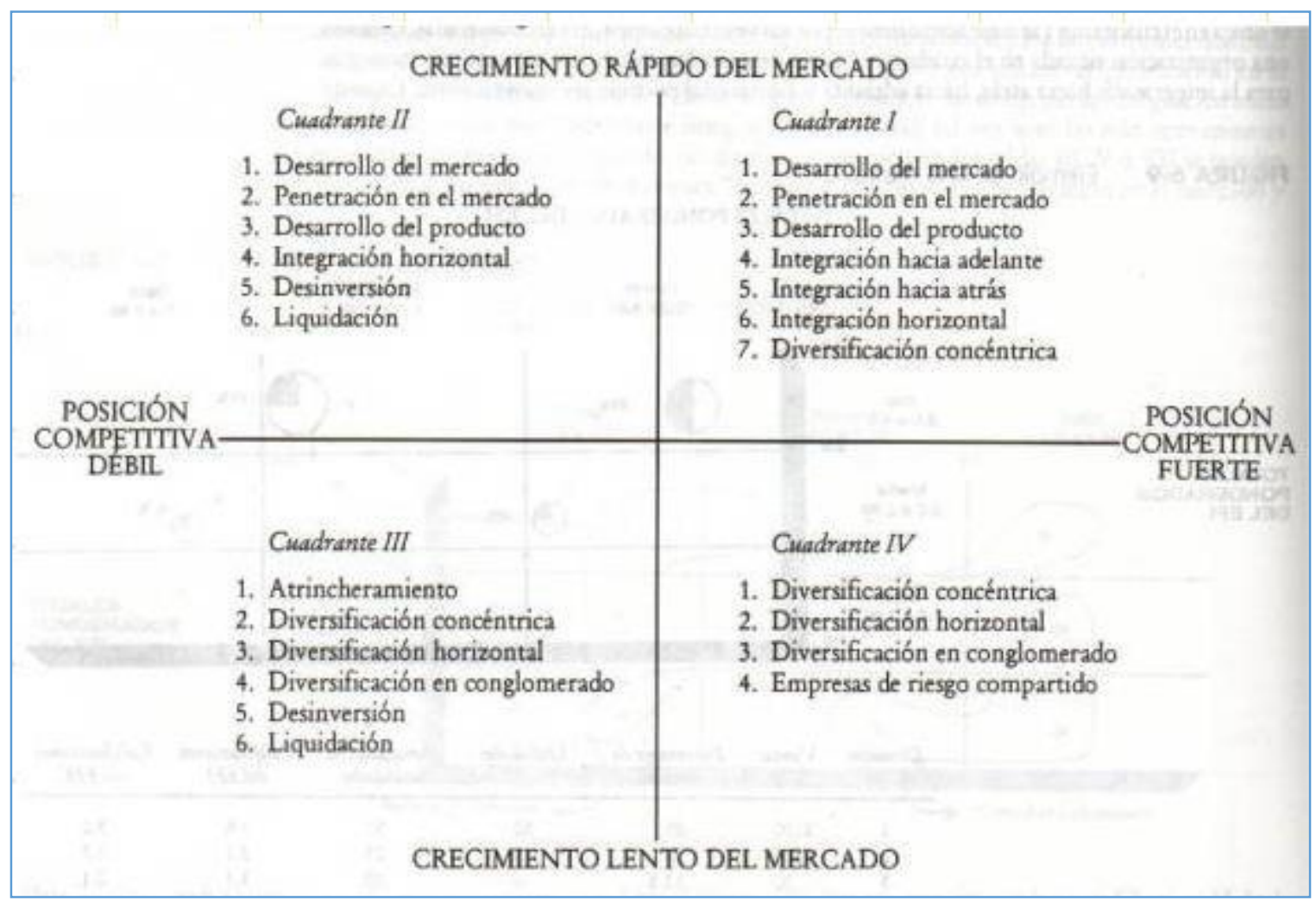

Figura 25. Matriz de la gran estrategia. Tomado de "Administración estratégica" por David, 2013, Editorial Pearson. Copyright 2013

Siguiendo este marco teórico se ha representado la matriz de la gran estrategia para la empresa Xternal Technological Solutions S.A.C. La figura 26 muestra el cuadrante al que pertenece la empresa. 


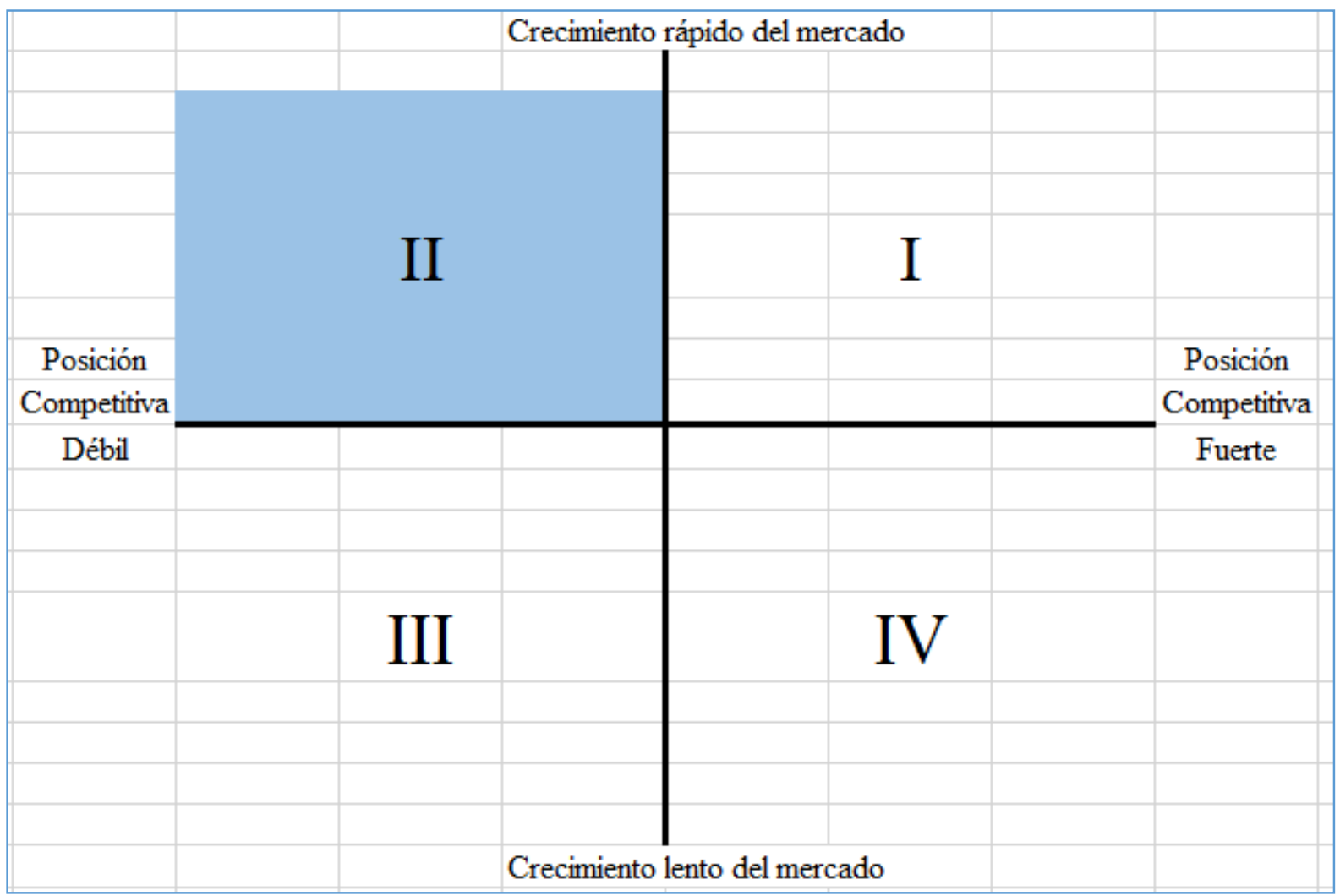

Figura 26. Matriz de la gran estrategia de Xternal Technological Solutions S.A.C. Adaptado de "Administración estratégica" por David, 2013, Editorial Pearson. Copyright 2013

Al igual que las matrices anteriores, las estrategias sugeridas en este cuadrante coinciden con las ya planteadas anteriormente. Las estrategias para aplicar son las de desarrollo de mercado, penetración de mercado y desarrollo de producto.

\subsection{Resumen de las Estrategias Formuladas}

Luego de analizar cada una de las matrices FODA, PEYEA, IE, BCG, y la Gran Estrategia, se ha coincidido en que las estrategias que se deben de aplicar son las de penetración de mercado y desarrollo de mercado. Se ha considerado que estas dos estrategias contribuirían en gran manera en la consecución de los objetivos estratégicos alineados a la misión, visión y valores propuestos para la empresa. 


\section{Penetración de mercado}

Dentro de lo que se ha planteado como estrategia de penetración de mercado se encuentra la repotenciación de las líneas de negocio de BA y Mobile. Las empresas de gran envergadura están siguiendo las tendencias tecnológicas de análisis de datos (grandes volúmenes de información) y flexibilidad en sus procesos internos para darles facilidades a sus colaboradores. Esto vislumbra una oportunidad en la que tiene que estar preparada para responder, sobre todo cuando los sectores en donde se encuentran sus clientes principales se están recuperando económicamente y en donde se proyecta un aumento en la inversión privada respecto a soluciones de tecnología de información.

Asimismo, estas dos líneas de negocio pueden ampliarse a fin de abarcar empresas de menor envergadura, como las pymes que disponen de sistemas de gestión empresarial o ERP's de menor inversión, pero que necesitan de tableros de control que los ayuden a saber en qué situación se encuentran y los ayuden a tomar decisiones que les permita crecer y ser sostenibles en el tiempo. El dinamismo propio de estas empresas permite ofrecer soluciones de portabilidad móviles que se adecúan perfectamente a sus necesidades.

Por estos motivos, estas dos líneas de negocio deben ser ampliadas mediante la contratación de personal experto y mediante la compra de herramientas de desarrollo y equipos que les permitan captar toda esa demanda insatisfecha existente en esa clase de empresas.

\section{Desarrollo de mercado}

Esta es otra de las estrategias planteadas que permitirá captar un mercado aún no explorado por la empresa Xternal Technological Solutions S.A.C. Esta estrategia consiste en la creación de una línea de negocio orientada a desarrollos diversos para PYMES, los cuales pueden abarcar soluciones web, aplicativos móviles e incluso BA. Lo que se está proponiendo es el aprovechar la fortaleza de la empresa en lo que se refiere a las 
competencias técnicas de sus colaboradores y reconocida en el mercado, a fin de brindar servicios que puedan satisfacer las demandas de ese tipo de empresas. Lo que se está buscando es aumentar el nivel de ingresos de la empresa, partiendo por un incremento en la participación de la industria del software nacional.

Adicionalmente, a manera de diversificación concéntrica, se está planteando la creación de una línea de negocio dedicada a la capacitación. El objetivo es diferenciarse de sus principales competidores quienes también ofrecen el mismo servicio, pero con un enfoque modular dentro del sistema SAP R/3. La capacitación que se propone tiene una orientación más holística, orientada a los procesos internos de las organizaciones, y tocando todos los puntos de automatización que existen en ellos. De esta manera, el colaborador capacitado podrá ubicarse de mejor manera dentro de la organización sabiendo de antemano quienes son los que proporcionan la información y de qué automatización proviene la misma para realizar sus labores cotidianas, y a quienes afecta o quienes dependen de la información que ellos trabajan. Con ello, se espera tener cursos que pueden tocar diversos módulos de SAP, y que garanticen que el conocimiento se mantenga dentro de la organización no dependiendo del colaborador en el caso que decida retirarse de la empresa.

Este tipo de capacitaciones son cada vez más requeridas en organizaciones de gran envergadura y que tienen como valor fundamental la excelencia en sus procesos internos. 


\section{Capítulo VIII: Selección de la Estrategia}

\subsection{Método de Factores Estratégicos Claves}

En este capítulo se analizará las diferentes matrices y los métodos de selección, se aplicará el método de escenarios y la matriz de planificación estratégica cuantitativa (MPEC), para la estrategia seleccionada y la de contingencia.

Según David (2013), para la formulación de las estrategias es necesaria la integración de las distintas técnicas las cuales a través de un modelo de toma de decisiones puede realizar en tres etapas como se muestra en la figura 27.

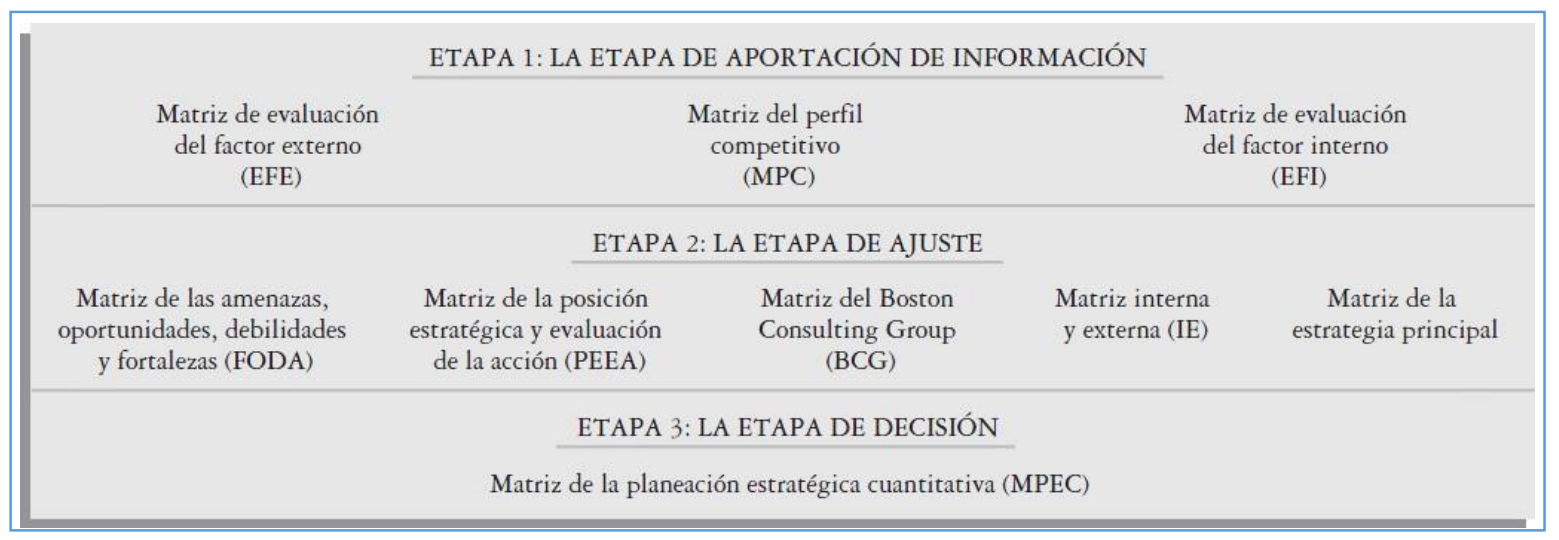

Figura 27. Modelo analítico para la formulación de estrategias. Tomado de "Conceptos de administración estratégica” por David, 2013, Editorial Pearson. Copyright 2013

De acuerdo con este modelo de toma de decisión en la primera etapa, llamada también Etapa de Insumos se consideran la Matriz de evaluación de factores externos, Matriz de evaluación de factores internos y Matriz de Perfil competitivo, de donde se obtiene la información básica para el diseño de estrategias.

Posteriormente durante la segunda etapa, conocida como Etapa de Adecuación, se analizan las matrices FODA, PEYEA, BCG, Matriz interna-externa y la Matriz de la estrategia principal o gran estrategia de manera de poder generar estrategias alternativas factibles, esto se realiza alineando los factores internos y externos que puedan ser considerados factores claves. 
Por último, en la Etapa de Decisión, última etapa del modelo de toma de decisiones, se utiliza la información obtenida en la primera etapa para evaluar las estrategias alternativas identificadas en la etapa 2, realizada a través de la Matriz Cuantitativa de la Planificación Estratégica (MCPE).

\subsubsection{Criterios de selección.}

Para determinar los criterios de selección se ha tomado en cuenta lo analizado anteriormente en la matriz FODA, de donde se obtiene la información necesaria de las Fortalezas y Debilidades de la empresa Xternal Technological Solutions S.A.C., así como las Oportunidades y Amenazas que existan en el ambiente externo donde compite la empresa.

Como parte complementaria de la matriz FODA, la información necesaria puede obtenerse de las matrices de evaluación de factores externos e internos, las matrices EFE y EFI, de este modo se busca determinar los factores clave que pueden ser aprovechados y mejorarlos así como también los puntos débiles que están afectando a la empresa y tomar las acciones necesarias para mitigar su impacto, del mismo modo tratar las amenazas de manera que se puedan tomar las precauciones para que no afecten en la consecución del éxito esperado.

\subsubsection{Matriz de selección.}

De acuerdo con el análisis de las matrices anteriormente presentadas, se ha podido determinar los criterios de selección o factores claves que servirán para poder elegir la estrategia que presenta mejores beneficios para su posterior implementación. En la siguiente tabla se puede observar la valoración de cada uno de estos criterios con relación a las estrategias propuestas (1 Muy débil; 2 Débil; 3 Regular; 4 Fuerte; 5 Muy Fuerte.). Los criterios de selección y sus respectivos pesos han sido determinados de acuerdo al juicio de expertos en las entrevistas a profundidad realizadas (ver Anexo 2). 
Tabla 30

Matriz de Selección

$\begin{array}{cc}\text { Potenciar } & \begin{array}{c}\text { Desarrollar línea de } \\ \text { BA/Mobile }\end{array} \\ \text { Con enfocio soluciones } \\ \text { diversas pymes y } \\ \text { capacitación }\end{array}$

\begin{tabular}{|c|c|c|c|c|c|}
\hline $\mathrm{N}^{\circ}$ & $\begin{array}{l}\text { Criterios de } \\
\text { Seleccion }\end{array}$ & Peso & $\begin{array}{c}\text { E1: } \\
\text { Penetración } \\
\text { de Mercado }\end{array}$ & P.P & $\begin{array}{l}\text { E2: } \\
\text { Desarrollo de P.P } \\
\text { Mercado }\end{array}$ \\
\hline
\end{tabular}

\begin{tabular}{|c|c|c|c|c|c|c|}
\hline 1 & $\begin{array}{l}\text { Participación de } \\
\text { Mercado }\end{array}$ & 0.15 & 4 & 0.6 & 5 & 0.8 \\
\hline 2 & $\begin{array}{l}\text { Personal Técnico } \\
\text { Especializado }\end{array}$ & 0.2 & 5 & 1 & 5 & 1 \\
\hline 3 & $\begin{array}{l}\text { Infraestructura } \\
\text { instalada }\end{array}$ & 0.1 & 4 & 0.4 & 3 & 0.3 \\
\hline 4 & $\begin{array}{l}\text { Inversión para } \\
\text { Implementación }\end{array}$ & 0.1 & 3 & 0.3 & 1 & 0.1 \\
\hline 5 & $\begin{array}{l}\text { Satisfacción del } \\
\text { Cliente } \\
\text { Demanda de }\end{array}$ & 0.2 & 4 & 0.8 & 3 & 0.6 \\
\hline 6 & $\begin{array}{l}\text { Servicios } \\
\text { Capacidad }\end{array}$ & 0.15 & 3 & 0.5 & 5 & 0.8 \\
\hline 7 & Financiera & 0.1 & 3 & 0.3 & 1 & 0.1 \\
\hline & $\begin{array}{l}\text { Clasificación de } \\
\text { Fortaleza General }\end{array}$ & 1 & & 3.9 & & 3.6 \\
\hline
\end{tabular}

Como se puede observar en la tabla 30, la estrategia de Penetración del Mercado es la que presenta más fortalezas por lo que debe tomarse atención en las acciones necesarias para la implementación de la estrategia.

\subsection{Método de Escenarios}

Según Chiavenato \& Sapiro (2011), el método de escenario nos sirve para construir diferentes imágenes y visiones alternativas favorables y desfavorables del ambiente futuro de los negocios. El objetivo principal de la construcción de escenarios es adaptar la estrategia de la organización con los objetivos que se busca lograr a futuro, a la vez sirve para evaluar 
premisas, explorar potenciales futuros y crear nuevos caminos, los cuales serán realizados para la toma de decisiones de hoy, para el logro de este método es importante preparar a las personas y las organizaciones para que identifiquen las señales de cambio antes de que se manifiesten plenamente. Con esta tarea se pretende reconocer los hechos, las tendencias y las estructuras subyacentes que fundamentan esas percepciones del futuro.

Hechos: Son visibles y perceptibles, los que ocurren.

Tendencias: Son los patrones de cambio que se identifican y que explican las dinámicas de los hechos.

Estructuras subyacentes: Proporcionan la referencia lógica de las tendencias que se identifican. La incertidumbre surge cuando las diferentes interpretaciones sobre las estructuras subyacentes explican las tendencias, pues provocan diferentes teorías de causa y efecto y producen diferentes perspectivas del futuro.

El futuro se clasificará en dos escenarios y se evaluará las posibles opciones que se encuentren en ellas.

\subsubsection{Descripción de escenarios considerados.}

Escenario 1 - Al 2022 (Conservador)

La actual política y económica del país se mantiene, a pesar de haber tenido un importante crecimiento a nivel comparativo, el Perú deja de ser uno de los más atractivos dentro de la región.

Se han tomado los valores de la proyección del crecimiento del PBI del estudio preparado por Apoyo. (Ver Tabla 31)

Sin embargo, el banco de inversión Credit Suisse aumentó su pronóstico de crecimiento para la economía peruana en el 2018 a 4.1\% desde una proyección anterior de $3.7 \%$. 
Tabla 31

Proyección de PBI escenario conservador

\begin{tabular}{cc}
\hline Año & PBI \\
\hline 2018 & $5.0 \%$ \\
2019 & $5.0 \%$ \\
2020 & $4.9 \%$ \\
2021 & $4.9 \%$ \\
2022 & $4.9 \%$ \\
\hline
\end{tabular}

Escenario 2 - Al 2022 (Pesimista)

El crecimiento del PBI se desacelera, los inversionistas extranjeros orientan sus recursos hacia otros países y las empresas retraen su inversión local.

Se ha tomado como referencia la proyección del crecimiento del PBI del estudio preparado por Apoyo Consultoría: "Estudio de proyecciones del PBI de largo plazo y la demanda de potencia y energía de principales proyectos 2011-2022”, en su proyección del escenario pesimista. Ver Tabla 32.

“El principal reto del gobierno será la recuperación exitosa de la inversión pública a través del impulso fiscal anunciado", indicó Luis Eduardo Falen de Intéligo SAB en una entrevista brindada a Gestión.

La economía fue golpeada por el fenómeno de El Niño, que causó daños en importantes áreas urbanas, y por ese motivo el Producto Bruto Interno (PBI) de los meses de marzo y abril mostrará sendas caídas, señaló Falen. 
Tabla 32

Proyección de PBI escenario pesimista

\begin{tabular}{cc}
\hline Año & PBI \\
\hline 2018 & $3.5 \%$ \\
2019 & $4.0 \%$ \\
2020 & $4.0 \%$ \\
2021 & $3.9 \%$ \\
2022 & $3.9 \%$ \\
\hline
\end{tabular}

Escenario 3 - Al 2022 (Optimista)

Los indicadores macroeconómicos se mantienen positivos y se cumplen con holgura los objetivos y proyecciones trazadas en el marco macroeconómico multianual. La tasa de crecimiento del PBI para el 2018 es de 6.4\%, para el 2019 es de 6.4\%, para el 2020 es de $6.3 \%$, para el 2021 es de $6.3 \%$ y para el 2022 es de $6.2 \%$. Ver Tabla 33.

El nivel de confianza de los inversionistas locales, extranjeros y del consumidor se mantiene en un nivel positivo.

Tabla 33

Proyección de PBI escenario optimista

\begin{tabular}{cc}
\hline Año & PBI \\
\hline 2018 & $6.4 \%$ \\
2019 & $6.4 \%$ \\
2020 & $6.3 \%$ \\
2021 & $6.3 \%$ \\
2022 & $6.2 \%$ \\
\hline
\end{tabular}

\subsubsection{Comparación de estrategias con escenarios.}

Al tener estos tres escenarios, es importante saber cómo las estrategias mencionadas en el capítulo anterior van a implementarse, para poder elegir a la que mejor se adecue y tenga el más alto desempeño. 
En la tabla 34 se puede apreciar los dos escenarios con las posibles estrategias a implementar.

Tabla 34

Escenarios vs posibles estrategias a implementar

\begin{tabular}{llcc}
\hline \multicolumn{1}{c}{ ESTRATEGIAS } & Conservador & $\begin{array}{c}\text { Escenario 2 } \\
\text { Pesimista }\end{array}$ & $\begin{array}{c}\text { Escenario 3 } \\
\text { Optimista }\end{array}$ \\
\hline $\begin{array}{l}\text { E1: Penetración de } \\
\text { Mercado }\end{array}$ & Favorable & Desfavorable & Muy Favorable \\
$\begin{array}{l}\text { E2: Desarrollo de } \\
\text { Mercado }\end{array}$ & Indiferente & Muy desfavorable & Muy Favorable \\
\hline
\end{tabular}

\subsection{Matriz de Planeación Estratégica Cuantitativa MPEC}

Según lo mencionado por David (2013), la matriz de planeación estratégica cuantitativa (MPEC) es una técnica que muestra de manera objetiva cuales son las mejores estrategias alternativas.

En esta matriz se resume lo obtenido en las matrices EFI, EFE y MPC junto con las matrices FODA, PEYEA, IE, BCG y la gran estrategia. La forma de evaluación consiste en evaluar las estrategias obtenidas respecto a los factores clave tanto internos como externos obtenidos con anterioridad.

En esta matriz se visualiza una columna en la parte izquierda que visualiza los factores clave externos e internos y una hilera superior en donde se muestran las estrategias a analizar. El peso de cada factor es el mismo que se tenía en cada matriz EFE y EFI de donde vienen, y luego se procede a la evaluación de la estrategia colocando valores de acuerdo con el nivel de atractividad de esta: 1 - no aceptable, 2 - posiblemente aceptable, 3 probablemente aceptable; 4 - lo más aceptable. Estos valores son multiplicados por los pesos mencionados anteriormente y se obtiene una calificación ponderada.

Finalmente, los resultados de cada factor son sumados obteniendo una calificación total que sirve de guía para la selección de la estrategia a seguir y la contingencia. La tabla 35 
muestra la matriz MPEC de la empresa Xternal Technological Solutions S.A.C., cuyos

resultados provienen de las matrices anteriormente evaluadas.

Tabla 35

Matriz de planeación estratégica cuantitativa (MPEC)

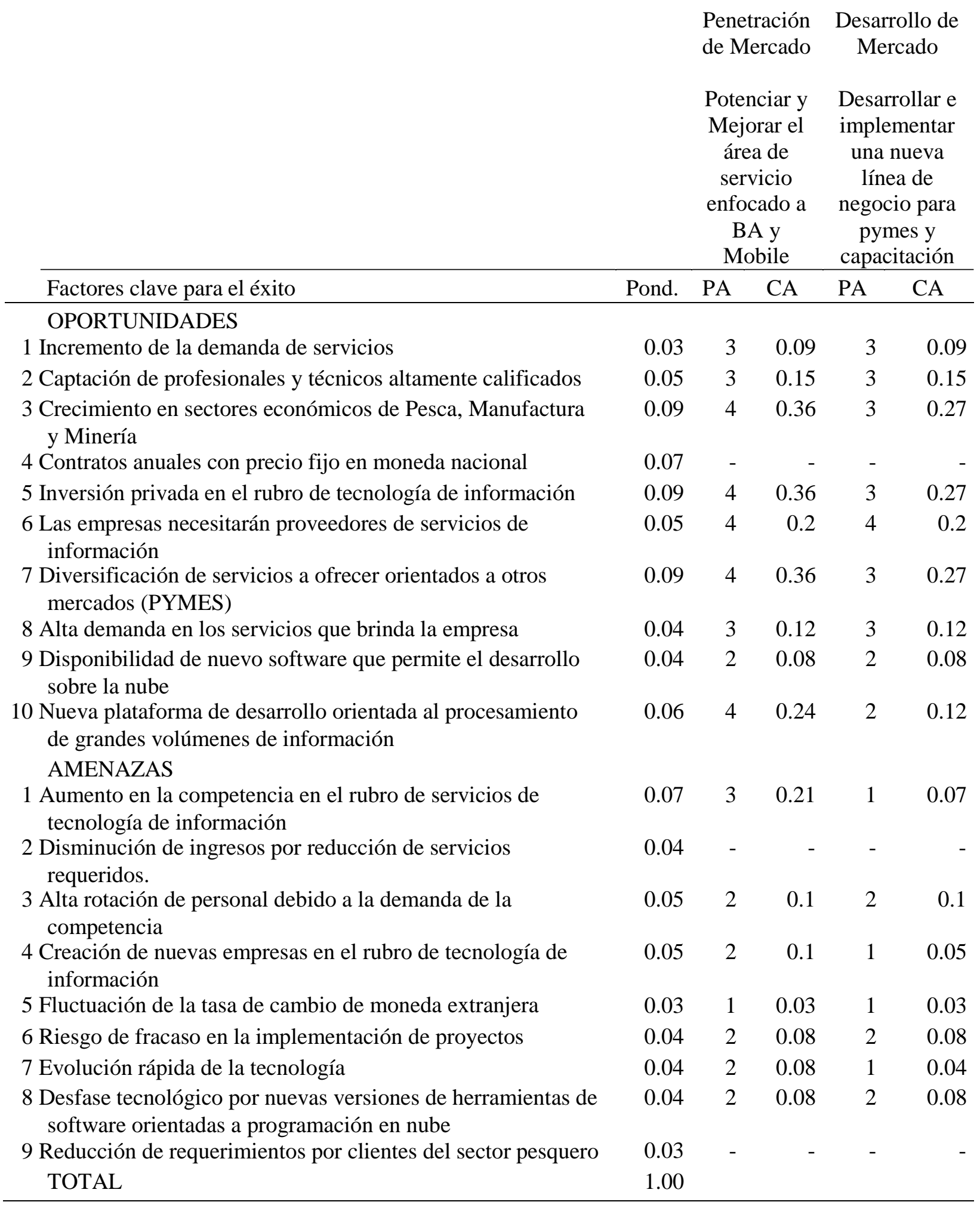


Tabla 35

Matriz de planeación estratégica cuantitativa (MPEC)

\begin{tabular}{|c|c|}
\hline $\begin{array}{l}\text { netración } \\
\text { Mercado }\end{array}$ & $\begin{array}{l}\text { Desarrollo de } \\
\text { Mercado }\end{array}$ \\
\hline Potenciar y & \\
\hline $\begin{array}{l}\text { Mejorar el } \\
\text { área de } \\
\text { servicio }\end{array}$ & $\begin{array}{l}\text { implementar } \\
\text { una nueva } \\
\text { línea de }\end{array}$ \\
\hline enfocado a & negocio para \\
\hline BA & y \\
\hline
\end{tabular}

\begin{tabular}{lrrrrr}
\hline Factores clave para el éxito & Pond. & PA & CA & PA & CA \\
\hline FORTALEZAS & & & & & \\
1 Contrato ventajoso con proveedor de servicios de internet & 0.05 & 3 & 0.15 & 3 & 0.15 \\
$\quad$ para disminuir costos & & & & & \\
2 Servicio post implementación de calidad. & 0.14 & 3 & 0.42 & 3 & 0.42 \\
3 Línea dedicada para atender remotamente a sus clientes. & 0.09 & 3 & 0.27 & 3 & 0.27 \\
4 Personal altamente capacitado para la atención al cliente. & 0.09 & 4 & 0.36 & 4 & 0.36 \\
5 Clima laboral agradable. & 0.05 & - & - & - & - \\
6 Sólida cultura organizacional. & 0.05 & - & - & - & - \\
& & & & & \\
DEBILIDADES & & & & & \\
& & & & & \\
1 Número limitado de recursos de programación. & 0.03 & 3 & 0.09 & 3 & 0.09 \\
2 Falta de delimitación del alcance de su servicio post & 0.05 & 2 & 0.10 & 3 & 0.15 \\
$\quad$ implementación. & & & & & \\
3 Dependencia excesiva de los arquitectos de software. & 0.06 & 2 & 0.12 & 1 & 0.06 \\
4 Desfase de tiempo en la comunicación de los informes de & 0.04 & - & - & - & - \\
$\quad$ avance a los clientes. & & & & & \\
5 Poca experiencia de gestión de negocios de sus directivos & 0.04 & - & - & - & - \\
6 Plana directiva ligada a actividades operativas en la empresa. & 0.06 & 4 & 0.24 & 4 & 0.24 \\
7 Carencia de un plan estratégico para un crecimiento & 0.05 & 4 & 0.2 & 4 & 0.2 \\
$\quad$ sostenido & & & & & \\
8 Carencia de un área dedicada a las ventas y comercialización & 0.06 & 3 & 0.18 & 3 & 0.18 \\
9 Falta de un plan de marketing para sus servicios & 0.02 & 3 & 0.06 & 3 & 0.06 \\
10 Concentración de la cartera de clientes & 0.06 & - & - & - & - \\
11 Manejo empírico del personal. & 0.04 & - & - & - & - \\
12 Falta de políticas de gestión del personal & 0.02 & - & - & - & - \\
$\quad$ TOTAL & 1.00 & & 4.83 & & 4.2 \\
\hline
\end{tabular}




\subsection{Descripción de Estrategia Seleccionada}

\section{Potenciar y mejorar el área de servicio enfocado a BA y mobile}

Esta alternativa significa potenciar el área de BA y mobile, seleccionando expertos para su implementación y poder ofrecer a más clientes esta nueva alternativa tecnológica.

Para el desarrollo de esta estrategia se contará con expertos calificados en esta tecnología, que a su vez capacitarán al personal a su cargo, este nuevo servicio deberá de ser ofrecido por el área de marketing de la empresa.

\subsection{Descripción de Estrategia Contingente}

\section{Desarrollar e implementar una nueva línea de negocio para pymes y}

\section{capacitación}

Esta alternativa significa desarrollar una nueva área dirigida a pymes que necesitan de servicios de tecnología para el crecimiento de su empresa. Esta nueva alternativa permitirá que esta clase de empresas puedan tener soluciones en tecnología de información que lo diferenciará de sus principales competidores.

Para ello, se necesitará realizar una inversión para el desarrollo de esta tecnología y el área de marketing se encargará de promocionar este nuevo giro de negocio.

De igual manera, para la línea de negocio de capacitación se espera una orientación hacia el mercado de las Pymes, orientando el servicio hacia un enfoque de procesos de manera transversal y no el modelo tradicional modular de manera vertical. 


\section{Capítulo IX: Implantación de la Estrategia}

\subsection{Mapa de la Estrategia}

De acuerdo con lo planteado por Kaplan \& Norton (2014), el mapa de la estrategia o cuadro de mando integral (CMI) es una herramienta que hace énfasis en la conversión de la visión y estrategias de la organización en objetivos e indicadores estratégicos. Asimismo, traduce la estrategia junto con la misión de la organización en acciones medibles que proporcionan la estructura necesaria para un sistema de gestión y medición estratégica.

Este cuadro de mando complementa los indicadores financieros tradicionales con los inductores de actuación futura, y observa el comportamiento de la organización desde cuatro perspectivas: la financiera, la de clientes, la de procesos internos y la de formación y aprendizaje.

- Perspectiva financiera: porque es necesario analizar los indicadores financieros para explicar las consecuencias económicas de las acciones realizadas por la organización. Es una manera de contrastar si la estrategia actual, su implementación y ejecución están contribuyendo a la mejora del objetivo mínimo planteado.

- Perspectiva de clientes: porque se necesita identificar los segmentos de clientes en donde se desenvolverá, así como las medidas de cómo va a interactuar con ellos. Esta perspectiva permite la articulación de la estrategia orientada al cliente para que genere los resultados financieros esperados.

- Perspectiva de procesos internos: porque es necesario identificar los procesos internos que más impacto pueden tener en la satisfacción del cliente y por consiguiente en la consecución del resultado financiero. Se basa en que los procesos deben estar en excelencia para proporcionar valor hacia sus clientes y 
se logre la fidelización de este en el segmento de mercado elegido.

- Perspectiva de formación y crecimiento: porque se necesita identificar la infraestructura requerida para la construcción de valor y crecimiento a largo plazo. La formación y crecimiento se obtiene de las personas, los sistemas y los procedimientos de la organización. De esta manera, los objetivos de las perspectivas financiera, de clientes y de procesos internos revelarán las brechas existentes entre las capacidades de las personas, sistemas y procedimientos, para determinar lo que es necesario para alcanzar el objetivo propuesto.

“Esto permitirá un equilibrio entre los objetivos a corto y a largo plazo, entre los resultados que se desean y los inductores de actuación de esos resultados, y entre las medidas objetivas, más duras, y las más suaves y subjetivas" (Kaplan \& Norton, 2014).

Siguiendo este marco teórico propuesto y tomando en cuenta que como resultado de la evaluación de matrices del capítulo anterior se seleccionó la estrategia de Penetración de Mercado", se ha elaborado el mapa de la estrategia o cuadro de mando integral de la empresa Xternal Technological Solutions S.A.C. El objetivo estratégico principal es el de aumentar la rentabilidad de la empresa. La figura 28 muestra el mapa propuesto. 


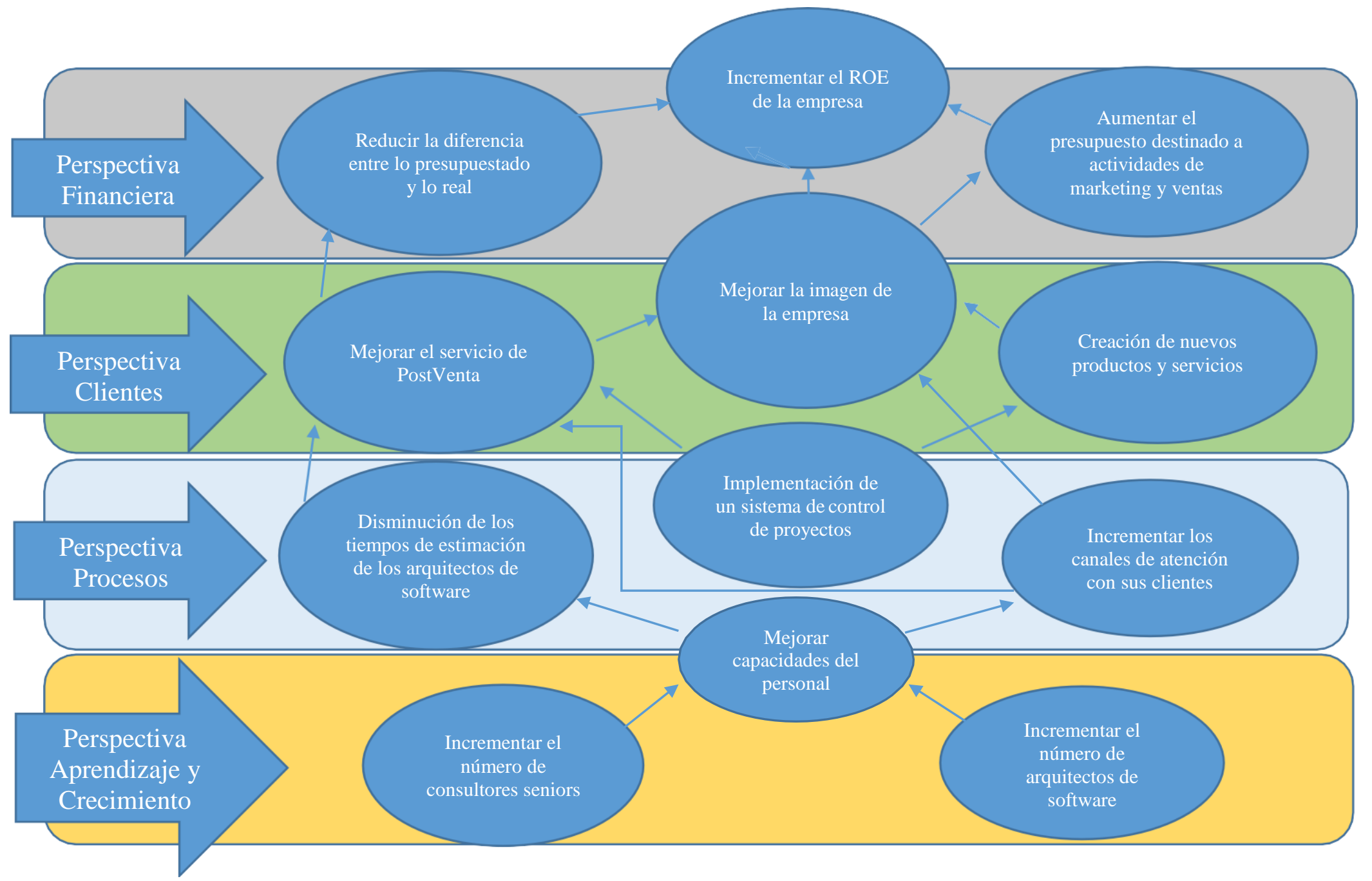

Figura 28. Mapa de la estrategia Xternal Technological Solutions S.A.C. Adaptado de "El cuadro de mando integral" por Kaplan y Norton, 2014, Ediciones Gestión 2000. Copyright 2014 


\subsection{Objetivos específicos según el Mapa de la Estrategia}

A fin de poder alcanzar el objetivo estratégico planteado, correspondiente a aumentar la rentabilidad de la empresa, se han definido los siguientes objetivos específicos por perspectiva del mapa de estrategias:

Perspectiva financiera

- Incrementar el ROE en 11 puntos porcentuales (20\%) en un tiempo de cinco años: este objetivo es perfectamente alcanzable si es que se implementa la estrategia de penetración de mercado, cuya meta es la captación de nuevos mercados repotenciando las líneas de negocio de BA y Mobile pero con un enfoque adicional que es el de incluir empresas catalogadas como pymes. Las proyecciones optimistas de los sectores económicos muestran una tendencia hacia la inversión privada en tecnología de información, lo que genera una oportunidad que se puede aprovechar en la consecución de este objetivo.

- Disminución del porcentaje de desvío entre lo presupuestado y lo real a un 2\% en un tiempo de cinco años: Actualmente el valor es de $8 \%$, lo que demuestra que se puede mejorar a nivel de planificación sobre todo en sus operaciones internas. Una mala planificación en los tiempos de los desarrollos puede hacer incurrir en penalidades no consideradas, al igual que lo referente al personal crítico (una alta rotación puede derivar en la contratación de personal especializado a precios elevados).

- Triplicar el presupuesto destinado a actividades de marketing y ventas en cinco años: es un objetivo fundamental que se alinea a la estrategia de penetración de mercado para obtener nuevos clientes en otros sectores empresariales. Esto implica la creación de un área dedicada exclusivamente a este fin y con experiencia en la captación de clientes en este sector. 
Perspectiva de clientes

- Incrementar el nivel de satisfacción del cliente en 1 punto porcentual por año: se ha planteado como objetivo alcanzar un nivel de satisfacción del 88\% (por encima del $85 \%$ que es el promedio del sector), por lo que este objetivo se alinea en la consecución de esa meta. El valor actual se encuentra en $83 \%$ y está determinado por los resultados de una encuesta realizada el año 2016.

- Incrementar las ventas anuales con un crecimiento sostenido no menor del 10\% anual al finalizar el quinto año: objetivo alcanzable con la captación de nuevos clientes mediante la estrategia planteada y el desarrollo de la línea de desarrollos diversos orientadas al mercado de las Pymes. Esto está alineado al aumento del presupuesto y creación de un área de marketing dedicada a la captación de nuevos clientes.

- Incrementar el porcentaje de clientes en las líneas de BA y Mobile a un 40\% en un tiempo de cinco años: siguiendo la estrategia establecida, este objetivo es perfectamente alcanzable si se repotencia las labores comerciales en la empresa.

Perspectiva de procesos internos

- Disminución de los tiempos de estimación de los arquitectos de software en un $80 \%$ al término del quinto año: este es un objetivo con un impacto directo en la satisfacción de clientes, sobre todo en la modalidad de contratos como fuerza de programación externa. La interacción con los consultores funcionales de las empresas se da a través de los arquitectos de software y en muchos casos se convierten en cuello de botella para la agilización del desarrollo. 
- Implementación de un sistema de control de proyectos en un plazo de un año: que permitirá la optimización de tiempos y recursos utilizados en los proyectos que mantiene la empresa con sus clientes. Se está proyectando que sus clientes también tengan acceso a visualizar el estado de los desarrollos.

- Incrementar los canales de atención con sus clientes en un plazo de un año: mediante la adquisición de una nueva central telefónica que permita tener más anexos para garantizar una comunicación fluida con los arquitectos de software y consultores internos.

Perspectiva de formación y crecimiento

- Triplicar el número de consultores seniors al término del quinto año: este objetivo está alineado directamente a la consecución del objetivo estratégico el poder revalorar su planilla y por consiguiente conseguir mayores ingresos por sus capacidades técnicas.

- Triplicar el número de arquitectos de software al término del quinto año: ofreciendo una línea de carrera atractiva para los consultores seniors de la empresa y mediante la captación de nuevos profesionales con esta experiencia en el sector. Resulta fundamental el incremento de personal en este puesto al plantear la penetración en mercados como las pymes.

\subsection{Indicadores para cada uno de los Objetivos Específicos}

Luego de lo descrito anteriormente referente a cada objetivo específico planteado, se puede visualizar en la tabla 36 los indicadores de medición para cada uno de ellos. 
Tabla 36

Indicadores de medición para cada objetivo específico

\begin{tabular}{ccc}
\hline Objetivo & Perspectiva Financiera & Indicadores \\
\hline
\end{tabular}

Incrementar el ROE en 11 puntos porcentuales (20\%) en un tiempo de cinco años

$\operatorname{ROE}(\%)$

Disminución del porcentaje de desvío entre lo presupuestado y lo real a un $2 \%$ en un tiempo de cinco años

Triplicar el presupuesto destinado a actividades de marketing y ventas en cinco años

\% desviación de costos/gastos vs presupuesto

presupuesto anual ventas

Perspectiva de clientes

Objetivo

Incrementar el nivel de satisfacción del cliente en 1

punto porcentual por año

Incrementar las ventas anuales con un crecimiento

sostenido no menor del 10\% anual al finalizar el Ventas anuales (en miles de soles) quinto año

Incrementar el porcentaje de clientes en las líneas de BA y Mobile a un $40 \%$ en un tiempo de cinco años
Indicadores

$\%$ de crecimiento de clientes por líneas de negocio índice de satisfacción al cliente

\section{Objetivo}

Perspectiva de procesos internos

Disminución de los tiempos de estimación de los arquitectos de software en un $20 \%$

Implementación de un sistema de control de proyectos en un plazo de un año

Incrementar los canales de atención con sus clientes en un plazo de un año

Perspectiva de formación y crecimiento

Objetivo

Indicadores

Triplicar el número de consultores seniors al término del quinto año

Triplicar el número de arquitectos de software al término del quinto año
Indicadores

Tiempo de demora en la estimación de requerimientos

Sistema implementado

\# de anexos
$\%$ de colaboradores contratados por puesto

\# de ascensos por puestos

$\%$ de colaboradores contratados por puesto

\# de ascensos por puestos 


\subsection{Metas para cada uno de los Objetivos Específicos}

De la misma manera se han definido para los indicadores anteriormente descritos, las metas asociadas a cada uno de ellos. La tabla 37 muestra en detalle cada una de estas metas. Tabla 37

Metas para cada objetivo específico

\begin{tabular}{|c|c|c|c|}
\hline \multicolumn{4}{|c|}{ Perspectiva Financiera } \\
\hline Objetivo & Medida & Meta & Indicadores \\
\hline $\begin{array}{l}\text { Incrementar el ROE en } 11 \text { puntos porcentuales } \\
(20 \%) \text { en un tiempo de cinco años }\end{array}$ & 9.37 & 20 & ROE (\%) \\
\hline $\begin{array}{l}\text { Disminución del porcentaje de desvío entre lo } \\
\text { presupuestado y lo real a un } 2 \% \text { en un tiempo de } \\
\text { cinco años }\end{array}$ & $8 \%$ & $2 \%$ & $\begin{array}{l}\text { \% desviación de } \\
\text { costos/gastos vs } \\
\text { presupuesto }\end{array}$ \\
\hline $\begin{array}{l}\text { Triplicar el presupuesto destinado a actividades de } \\
\text { marketing y ventas en cinco años }\end{array}$ & 20 & 60 & $\begin{array}{l}\text { presupuesto anual } \\
\text { ventas }\end{array}$ \\
\hline \multicolumn{4}{|c|}{ Perspectiva de clientes } \\
\hline $\begin{array}{l}\text { Incrementar el nivel de satisfacción del cliente en } 1 \\
\text { punto porcentual por año }\end{array}$ & $83 \%$ & $88 \%^{1}$ & $\begin{array}{l}\text { índice de satisfacción } \\
\text { al cliente }\end{array}$ \\
\hline $\begin{array}{l}\text { Incrementar las ventas anuales con un crecimiento } \\
\text { sostenido no menor del } 10 \% \text { anual al finalizar el } \\
\text { quinto año }\end{array}$ & 1641 & 2994 & $\begin{array}{l}\text { Ventas anuales (en } \\
\text { miles de soles) }\end{array}$ \\
\hline $\begin{array}{l}\text { Incrementar el porcentaje de clientes en las líneas } \\
\text { de BA y Mobile a un } 40 \% \text { en un tiempo de cinco } \\
\text { años }\end{array}$ & $0 \%$ & $40 \%$ & $\begin{array}{l}\% \text { de crecimiento de } \\
\text { clientes por líneas de } \\
\text { negocio }\end{array}$ \\
\hline \multicolumn{4}{|c|}{ Perspectiva de procesos internos } \\
\hline $\begin{array}{l}\text { Disminución de los tiempos de estimación de los } \\
\text { arquitectos de software en un } 80 \%\end{array}$ & 5 & 1 & $\begin{array}{l}\text { Tiempo de demora en } \\
\text { la estimación de } \\
\text { requerimientos (días) }\end{array}$ \\
\hline $\begin{array}{l}\text { Implementación de un sistema de control de } \\
\text { proyectos en un plazo de un año }\end{array}$ & 0 & 1 & Sistema implementado \\
\hline $\begin{array}{l}\text { Incrementar los canales de atención con sus clientes } \\
\text { en un plazo de un año }\end{array}$ & 3 & 6 & \# de anexos \\
\hline \multicolumn{4}{|c|}{ Perspectiva de formación y crecimiento } \\
\hline $\begin{array}{l}\text { Triplicar el número de consultores seniors al } \\
\text { término del quinto año }\end{array}$ & 10 & 30 & $\begin{array}{l}\text { \% de colaboradores } \\
\text { contratados por puesto } \\
\text { \# de ascensos por } \\
\text { puestos }\end{array}$ \\
\hline $\begin{array}{l}\text { Triplicar el número de arquitectos de software al } \\
\text { término del quinto año }\end{array}$ & 2 & 7 & $\begin{array}{l}\% \text { de colaboradores } \\
\text { contratados por puesto } \\
\text { \# de ascensos por } \\
\text { puestos }\end{array}$ \\
\hline
\end{tabular}


La tabla 38 muestra en un horizonte temporal de cinco años las metas anualizadas planteadas anteriormente:

Tabla 38

Línea temporal de las metas anualizadas planteadas

\begin{tabular}{|c|c|c|c|c|c|}
\hline \multicolumn{6}{|c|}{ Perspectiva Financiera } \\
\hline Línea Base & 2017 & 2018 & 2019 & 2020 & 2021 \\
\hline $9.37 \%$ & $-9 \%$ & $9 \%$ & $17 \%$ & $19 \%$ & $20 \%$ \\
\hline $8 \%$ & $6 \%$ & $5 \%$ & $4 \%$ & $3 \%$ & $2 \%$ \\
\hline 20 & 28 & 36 & 44 & 52 & 60 \\
\hline \multicolumn{6}{|c|}{ Perspectiva de clientes } \\
\hline $83 \%$ & $84 \%$ & $85 \%$ & $86 \%$ & $87 \%$ & $88 \%$ \\
\hline 1,641 & 1,894 & 2,153 & 2,423 & 2,702 & 2,994 \\
\hline 0 & $10 \%$ & $18 \%$ & $26 \%$ & $34 \%$ & $40 \%$ \\
\hline \multicolumn{6}{|c|}{ Perspectivas de procesos internos } \\
\hline 5 & 4 & 3 & 2 & 1 & 1 \\
\hline 0 & 1 & 1 & 1 & 1 & 1 \\
\hline 3 & 6 & 6 & 6 & 6 & 6 \\
\hline \multicolumn{6}{|c|}{ Perspectivas de formación y crecimiento } \\
\hline 10 & 14 & 18 & 22 & 26 & 30 \\
\hline 2 & 3 & 4 & 5 & 6 & 7 \\
\hline
\end{tabular}

9.5. Iniciativas (acciones a llevar a cabo para cada uno de los objetivos específicos), Estrategias, Programas, Políticas, Reglas, Procedimiento

Las iniciativas para cada objetivo específico pueden ser visualizadas en la tabla 39. 
Tabla 39

Iniciativas para cada objetivo específico

Perspectiva Financiera

Objetivo

Iniciativas

Incrementar el ROE en 11 puntos porcentuales Repotenciar líneas de negocio de BA y Mobile (20\%) en un tiempo de cinco años orientada a Pymes

Disminución del porcentaje de desvío entre lo presupuestado y lo real a un $2 \%$ en un tiempo de cinco años

Triplicar el presupuesto destinado a actividades de marketing y ventas en cinco años

Implementación de nuevas metodologías de desarrollo de software

Creación de un área de marketing y ventas. Captación de nuevo personal especializado

Perspectiva de clientes

Objetivo

Incrementar el nivel de satisfacción del cliente en 1 punto porcentual por año

Incrementar las ventas anuales con un crecimiento sostenido no menor del $10 \%$ anual al finalizar el quinto año

Incrementar el porcentaje de clientes en las líneas de BA y Mobile a un $40 \%$ en un tiempo de cinco años
Iniciativas

Implementación de encuestas de satisfacción de clientes. Evaluación periódica semestral.

Desarrollo de línea de negocio de soluciones diversas orientadas a Pymes

Incrementar el número de participaciones en ferias y exposiciones ligadas a SAP

Perspectiva de procesos internos

\section{Objetivo}

Disminución de los tiempos de estimación de los arquitectos de software en un $80 \%$

Implementación de un sistema de control de proyectos en un plazo de un año

Incrementar los canales de atención con sus clientes en un plazo de un año
Iniciativas

Implementación de nuevas metodologías de desarrollo de software

Compra de un nuevo sistema de control de proyectos

Compra de una nueva central telefónica

Perspectiva de formación y crecimiento

\section{Objetivo}

Triplicar el número de consultores seniors al término del quinto año

Triplicar el número de arquitectos de software al término del quinto año
Iniciativas

Realizar capacitaciones en técnicas de desarrollo de software

Realizar capacitaciones en metodología de control de proyectos a consultores seniors 
Iniciativas perspectiva financiera

Repotenciar líneas de negocio de BA y Mobile orientada a Pymes

¿Qué es lo que se busca?

- Aumentar el ROE de la empresa incrementando el nivel de ventas de servicios prestados, siendo eficientes en los gastos actuales y buscando en todo momento la reducción de estos.

¿Cómo hacerlo?

- Aprovechando las dos líneas de negocio con mucho potencial de crecimiento de acuerdo con las tendencias tecnológicas actuales (business analytics y desarrollo de aplicaciones para dispositivos móviles)

- Reorientando el enfoque de empresas PRICOS a pymes que cuenten con sistemas de información que les permite sostener la formalidad de sus operaciones y cumplir con sus obligaciones tributarias.

- Captando a las pymes con disposición a invertir en soluciones de tecnología de información que les permitiría dar un gran paso en su crecimiento, ya que agilizaría sus procesos internos y tendrían a disposición información oportuna para la toma de decisiones. Una forma de hacerlo es participando en ferias como ExpoTIC (la más importante del país).

- Contratando y capacitando a nuevo personal (dos para BA y dos para mobile). Para la línea de BA se necesita de personal que tenga por lo menos un año de experiencia en proyectos de este tipo, mientras que para mobile se requiere más un conocimiento técnico en el desarrollo de aplicaciones para las plataformas de Android y IOS.

- Reestructurando los equipos de trabajo de las líneas y empoderando a su personal actual para que asuman roles de líderes de proyecto, lo que prepararía 
a la empresa para asumir nuevos compromisos de estos sectores a los que se estaría enfocando.

Implementación de nuevas metodologías de desarrollo de software

¿Qué es lo que se busca?

- Disminuir el índice de desvío entre lo presupuestado y lo real. Evitar retrasos en los proyectos que justifiquen la contratación de recursos experimentados caros.

¿Cómo hacerlo?

- Implementando una metodología de desarrollo y seguimiento de proyectos, acorde con cada servicio brindado por la empresa y que prevenga posibles eventos que provoquen estos retrasos.

- Capacitando al personal de desarrollo de proyectos en la metodología elegida para cada servicio brindado.

Creación de un área de marketing y ventas

¿Qué es lo que se busca?

- Incrementar el número de clientes y el nivel de ventas de la empresa, duplicando el presupuesto actual destinado para este fin.

¿Cómo hacerlo?

- Reestructurando el área de comercialización actual, asignarle un espacio físico dentro de la empresa dedicado a este fin.

- Contratando personal especializado en ventas de servicios en el sector e impulsando a que las personas que actualmente tienen esta responsabilidad se dediquen de lleno a esta actividad y se desliguen de la parte operativa de la empresa. 
Iniciativas perspectiva clientes

Implementación de encuestas de satisfacción de clientes.

¿Qué es lo que se busca?

- Incrementar el nivel de aceptación del cliente de los servicios proporcionados por la empresa.

¿Cómo hacerlo?

- Implementando una encuesta en línea que permita la evaluación del servicio prestado en sus clientes. Establecer una frecuencia semestral de evaluación y las respuestas categorizadas en la escala de Likert.

- Fijando criterios de evaluación que le permitan detectar rápidamente puntos de disconformidad y tomar acción de manera inmediata. Estos criterios deben ser: calidad del servicio, eficiencia y atención.

Desarrollo de línea de negocio de soluciones diversas orientadas a pymes

¿Qué es lo que se busca?

- Incrementar el nivel de ventas captando nuevos clientes

¿Cómo hacerlo?

- Reestructurando el equipo actual de desarrollo de portal SAP, aprovechando su conocimiento en programación Java para reorientarlo a soluciones para empresas pymes.

- Conformando equipos de desarrollo en BA y Mobile, aprovechando la llegada de recursos destinados a ese fin. 
Incrementar el número de participaciones en ferias y exposiciones ligadas a SAP ¿Qué es lo que se busca?

- Aumentar el número de proyectos/clientes relacionados con las líneas de negocio ya establecidas para dar soporte a SAP.

¿Cómo hacerlo?

- Participando en ferias o exposiciones de tecnologías ligadas a SAP.

- Aumentando el presupuesto para la parte comercial que permita el alquiler de stands y preparación de brochures

Iniciativas perspectiva procesos internos

Compra de un nuevo sistema de control de proyectos

¿Qué es lo que se busca?

- Disminución de retrasos en estimaciones de tiempos que afectan las relaciones con los clientes directos. Conocer el estado actual de cualquiera de los proyectos que la empresa maneja, a fin de tomar decisiones inmediatas ante cualquier eventualidad. Ser eficientes en el manejo de los recursos asignados a los proyectos.

¿Cómo hacerlo?

- Compra de un sistema de gestión de proyectos que se ajuste a las especificaciones requeridas para cada proyecto de las líneas de negocio de la empresa

Compra de una nueva central telefónica

¿Qué es lo que se busca?

- Incrementar los canales de comunicación para con sus clientes 
¿Cómo hacerlo?

- Comprando una nueva central telefónica que permita la implementación de anexos para cada equipo de trabajo por líneas de negocio. Esto involucra una reorganización en la disposición actual de los anexos existentes físicamente.

Iniciativas perspectiva formación y crecimiento

Realizar capacitaciones en técnicas y metodologías de desarrollo de software

¿Qué es lo que se busca?

- Transferencia de conocimiento entre el personal de desarrollo de software

¿Cómo hacerlo?

- Coordinando capacitaciones periódicas dictadas por consultores seniors y arquitectos de software internos.

\subsection{Responsable de cada una de las iniciativas}

Como responsable de cada una de las iniciativas planteadas en el cuadro anterior, se han definido a diferentes áreas de la empresa. La relación responsable-iniciativa se puede visualizar en la tabla 40. 
Tabla 40

Responsable para cada iniciativa formulada

\begin{tabular}{|c|c|c|}
\hline \multicolumn{3}{|c|}{ Perspectiva Financiera } \\
\hline Objetivo & Iniciativas & Responsables \\
\hline $\begin{array}{l}\text { Incrementar el ROE en } 11 \\
\text { puntos porcentuales } \\
(20 \%) \text { en un tiempo de } \\
\text { cinco años }\end{array}$ & $\begin{array}{l}\text { Repotenciar líneas de negocio de BA y Mobile } \\
\text { orientada a pymes }\end{array}$ & $\begin{array}{l}\text { Gerencia de } \\
\text { Unidad BA y } \\
\text { Gerencia de } \\
\text { Unidad Portal }\end{array}$ \\
\hline $\begin{array}{l}\text { Disminución del } \\
\text { porcentaje de desvío entre } \\
\text { lo presupuestado y lo real } \\
\text { a un } 2 \% \text { en un tiempo de } \\
\text { cinco años }\end{array}$ & $\begin{array}{l}\text { Implementación de nuevas metodologías de } \\
\text { desarrollo de software }\end{array}$ & $\begin{array}{l}\text { Gerencias de } \\
\text { Unidad Abap y } \\
\text { Portal }\end{array}$ \\
\hline $\begin{array}{l}\text { Triplicar el presupuesto } \\
\text { destinado a actividades de } \\
\text { marketing y ventas en } \\
\text { cinco años }\end{array}$ & $\begin{array}{l}\text { Creación de un área de marketing y ventas. } \\
\text { Captación de nuevo personal especializado }\end{array}$ & $\begin{array}{l}\text { Gerencia } \\
\text { General y } \\
\text { Gerencia de } \\
\text { Administración }\end{array}$ \\
\hline Objetivo & $\begin{array}{c}\text { Perspectiva de clientes } \\
\text { Iniciativas }\end{array}$ & Responsables \\
\hline $\begin{array}{l}\text { Incrementar el nivel de } \\
\text { satisfacción del cliente en } \\
1 \text { punto porcentual por } \\
\text { año }\end{array}$ & $\begin{array}{l}\text { Implementación de encuestas de satisfacción } \\
\text { de clientes. Evaluación periódica semestral. }\end{array}$ & $\begin{array}{l}\text { Gerencia } \\
\text { Comercial }\end{array}$ \\
\hline $\begin{array}{l}\text { Incrementar las ventas } \\
\text { anuales con un } \\
\text { crecimiento sostenido no } \\
\text { menor del } 10 \% \text { anual al } \\
\text { finalizar el quinto año }\end{array}$ & $\begin{array}{l}\text { Desarrollo de línea de negocio de soluciones } \\
\text { diversas orientadas a pymes }\end{array}$ & $\begin{array}{l}\text { Gerencia } \\
\text { General }\end{array}$ \\
\hline $\begin{array}{l}\text { Incrementar el porcentaje } \\
\text { de clientes en las líneas de } \\
\text { BA y Mobile a un } 40 \% \text { en } \\
\text { un tiempo de cinco años }\end{array}$ & $\begin{array}{l}\text { Incrementar el número de participaciones en } \\
\text { ferias y exposiciones ligadas a SAP }\end{array}$ & $\begin{array}{l}\text { Gerencia } \\
\text { Comercial }\end{array}$ \\
\hline
\end{tabular}


Responsable para cada iniciativa formulada

\begin{tabular}{|c|c|c|}
\hline \multicolumn{3}{|c|}{ Perspectiva de procesos internos } \\
\hline Objetivo & Iniciativas & Responsables \\
\hline $\begin{array}{l}\text { Disminución de los } \\
\text { tiempos de estimación de } \\
\text { los arquitectos de } \\
\text { software en un } 80 \%\end{array}$ & $\begin{array}{l}\text { Implementación de nuevas metodologías de } \\
\text { desarrollo de software }\end{array}$ & $\begin{array}{l}\text { Gerencias de } \\
\text { Unidad Abap y } \\
\text { Portal }\end{array}$ \\
\hline $\begin{array}{l}\text { Implementación de un } \\
\text { sistema de control de } \\
\text { proyectos en un plazo de } \\
\text { un año }\end{array}$ & $\begin{array}{l}\text { Compra de un nuevo sistema de control de } \\
\text { proyectos }\end{array}$ & $\begin{array}{l}\text { Gerencia } \\
\text { Administrativa } \\
\text { y Gerencia de } \\
\text { Unidad Abap, } \\
\text { Portal y BA }\end{array}$ \\
\hline $\begin{array}{l}\text { Incrementar los canales de } \\
\text { atención con sus clientes } \\
\text { en un plazo de un año }\end{array}$ & Compra de una nueva central telefónica & $\begin{array}{l}\text { Gerencia } \\
\text { Administrativa }\end{array}$ \\
\hline \multicolumn{3}{|c|}{ Perspectiva de formación y crecimiento } \\
\hline Objetivo & Iniciativas & Responsables \\
\hline $\begin{array}{l}\text { Triplicar el número de } \\
\text { consultores seniors al } \\
\text { término del quinto año }\end{array}$ & $\begin{array}{l}\text { Realizar capacitaciones en técnicas de } \\
\text { desarrollo de software }\end{array}$ & $\begin{array}{l}\text { Gerencia de } \\
\text { Unidad Abap, } \\
\text { Portal y BA }\end{array}$ \\
\hline $\begin{array}{l}\text { Triplicar el número de } \\
\text { arquitectos de software al } \\
\text { término del quinto año }\end{array}$ & $\begin{array}{l}\text { Realizar capacitaciones en metodología de } \\
\text { control de proyectos a consultores seniors }\end{array}$ & $\begin{array}{l}\text { Gerencia de } \\
\text { Unidad Abap, } \\
\text { Portal y BA }\end{array}$ \\
\hline
\end{tabular}

\subsection{Presupuesto de cada una de las iniciativas}

Cada una de las iniciativas planteadas en los cuadros anteriores deben tener un sustento económico, a fin de que puedan ser presupuestadas para ser llevadas a cabo. La tabla 41 muestra el presupuesto elaborado para cada iniciativa. 


\section{Tabla 41}

Presupuesto por cada una de las iniciativas

\begin{tabular}{|c|c|c|c|c|c|}
\hline Iniciativa & 2017 & 2018 & 2019 & 2020 & 2021 \\
\hline $\begin{array}{l}\text { Repotenciar líneas de negocio de BA y } \\
\text { Mobile orientada a pymes }\end{array}$ & S/. $64,875.00$ & S/. 90,300.00 & S/. $138,300.00$ & S/. $138,300.00$ & S/. $150,300.00$ \\
\hline $\begin{array}{l}\text { Contratación de nuevos recursos BA } \\
\text { (x2) }\end{array}$ & S/. 24,000.00 & S/. 48,000.00 & S/. $72,000.00$ & S/. $72,000.00$ & S/. $76,800.00$ \\
\hline Contratación de nuevos recursos & S/. $18,000.00$ & S/. 36,000.00 & S/. $60,000.00$ & S/. $60,000.00$ & S/. $67,200.00$ \\
\hline
\end{tabular}

Mobile (x2)

Capacitación recursos BA

Capacitación recursos Mobile

\begin{tabular}{|c|c|c|c|c|c|}
\hline Adquisición de equipos de cómputo & S/. $15,600.00$ & & & & \\
\hline $\begin{array}{l}\text { Rediseño de página web - opción } \\
\text { servicios - SAP BA }\end{array}$ & S/. 975.00 & & & & \\
\hline $\begin{array}{l}\text { Participación en ferias (stand, } \\
\text { merchandising) }\end{array}$ & S/. 6,300.00 & S/. 6,300.00 & S/. 6,300.00 & S/. 6,300.00 & S/. $6,300.00$ \\
\hline $\begin{array}{l}\text { Implementación de nuevas } \\
\text { metodologías de desarrollo de software }\end{array}$ & S/. 600.00 & S/. - & S/. - & S/. - & $\mathrm{S} /$. \\
\hline Capacitación de personal de desarrollo & S/. 600.00 & & & & \\
\hline $\begin{array}{l}\text { Creación de un área de marketing y } \\
\text { ventas. } \\
\text { Captación de nuevo personal } \\
\text { especializado }\end{array}$ & S/. $81,120.00$ & S/. $73,000.00$ & S/. $73,000.00$ & S/. $73,000.00$ & S/. $73,000.00$ \\
\hline $\begin{array}{l}\text { Contratación del personal } \\
\text { especializado (x2) }\end{array}$ & S/. $73,000.00$ & S/. $73,000.00$ & S/. $73,000.00$ & S/. $73,000.00$ & S/. $73,000.00$ \\
\hline Acondicionamiento del lugar físico & S/. 970.00 & & & & \\
\hline
\end{tabular}

Compra de equipos de cómputo

S/. 7,150.00

Implementación de encuestas de satisfacción de clientes. Evaluación

S/. S/. S/ S/. S/. periódica semestral.

Elaboración de la encuesta en google docs

Elaboración de tablero de gestión

Desarrollo de línea de negocio de soluciones diversas orientadas a Pymes

Rediseño de página web - opción servicios - Soluciones pymes

Incrementar el número de $\begin{array}{lllll}\text { S/. } 7,500.00 & \text { S/. } 7,500.00 & \text { S/.7.500.00 } & \text { S/. 7,500.00 } & \text { S/.7,500.00 }\end{array}$ participaciones en ferias y exposiciones ligadas a SAP Stands, merchandising

S/. 7,500.00

S/. 7,500.00

S/. 7,500.00 S/. 7,500.00

S/. $7,500.00$

Compra de un nuevo sistema de

S/. $6,500.00$

control de proyectos

Compra de una nueva central

S/ $9,750.00$

telefónica

Realizar capacitaciones en técnicas de

desarrollo de software

Realizar capacitaciones en

metodología de control de proyectos a

consultores seniors 


\subsection{Cronograma de cada una de las iniciativas}

Cada una de las iniciativas propuestas deben tener una fecha de implementación a fin de que se pueda desplegar la estrategia de acuerdo con lo planificado. Para ello, se ha elaborado un cronograma de implementación que puede ser visualizado en la tabla 42.

Tabla 42

Cronograma de cada una de las iniciativas

\begin{tabular}{|c|c|c|c|c|c|c|c|c|c|c|}
\hline \multirow[t]{2}{*}{ Iniciativas } & \multicolumn{2}{|c|}{2017} & \multicolumn{2}{|c|}{2018} & \multicolumn{2}{|c|}{2019} & \multicolumn{2}{|c|}{2020} & \multicolumn{2}{|c|}{2021} \\
\hline & 1 & 2 & 1 & 2 & 1 & 2 & 1 & 2 & 1 & 2 \\
\hline $\begin{array}{l}\text { Repotenciar líneas de negocio de BA y Mobile } \\
\text { orientada a pymes }\end{array}$ & & & & & & & & & & \\
\hline Contratación de nuevos recursos BA (x2) & & & & & & & & & & \\
\hline Contratación de nuevos recursos Mobile (x2) & & & & & & & & & & \\
\hline Capacitación recursos BA & & & & & & & & & & \\
\hline Capacitación recursos Mobile & & & & & & & & & & \\
\hline Adquisición de equipos de cómputo & & & & & & & & & & \\
\hline Rediseño de página web - opción servicios - & & & & & & & & & & \\
\hline SAP BA & & & & & & & & & & \\
\hline Participación en ferias (stand, merchandising) & & & & & & & & & & \\
\hline $\begin{array}{l}\text { Implementación de nuevas metodologías de } \\
\text { desarrollo de software }\end{array}$ & & & & & & & & & & \\
\hline Capacitación de personal de desarrollo & & & & & & & & & & \\
\hline Creación de un área de marketing y ventas. & & & & & & & & & & \\
\hline Captación de nuevo personal especializado & & & & & & & & & & \\
\hline Contratación del personal especializado (x2) & & & & & & & & & & \\
\hline Acondicionamiento del lugar físico & & & & & & & & & & \\
\hline Compra de equipos de cómputo & & & & & & & & & & \\
\hline $\begin{array}{l}\text { Implementación de encuestas de satisfacción de } \\
\text { clientes. Evaluación periódica semestral. }\end{array}$ & & & & & & & & & & \\
\hline Elaboración de la encuesta en google docs & & & & & & & & & & \\
\hline Elaboración de tablero de gestión & & & & & & & & & & \\
\hline $\begin{array}{l}\text { Desarrollo de línea de negocio de soluciones } \\
\text { diversas orientadas a pymes }\end{array}$ & & & & & & & & & & \\
\hline Rediseño de página web - opción servicios - & & & & & & & & & & \\
\hline Soluciones Pymes & & & & & & & & & & \\
\hline $\begin{array}{l}\text { Incrementar el número de participaciones en } \\
\text { ferias y exposiciones ligadas a SAP }\end{array}$ & & & & & & & & & & \\
\hline Stands, merchandising & & & & & & & & & & \\
\hline $\begin{array}{l}\text { Compra de un nuevo sistema de control de } \\
\text { proyectos }\end{array}$ & & & & & & & & & & \\
\hline Compra de una nueva central telefónica & & & & & & & & & & \\
\hline $\begin{array}{l}\text { Realizar capacitaciones en técnicas de desarrollo } \\
\text { de software }\end{array}$ & & & & & & & & & & \\
\hline $\begin{array}{l}\text { Realizar capacitaciones en metodología de } \\
\text { control de proyectos a consultores seniors }\end{array}$ & & & & & & & & & & \\
\hline
\end{tabular}




\section{Capítulo X: Evaluación}

En el presente capítulo, se evaluará la estrategia planteada, considerando todos los aspectos que esta conlleva, analizando la información financiera de la empresa y proyectando los resultados dentro del horizonte de tiempo estipulado en el plan estratégico.

La forma en la que se realizará la evaluación será a través de una evaluación cualitativa de las dos estrategias que obtuvieron el mayor puntaje en la matriz MPEC. Además, se proyectarán los estados financieros, bajo los escenarios que se han contemplado para poder establecer qué estrategia se debe llevar a cabo.

\subsection{Evaluación Cualitativa}

Según Rumelt (2011), "la evaluación cualitativa de la estrategia se puede realizar en base a 4 criterios: congruencia, consonancia, viabilidad y ventaja. La consonancia y la ventaja se basan principalmente en la evaluación externa de una empresa, mientras que la congruencia y la viabilidad están basadas, en gran parte, en la evaluación interna” (p. 231).

Realizar la evaluación cualitativa de la estrategia es importante, dado que las matrices tienen un grado determinado de subjetividad en su elaboración, por lo que se trata de analizar los resultados siguiendo ciertos parámetros que permitan reducir al máximo este nivel de subjetividad e incrementar la objetividad del trabajo realizado.

David (2013), menciona lo siguiente: “La evaluación de la estrategia incluye tres actividades básicas: (a) examinar las bases subyacentes a la estrategia de una empresa, (b) comparar los resultados esperados con los resultados reales; y (c) tomar acciones correctivas para asegurarse de que el desempeño va de acuerdo con los planes".

Una evaluación periódica y detallada de las estrategias de una organización resulta ser importante, dado que el escenario en el que se desarrolla una empresa es muy cambiante, debido a factores externos e internos. 


\subsubsection{Criterios de evaluación}

Los criterios para llevar a cabo la evaluación de la estrategia son señalados por Rumelt (2011), quien menciona cuatro criterios que resultan útiles para evaluar una estrategia: consistencia, consonancia, factibilidad y ventaja.

- Consistencia: la estrategia debe ser congruente con las políticas de la organización e integrar a las áreas.

- Consonancia: la estrategia debe considerar una rápida respuesta a los factores internos y externos.

- Viabilidad: la estrategia debe ser objetiva y factible.

- Ventaja: la estrategia debe fomentar y mantener las ventajas competitivas de la organización.

\subsubsection{Comparación de la estrategia con los criterios}

Según los criterios señalados en el apartado anterior, se analiza la estrategia planteada para Xternal Technological Solutions S.A.C.:

Congruencia: Las estrategias de penetración de mercado y desarrollo de producto, están alineadas con la visión, misión, valores y objetivos estratégicos planteados para Xternal Technological Solutions S.A.C. Sin embargo, es preciso señalar que la congruencia también se deriva de una política gerencial que respalde el cumplimiento de los objetivos planteados, para evitar que se presente alguna incongruencia.

Consonancia: La estrategia planteada, tiene relación directa con el desarrollo actual de la industria de la tecnología de la información, dado que en la actualidad es necesario estar al tanto de las innovaciones tecnológicas para el éxito de cualquier organización. Además, se tiene en cuenta que los factores externos como la situación macroeconómica del país, pueden afectar a los objetivos organizacionales, por lo que la estrategia propuesta responde a los posibles cambios que se produzcan. Esta conclusión deviene del análisis de las matrices 
elaboradas, para realizar finalmente la selección de la estrategia. Es necesario señalar, que las propuestas realizadas se tienen que adecuar a diferentes escenarios contemplados en el análisis, lo que permite anticipar los cambios y decisiones correctivas necesarias.

Viabilidad: A partir de las proyecciones realizadas, las estrategias propuestas son posibles tanto a nivel económico, como a nivel financiero. También se puede señalar que el capital humano con el que cuenta la empresa en la actualidad es capaz de poner en marcha estas estrategias sin mayor inconveniente. La inversión y gastos generados a partir de estas propuestas son totalmente viables, tomando en cuenta que Xternal Technological Solutions S.A.C. cuenta con números positivos y tiene una tendencia al crecimiento. Es acertado esperar que la organización pueda invertir en infraestructura, equipos y dotación de personal, para que se encuentre preparada para los posibles cambios y escenarios futuros que tenga que afrontar.

Ventaja: Xternal Technological Solutions S.A.C. es una empresa relativamente joven y es reconocida porque brinda un servicio personalizado a precios competitivos. Las estrategias de penetración de mercado y desarrollo de producto pueden mantener e incrementar las ventajas actuales de la organización. El clima laboral de la empresa también se podría ver impactado de manera positiva, debido a las mejoras que la estrategia planteada puede representar para toda la organización. Cabe mencionar también que Xternal Technological Solutions S.A.C. se podría ver beneficiada frente a la competencia, dado que la estrategia propuesta puede ser sostenible en la industria.

Al realizar el análisis de las estrategias identificadas, se observa que todas cumplen con los criterios requeridos. La evaluación de cada estrategia según los criterios mencionados se puede apreciar en la tabla 43. 
Tabla 43

Matriz Rumelt

\begin{tabular}{llcccc}
\hline & Estrategias Comerciales & Congruencia & Consonancia & Viabilidad & Ventaja \\
\hline E-1 & Penetración de mercado & SI & SI & SI & SI \\
E-2 & Desarrollo de mercado & SI & SI & SI & SI \\
\hline
\end{tabular}

\subsection{Evaluación Financiera de la Estrategia}

Es necesario efectuar una planificación financiera de la estrategia para asegurar que esta pueda ser sostenible durante el periodo propuesto y se logre alcanzar los objetivos planteados, para tal fin y según Gitman \& Zutter (2012), se debe considerar tres aspectos:

Tiempo: El tiempo de rendimiento de la inversión es importante puesto que una recepción de fondos en un corto plazo es mucho mejor que aquella que tome un plazo mayor.

Flujo de efectivo: Las utilidades no necesariamente generan flujos de efectivo que estén a disposición de los accionistas, únicamente cuando las ganancias tengan un incremento acompañado de un incremento en los flujos de efectivo futuro, se puede esperar un precio mayor en las acciones.

Riesgo: Como en toda proyección existe el riesgo que lo resultados esperados no sean similares a los resultados reales obtenidos, por lo que es necesario considerar como factores determinantes clave del precio de las acciones al rendimiento y al riesgo. Esto ocurre porque los accionistas tienen aversión al riesgo, es decir recibir una compensación por un riesgo mayor.

Es así, que para la evaluación financiera considerando estos aspectos se realiza en cada uno de los escenarios planteados en el capítulo VIII como son los escenarios conservador, optimista y pesimista, para esta proyección se está considerando la variación proyectada del PBI durante el periodo de cinco años desde la implementación de la estrategia. 
La proyección del PBI considerado en el capítulo VIII, se ha comparado con el porcentaje de crecimiento de la inversión en el sector de Tecnología de Información que hubo durante el año 2016, equivalente a $2.3 \%$, por lo cual al ser necesario proyectar el crecimiento del sector se ha considerado una variación proporcional al crecimiento del PBI, asimismo considerando la participación del mercado de la empresa Xternal Technological Solutions S.A.C es equivalente al $0.11 \%$ de la inversión nacional en el sector se han obtenido las siguientes tablas 44, 45 y 46. 
Tabla 44

Proyección escenario optimista - Sin estrategia (Años 2017 - 2021)

\begin{tabular}{|c|c|c|c|c|c|c|}
\hline Escenario Optimista & 2016 & 2017 & 2018 & 2019 & 2020 & 2021 \\
\hline Proyección del Crecimiento del PBI & $6.10 \%$ & $6.60 \%$ & $6.40 \%$ & $6.40 \%$ & $6.30 \%$ & $6.30 \%$ \\
\hline Proyección del Crecimiento de la Inversión & & & & & & \\
\hline TI & $2.81 \%$ & $3.04 \%$ & $2.94 \%$ & $2.94 \%$ & $2.90 \%$ & $2.90 \%$ \\
\hline Inversión en TI en US \$ & $\$ 450,000,000$ & $\$ 463,662,000$ & $\$ 477,312,209$ & $\$ 491,364,281$ & $\$ 505,604,018$ & $\$ 520,256,422$ \\
\hline Inversión en TI en S/. & S/. $1,464,750,000$ & S/. $1,509,219,810$ & S/. $1,553,651,241$ & S/. 1,599,390,734 & S/. $1,645,741,077$ & S/. $1,693,434,654$ \\
\hline Participación de Mercado Xternal & $0.11 \%$ & $0.11 \%$ & $0.11 \%$ & $0.11 \%$ & $0.11 \%$ & $0.11 \%$ \\
\hline Ventas Xternal & S/. $1,641,785.76$ & S/. $1,691,630.38$ & S/. $1,741,431.97$ & S/. $1,792,699.73$ & S/. $1,844,652.17$ & S/. $1,898,110.19$ \\
\hline
\end{tabular}

\section{Tabla 45}

Proyección escenario conservador - Sin estrategia (Años 2017 - 2021)

\begin{tabular}{|c|c|c|c|c|c|c|}
\hline Escenario Conservador & 2016 & 2017 & 2018 & 2019 & 2020 & 2021 \\
\hline Proyección del Crecimiento del PBI & $5.00 \%$ & $5.60 \%$ & $5.00 \%$ & $5.00 \%$ & $4.90 \%$ & $4.90 \%$ \\
\hline \multicolumn{7}{|c|}{ Proyección del Crecimiento de la Inversión } \\
\hline $\mathrm{TI}$ & $2.30 \%$ & $2.58 \%$ & $2.30 \%$ & $2.30 \%$ & $2.25 \%$ & $2.25 \%$ \\
\hline Inversión en TI en US \$ & $\$ 450,000,000$ & $\$ 461,592,000$ & $\$ 472,208,616$ & $\$ 483,069,414$ & $\$ 493,957,799$ & $\$ 505,091,608$ \\
\hline Inversión en TI en S/. & S/. $1,464,750,000$ & S/. $1,502,481,960$ & S/. $1,537,039,045$ & S/. $1,572,390,943$ & S/. $1,607,832,635$ & S/. $1,644,073,183$ \\
\hline Participación de Mercado Xternal & $0.11 \%$ & $0.11 \%$ & $0.11 \%$ & $0.11 \%$ & $0.11 \%$ & $0.11 \%$ \\
\hline Ventas Xternal & S/. $1,641,785.76$ & S/. $1,684,078.16$ & S/. $1,722,811.96$ & S/. $1,762,436.63$ & S/. $1,802,161.96$ & S/. $1,842,782.69$ \\
\hline
\end{tabular}


Tabla 46

Proyección escenario pesimista - Sin estrategia (Años 2017 - 2021)

\begin{tabular}{|c|c|c|c|c|c|c|}
\hline Escenario Pesimista & 2016 & 2017 & 2018 & 2019 & 2020 & 2021 \\
\hline Proyección del Crecimiento del PBI & $3.30 \%$ & $4.00 \%$ & $3.50 \%$ & $4.00 \%$ & $4.00 \%$ & $3.90 \%$ \\
\hline \multicolumn{7}{|c|}{ Proyección del Crecimiento de la Inversión } \\
\hline $\mathrm{TI}$ & $1.52 \%$ & $1.84 \%$ & $1.61 \%$ & $1.84 \%$ & $1.84 \%$ & $1.79 \%$ \\
\hline Inversión en TI en US \$ & $\$ 450,000,000$ & $\$ 458,280,000$ & $\$ 465,658,308$ & $\$ 474,226,421$ & $\$ 482,952,187$ & $\$ 491,616,349$ \\
\hline Inversión en TI en S/. & S/. $1,464,750,000$ & S/. $1,491,701,400$ & S/. $1,515,717,793$ & S/. $1,543,607,000$ & S/. 1,572,009,369 & S/. $1,600,211,217$ \\
\hline Participación de Mercado Xternal & $0.11 \%$ & $0.11 \%$ & $0.11 \%$ & $0.11 \%$ & $0.11 \%$ & $0.11 \%$ \\
\hline Ventas Xternal & S/. $1,641,785.76$ & S/. 1,671,994.62 & S/. $1,698,913.73$ & S/. 1,730,173.74 & S/. 1,762,008.94 & S/. 1,793,619.38 \\
\hline
\end{tabular}


En estos escenarios se ha considerado que la participación de la empresa respecto al total de ventas del sector se va a mantener, ya que no se está aplicando las estrategias propuestas. Estas tienen incidencia directa en la participación del mercado, ya que se está reorientando el enfoque para captar más clientes de empresas pymes y un fortalecimiento de las líneas de negocio existentes para captar más proyectos en el mercado actual. La diferencia se va a poder apreciar al momento de realizar las proyecciones ya aplicando las estrategias planteadas.

\subsubsection{Proyección de estados financieros (situación actual y con la nueva} estrategia)

Para la proyección de los Estados Financieros se ha considerado lo valores obtenidos de las ventas proyectadas de la empresa Xternal Technological Solutions S.A.C sin estrategia, y para proyectar los costos de las ventas se ha considerado que estas son el $75 \%$ del valor de las ventas anuales. Respecto a los gastos de administración y ventas, se ha considerado los valores proyectados de la planilla aumentada con el personal que se quiere contratar y los gastos de publicidad en ferias y stands referente al rubro de ventas.

Por otro lado, según lo propuesto en los objetivos se ha considerado un aumento progresivo de $1 \%$ anual respecto a la participación de la empresa en el mercado, que junto a un crecimiento proyectado del sector nos permite obtener las cifras de ventas esperadas para el período 2017-2021 para la empresa Xternal Technological Solutions S.A.C. Las proyecciones se pueden observar en las tablas 47, 48 y 49 aplicando las estrategias de penetración de mercado. 
Tabla 47

Proyección escenario optimista - Con estrategia (Años 2017 - 2021)

\begin{tabular}{|c|c|c|c|c|c|c|}
\hline Escenario Optimista & 2016 & 2017 & 2018 & 2019 & 2020 & 2021 \\
\hline Proyección del Crecimiento del PBI & $6.10 \%$ & $6.60 \%$ & $6.40 \%$ & $6.40 \%$ & $6.30 \%$ & $6.30 \%$ \\
\hline Proyección del crecimiento de la Inversión & & & & & & \\
\hline TI & $2.81 \%$ & $3.04 \%$ & $2.94 \%$ & $2.94 \%$ & $2.90 \%$ & $2.90 \%$ \\
\hline Inversión en TI en US \$ & $\$ 450,000,000$ & $\$ 463,662,000$ & $\$ 477,312,209$ & $\$ 491,364,281$ & $\$ 505,604,018$ & $\$ 520,256,422$ \\
\hline Inversión en TI en S/. & S/. $1,464,750,000$ & S/. $1,509,219,810$ & S/. $1,553,651,241$ & S/. $1,599,390,734$ & S/. $1,645,741,077$ & S/. $1,693,434,654$ \\
\hline Participación de Mercado Xternal & $0.112 \%$ & $0.126 \%$ & $0.140 \%$ & $0.154 \%$ & $0.168 \%$ & $0.182 \%$ \\
\hline Ventas Xternal & S/. $1,641,785.76$ & S/. 1,902,921.15 & S/. $2,176,454.32$ & S/. 2,464,443.84 & S/. 2,766,267.17 & S/. 3,083,514.45 \\
\hline
\end{tabular}

Tabla 48

Proyección escenario conservador - Con estrategia (Años 2017 - 2021)

\begin{tabular}{|c|c|c|c|c|c|c|}
\hline Escenario Conservador & 2016 & 2017 & 2018 & 2019 & 2020 & 2021 \\
\hline Proyección del Crecimiento del PBI & $5.00 \%$ & $5.60 \%$ & $5.00 \%$ & $5.00 \%$ & $4.90 \%$ & $4.90 \%$ \\
\hline Proyección del crecimiento de la Inversión & & & & & & \\
\hline TI & $2.30 \%$ & $2.58 \%$ & $2.30 \%$ & $2.30 \%$ & $2.25 \%$ & $2.25 \%$ \\
\hline Inversión en TI en US \$ & $\$ 450,000,000$ & $\$ 461,592,000$ & $\$ 472,208,616$ & $\$ 483,069,414$ & $\$ 493,957,799$ & $\$ 505,091,608$ \\
\hline Inversión en TI en S/. & S/. $1,464,750,000$ & S/. $1,502,481,960$ & S/. $1,537,039,045$ & S/. $1,572,390,943$ & S/. $1,607,832,635$ & S/. $1,644,073,183$ \\
\hline Participación de Mercado Xternal & $0.112 \%$ & $0.126 \%$ & $0.140 \%$ & $0.154 \%$ & $0.168 \%$ & $0.182 \%$ \\
\hline Ventas Xternal & S/. $1,641,785.76$ & S/. $1,894,425.64$ & S/. 2,153,182.89 & S/. $2,422,840.83$ & S/. 2,702,548.23 & S/. 2,993,633.91 \\
\hline
\end{tabular}


Tabla 49

Proyección escenario pesimista - Con estrategia (Años 2017 - 2021)

\begin{tabular}{|c|c|c|c|c|c|c|}
\hline Escenario Pesimista & 2016 & 2017 & 2018 & 2019 & 2020 & 2021 \\
\hline $\begin{array}{l}\text { Proyección del Crecimiento del PBI } \\
\text { Proyección del crecimiento de la Inversión }\end{array}$ & $3.30 \%$ & $4.00 \%$ & $3.50 \%$ & $4.00 \%$ & $4.00 \%$ & $3.90 \%$ \\
\hline TI & $1.52 \%$ & $1.84 \%$ & $1.61 \%$ & $1.84 \%$ & $1.84 \%$ & $1.79 \%$ \\
\hline Inversión en TI en US \$ & $\$ 450,000,000$ & $\$ 458,280,000$ & $\$ 465,658,308$ & $\$ 474,226,421$ & $\$ 482,952,187$ & $\$ 491,616,349$ \\
\hline Inversión en TI en S/. & S/. $1,464,750,000$ & $1,491,701,400$ & S/. 1,515,717,793 & S/. 1,543,607,000 & S/. 1,572,009,369 & S/. $1,600,211,217$ \\
\hline Participación de Mercado Xternal & $0.112 \%$ & $0.126 \%$ & $0.140 \%$ & $0.154 \%$ & $0.168 \%$ & $0.182 \%$ \\
\hline Ventas Xternal & S/. $1,641,785.76$ & S/. $1,880,832.81$ & S/. 2,123,314.71 & S/. $2,378,488.68$ & S/. 2,642,334.19 & S/. $2,913,767.23$ \\
\hline
\end{tabular}


Asimismo, se debe de mencionar que se ha proyectado un crecimiento promedio del sector de servicios de consultoría de TI del 2.3\%. En las proyecciones de ventas con la estrategia propuesta se está considerando el aumento progresivo de acuerdo con el porcentaje anteriormente mencionado y el crecimiento del $1 \%$ por concepto de la aplicación de la estrategia de penetración de mercados.

\subsubsection{Estado de resultados (situación actual y con la nueva estrategia)}

Para obtener la proyección del estado de resultados sin aplicar la estrategia propuesta se ha considerado los valores de ventas en el escenario conservador. Los valores de crecimiento del sector son los mismos y se ha partido por el estado de resultados proporcionado por la empresa Xternal Technological Solutions S.A.C. al 31 de diciembre del 2016. Estos resultados se pueden visualizar en la tabla 50.

Tabla 50

Estado de resultados proyectado de Xternal Technological Solutions - sin estrategia

\begin{tabular}{|c|c|c|c|c|c|c|}
\hline & 2016 & 2017 & 2018 & 2019 & 2020 & 2021 \\
\hline $\begin{array}{l}\text { Ventas Netas (ingresos } \\
\text { operacionales) }\end{array}$ & $1,641,786$ & $1,684,078$ & $1,722,812$ & $1,762,437$ & $1,802,162$ & $1,842,783$ \\
\hline Costo de ventas & $(1,245,357)$ & $(1,263,059)$ & $(1,292,109)$ & $(1,321,827)$ & $(1,351,621)$ & $(1,382,087)$ \\
\hline Utilidad Bruta & 396,429 & 421,020 & 430,703 & 440,609 & 450,540 & 460,696 \\
\hline \multicolumn{7}{|l|}{ Gastos Operacionales } \\
\hline Gastos de Administración & $(354,251)$ & $(361,336)$ & $(368,562)$ & $(375,934)$ & $(383,452)$ & $(391,121)$ \\
\hline Gastos de Venta & $(8,465)$ & $(8,634)$ & $(8,807)$ & $(8,983)$ & $(9,163)$ & $(9,346)$ \\
\hline Utilidad Operativa & 33,713 & 51,049 & 53,334 & 55,692 & 57,925 & 60,228 \\
\hline \multicolumn{7}{|l|}{ Otros Ingresos (gastos) } \\
\hline Ingresos Financieros & 322 & 322 & 322 & 322 & 322 & 322 \\
\hline Gastos Financieros & $(528)$ & $(528)$ & $(528)$ & $(528)$ & $(528)$ & $(528)$ \\
\hline \multicolumn{7}{|l|}{ Otros Ingresos } \\
\hline \multicolumn{7}{|l|}{ Otros Gastos } \\
\hline \multicolumn{7}{|l|}{ Resultados antes de } \\
\hline \multicolumn{7}{|l|}{ Participaciones, } \\
\hline \multicolumn{7}{|l|}{ Impuesto a la Renta y Partidas } \\
\hline Extraordinarias & 33,507 & 50,843 & 53,127 & 55,486 & 57,719 & 60,022 \\
\hline Participaciones & & & & & & \\
\hline Impuesto a la Renta & $(6,912)$ & $(5,084)$ & $(5,313)$ & $(5,549)$ & $(5,772)$ & $(6,002)$ \\
\hline \multicolumn{7}{|l|}{ Utilidad (Pérdida) Neta del } \\
\hline Ejercicio & 26,596 & 45,759 & 47,815 & 49,938 & 51,947 & 54,020 \\
\hline
\end{tabular}


En las proyecciones anteriormente descritas se ha considerado un aumento del $2 \%$ anual por conceptos de gastos administrativos y gastos de ventas.

\section{Supuestos Proyectado de Estado de Resultado}

- Se asume la proyección de ventas de la empresa como un crecimiento progresivo en $1 \%$ anual respecto a la participación de la empresa en el mercado con relación al crecimiento proyectado del sector de Tecnología.

- Se asume que la proyección de ventas es un porcentaje de la inversión en el sector de TI, el cual tiene un $2.3 \%$ de crecimiento promedio del sector de servicios de consultoría de TI más la variación proporcional al crecimiento del PBI.

- Según los objetivos se ha considerado un aumento del 10\% de las ventas para el primer año y a partir del 2do año un incremento progresivo del $2 \%$.

- Se asume que los costos de las ventas son el $75 \%$ del valor de las ventas anuales de la empresa.

- Se está considerando la tasa de $20.50 \%$ por un periodo de cinco años correspondiente al préstamo bancario de 50,000 soles para el financiamiento de la estrategia propuesta

- Se asume que los precios de proyección de ventas son corrientes.

Para realizar la proyección del estado de resultados en el horizonte de tiempo del 2017 al 2021 (alcance de este plan estratégico) se han considerados los presupuestos proyectados de ventas, compras, gastos administrativos, gastos de ventas y gastos financieros.

Estos presupuestos pueden apreciarse en las tablas 51, 52, 53, 56 y 58.

Adicionalmente, se ha elaborado los cuadros de depreciación, amortización y cronograma de 
la deuda adquirida para financiar una parte de la estrategia propuesta. Los valores se pueden apreciar en la tabla 54,55 y 57.

Finalmente, el estado de resultados proyectado se puede visualizar en la tabla 59 para el horizonte de tiempo del 2017 al 2021. 
Tabla 51

Presupuesto de ventas proyectado - Escenario conservador con estrategia

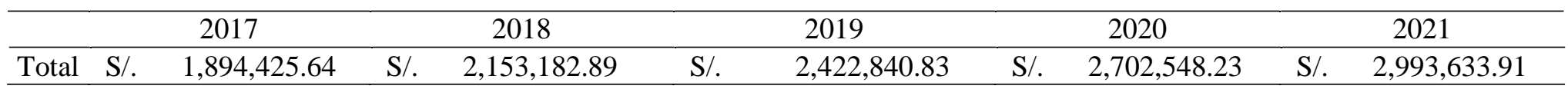

Tabla 52

Presupuesto de compras proyectado - Escenario conservador con estrategia

\begin{tabular}{cccccc}
\hline & 2017 & 2018 & 2019 & 2020 & 2021 \\
\hline Total & S/. 1,401,874.97 & S/. 1,593,355.34 & S/. 1,792,902.21 & S/. 1,999,885.69 & S/. 2,215,289.10 \\
\hline
\end{tabular}

Tabla 53

Presupuesto de gastos administrativos proyectado - Escenario conservador con estrategia

\begin{tabular}{|c|c|c|c|c|c|c|c|c|c|c|}
\hline & & 2017 & & 2018 & & 2019 & & 2020 & & 2021 \\
\hline Planilla & $\mathrm{S} /$. & $391,251.00$ & S/. & $391,251.00$ & S/. & $391,251.00$ & $\mathrm{~S} /$. & $391,251.00$ & S/. & $391,251.00$ \\
\hline Depreciación & S/. & $26,158.03$ & S/. & $11,105.04$ & $\mathrm{~S} /$. & $11,105.04$ & $\mathrm{~S} /$. & $11,105.04$ & S/. & $3,976.91$ \\
\hline Luz, agua, telf. & $\mathrm{S} /$. & $7,176.00$ & $\mathrm{~S} /$. & $7,176.00$ & $\mathrm{~S} /$. & $7,176.00$ & $\mathrm{~S} /$. & $7,176.00$ & $\mathrm{~S} /$. & $7,176.00$ \\
\hline Alquiler & S/. & $78,000.00$ & $\mathrm{~S} /$. & $78,000.00$ & $\mathrm{~S} /$. & $78,000.00$ & $\mathrm{~S} /$. & $78,000.00$ & $\mathrm{~S} /$. & $78,000.00$ \\
\hline $\begin{array}{l}\text { Otros } \\
\text { Amortiz. }\end{array}$ & $\mathrm{S} /$. & $6,000.00$ & $\mathrm{~S} /$. & $6,000.00$ & $\mathrm{~S} /$. & $6,000.00$ & $\mathrm{~S} /$. & $6,000.00$ & $\mathrm{~S} /$. & $6,000.00$ \\
\hline Intang. & $\mathrm{S} /$. & $1,495.00$ & S/. & $1,495.00$ & S/. & $1,495.00$ & $\mathrm{~S} /$. & $1,495.00$ & $\mathrm{~S} /$. & $1,495.00$ \\
\hline Total & $\mathrm{S} /$. & $510,080.03$ & $\mathrm{~S} /$. & $495,027.04$ & $\mathrm{~S} /$. & $495,027.04$ & $\mathrm{~S} /$. & $495,027.04$ & $\mathrm{~S} /$. & $487,898.91$ \\
\hline
\end{tabular}


A fin de considerar los valores correctos para la depreciación y amortización, se ha considerado el detalle de la inversión en activos los cuales se pueden apreciar en la tabla 54.

Tabla 54

Inversión de estrategia

\begin{tabular}{lcr}
\hline Descripción & & Monto \\
\hline Muebles de oficina & S/. & 970.00 \\
Computadoras & S/. & $19,500.00$ \\
Central telefónica & S/. & $9,750.00$ \\
Rediseño de la pag. Web & $\mathrm{S} /$. & 975.00 \\
Licencias nuevo sistema proyectos & $\mathrm{S} /$. & $6,500.00$ \\
Capital Trabajo & $\mathrm{S} /$. & $167,000.00$ \\
Total & $\mathrm{S} /$. & $204,695.00$ \\
\hline
\end{tabular}

Se ha considerado el monto que falta depreciar de acuerdo con el tipo de activo y que se viene arrastrando de ejercicios anteriores. Los montos equivalen a S/. 9,916.63 para los muebles de oficina y S/. 15,052.99 por computadoras. Se ha prorrateado estos valores en proporción para obtener la depreciación anual correspondiente sumado los nuevos activos adquiridos. En la tabla 55 se puede apreciar la depreciación de los activos considerando cuatro años para las computadoras, diez años para los muebles y enseres y cinco para los intangibles. 
Tabla 55

Depreciación de activos

\begin{tabular}{|c|c|c|c|c|c|c|c|c|c|c|}
\hline \multicolumn{2}{|l|}{ Depreciación } & \multicolumn{2}{|l|}{2017} & \multicolumn{2}{|l|}{2018} & \multicolumn{2}{|l|}{2019} & \multicolumn{2}{|l|}{2020} & 2021 \\
\hline Muebles de oficina & $\mathrm{S} /$. & 194.00 & $\mathrm{~S} /$. & 194.00 & $\mathrm{~S} /$. & 194.00 & $\mathrm{~S} /$. & 194.00 & $\mathrm{~S} /$. & 194.00 \\
\hline Computadoras & S/. & $4,875.00$ & S/. & $4,875.00$ & $\mathrm{~S} /$. & $4,875.00$ & $\mathrm{~S} /$. & $4,875.00$ & $\mathrm{~S} /$ & - \\
\hline Central Telefónica & $\mathrm{S} /$. & 975.00 & $\mathrm{~S} /$. & 975.00 & $\mathrm{~S} /$. & 975.00 & S/. & 975.00 & $\mathrm{~S} /$ & 975.00 \\
\hline Intangible & S/. & $1,495.00$ & S/. & $1,495.00$ & $\mathrm{~S} /$. & $1,495.00$ & $\mathrm{~S} /$ & $1,495.00$ & $\mathrm{~S} /$ & $1,495.00$ \\
\hline & & & & & & & Valor & ual & S/. & $1,609.63$ \\
\hline
\end{tabular}

Tabla 56

Presupuesto de gastos de ventas proyectado - Escenario conservador con estrategia

\begin{tabular}{|c|c|c|c|c|c|c|c|c|c|c|}
\hline & \multicolumn{2}{|c|}{2017} & \multicolumn{2}{|c|}{2018} & \multicolumn{2}{|c|}{2019} & \multicolumn{2}{|c|}{2020} & \multicolumn{2}{|c|}{2021} \\
\hline Página Web & $\mathrm{S} /$. & $1,000.00$ & $\mathrm{~S} /$. & $1,000.00$ & $\mathrm{~S} /$. & $1,000.00$ & $\mathrm{~S} /$. & $1,000.00$ & $\mathrm{~S} /$. & $1,000.00$ \\
\hline $\begin{array}{l}\text { Tarjetas presentación } \\
\text { Ferias, Stands, }\end{array}$ & $\mathrm{S} /$. & 900.00 & $\mathrm{~S} /$. & 900.00 & S/. & 900.00 & $\mathrm{~S} /$. & 900.00 & $\mathrm{~S} /$. & 900.00 \\
\hline Merchandising & $\mathrm{S} /$. & $7,500.00$ & $\mathrm{~S} /$. & $7,500.00$ & $\mathrm{~S} /$. & $7,500.00$ & $\mathrm{~S} /$. & $7,500.00$ & $\mathrm{~S} /$. & $7,500.00$ \\
\hline Total & $\mathrm{S} /$. & $9,400.00$ & S/. & $9,400.00$ & $\mathrm{~S} /$. & $9,400.00$ & $\mathrm{~S} /$. & $9,400.00$ & $\mathrm{~S} /$. & $9,400.00$ \\
\hline
\end{tabular}

Para financiar la estrategia propuesta se está solicitando un préstamo bancario por 50,000 soles a una tasa de $20.5 \%$ anual a un período de cinco años. El cronograma de la deuda se puede apreciar en la tabla 57. 
Tabla 57

Cronograma de la deuda

\begin{tabular}{|c|c|c|c|c|c|c|c|c|c|c|}
\hline & \multicolumn{2}{|c|}{ Año 1} & \multicolumn{2}{|c|}{ Año 2} & \multicolumn{2}{|c|}{ Año 3} & \multicolumn{2}{|c|}{ Año 4} & \multicolumn{2}{|c|}{ Año 5} \\
\hline Deuda & S/. & $43,346.72$ & S/. & $35,329.52$ & $\mathrm{~S} /$. & $25,668.79$ & $\mathrm{~S} /$. & $14,027.62$ & S/. & - \\
\hline Interés & S/. & $10,250.00$ & $\mathrm{~S} /$. & $8,886.08$ & S/. & $7,242.55$ & $\mathrm{~S} /$. & $5,262.10$ & S/. & $2,875.66$ \\
\hline Amortización & S/. & $6,653.28$ & $\mathrm{~S} /$. & $8,017.20$ & S/. & $9,660.73$ & $\mathrm{~S} /$. & $11,641.18$ & $\mathrm{~S} /$. & $14,027.62$ \\
\hline Cuota & $\mathrm{S} /$. & $16,903.28$ & $\mathrm{~S} /$. & $16,903.28$ & $\mathrm{~S} /$. & $16,903.28$ & $\mathrm{~S} /$. & $16,903.28$ & $\mathrm{~S} /$. & $16,903.28$ \\
\hline
\end{tabular}

Tabla 58

Presupuesto de gastos financieros proyectados - Escenario conservador con estrategia

\begin{tabular}{|c|c|c|c|c|c|c|c|c|c|c|}
\hline & & 2017 & & 2018 & & 2019 & & 2020 & & 2021 \\
\hline Intereses & $\mathrm{S} /$. & $10,250.00$ & $\mathrm{~S} /$. & $8,886.08$ & $\mathrm{~S} /$. & $7,242.55$ & $\mathrm{~S} /$. & $5,262.10$ & $\mathrm{~S} /$. & $2,875.66$ \\
\hline Total & S/. & $10,250.00$ & $\mathrm{~S} /$. & $8,886.08$ & $\mathrm{~S} /$. & $7,242.55$ & $\mathrm{~S} /$. & $5,262.10$ & S/. & $2,875.66$ \\
\hline
\end{tabular}


Tabla 59

Estado de resultados proyectados - escenario conservador con estrategia

\begin{tabular}{|c|c|c|c|c|c|c|c|c|c|c|}
\hline & \multicolumn{2}{|r|}{2017} & \multicolumn{2}{|r|}{2018} & \multicolumn{2}{|r|}{2019} & \multicolumn{2}{|r|}{2020} & \multicolumn{2}{|r|}{2021} \\
\hline Ventas & & $, 894,425.64$ & & $, 153,182.89$ & S/. & $2,422,840.83$ & S/. & $2,702,548.23$ & & 993,633.91 \\
\hline Costo de ventas & & ,401,874.97 & & ,593,355.34 & S/. & $1,792,902.21$ & $\mathrm{~S} /$. & $1,999,885.69$ & & $, 215,289.10$ \\
\hline Utilidad bruta & $\mathrm{S} /$. & $492,550.67$ & $\mathrm{~S} /$. & $559,827.55$ & $\mathrm{~S} /$. & $629,938.62$ & $\mathrm{~S} /$. & $702,662.54$ & $\mathrm{~S} /$. & $778,344.82$ \\
\hline $\begin{array}{l}\text { Gastos } \\
\text { Administrativos }\end{array}$ & $\mathrm{S} /$. & $510,080.03$ & S/. & $495,027.04$ & S/. & $495,027.04$ & $\mathrm{~S} /$. & $495,027.04$ & S/. & $487,898.91$ \\
\hline $\begin{array}{l}\text { Gastos Ventas } \\
\text { Utilidad }\end{array}$ & $\mathrm{S} /$. & $9,400.00$ & $\mathrm{~S} /$. & $9,400.00$ & $\mathrm{~S} /$. & $9,400.00$ & $\mathrm{~S} /$. & $9,400.00$ & $\mathrm{~S} /$. & $9,400.00$ \\
\hline Operativa & S/. & $-26,929.37$ & S/. & $55,400.51$ & S/. & $125,511.57$ & S/. & $198,235.50$ & S/. & $281,045.91$ \\
\hline $\begin{array}{l}\text { Intereses } \\
\text { Utilidad antes } \\
\text { de IR }\end{array}$ & S/. & $10,250.00$ & S/. & $46,514.43$ & $\mathrm{~S} /$. & $118,269.02$ & $\mathrm{~S} /$. & $192,973.40$ & S/. & $278,170.25$ \\
\hline Impuesto renta & $\mathrm{S} /$. & - & $\mathrm{S} /$. & $4,651.44$ & S/. & $23,043.11$ & $\mathrm{~S} /$. & $45,080.90$ & $\mathrm{~S} /$. & $70,213.97$ \\
\hline Utilidad Neta & S/. & $-37,179.37$ & S/. & $41,862.99$ & S/. & $95,225.91$ & $\mathrm{~S} /$. & $147,892.49$ & $\mathrm{~S} /$. & $207,956.27$ \\
\hline
\end{tabular}

En los estados de resultados proyectados se puede apreciar que, producto de la inversión inicial realizada para la implementación de la estrategia, la empresa termina el ejercicio del año 2017 con una pérdida de S/. -37,179.37. A pesar de que el nivel de ventas incrementa, el gasto administrativo y las obligaciones adquiridas por concepto de la deuda financiada son considerablemente altos.

Para el segundo año, se observa una recuperación en la empresa obteniendo utilidad positiva muy similar a lo que obtuvo en el año 2016. La principal causa es el aumento en el nivel de ventas y la progresiva disminución de los intereses de la deuda.

Asimismo, al ya obtener resultados positivos respecto a la utilidad, se aprecia el pago del impuesto a la renta. Este último ha sido calculado en base a lo especificado en la ley de MYPES en donde se menciona que si una empresa no excede en ventas las 1,700 UIT puede acogerse a este beneficio. Este consiste en pagar por las primeras 15 UIT el 10\% por impuesto a la renta y el resto si estaría afecto al $29.5 \%$. 
Finalmente, al finalizar el ejercicio del año 2021, se puede visualizar que la utilidad neta es considerablemente mayor comparada con la obtenida en el año 2016, lo que es un indicador del posible éxito de la estrategia a implementar.

\subsubsection{Balance general (situación actual y con la nueva estrategia)}

A fin de conocer la situación actual de la empresa, se ha procedido a mostrar en la tabla 60 el estado de situación financiera (balance general) al 31 de diciembre del 2016.

\section{Tabla 60}

Balance general al 31 de diciembre 2016 - Sin estrategia

\begin{tabular}{|c|c|c|c|}
\hline ACTIVO & & PASIVOY PATRIMONIO & \\
\hline ACTIVO CORRIENTE & & PASIVO CORRIENTE & \\
\hline Efectivo y equivalentes de efectivo & 79,230 & Otras Cuentas por Pagar & 110,593 \\
\hline Cuentas por Cobrar Comerciales & 161,518 & TOTAL PASIVO CORRIENTE & 110,593 \\
\hline Otras Cuentas por cobrar & 244 & & \\
\hline \multirow[t]{2}{*}{ TOTAL ACTIVO CORRIENTE } & 240,992 & & \\
\hline & & TOTAL PASIVO & 110,593 \\
\hline ACTIVO NO CORRIENTE & & PATRIMONIO NETO & \\
\hline Inmuebles, Maquinaria y Equipo (neto de depreciación) & 46,494 & Capital & 3,000 \\
\hline Impuesto a la Renta y Participaciones Diferidos Activo & 49,220 & Reservas Legales & 600 \\
\hline Otros Activos & 57,650 & Resultados Acumulados & 280,164 \\
\hline TOTAL ACTIVO NO CORRIENTE & 153,365 & TOTAL PATRIMONIO NETO & 283,764 \\
\hline TOTALACTIVO & 394,357 & TOTAL PASIVO Y PATRIMONIO NETO & 394,357 \\
\hline
\end{tabular}

Luego de haber conocido la situación actual de la empresa, se ha procedido a realizar una proyección anual desde el 2017 al 2021 en base a lo calculado en el flujo de caja para la inversión que se está planteando implementar. Los resultados se muestran a continuación en la tabla 61 . 


\section{Tabla 61}

Balance general - Con estrategia

\begin{tabular}{|c|c|c|c|c|c|c|}
\hline & 2016 & 2017 & 2018 & 2019 & 2020 & 2021 \\
\hline \multicolumn{7}{|l|}{ ACTIVO CORRIENTE } \\
\hline Caja y bancos & 79,230 & 138,950 & 130,009 & 228,120 & 398,776 & 634,042 \\
\hline \multicolumn{7}{|l|}{ Cuentas por cobrar } \\
\hline Comerciales & 161,518 & 186,285 & 254,076 & 285,895 & 318,901 & 353,249 \\
\hline Préstamos a terceros & 0 & 0 & 0 & 0 & 0 & 0 \\
\hline \multirow[t]{2}{*}{ Cuentas por cobrar diversas } & 244 & 0 & 0 & 0 & 0 & 0 \\
\hline & 161,762 & 186,285 & 254,076 & 285,895 & 318,901 & 353,249 \\
\hline Crédito tributario & 49,220 & 49,220 & 49,220 & 49,220 & 49,220 & 49,220 \\
\hline Imp. $\mathrm{y}$ gastos pag. $\mathrm{x}$ anticipado & 57,650 & 81,917 & 73,031 & 57,066 & 42,075 & 39,199 \\
\hline Total activo corriente & 347,863 & 456,373 & 506,336 & 620,301 & 808,971 & $1,075,710$ \\
\hline \multicolumn{7}{|l|}{ INMUEBLES,MAQ. Y EQUIPO } \\
\hline Inmuebles Maquinarias y equipos & 154,627 & 184,847 & 184,847 & 184,847 & 184,847 & 184,847 \\
\hline \multirow[t]{2}{*}{ Depreciación acumulada } & $-108,132$ & $-134,290$ & $-145,395$ & $-156,501$ & $-167,606$ & $-171,582$ \\
\hline & 46,494 & 50,556 & 39,451 & 28,346 & 17,241 & 13,264 \\
\hline \multirow[t]{2}{*}{ OTROS ACTIVOS } & 0 & 5,980 & 4,485 & 2,990 & 1,495 & 0 \\
\hline & 394,357 & 512,909 & 550,272 & 651,637 & 827,707 & $1,088,974$ \\
\hline \multicolumn{7}{|l|}{ PASIVO CORRIENTE } \\
\hline \multicolumn{7}{|l|}{ Sobregiros y préstamos bancarios } \\
\hline Cuentas por pagar comerciales & 0 & 0 & 0 & 0 & 0 & 0 \\
\hline \multicolumn{6}{|l|}{ Tributos, remuneraciones y otras } & 51,767 \\
\hline Total pasivo corriente & 110,593 & 111,629 & 102,477 & 85,574 & 68,670 & 51,767 \\
\hline \multicolumn{7}{|l|}{ PATRIMONIO NETO } \\
\hline Capital social & 3,000 & 3,000 & 3,000 & 3,000 & 3,000 & 3,000 \\
\hline Capital social Adicional & 0 & 154,695 & 154,695 & 154,695 & 154,695 & 154,695 \\
\hline Reserva Legal & 600 & 600 & 600 & 600 & 600 & 600 \\
\hline Resultados acumulados & 280,164 & 280,164 & 242,985 & 289,499 & 407,768 & 600,741 \\
\hline \multirow[t]{3}{*}{ Resultados del ejercicio } & 0 & $-37,179$ & 46,514 & 118,269 & 192,973 & 278,170 \\
\hline & 283,764 & 401,280 & 447,794 & 566,063 & 759,036 & $1,037,207$ \\
\hline & 394,357 & 512,909 & 550,272 & 651,637 & 827,707 & $1,088,974$ \\
\hline
\end{tabular}


Esta última proyección servirá de base para el análisis de los ratios financieros con la estrategia aplicada, que se visualizará en el punto 10.2.6.

\subsubsection{Flujo de efectivo (situación actual y con la nueva estrategia)}

De acuerdo con los escenarios descritos en puntos anteriores, se ha realizado una proyección de los flujos de efectivo con la nueva estrategia tomando en consideración el estado actual de la empresa. Estos flujos pueden ser visualizados en la tabla 62.

Tabla 62

Flujo de efectivo - Con estrategia

\begin{tabular}{|c|c|c|c|c|c|c|}
\hline & 0 & 2,017 & 2,018 & 2,019 & 2,020 & 2,021 \\
\hline $\begin{array}{l}\text { Ventas al Contado } \\
\text { (con IGV) }\end{array}$ & & $2,049,137$ & $2,329,026$ & $2,620,706$ & $2,923,256$ & $3,238,114$ \\
\hline $\begin{array}{l}\text { Ventas al Crédito (con } \\
\text { IGV) }\end{array}$ & & (1) & 186,285 & 211,730 & 238,246 & 265,751 \\
\hline $\begin{array}{l}\text { Costo Ventas (con } \\
\text { IGV) }\end{array}$ & & $1,654,212$ & $1,880,159$ & $2,115,625$ & $2,359,865$ & $2,614,041$ \\
\hline $\begin{array}{l}\text { Gastos } \\
\text { Administrativos }\end{array}$ & & 454,823 & 498,839 & 498,839 & 498,839 & 498,839 \\
\hline Gasto Ventas & & 11,092 & 11,092 & 11,092 & 11,092 & 11,092 \\
\hline Impuesto a la Renta & & 0 & 4,651 & 23,043 & 45,081 & 70,214 \\
\hline $\begin{array}{l}\text { IGV } \\
\text { FLUJO DE CAJA }\end{array}$ & & 63,770 & 82,665 & 95,285 & 108,376 & 121,998 \\
\hline IGV & & $-134,761$ & 37,905 & 88,552 & 138,250 & 187,680 \\
\hline
\end{tabular}

Al igual que en el estado de resultados, se puede apreciar que para el ejercicio del 2017 tenemos un flujo operativo en negativo. A pesar de que se nota un incremento en el nivel de ventas a comparación del año 2016, este no es suficiente para poder hacer frente a sus diferentes obligaciones. Esto se puede explicar por el inicio de la implementación de la estrategia.

Esta situación mejora considerablemente en el año 2018, ya con la estrategia totalmente implementada, en donde se aprecia un nivel de ventas con un aumento 
considerable (12\%). Adicionalmente, se deja de considerar el costo inicial de los activos adquiridos, por lo que se aprecia una disminución en el rubro de gastos administrativos.

Finalmente, al mantenerse la tendencia al alza (producto de la estrategia implementada) se espera culminar el ejercicio del año 2021 con un flujo operativo en positivo y superior al inicial.

\subsubsection{Proyección de flujos (situación actual y con la nueva estrategia)}

A fin de calcular los valores a proyectar para los años posteriores se ha tomado en consideración los cálculos elaborados anteriormente respecto a la operación misma de la empresa (tablas 51 a la 58). Adicionalmente, se ha calculado el capital de trabajo requerido para sostener la operación bajo esas condiciones establecidas. Este cálculo se puede apreciar en la tabla 63.

Tabla 63

Cálculo del capital de trabajo - Con estrategia

\begin{tabular}{|c|c|c|c|c|c|c|}
\hline INGRESOS & 0 & 2,017 & 2,018 & 2,019 & 2,020 & 2,021 \\
\hline Ventas al Contado & & $2,049,137$ & $2,329,026$ & $2,620,706$ & $2,923,256$ & $3,238,114$ \\
\hline Ventas al Crédito & & & 186,285 & 211,730 & 238,246 & 265,751 \\
\hline Flujo de Ingresos & 0 & $2,049,137$ & $2,515,311$ & $2,832,436$ & $3,161,502$ & $3,503,865$ \\
\hline \multicolumn{7}{|l|}{ EGRESOS } \\
\hline $\begin{array}{l}\text { Costo de Ventas } \\
\text { Gastos }\end{array}$ & & $1,654,212$ & $1,880,159$ & $2,115,625$ & $2,359,865$ & $2,614,041$ \\
\hline Administrativos & & 454,823 & 498,839 & 498,839 & 498,839 & 498,839 \\
\hline Gasto Ventas & & 11,092 & 11,092 & 11,092 & 11,092 & 11,092 \\
\hline Flujo de Egresos & 0 & $2,120,127$ & $2,390,090$ & $2,625,555$ & $2,869,796$ & $3,123,972$ \\
\hline Saldo de Periodo & & $-70,990$ & 125,221 & 206,881 & 291,707 & 379,893 \\
\hline \multirow[t]{2}{*}{ Saldo Acumulado } & & $-70,990$ & 54,231 & 261,112 & 552,818 & 932,711 \\
\hline & 2,016 & 2,017 & 2,018 & 2,019 & 2,020 & 2,021 \\
\hline Capital Trabajo & & $-70,990$ & $-80,546$ & $-91,389$ & $-103,691$ & $-117,648$ \\
\hline $\begin{array}{l}\text { Capital de trabajo } \\
\text { incremental }\end{array}$ & $-70,990$ & $-9,556$ & $-10,842$ & $-12,302$ & $-13,958$ & \\
\hline $\begin{array}{l}\text { Recuperación de cap } \\
\text { trabajo }\end{array}$ & & & & & & 117,648 \\
\hline
\end{tabular}


Como demuestra la tabla 63, el capital de trabajo necesario para solventar toda la operación con la estrategia planteada es de S/. 117,648. Con este valor obtenido, ya es posible completar la proyección de los flujos de caja hasta el año 2021, los cuales se pueden visualizar en la tabla 64.

Tabla 64

Flujo de caja proyectado - Con estrategia

\begin{tabular}{|c|c|c|c|c|c|c|}
\hline & 0 & 2,017 & 2,018 & 2,019 & 2,020 & 2,021 \\
\hline Ventas al Contado (con IGV) & & $2,049,137$ & $2,329,026$ & $2,620,706$ & $2,923,256$ & $3,238,114$ \\
\hline Ventas al Crédito (con IGV) & & 0 & 186,285 & 211,730 & 238,246 & 265,751 \\
\hline Costo Ventas (con IGV) & & $1,654,212$ & $1,880,159$ & $2,115,625$ & $2,359,865$ & $2,614,041$ \\
\hline Gastos Administrativos & & 454,823 & 498,839 & 498,839 & 498,839 & 498,839 \\
\hline Gasto Ventas & & 11,092 & 11,092 & 11,092 & 11,092 & 11,092 \\
\hline Impuesto a la Renta & & 0 & 4,651 & 23,043 & 45,081 & 70,214 \\
\hline $\begin{array}{l}\text { IGV } \\
\text { FLUJO DE CAJA }\end{array}$ & & 63,770 & 82,665 & 95,285 & 108,376 & 121,998 \\
\hline $\begin{array}{l}\text { OPERATIVO con IGV } \\
\text { Inversión Activo Fijo e } \\
\text { Intangibles }\end{array}$ & $-44,480$ & $-134,761$ & 37,905 & 88,552 & 138,250 & 187,680 \\
\hline Valor de Salvamento & & & & & & 1,610 \\
\hline Capital de Trabajo (KW) & $-70,990$ & $-9,556$ & $-10,842$ & $-12,302$ & $-13,958$ & \\
\hline $\begin{array}{l}\text { Recuperación KW } \\
\text { FLUJO DE CAJA }\end{array}$ & & & & & & 117,648 \\
\hline INVERSION con IGV & $-115,470$ & $-9,556$ & $-10,842$ & $-12,302$ & $-13,958$ & 119,258 \\
\hline $\begin{array}{l}\text { FLUJO DE CAJA } \\
\text { ECONÓMICO con IGV }\end{array}$ & $-115,470$ & $-144,317$ & 27,062 & 76,250 & 124,292 & 306,938 \\
\hline Préstamo & 50,000 & & & & & \\
\hline Pago de Cuota & & $-16,903$ & $-16,903$ & $-16,903$ & $-16,903$ & $-16,903$ \\
\hline $\begin{array}{l}\text { Escudo Fiscal } \\
\text { FLUJO DE CAJA }\end{array}$ & & 5,071 & 5,071 & 5,071 & 5,071 & 5,071 \\
\hline FINANCIERO con IGV & $-65,470$ & $-156,149$ & 15,230 & 64,418 & 112,460 & 295,106 \\
\hline
\end{tabular}

Como se puede apreciar en esta proyección, se ha considerado el pago de la deuda adquirida por concepto de la inversión inicial que se está planteando hacer, así como el escudo fiscal, la recuperación del capital de trabajo y el valor residual producto de la depreciación y amortización de intangibles. 


\subsubsection{Evaluación financiera (VAN, TIR y ratios financieros)}

De acuerdo con lo planteado por Gitman \& Zutter (2012), "El análisis de razones financieras incluye métodos de cálculo e interpretación de las razones financieras para analizar y supervisar el desempeño de la empresa” (p. 61). De acuerdo con esto, más importante que el valor obtenido para cada uno de los ratios o razones, es la interpretación que se le pueda dar a ese valor.

A continuación, se describen los ratios financieros de acuerdo con su clasificación y en donde se puede apreciar la fórmula para poder calcularlos.:

- Ratios de liquidez: Miden la capacidad que tiene la empresa de pagar sus obligaciones o pasivos de corto plazo o corrientes con activos de corto plazo o corrientes. Esto son:

Liquidez general $=$ Activo corriente $/$ Pasivo corriente Prueba ácida $=$ Activo corriente - Existencias- GPA $/$ Pasivo corriente Prueba defensiva $=$ Caja y bancos + valores negociables $/$ Pasivo corriente Capital de trabajo neto $=$ Activo corriente - Pasivo corriente $/$ Ventas

- Ratios de apalancamiento: miden la capacidad que tiene la empresa para responder por las deudas de corto y largo plazo. Permiten conocer el respaldo con el que afrontan el total de sus deudas. Estos son:

Solvencia patrimonial $=$ Pasivo total $/$ Patrimonio

Grado de endeudamiento total $=$ Pasivo total $/$ activo total

Multiplicador de capital $=$ Total activos $/$ patrimonio

Cobertura de intereses $=$ Utilidad operativa $/$ gastos financieros

- Ratios de actividad: evalúan el impacto de las decisiones y políticas que la empresa aplica para el uso de sus recursos. Miden la eficacia del uso de estos recursos. Estos son: 
Rotación de cuentas por cobrar $=$ ventas al crédito $/$ cuentas por cobrar comerciales

Período promedio de cobro $=$ clientes $\times 360 /$ ventas

Rotación de cuentas por pagar = compras al crédito / cuentas por pagar comerciales

Período promedio de pago $=$ proveedores $\times 360 /$ compras

Rotación de inventarios $=$ costo de ventas $/$ existencias

Período promedio de inventarios $=$ existencias $\times 360 /$ costo de ventas

Rotación de activos totales $=$ ventas totales $/$ activos totales

De todos estos ratios sólo se analizará la rotación de activos totales y el

período promedio de cobro, a fin de determinar el ingreso de real de efectivo y

la eficiencia del uso de sus recursos.

- Ratios de rentabilidad: permiten la evaluación de los resultados de la gestión empresarial, es decir, la capacidad de obtener un rendimiento sobre los recursos obtenidos. Estos son:

Margen Bruto $=$ utilidad bruta $/$ ventas

Margen Operativo = utilidad operativa $/$ ventas

Margen Neto $=$ utilidad neta $/$ ventas

Poder adquisitivo básico $=$ utilidad operativa / activo

Rentabilidad del patrimonio $=$ utilidad neta $/$ patrimonio

Rendimiento operativo del activo total $=$ utilidad neta $/$ activo

- Ratios de mercado: permite ver la relación entre los valores de la contabilidad y los valores del mercado de acciones. Estos son:

Precio sobre UPA $($ PER $)=$ precio de mercado acción / utilidad por acción Dividend Yield $=$ dividendos por acción / precio mercado acción 
Mercado a libros acción = precio mercado acción / valor libros por acción

De todos los ratios anteriormente descritos, no se analizarán los correspondientes a los ratios de mercado debido a que no se cuenta con información suficiente para obtenerlos.

De acuerdo con el marco teórico anteriormente descrito, se ha podido obtener los diferentes ratios financieros para la empresa Xternal Technological Solutions S.A.C. Estos serán interpretados bajo un escenario con la estrategia planteada. Los ratios financieros pueden ser apreciados en la tabla 69.

Adicionalmente, se ha analizado los flujos de caja financieros proyectados a fin de poder realizar la evaluación del valor actual neto (VAN), la tasa de interés de retorno (TIR) y el WACC. Para iniciar con los cálculos de los indicadores necesarios para la evaluación, es necesario conocer la estructura de la deuda de la empresa (ver Tabla 65).

Tabla 65

Estructura de deuda de la empresa

\begin{tabular}{lrrrrrr}
\hline & Año 0 & 2017 & 2018 & 2019 & 2020 & 2021 \\
\hline Deuda & $50,000.00$ & $43,346.72$ & $35,329.52$ & $25,668.79$ & $14,027.62$ & - \\
Patrimonio & $204,695.00$ & $167,515.63$ & $209,378.62$ & $304,604.54$ & $452,497.03$ & $660,453.30$ \\
Total & $254,695.00$ & $210,862.36$ & $244,708.14$ & $330,273.33$ & $466,524.65$ & $660,453.30$ \\
& & & & & & \\
\%Deuda & $20 \%$ & $21 \%$ & $14 \%$ & $8 \%$ & $3 \%$ & $0 \%$ \\
\%Patrimonio & $80 \%$ & $79 \%$ & $86 \%$ & $92 \%$ & $97 \%$ & $100 \%$ \\
\hline
\end{tabular}

El costo de la deuda se ha calculado en base a la tasa de interés del préstamo (20.5\%) y el impuesto a la renta (29.5\%). El resultado se visualiza a continuación:

Costo de la deuda $(\mathrm{kd})=20.5 \% *(1-29.5 \%)=14 \%$.

Se ha obtenido un beta desapalancado de la industria de servicios de software (damodaran) de 0.94. Adicionalmente, se ha considerado una tasa de libre riesgo (rf) de 
$5.18 \%$ y una tasa de riesgo de mercado de $11.42 \%$ (datos proporcionados en la base de damodaran). La tasa de riesgo país considerada es de $1.27 \%$.

Con estos valores se ha procedido a apalancar el beta a la estructura de deuda de la empresa y se ha calculado el cok y el wacc de la inversión propuesta. La tabla 66 muestra los valores utilizados en el cálculo del cok de la empresa y su procedencia. La tabla 67 muestra la estructura de la deuda y los resultados finales de ese cálculo se aprecian en la tabla 68.

Tabla 66

Variables utilizadas en el cálculo del cok y su procedencia

\begin{tabular}{lcc}
\hline \multicolumn{1}{c}{ Variable } & \multicolumn{1}{c}{ Valor } & Fuente \\
\hline Riesgo País & $1.27 \mathrm{http} / / /$ www.ambito.com/economia/mercados/riesgo-pais/info/?id=13 \\
Tasa de libre riesgo (rf) & $5.18 \mathrm{http} / / /$ pages.stern.nyu.edu/ adamodar/ (Aritmethics Average - 1928/2016) \\
Riesgo del mercado (rm) & $11.42 \mathrm{http} / / /$ pages.stern.nyu.edu/ adamodar/ (Aritmethics Average - 1928/2016) \\
Prima de riesgo [rm-rf] & 6.24 Dato calculado [rm-rf] \\
Beta desapalancado $(\beta \mathrm{a})$ & 0.94 http://pages.stern.nyu.edu/ adamodar/ (Software System/Applications) \\
\hline
\end{tabular}

Tabla 67

Estructura de la deuda de la empresa Xternal Technological Solutions S.A.C.

\begin{tabular}{lrrrrrr}
\hline Estructura & 2016 & 2017 & 2018 & 2019 & 2020 & 2021 \\
\hline$\%$ Deuda & $20 \%$ & $21 \%$ & $14 \%$ & $8 \%$ & $3 \%$ & $0 \%$ \\
$\%$ Patrimonio & $80 \%$ & $79 \%$ & $86 \%$ & $92 \%$ & $97 \%$ & $100 \%$ \\
\hline
\end{tabular}

Tabla 68

Cálculo de cok y wacc de la inversión

\begin{tabular}{lrrrrr}
\hline & 2017 & 2018 & 2019 & 2020 & 2021 \\
\hline Beta Apalancado & 1.11 & 1.05 & 1.00 & 0.96 & 0.94 \\
Cok & $13.39 \%$ & $13.01 \%$ & $12.66 \%$ & $12.44 \%$ & $12.32 \%$ \\
& & & & & \\
WACC & $13.60 \%$ & $13.22 \%$ & $12.80 \%$ & $12.50 \%$ & $12.32 \%$ \\
\hline
\end{tabular}

De acuerdo con estos valores, y en base a lo proyectado en el flujo de cada financiero, se ha procedido a calcular el VAN y el TIR de la inversión cuyo resultado es:

$\mathrm{VAN}=76,285$

$\mathrm{TIR}=24.09 \%$ 
$\mathrm{Al}$ obtener un VAN positivo y un TIR superior al WACC, se puede afirmar que la inversión es viable.

Tabla 69

Ratios financieros

\begin{tabular}{|c|c|c|c|c|c|c|}
\hline Liquidez & 2016 & 2017 & 2018 & 2019 & 2020 & 2021 \\
\hline Liquidez general & 3.15 & 4.09 & 4.94 & 7.25 & 11.78 & 20.78 \\
\hline Prueba ácida & 3.15 & 4.09 & 4.94 & 7.25 & 11.78 & 20.78 \\
\hline Prueba defensiva & 0.72 & 1.24 & 1.27 & 2.67 & 5.81 & 12.25 \\
\hline Capital trabajo neto & 0.14 & 0.18 & 0.19 & 0.22 & 0.27 & 0.34 \\
\hline \multicolumn{7}{|l|}{ Apalancamiento } \\
\hline Solvencia patrimonial & 3.57 & 4.59 & 5.37 & 7.61 & 12.05 & 21.04 \\
\hline $\begin{array}{l}\text { Grado de } \\
\text { endeudamiento total }\end{array}$ & 0.28 & 0.22 & 0.19 & 0.13 & 0.08 & 0.05 \\
\hline Multiplicador de capital & 1.39 & 1.28 & 1.23 & 1.15 & 1.09 & 1.05 \\
\hline Cobertura de intereses & -63.86 & -2.63 & 6.23 & 17.33 & 37.67 & 97.73 \\
\hline \multicolumn{7}{|l|}{ Actividad } \\
\hline $\begin{array}{l}\text { Rotación de cuentas } \mathrm{x} \\
\text { cobrar }\end{array}$ & 35.42 & 30.74 & 31.15 & 37.75 & 38.08 & 38.35 \\
\hline $\begin{array}{l}\text { Rotación de activos } \\
\text { totales }\end{array}$ & 4.16 & 5.45 & 4.72 & 4.79 & 4.36 & 3.70 \\
\hline \multicolumn{7}{|l|}{ Rentabilidad } \\
\hline $\begin{array}{l}\text { Margen bruto sobre } \\
\text { ventas }\end{array}$ & 0.24 & 0.26 & 0.26 & 0.26 & 0.26 & 0.26 \\
\hline $\begin{array}{l}\text { Margen operativo sobre } \\
\text { ventas }\end{array}$ & 0.02 & -0.01 & 0.03 & 0.05 & 0.07 & 0.09 \\
\hline $\begin{array}{l}\text { Margen neto sobre } \\
\text { ventas }\end{array}$ & 0.02 & -0.02 & 0.02 & 0.04 & 0.05 & 0.07 \\
\hline $\begin{array}{l}\text { Poder adquisitivo } \\
\text { básico }\end{array}$ & 0.14 & -0.08 & 0.12 & 0.25 & 0.32 & 0.35 \\
\hline $\begin{array}{l}\text { Rentabilidad del } \\
\text { patrimonio }\end{array}$ & 0.09 & -0.09 & 0.09 & 0.17 & 0.19 & 0.20 \\
\hline $\begin{array}{l}\text { Rendimiento operativo } \\
\text { del activo total }\end{array}$ & 0.07 & -0.07 & 0.08 & 0.15 & 0.18 & 0.19 \\
\hline
\end{tabular}

En base a los resultados obtenidos del análisis financiero realizado a los estados

financieros de la empresa, se puede observar que la liquidez va aumentando siendo este un indicador propio de las empresas de servicios de TI. Es positivo que este tipo de empresas cuente con liquidez a fin de afrontar posibles contrataciones de consultores externos para 
responder a proyectos específicos que surgen de nuevos requerimientos no planificados por sus clientes o no clientes. Asimismo, se puede visualizar que en un escenario con la estrategia propuesta se alcanza el objetivo estratégico de incrementar el ROE a un $20 \%$ al finalizar el 5to año de la implementación del presente plan. También se puede afirmar que la empresa se vuelve más eficiente en el uso de sus activos respecto a la utilidad obtenida, teniendo una tendencia al alza en el ratio del ROA. 


\section{Conclusiones}

- Xternal Technological Solutions S.A.C. es una empresa relativamente joven y en crecimiento. Para lograr alcanzar sus objetivos organizacionales se tiene que seguir una serie de políticas y estrategias que consoliden este crecimiento en el tiempo para que resulte ser sostenible.

- A partir del análisis realizado en el presente trabajo se han concretado una serie de estrategias, que podrían utilizarse en la intención de asegurar la consecución de los objetivos planteados por la organización.

- Luego de las reuniones realizadas con los representantes de Xternal Technological Solutions S.A.C. se puede afirmar que es una empresa que, por estar en crecimiento, tiene muchos aspectos posibles de mejorar dado que no contaban con un proceso de planificación estratégica.

- Se puede señalar que adolecen de la falta de un área de Capital Humano que se encarga del bienestar de sus colaboradores, que promueva un mejor clima laboral y que estos factores se vean reflejados en los resultados de la empresa Xternal Technological Solutions S.A.C..

- El plan estratégico planteado, toma en cuenta la implementación de acciones orientadas a mejorar el clima laboral de la empresa. Se proponer revisar y reformular el organigrama y la descripción de puestos, elaborar el manual de organización y funciones, revisar políticas de remuneración, desarrollar un plan de capacitación de personal.

- A partir del análisis de sus procesos operativos, se observan muchas oportunidades de mejora. Respecto a la calidad del servicio que brindan es un punto fuerte, pero podrían implementar actividades para mejorar sus procesos, con la intención reducir costos de operación. 
- En el aspecto comercial, la estrategia no ha estado orientada a seguir creciendo, sino a continuar con sus fortalezas actuales, por lo que se plantea en el presente trabajo reducir el riesgo de centrarse en una sola línea de negocio y lograr una mayor participación de mercado, frente a sus competidores directos.

- Se está planteando una estrategia de penetración de mercado, que busca que la organización no reduzca su posicionamiento de marca, sino que pueda alcanzar un prestigio también en otros nichos dentro del mercado, que pueda alcanzar nuevos y mayores clientes.

- A partir de la implementación exitosa de las estrategias planteadas en el presente trabajo, se espera que Xternal Techonological Solutions S.A.C. pueda alcanzar sus objetivos organizacionales, planteados dentro de un periodo de 5 años. 


\section{Recomendaciones}

- Se recomienda que la empresa Xternal Technological Solutions S.A.C. implemente el presente plan estratégico formulado, el cual permitiría alcanzar los objetivos estratégicos y específicos planteados para el período 2017-2021.

- Debido a que cuentan con una excelente plana de recursos humanos, se recomienda la creación de un centro de capacitación en el cual los expertos brinden asesorías a técnicos con el propósito de contar con la cantidad y calidad necesaria de recursos humanos cuando la empresa requiera de personal. Además, se requiere reforzar el área de recursos humanos de la empresa para tener una mejor administración de ellas.

- Debido a la gran cantidad de pymes en el país, se recomienda brindar servicios tecnológicos acorde a la necesidad de ese sector con el propósito de que la tecnología ayude a las pymes a ordenarse contablemente y lograr el crecimiento de ellas.

- Ante la reorientación de los esfuerzos apuntando hacia un nuevo mercado (empresas Pymes), se recomienda la creación de un área de marketing y comercialización especializada para que se encargue de la captación de los nuevos probables clientes.

- Se recomienda que los dueños de la empresa se desliguen en un corto plazo de la operatividad diaria, a fin de reenfocar sus esfuerzos en la gestión de la empresa. 


\section{Referencias}

02.01.2015. (n. d.). Press release display page (ESP). Recuperado de http://www.strategyand.pwc.com/es/home/prensa/prensa-estudios/display/ict-50-esp

Alineamiento estratégico de la gestión del capital humano en el sector minero metalúrgico. Recuperado de http://revistasinvestigación.unmsm.edu.pe/index.php/idata/article/view/11921/10666/ 11921-41551-1-PB.pdf

Barrios, H.J., Castillo, G., Cornejo, M.,\& Gutiérrez, K. (2015). Plan estratégico para la empresa Arco Publicidad Exterior S.A.. San Ignacio de Loyola, Lima.

cdi.org.pe. (n. d.). CDI -- WEF -Informe Global de tecnología de la información 2016. Recuperado de http://www.cdi.org.pe/InformeGlobaldeInformacion/GITR2016.html Chiavenato, I., \& Sapiro, A. (2011). Planeación estratégica. Fundamentos y aplicaciones (2. ${ }^{a}$ ed.). McGraw-Hill Interamericana.

David, F. (2013). Conceptos de administración estratégica (14. $\left.{ }^{\mathrm{a}} \mathrm{ed}.\right)$. Pearson.

el peruano.pe. (2013). DECRETO SUPREMO N 013-2013-PRODUCE - Norma Legal Diario Oficial El Peruano. Recuperado de http://busquedas.elperuano.com.pe/normaslegales/aprueban-texto-unico-ordenado-dela-ley-de-impulso-al-desarr-decreto-supremo-n-013-2013-produce-1033071-5/ gestion.pe. (2015, mayo 25). Un 40\% de empresas peruanas utiliza tecnología en la nube. Recuperado de http://gestion.pe/tecnologia/40-empresas-peruanas-utilizan-tecnologianube-2132826

gestion.pe. (2016a, mayo 21). Industria del software peruano seguirá creciendo a dos dígitos, según experto. Recuperado de http://gestion.pe/tecnologia/industria-softwareperuano-seguira-creciendo-dos-digitos-segun-experto-2161373 
gestion.pe. (2016b, junio 8). Mercado laboral demanda 20,000 profesionales en redes TIC.

Recuperado de http://gestion.pe/empleo-management/mercado-laboral-demanda20000-profesionales-redes-tic-2162755

gestion.pe. (2016c, agosto 15). Las nuevas reinas de Wall Street son empresas tecnológicas. Recuperado de http://gestion.pe/empresas/nuevas-reinas-wall-street-son-empresastecnologicas-2167768

gestion.pe. (2016d, febrero 19). Cerca de S/ 6 millones serán destinados a deducción tributaria para mypes que inviertan en tecnología. Recuperado de https://gestion.pe/tecnologia/cerca-s-6-millones-seran-destinados-deducciontributaria-mypes-inviertan-tecnologia-145201

gestion.pe. (2017, febrero 27). Perú en el top 5 de países con mayor demanda de ERP en América Latina. Recuperado de http://gestion.pe/tecnologia/peru-top-5-paises-mayordemanda-erp-america-latina-2183213

Gitman, L., \& Zutter, C. (2012). Principios de administración financiera (12. a ed.). Mexico: Pearson.

Hernández, A., \& Gomez, P. (2014). Factores claves de éxito y la competitividad de las empresas en el valle del Cauca. ICESI, Santiago de Cali, Colombia.

Hitt, M. A., Ireland, R. D., \& Hoskisson, R. E. (2015). Administración Estratégica Competetitividad y Globalización: Conceptos y Casos (11. a ed.). Cencage Learning. Hunger, J. D., \& Wheeler, T. L. (2013). Administración estratégica y política de negocio (13. ${ }^{\mathrm{a}}$ ed.). Pearson.

inei.gob.pe. (2016). Más de 235 mil empresas se crearon en el 2015. Recuperado de https://www.inei.gob.pe/prensa/noticias/mas-de-235-mil-empresas-se-crearon-en-el2015-8817/ 
Kaplan, R., \& Norton, D. (2014). El cuadro de mando integral (tercera). Ediciones Gestion 2000.

Kotler, P., \& Armstrong, G. (2012). Marketing (14. ${ }^{\mathrm{a}}$ ed.). Mexico: Pearson.

Laudon, K. C., \& Laudon, J. P. (2016). Sistemas de Información Gerencial (14. ${ }^{a}$ ed.). Mexico: Pearson.

Lay, D., Lazaro, C., \& Randish, C. (2014). Plan estratégico para la galería Multicentro Santa Clara. San Ignacio de Loyola, Lima.

MMM_2017_2019_Revisado.pdf. (n. d.). Recuperado de https://www.mef.gob.pe/contenidos/pol_econ/marco_macro/MMM_2017_2019_Revi sado.pdf

Moragues, A (2014). Plan de negocio "Empresa distribuidora de productos de estética". Universidad Politécnica de Valencia, Valencia, España.

Muñiz, R., \& Muñiz, V. (2016). Marketing en el siglo XXI (1. ${ }^{a}$ ed.). España: Centro de Estudios Financieros.

portal.concytec.gob.pe (2016). Concytec: Fondos para ciencia y tecnología deben dirigirse a las líneas prioritarias nacionales. Recuperado de https://portal.concytec.gob.pe/index.php/noticias/773-concytec-fondos-para-ciencia-ytecnologia-deben-dirigirse-a-las-lineas-prioritarias-nacionales)

reporte-de-inflacion-diciembre-2016-presentacion.pdf. (n. d.). Recuperado de http://www.bcrp.gob.pe/docs/Publicaciones/ReporteInflacion/2016/diciembre/reporte-de-inflacion-diciembre-2016-presentacion.pdf Tendencias en Tecnología para 2017 según Gartner Inc. (n. d.). Recuperado de http://omegasoftve.com/tendencias-en-tecnologia-para-2017-segun-gartner-inc/ Thompson, A. A., Gamble, J., Peteraf, M., \& Strickland III, A. J. (2012). Administración estratégica Teoría y casos (18. ${ }^{\mathrm{a}}$ ed.). Mexico: McGraw-Hill Interamericana. 
Tineo, R. (2016, diciembre 1). Perú destina 2.57\% del PBI a inversiones en tecnología, por encima del promedio en Latinoamérica. Recuperado de http://gestion.pe/economia/peru-destina-257-pbi-inversiones-tecnologia-encimapromedio-latinoamerica-2176083 


\section{Anexos}

\section{Anexo1}

Ficha técnica de la entrevista

\begin{tabular}{|l|l|}
\hline Técnica empleada: & Entrevista profundidad \\
\hline Localización: & Lima Metropolitana \\
\hline \multirow{4}{*}{ Objetivo del estudio: } & $\begin{array}{l}\text { Obtener información acerca de la empresa Xternal } \\
\text { Technological Solutions S.A.C. para poder elaborar } \\
\text { su Planeación Estratégica. Tratando temas como su } \\
\text { misión, visión, valores, análisis interno, análisis } \\
\text { externo, objetivos y estrategias de la organización. }\end{array}$ \\
\hline \multirow{5}{*}{ Temas estudiados: } & a. Visión, Misión y Valores \\
\cline { 2 - 2 } & b. Análisis Interno \\
\cline { 2 - 2 } & c. Análisis externo \\
\cline { 2 - 2 } & $\begin{array}{l}\text { d. Formulación de Objetivos y Diseño de las } \\
\text { Estrategias }\end{array}$ \\
\cline { 2 - 2 } & e. Evaluación \\
\hline \multirow{2}{*}{ Fechas de estudio: } & $\cdot$ Lunes 13 de marzo de 2017 \\
\cline { 2 - 2 } Hora: & $\cdot$ Miércoles 15 de marzo de 2017 \\
\hline Duración: & $\cdot 7$ pm \\
\hline
\end{tabular}

Ficha técnica del entrevistado

\begin{tabular}{|l|l|}
\hline Nombre: & Carlos Lahura \\
\hline Edad: & 42 años \\
\hline Nacionalidad: & Peruano \\
\hline Ocupación: & Gerente General \\
\hline Profesión: & Ingeniero de Sistemas \\
\hline $\begin{array}{l}\text { Distrito de } \\
\text { Residencia: }\end{array}$ & Carabayllo \\
\hline Breve reseña: & $\begin{array}{l}\text { Se desempeña como Gerente General y a su vez como Gerente } \\
\text { de la unidad Portal de la empresa Xternal Technological } \\
\text { Solutions. }\end{array}$ \\
\hline
\end{tabular}




\begin{tabular}{|l|l|}
\hline Nombre: & Felipe Pari \\
\hline Edad: & 42 años \\
\hline Nacionalidad: & Peruano \\
\hline Ocupación: & Gerente de Unidad ABAP \\
\hline Profesión: & Ingeniero de Sistemas \\
\hline $\begin{array}{l}\text { Distrito de } \\
\text { Residencia: }\end{array}$ & Pueblo Libre \\
\hline Breve reseña: & $\begin{array}{l}\text { Se desempeña como Gerente de Unidad ABAP en la empresa } \\
\text { Xternal Technological Solutions S.A. }\end{array}$ \\
\hline
\end{tabular}

Guía de la entrevista

\begin{tabular}{|c|c|c|}
\hline \multicolumn{2}{|l|}{ Día: 15 de marzo del 2017} & Hora: 08:00pm \\
\hline \multicolumn{2}{|c|}{$\begin{array}{l}\text { Lugar: Instalaciones de Xternal Technological } \\
\text { Solutions S.A.C. }\end{array}$} & Entrevistado: Carlos Lahura, Felipe Pari \\
\hline \multicolumn{3}{|c|}{ Tema: Misión, Visión, Valores y Matrices Estratégicas } \\
\hline Pregunta 1: & \multicolumn{2}{|c|}{$\begin{array}{l}\text { ¿Cuáles serán sus clientes mañana, serán los mismos? ¿Cuáles } \\
\text { serán sus principales necesidades? ¿Serán más exigentes? } \\
\text { ¿Respecto de qué? ¿A través de que canales se llegará mejor a } \\
\text { ellos? ¿Habrá cambios relevantes en sus estilos de vida, } \\
\text { hábitos, preferencias, etc.? }\end{array}$} \\
\hline TÓPICO - MERCADO & \multicolumn{2}{|c|}{$\begin{array}{l}\text { Apuntes: La empresa considera en caso tuviese inconvenientes } \\
\text { dentro del sector que está cubriendo actualmente desarrollarían } \\
\text { servicios de tecnología acorde de las necesidades de las pymes. }\end{array}$} \\
\hline Pregunta 2: & \multicolumn{2}{|c|}{$\begin{array}{l}\text { ¿Cuál será la importancia de sus productos o servicios actuales } \\
\text { para ellos? ¿Qué grado de sustituibilidad tendrán sus productos } \\
\text { y servicios? }\end{array}$} \\
\hline TÓPICO - MERCADO & \multicolumn{2}{|c|}{$\begin{array}{l}\text { Apuntes: Sus productos son sustituibles lo que consideran una } \\
\text { amenaza para ellos, siendo necesario encontrar un valor } \\
\text { agregado a sus productos }\end{array}$} \\
\hline Pregunta 3: & \multicolumn{2}{|c|}{$\begin{array}{l}\text { ¿Quiénes serán sus competidores? ¿Serán los mismos de hoy } \\
\text { día? ¿Cuáles serán las principales características de la } \\
\text { competencia? ¿Tiende a cambiar su perfil? }\end{array}$} \\
\hline $\begin{array}{l}\text { TÓPICO - } \\
\text { COMPETENCIA }\end{array}$ & \multicolumn{2}{|c|}{$\begin{array}{l}\text { Apuntes: Las barreras de entradas al mercado de nuevas } \\
\text { empresas no son muy altas por lo que es probable la aparición } \\
\text { de nuevos competidores. }\end{array}$} \\
\hline Pregunta 4: & \multicolumn{2}{|c|}{$\begin{array}{l}\text { ¿Cómo luce la calidad de sus productos y servicios frente a los } \\
\text { de la competencia? }\end{array}$} \\
\hline $\begin{array}{l}\text { TÓPICO - } \\
\text { COMPETENCIA }\end{array}$ & \multicolumn{2}{|c|}{$\begin{array}{l}\text { Apuntes: La empresa busca ser reconocida por brindar servicios } \\
\text { de calidad }\end{array}$} \\
\hline Pregunta 5: & \multicolumn{2}{|c|}{$\begin{array}{l}\text { ¿Cuáles serán las principales características, preocupaciones o } \\
\text { cambios relevantes que se producirán en nuestro sector? ¿Será }\end{array}$} \\
\hline
\end{tabular}




\begin{tabular}{|c|c|}
\hline & $\begin{array}{l}\text { un sector concentrado? ¿Fragmentado? ¿En qué fase del ciclo } \\
\text { de vida se encontrará en los próximos } 5 \text { años? }\end{array}$ \\
\hline $\begin{array}{l}\text { TÓPICO - SECTOR } \\
\text { ECONÓMICO }\end{array}$ & $\begin{array}{l}\text { Apuntes: La tecnología va evolucionando por ende la empresa } \\
\text { debe mantener el crecimiento al mismo ritmo para poder } \\
\text { sobrevivir en el mercado }\end{array}$ \\
\hline Pregunta 6: & $\begin{array}{l}\text { ¿En general, cómo ven la economía nacional? (Producción, } \\
\text { ahorro, inversión, etc.) }\end{array}$ \\
\hline $\begin{array}{l}\text { TÓPICO - ECONOMÍA } \\
\text { NACIONAL }\end{array}$ & $\begin{array}{l}\text { Apuntes: Se puede observar un crecimiento importante de } \\
\text { empresas pequeñas y por lo tanto muchas de ellas buscan } \\
\text { invertir en tecnología. }\end{array}$ \\
\hline Pregunta 7: & ¿Qué rendimientos quieren brindar al capital aportado? \\
\hline TÓPICO - ACCIONISTAS: & $\begin{array}{l}\text { Apuntes: Un incremento significativo en la rentabilidad que } \\
\text { haga atractivo la inversión en la empresa }\end{array}$ \\
\hline Pregunta 8: & ¿Cuáles serán sus principales indicadores financieros? \\
\hline TÓPICO - ACCIONISTAS: & $\begin{array}{l}\text { Apuntes: Los principales ratios financieros serán el ROE, la } \\
\text { liquidez y margen neto }\end{array}$ \\
\hline Pregunta 9: & ¿Cómo quieren manejar la relación con sus colaboradores? \\
\hline $\begin{array}{l}\text { TÓPICO - RECURSOS } \\
\text { HUMANOS }\end{array}$ & $\begin{array}{l}\text { Apuntes: Tener una relación de confiabilidad brindando } \\
\text { transparencia en las acciones que realiza la empresa }\end{array}$ \\
\hline Pregunta 10: & ¿Cómo atenderán sus necesidades? \\
\hline $\begin{array}{l}\text { TÓPICO - RECURSOS } \\
\text { HUMANOS }\end{array}$ & $\begin{array}{l}\text { Apuntes: Las necesidades de conocimiento serán atendidas a } \\
\text { través de capacitaciones constantes para brindar un servicio de } \\
\text { calidad, puesto que cada uno de ellos representa a la empresa }\end{array}$ \\
\hline Pregunta 11: & ¿Cuáles serán las competencias fundamentales? \\
\hline $\begin{array}{l}\text { TÓPICO - RECURSOS } \\
\text { HUMANOS }\end{array}$ & $\begin{array}{l}\text { Apuntes: Las competencias fundamentales serán los que } \\
\text { representan a la empresa como honestidad, trabajo en equipo, } \\
\text { excelencia y creatividad }\end{array}$ \\
\hline Pregunta 12: & ¿Qué los diferenciará del resto de las empresas? \\
\hline $\begin{array}{l}\text { TÓPICO - RECURSOS } \\
\text { HUMANOS }\end{array}$ & $\begin{array}{l}\text { Apuntes: Se busca que todo el personal cuente con un alto nivel } \\
\text { de conocimiento de la especialidad que desarrollan a fin de } \\
\text { crear una marca confiable }\end{array}$ \\
\hline Pregunta 13: & ¿Cómo quieren ser reconocidos por los clientes? \\
\hline
\end{tabular}




\begin{tabular}{|c|c|}
\hline TÓPICO - CLIENTES & Apuntes: Por alta calidad de conocimiento de sus colaboradores \\
\hline Pregunta 14: & ¿Qué necesidades quieren atender? \\
\hline TÓPICO - CLIENTES & $\begin{array}{l}\text { Apuntes: Atender sus necesidades de comunicación entre sus } \\
\text { trabajadores y que puedan gestionar de manera adecuada sus } \\
\text { procesos }\end{array}$ \\
\hline Pregunta 15: & ¿Qué tipo de productos ofrecerán? \\
\hline TÓPICO - CLIENTES & $\begin{array}{l}\text { Apuntes: La empresa cuenta con cuatro productos de los cuales } \\
\text { dos se encuentran en un alto nivel de desarrollo los cuales son } \\
\text { SAP portal y programación ABAP; y los dos restantes se } \\
\text { encuentran en crecimiento los cuales son BA y mobile }\end{array}$ \\
\hline Pregunta 16: & ¿Cómo se diferenciarán? \\
\hline TÓPICO - CLIENTES & $\begin{array}{l}\text { Apuntes: La diferencia que se tiene es el servicio de post-venta } \\
\text { el cual se brinda de manera gratuita ante posibles } \\
\text { eventualidades }\end{array}$ \\
\hline Pregunta 17: & ¿Qué mercados quieren atender? \\
\hline TÓPICO - CLIENTES & $\begin{array}{l}\text { Apuntes: La empresa tiene pensando continuar brindando } \\
\text { servicios a las empresas que cuenten con SAP }\end{array}$ \\
\hline Pregunta 18: & ¿Cómo lograrán su lealtad? \\
\hline TÓPICO - CLIENTES & $\begin{array}{l}\text { Apuntes: Mantendrán precios de sus servicios por debajo del } \\
\text { mercado }\end{array}$ \\
\hline Pregunta 19: & ¿Cuáles serán sus estándares de servicio? \\
\hline TÓPICO - CLIENTES & Apuntes: Brindarán un servicio de tecnología con alta calidad \\
\hline Pregunta 20: & ¿Cómo monitorearán sus procesos? \\
\hline TÓPICO - PROCESOS & $\begin{array}{l}\text { Apuntes: Los procesos serán monitoreados a través de } \\
\text { indicadores de cumplimiento de objetivos }\end{array}$ \\
\hline Pregunta 21: & ¿Cuál será la forma de mejorarlos continuamente? \\
\hline TÓPICO - PROCESOS & $\begin{array}{l}\text { Apuntes: Efectuando capacitaciones continuas a los } \\
\text { colaboradores para que se encuentren actualizados con los } \\
\text { avances tecnológicos. }\end{array}$ \\
\hline
\end{tabular}




\begin{tabular}{|l|l|}
\cline { 2 - 2 } Pregunta 22: & ¿Cuáles serán sus principales indicadores? \\
\hline TÓPICO - PROCESOS & $\begin{array}{l}\text { Apuntes: Sus principales indicadores serian el cumplimiento de } \\
\text { los requerimientos y la calidad de servicio }\end{array}$ \\
\hline Pregunta 23: & ¿Cuál será la relación con sus principales proveedores? \\
\hline TÓPICO - PROCESOS & $\begin{array}{l}\text { Apuntes: A través de las alianzas estratégicas con sus } \\
\text { proveedores }\end{array}$ \\
\hline
\end{tabular}

Foto de la entrevista

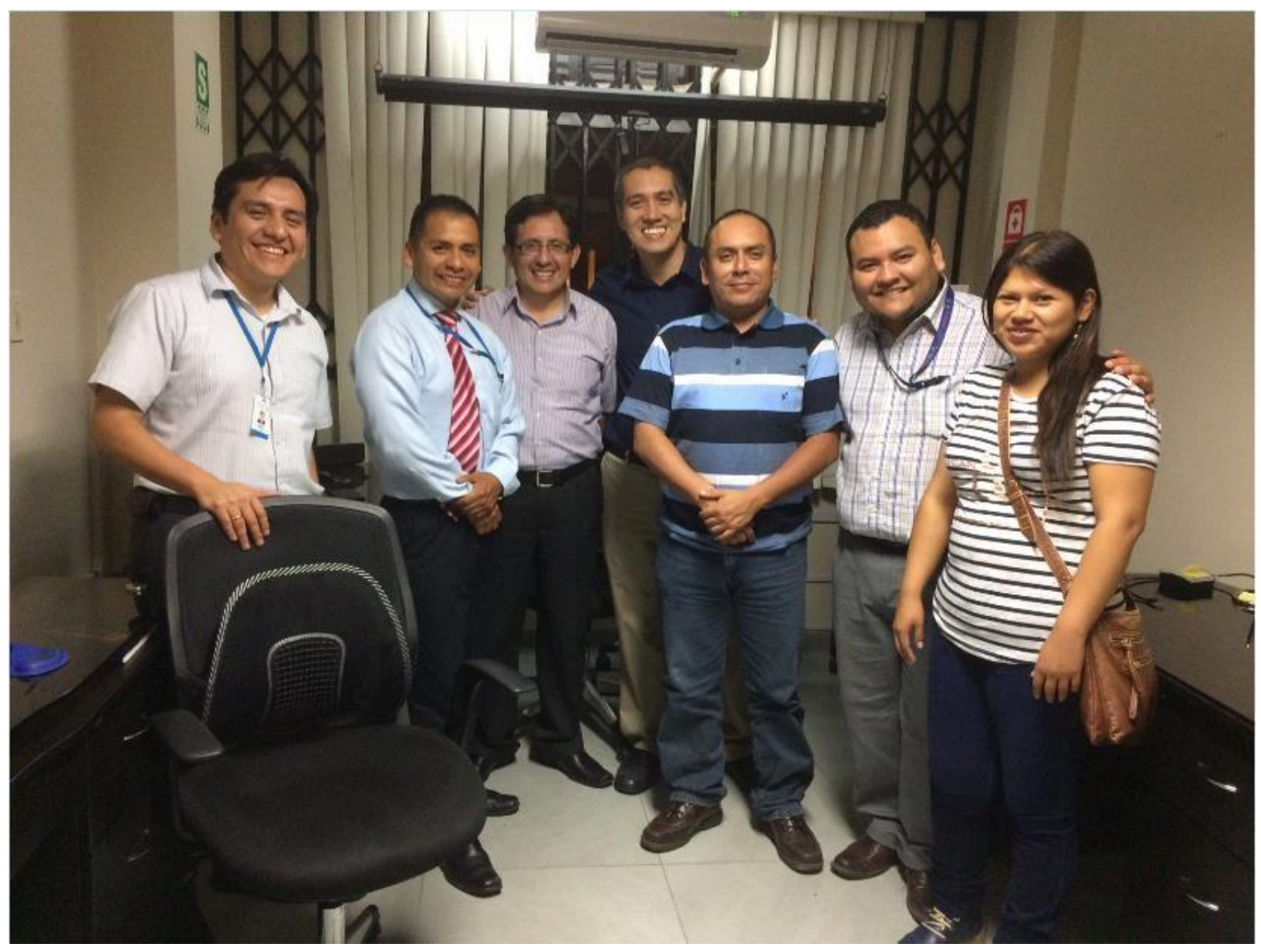




\section{Anexo 2}

Ficha técnica de la entrevista

\begin{tabular}{|l|l|}
\hline Técnica empleada: & Entrevista profundidad - Expertos del Sector \\
\hline Localización: & Lima Metropolitana \\
\hline \multirow{4}{*}{ Objetivo del estudio: } & $\begin{array}{l}\text { Obtener información acerca del sector de tecnología } \\
\text { de información, tratando temas competentes sobre } \\
\text { los factores externos que lo afectan, oportunidades y } \\
\text { amenazas, así como los factores que se consideran } \\
\text { críticos para el éxito en el sector. }\end{array}$ \\
\hline \multirow{2}{*}{ Temas estudiados: } & Análisis Interno \\
\cline { 2 - 2 } & Análisis Externo \\
\cline { 2 - 2 } & $\begin{array}{l}\text { Factores críticos de éxito (Perfil competitivo de } \\
\text { empresas) }\end{array}$ \\
\hline Fechas de estudio: & Jueves 6 de abril de 2017 \\
\hline Hora: & 5 pm (Entrevistado 1) - 8 pm (Entrevistado 2) \\
\hline Duración: & 45 minutos \\
\hline
\end{tabular}

Ficha técnica del entrevistado

\begin{tabular}{|l|l|}
\hline Nombre: & Pablo Rios Velarde \\
\hline Edad: & 54 años \\
\hline Nacionalidad: & Peruano \\
\hline Ocupación: & Gerente de Operaciones - Systems Support \& Services \\
\hline Profesión: & Ingeniero Industrial \\
\hline $\begin{array}{l}\text { Distrito de } \\
\text { Residencia: }\end{array}$ & San Borja \\
\hline & $\begin{array}{l}\text { Se desempeña como Gerente de Operaciones de Systems } \\
\text { Support \& Services. Amplia trayectoria en empresas del sector } \\
\text { público y privado. }\end{array}$ \\
\hline
\end{tabular}




\begin{tabular}{|l|l|}
\hline Nombre: & Julio Yzaguirre \\
\hline Edad: & 43 años \\
\hline Nacionalidad: & Peruano \\
\hline Ocupación: & Gerente de sistemas - GMD \\
\hline Profesión: & Ingeniero de Sistemas \\
\hline $\begin{array}{l}\text { Distrito de } \\
\text { Residencia: }\end{array}$ & Miraflores \\
\hline Breve reseña: & $\begin{array}{l}\text { Se desempeña como Gerente de sistemas en GMD. Cuenta con } \\
\text { una vasta experiencia en empresas del sector privado focalizadas } \\
\text { en servicios al cliente. }\end{array}$ \\
\hline
\end{tabular}

\section{Guía de Pautas}

\section{Introducción:}

- Presentación del moderador y la modalidad de trabajo.

- Presentación del objetivo de la entrevista

\section{Presentación del moderador y la modalidad de trabajo:}

"Buenas noches Sr., muchas gracias por el tiempo que nos brinda para la realización de esta entrevista. El objetivo de esta es conocer, en base a su experiencia, el sector de la tecnología de la información, cómo vislumbra su evolución y que considera clave para su desarrollo a futuro. A continuación, se le formulará un grupo de preguntas en donde le solicitamos sea lo más conciso posible en el tema propuesto.”

1) ¿Cómo analiza Ud. el entorno político actual y de qué manera influencia el sector de la tecnología de información? ¿Qué oportunidades y amenazas identifica para el sector?

2) ¿Cuál es su apreciación respecto a la coyuntura económica que atraviesa el país? ¿Qué oportunidades y amenazas visualiza para el sector? 
3) ¿Qué factores desde el punto de vista de leyes cree que influencian a las empresas del sector? ¿Qué oportunidades y amenazas identifica para el sector?

4) ¿Considera Ud. que culturalmente las empresas tienen mayor apertura para invertir en tecnologías de información? ¿Qué oportunidades y amenazas identifica para el sector?

5) ¿Cómo se pueden aprovechar las tendencias tecnológicas actuales en beneficios de las empresas? ¿Qué demandan más a las empresas del sector?

6) ¿Las iniciativas ecológicas actuales, de qué manera influyen a las empresas del sector? ¿Qué oportunidades o amenazas identifican en este rubro?

7) ¿Qué factores de éxito consideran críticos para una empresa de servicios de tecnología de la información?

8) ¿Qué ventajas competitivas debe poseer una empresa de servicios de tecnología de la información?

9) ¿Quién considera como líder o líderes dentro del sector de servicios de tecnología de la información?

\section{Análisis.}

Producto de las respuestas obtenidas por nuestros entrevistados expertos en el sector, se pudo identificar oportunidades y amenazas como factores externos que afectan al sector. Asimismo, se han podido determinar lo que a su juicio son los factores críticos de éxito de una empresa de servicios en tecnología de la información. A continuación, listamos el resumen de las oportunidades, amenazas y factores críticos de éxito identificados. Dentro de las oportunidades:

- La estabilidad política que se vive proyecta confianza en el empresariado para invertir en servicios de tecnología de información. Esto justificará un 
incremento en la demanda de servicios y un crecimiento sostenido de las empresas.

- Los sectores en donde se puede ver un crecimiento pertenecen a rubros de la pesca, manufactura y minería.

- El control del tipo de cambio alienta a las empresas a generar contratos en moneda nacional con un horizonte de tiempo de un año.

- Las tendencias en tecnología están dando paso a la formación de profesionales altamente capacitados.

- Muchas empresas están aprovechando en invertir en compra de equipamiento en moneda extranjera debido al tipo de cambio bajo y su incremento en ganancias.

- Las entidades bancarias están ofreciendo productos ventajosos a modo de financiamiento de proyectos a largo plazo.

- Existen leyes (ley 28303) que favorecen a los proveedores de servicios de tecnología

- Nuevos mercados y crecimiento de demanda en empresas del sector de las PYMES

- Tendencias tecnológicas que favorecen la cartera de servicios de las empresas del sector y que abaratan costos de implementación (cloud computing, big data, analytics, internet de las cosas).

Dentro de las amenazas:

- Crecimiento de la competencia en empresas del sector.

- Posibilidad de una disminución de la demanda de servicios de consultoría en tecnologías o tendencias tradicionales. 
- Alta rotación de personal entre las empresas del sector. Captación de los profesionales de los proveedores al cliente.

- Creación de nuevas empresas en el sector. Poco costo de funcionamiento.

- Posibles fluctuaciones en el tipo de cambio.

- Políticas extranjeras que afecten a los posibles clientes (empresas), sobre todo del gobierno americano.

- Endurecimiento en aplicación de sanciones en leyes laborales.

- Evolución rápida de las tendencias tecnológicas

- Obsolescencia tecnológica adelantada.

- Equipos de manufactura con software propio y que requieren de mayor conocimiento para su integración a los sistemas de las organizaciones.

- Reducción de clientes en los rubros de manufactura.

Las oportunidades y amenazas identificadas han sido tomadas en cuenta para la elaboración de la matriz EFE.

Respecto a los factores críticos de éxito de una empresa de servicios de tecnología de la información, los expertos coinciden en que factores como la calidad del servicio y la especialización en el sector son los de mayor peso al momento de realizar una elección de este tipo de empresas. También se toman en cuenta la infraestructura tecnológica que la respalda, el conocimiento/experiencia de su personal, y en menor medida su participación en el mercado, solidez financiera y alianzas estratégicas que tenga a nivel de hardware o software. 


\section{Anexo 3}

Ficha técnica de la entrevista

\begin{tabular}{|l|l|}
\hline Técnica empleada: & Entrevista profundidad - No clientes \\
\hline Localización: & Lima Metropolitana \\
\hline \multirow{2}{*}{ Objetivo del estudio: } & $\begin{array}{l}\text { Obtener información acerca del sector de tecnología } \\
\text { de información, tratando temas competentes sobre las } \\
\text { fortalezas y debilidades de las empresas del sector, } \\
\text { así como los factores críticos que toman en cuenta } \\
\text { para la elección de un proveedor de servicios de este } \\
\text { tipo. }\end{array}$ \\
\hline \multirow{2}{*}{ Temas estudiados: } & Análisis Interno \\
\cline { 2 - 2 } & $\begin{array}{l}\text { Factores críticos de éxito (Perfil competitivo de } \\
\text { empresas) }\end{array}$ \\
\hline Fechas de estudio: & Viernes 17 de abril de 2017 \\
\hline Hora: & 7 pm \\
\hline Duración: & 45 minutos \\
\hline
\end{tabular}

Ficha técnica del entrevistado

\begin{tabular}{|l|l|}
\hline Nombre: & Miguel Lau Mou \\
\hline Edad: & 43 años \\
\hline Nacionalidad: & Peruano \\
\hline Ocupación: & Gerente de Sistemas - Grupo Talma \\
\hline Profesión: & Administrador \\
\hline $\begin{array}{l}\text { Distrito de } \\
\text { Residencia: }\end{array}$ & Miraflores \\
\hline & $\begin{array}{l}\text { Se desempeña como Gerente de Sistemas del Grupo Talma. } \\
\text { Experiencia en empresas privadas de manufactura y logística. }\end{array}$ \\
\hline
\end{tabular}

\section{Guía de Pautas}

\section{Introducción:}

- Presentación del moderador y la modalidad de trabajo.

- Presentación del objetivo de la entrevista

Presentación del moderador y la modalidad de trabajo: 
"Buenas noches Sr., muchas gracias por el tiempo que nos brinda para la realización de esta entrevista. El objetivo de esta es conocer, en base a su experiencia, los factores que determinan la elección de una empresa proveedora de servicios de tecnología de información.”

1) ¿Cuáles son las fortalezas que debe de tener una empresa de servicios de tecnología de la información? ¿Cuáles son las que valora más?

2) ¿Qué tipo de debilidades aprecia en empresas del sector de tecnología de la información y que influyen en su evaluación? ¿Cuáles son las más determinantes?

3) ¿Cuáles son los factores críticos de éxito de una empresa que brinda servicios de tecnología de la información?

4) ¿Qué ventajas competitivas considera Ud. que debe de tener una empresa que brinda servicios de tecnología de la información?

5) ¿Quién considera como líder o líderes dentro del sector de servicios de tecnología de la información?

\section{Análisis.}

Producto de las respuestas obtenidas por nuestro entrevistado, se pudo identificar algunas fortalezas y debilidades que él toma en consideración al momento de elegir a un proveedor de servicios de tecnología de información. De igual modo, se han podido determinar lo que a su juicio son ventajas competitivas que puede tener una empresa de este tipo en el sector. A continuación, listamos el resumen de la información identificada.

Dentro de las fortalezas:

- Se valora mucho la experiencia en el equipo de desarrollo.

- El servicio post venta debe ser de calidad. 
- La atención rápida y la disponibilidad de recursos.

- Experiencia en la gestión de proyectos de envergadura

- Trayectoria de la plana directiva.

- Actualización en tendencias tecnológicas actuales

- Reputación en el sector.

Dentro de las debilidades:

- Recursos limitados de hardware y personal calificado

- Dependencia de partners externos para brindar servicios.

- Experiencia del personal que participa del proyecto.

- Falta de comunicación entre cliente y proveedor.

- Cartera de clientes y servicios

- Presencia en eventos del sector

- Imagen de poco crecimiento en el sector.

Las oportunidades y amenazas identificadas han sido tomadas en cuenta para la elaboración de la matriz EFI.

Respecto a las ventajas competitivas que debe de tener una empresa que brinda este tipo de servicios en el sector, considera que la experiencia de la empresa en el sector juntamente con el servicio brindado es muy importante para ellas. La referencia de una cartera de clientes de prestigio también es tomada en cuenta. Esto será tomado en cuenta para la matriz peyea. El entrevistado considera a IBM, Oracle, Microsoft y SAP como empresas referentes en el sector. 


\section{Anexo 4}

Ficha técnica de la entrevista

\begin{tabular}{|l|l|}
\hline Técnica empleada: & Entrevista profundidad - clientes \\
\hline Localización: & Lima Metropolitana \\
\hline \multirow{2}{*}{ Objetivo del estudio: } & $\begin{array}{l}\text { Obtener información acerca del sector de tecnología } \\
\text { de información, tratando temas competentes sobre las } \\
\text { fortalezas y debilidades de las empresas del sector, } \\
\text { así como los factores críticos que toman en cuenta } \\
\text { para la elección de un proveedor de servicios de este } \\
\text { tipo. Estrategias }\end{array}$ \\
\hline \multirow{2}{*}{ Temas estudiados: } & Análisis Interno \\
\cline { 2 - 2 } & $\begin{array}{l}\text { Factores críticos de éxito (Perfil competitivo de } \\
\text { empresas) }\end{array}$ \\
\hline Fechas de estudio: & Lunes 24 de abril de 2017 \\
\hline Hora: & 7 pm \\
\hline Duración: & 45 minutos \\
\hline
\end{tabular}

Ficha técnica del entrevistado

\begin{tabular}{|l|l|}
\hline Nombre: & Roberto Da Cruz Cam \\
\hline Edad: & 54 años \\
\hline Nacionalidad: & Peruano \\
\hline Ocupación: & Gerente de TI - TASA \\
\hline Profesión: & Ingeniero Industrial \\
\hline $\begin{array}{l}\text { Distrito de } \\
\text { Residencia: }\end{array}$ & Santa Catalina \\
\hline & $\begin{array}{l}\text { Se desempeña como Gerente de TI de TASA. Amplia } \\
\text { experiencia en empresas del sector público y privado. }\end{array}$ \\
\hline
\end{tabular}

\section{Guía de Pautas}

\section{Introducción:}

- Presentación del moderador y la modalidad de trabajo.

- Presentación del objetivo de la entrevista

Presentación del moderador y la modalidad de trabajo: 
"Buenas noches Sr., muchas gracias por el tiempo que nos brinda para la realización de esta entrevista. El objetivo de esta es conocer, en base a su experiencia, los factores que determinan la elección de una empresa proveedora de servicios de tecnología de información."

1) ¿Cuáles son las fortalezas que debe de tener una empresa de servicios de tecnología de la información? ¿Cuáles son las que valora más?

2) ¿Qué tipo de debilidades aprecia en empresas del sector de tecnología de la información y que influyen en su evaluación? ¿Cuáles son las más determinantes?

3) ¿Cuáles son los factores críticos de éxito de una empresa que brinda servicios de tecnología de la información?

4) ¿Qué ventajas competitivas considera Ud. que debe de tener una empresa que brinda servicios de tecnología de la información?

5) ¿Quién considera como líder o líderes dentro del sector de servicios de tecnología de la información?

\section{Análisis.}

Producto de las respuestas obtenidas por nuestro entrevistado, se pudo identificar algunas fortalezas y debilidades que él toma en consideración al momento de elegir a un proveedor de servicios de tecnología de información. De igual modo, se han podido determinar lo que a su juicio son ventajas competitivas que puede tener una empresa de este tipo en el sector. A continuación, listamos el resumen de la información identificada.

Dentro de las fortalezas:

- La disponibilidad de personal calificado para los diferentes proyectos del área.

- Reputación en el sector de la plana directiva. 
- Actualización en tendencias tecnológicas actuales

- Posibilidad de ofrecer servicios de calidad a bajo costo

Dentro de las debilidades:

- Informalidad en el manejo de proyectos.

- Experiencia del personal que participa del proyecto.

- Falta de comunicación entre cliente y proveedor.

- Falta de cumplimiento en plazos y costos de los proyectos.

Las oportunidades y amenazas identificadas han sido tomadas en cuenta para la elaboración de la matriz EFI.

Respecto a las ventajas competitivas que debe de tener una empresa que brinda este tipo de servicios en el sector, considera que el servicio post venta es fundamental con una predisposición a proporcionar los recursos que esté a su alcance para lograr una buena atención. El conocimiento y preparación de su personal es altamente valorado y le da un valor diferencial sobre sus competidores. Finalmente, su solvencia económica que le permita invertir en tecnologías siguiendo las tendencias actuales. Esto será tomado en cuenta para la matriz peyea.

El entrevistado consideró a IBM y SAP como los líderes en el sector. 
Anexo 5

\begin{tabular}{|c|c|}
\hline & FICHA TÉCNICA \\
\hline Técnica de Recolección de Datos: & Focus Group \\
\hline Participantes: & $\begin{array}{l}\text { Colaboradores de la empresa Xternal Technological } \\
\text { Solutions S.A.C. }\end{array}$ \\
\hline Número de Participantes: & Seis personas \\
\hline Reclutamiento: & $\begin{array}{l}\text { Se convocó a colaboradores con un tiempo mayor a } 12 \\
\text { meses en la empresa. }\end{array}$ \\
\hline Duración: & 60 minutos \\
\hline Localización: & $\begin{array}{l}\text { Local de la empresa Xternal Technological Solutions } \\
\text { S.A.C. }\end{array}$ \\
\hline Fecha: & Lunes, 24 de abril de 2017 \\
\hline Hora: & 10:00 am \\
\hline Responsable: & Los miembros del equipo de investigación \\
\hline Equipo de trabajo: & Guía de entrevista y equipo de grabación de audio. \\
\hline Objetivo del estudio: & $\begin{array}{l}\text { Recopilar la información necesaria para conocer la } \\
\text { situación actual de la empresa Xternal Technological } \\
\text { Solutions S.A.C. Tratando temas como su misión, } \\
\text { visión, valores y análisis interno. }\end{array}$ \\
\hline \multirow{4}{*}{ Temas estudiados: } & a. Visión \\
\hline & b. Misión \\
\hline & c. Valores \\
\hline & d. Análisis Interno \\
\hline
\end{tabular}

\section{Guía de Pautas}

\section{Introducción:}

- Presentación del moderador y la modalidad de trabajo.

- Presentación de los participantes: nombre, puesto y tiempo en la empresa.

Presentación del moderador y la modalidad de trabajo:

"Es importante que ustedes conozcan los temas que vamos a abordar, tratando de entender la importancia para el futuro de su negocio. Por ello, les pedimos que respondan a cada una de estas preguntas lo mejor que cada uno de ustedes pueda. Aquí les pido que se tomen el tiempo y le den la importancia que estas cuestiones tienen para la mejor realización de su trabajo. Si no saben la respuesta, o si no están 100\% seguros de cuál es la correcta, es importante que igual mencionen las ideas que le vienen a la mente". 
1) ¿Conoce la visión, misión y valores de la empresa?

2) ¿Considera que la misión está relacionada con las actividades que realiza la empresa?

3) ¿Considera que los valores organizacionales se aplican en la empresa?

4) ¿Qué fortalezas y debilidades puede identificar en su área y en la empresa?

5) ¿Cómo definiría la comunicación interna dentro de la empresa?

6) ¿Conoce cuáles son los principales procesos de la empresa?

7) ¿En cuáles de esos procesos participa directamente?

8) ¿Su trabajo los mantiene motivados?

9) ¿Cómo definiría el liderazgo de los directivos de la empresa?

10) ¿Qué actividades realiza dentro de su área?

11) ¿Qué actividades considera fundamentales en su área?

12) ¿Qué cosa cree usted mejoraría el desempeño de esas actividades fundamentales?

13) ¿Cómo considera la comunicación que existe dentro de la empresa?

14) ¿Considera que tiene posibilidades de desarrollo profesional en la empresa?

15) ¿Considera que sus inquietudes son escuchadas?

\section{Muestra.}

En base a la información obtenida de la estructura organizacional formal de la empresa se aplicó un focus group a los empleados de la empresa Xternal Technological Solutions S.A.C. El grupo estuvo conformado por seis participantes, tres mujeres y tres hombres. Todos los participantes cuentan con un año de permanencia como mínimo en la empresa. 


\section{Análisis.}

Del análisis de las percepciones de los colaboradores se pudo recabar la siguiente información:

- Consideran que la organización está en crecimiento.

- $\quad$ No recuerdan con exactitud la misión y la visión de la empresa ya que no ha sido muy difundida.

- La mayoría de los colaboradores no conoce específicamente los valores de la empresa.

- Consideran que las principales fortalezas son: Calidad en el servicio, profesionales competitivos, clima laboral agradable y una cultura organizacional sólida

- Consideran que las principales debilidades son: Directivos inmersos en labores operativas, la mayoría de los proyectos son para una cartera reducida de clientes, falta de automatización en algunos procesos, tiempo de respuesta a los clientes.

- La comunicación es fluida, es una organización predominantemente horizontal.

- La mayoría de los colaboradores se encuentran motivados.

- Se ha podido determinar a partir de las declaraciones de los colaboradores, que existe un liderazgo principalmente paternalista.

- La mayoría de los colaboradores considera que tiene posibilidades de crecimiento, desarrollo profesional y personal.

- Con respecto al clima laboral, los colaboradores señalan que perciben un ambiente laboral adecuado, con una cultura de formación y de respeto a las normas bastante fuertes. 